\title{
Microvascular dysfunction and diabetes: a vicious cycle?
}

Citation for published version (APA):

Muris, D. M. J. (2015). Microvascular dysfunction and diabetes: a vicious cycle? [Doctoral Thesis, Maastricht University]. Maastricht University. https://doi.org/10.26481/dis.20150513dm

Document status and date:

Published: 01/01/2015

DOI:

10.26481/dis.20150513dm

Document Version:

Publisher's PDF, also known as Version of record

\section{Please check the document version of this publication:}

- A submitted manuscript is the version of the article upon submission and before peer-review. There can be important differences between the submitted version and the official published version of record.

People interested in the research are advised to contact the author for the final version of the publication, or visit the DOI to the publisher's website.

- The final author version and the galley proof are versions of the publication after peer review.

- The final published version features the final layout of the paper including the volume, issue and page numbers.

Link to publication

\footnotetext{
General rights rights.

- You may freely distribute the URL identifying the publication in the public portal. please follow below link for the End User Agreement:

www.umlib.nl/taverne-license

Take down policy

If you believe that this document breaches copyright please contact us at:

repository@maastrichtuniversity.nl

providing details and we will investigate your claim.
}

Copyright and moral rights for the publications made accessible in the public portal are retained by the authors and/or other copyright owners and it is a condition of accessing publications that users recognise and abide by the legal requirements associated with these

- Users may download and print one copy of any publication from the public portal for the purpose of private study or research.

- You may not further distribute the material or use it for any profit-making activity or commercial gain

If the publication is distributed under the terms of Article $25 \mathrm{fa}$ of the Dutch Copyright Act, indicated by the "Taverne" license above, 


\section{MICROVASCULAR DYSFUNCTION AND DIABETES:}

A VICIOUS CYCLE? 
(C) Dennis Muris, Maastricht 2015

Cover picture: Zastavski.com desktop wallpapers and images \& Vector tree art by Mu6 Cover design: Jason Pluim Mentz

Production: Ricoh Nederland B.V., 's-Hertogenbosch

ISBN: $978-90-9028914-4$ 


\title{
MICROVASCULAR DYSFUNCTION AND DIABETES: A VICIOUS CYCLE?
}

\author{
PROEFSCHRIFT \\ ter verkrijging van de graad van doctor aan de Universiteit Maastricht, \\ op gezag van de Rector Magnificus, Prof. dr. L.L.G. Soete, \\ volgens het besluit van het College van Decanen, \\ in het openbaar te verdedigen \\ op woensdag 13 mei 2015 om 12.00 uur
}

door

Dennis Maria Jacobus Muris 


\section{Promotores}

Prof. dr. C.D.A. Stehouwer

Copromotor

Dr. A.J.H.M. Houben

Dr. M.T. Schram

\section{Beoordelingscommissie}

Prof. dr. P.W. de Leeuw (voorzitter)

Dr. L. Engelen

Prof. dr. A.C. Nieuwenhuijzen Kruseman

Dr. E.H. Serné, VUMC Amsterdam

Prof. dr. A.J. Smit, UMCG

Financial support by Perimed and KKtechnology for the publication of this thesis is gratefully acknowledged.

Financial support by the Dutch Heart Foundation for the publication of this thesis is gratefully acknowledged. 


\section{CONTENTS}

$\begin{array}{lll}\text { Chapter } 1 & \text { General introduction } & 7\end{array}$

$\begin{array}{lll}\text { Chapter } 2 & \text { Methods } & 27\end{array}$

Chapter 2.1 Study population 29

Chapter 2.2 Assessment of microvascular function 33

Chapter 2.3 Semi-automatic assessment of skin capillary density: proof of 39 prinicple and validation

Chapter 3 Microvascular dysfunction is associated with a higher incidence of 57 type 2 diabetes mellitus: a systematic review and meta-analysis

Chapter 4 Type 2 diabetes mellitus and hyperglycaemia are associated with 85 microvascular dysfunction: the Maastricht Study

Chapter 5 Age, waist circumference and blood pressure are associated with 103 skin microvascular flow motion: the Maastricht Study

Chapter 6 Summary and discussion

Samenvatting 139

Valorisation addendum 145

Dankwoord 151

Curriculum vitae 155

List of publications 157 



\title{
Chapter 1
}

\section{General introduction}

\begin{abstract}
Adapted from
Microvascular dysfunction: an emerging pathway in the pathogenesis of obesity-related insulin resistance

Dennis M. J. Muris, Alfons J. H. M. Houben, Miranda T. Schram, Coen D. A. Stehouwer
\end{abstract}

Rev Endocr Metab Disord 2013;14:29-38

and

Microvascular dysfunction as a link between obesity, insulin resistance and hypertension Ümit Karaça, Miranda T. Schram, Alfons J. H. M. Houben, Dennis M. J. Muris, Coen D. A. Stehouwer

Diabetes Res Clin Pract 2014;103:382-7 


\section{INTRODUCTION}

The prevalence of obesity is increasing worldwide and has reached epidemic proportions in Western society. ${ }^{1}$ Central obesity and a sedentary lifestyle are main causes of type 2 diabetes mellitus (T2DM). ${ }^{2}$ Consequently, the increases in their prevalence results in an increased prevalence of T2DM. ${ }^{3}$ However, how obesity leads to T2DM is incompletely understood. We and others have advanced the hypothesis that microvascular dysfunction may function as an intermediate step linking central obesity to T2DM. ${ }^{4-7}$ Understanding this pathophysiology may contribute to more precise risk assessment for the development of T2DM, and additionally to new treatment targets for prevention of these obesityrelated disorders.

Microvascular dysfunction may be both cause and consequence of T2DM. On the one hand, it is generally accepted that T2DM cause microvascular dysfunction and microvascular complications such as retinopathy, neuropathy, and nephropathy. ${ }^{8-10}$ On the other hand, microvascular dysfunction has been identified as an antecedent of T2DM. $^{7,9,11}$ In addition, we ${ }^{12-14}$ and others ${ }^{15,16}$ have demonstrated that microvascular dysfunction is impaired in (central) obesity, and obesity has been suggested as a primary cause of microvascular dysfunction. ${ }^{6}$ Therefore, microvascular dysfunction may be an intermediate step linking central obesity to $\mathrm{T}^{\mathrm{DDM}} .^{4-7}$ In the following subsections we will discuss the definition, function, and assessment of microvascular (dys)function. In addition, we will discuss the role for microvascular dysfunction as an intermediate step linking central obesity to insulin resistance and subsequent T2DM in detail. Finally, we will discuss the general aim and outline of this thesis.

\section{MICROCIRCULATION: DEFINITION, FUNCTION, AND ASSESSMENT}

\section{DEFINITION AND FUNCTION}

The microcirculation can be defined anatomically, i.e., as vessels less than $150 \mu \mathrm{m}$ in diameter, including all capillaries and venules and small arterioles. ${ }^{11}$ However, this definition excludes larger arterioles with a diameter above $150 \mu \mathrm{m}$, which may be important to microcirculatory function. ${ }^{11}$ An alternative definition is based on 
arterial/arteriolar vessel physiology, and includes all vessels that respond to increased pressure by a myogenic reduction in lumen diameter. Such a definition also includes the larger arterioles in the microcirculation in addition to capillaries and venules. ${ }^{6,11,17}$

The microcirculation has three essential functions which serve to regulate whole body and tissue metabolism, and blood pressure $\left.{ }^{4,5}: 1\right)$ regulation of the exchange of nutrients, oxygen, and hormones; 2) avoidance of large fluctuations in hydrostatic pressure at the capillary level; and 3) determining the overall peripheral resistance, since the quantitatively most substantial drop in hydrostatic pressure occurs at the level of the microcirculation. ${ }^{11}$ Microvascular dysfunction is defined as an impairment in one or more of these functions.

\section{ASSESSMENT}

\section{ESTIMATES OF MICROVASCULAR FUNCTION}

Currently, several types of estimates of microvascular (endothelial or smooth muscle cell) function are available. ${ }^{18}$ First, assessment of microvascular function in specific microvascular beds is frequently used, such as in 1) skin (by capillaroscopy and laserDoppler flowmetry); 2) muscle (by plethysmography and contrast-enhanced ultrasonography); 3) conjunctival bed (by intravital microscopy) and 4) retina (by photography). Responses can be studied in the basal state and after applying a stimulus, such as reactive hyperemia, heating, or local or systemic administration of endothelium(in)dependent vasoactive agents such as acetylcholine and sodium nitroprusside, with lower responses in general reflecting microvascular dysfunction. ${ }^{19-21}$ In addition, in the

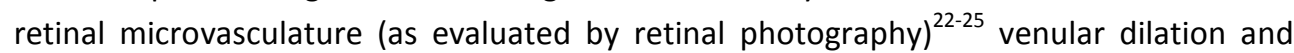
arteriolar narrowing have been associated with, and may be markers of, endothelial dysfunction. ${ }^{26}$ Moreover, responses of the retinal microvasculature can be studied after applying a flicker-light stimulus, with lower responses thought to reflect endothelial dysfunction. ${ }^{27}$ Second, microvascular function can be assessed with the use of biomarkers. Thus, measurement of plasma levels of endothelium-derived regulatory proteins (e.g., soluble E-selectin (sE-selectin), soluble intercellular adhesion molecule 1 (sICAM-1), soluble vascular adhesion molecule 1 (sVCAM-1), and von Willebrand factor $(\mathrm{VWF})^{28}$ ) is often used. Increased levels of these markers are thought to reflect endothelial permeability to leucocytes (i.e., sE-selectin, sICAM-1, and SVCAM-1) ${ }^{28-31}$, and prothrombotic and procoagulant activity (i.e., vWF). ${ }^{28,30,31}$ Note that the microvascular endothelium is the most important determinant of these plasma markers of endothelial dysfunction ${ }^{28,32-34}$, because of its large surface area and production capacity (i.e., the microvasculature covers $98 \%$ of the total vascular surface area ${ }^{35}$ ). For these reasons, it is 
plausible to assume that higher circulating concentrations of these markers reflect microvascular endothelial dysfunction. Another biomarker of microvascular function is urinary albumin excretion or microalbuminuria, which is thought to reflect a generalized increase in endothelial permeability ${ }^{28}$, and is frequently used as a marker of general endothelial dysfunction. ${ }^{28,30,31,36-38}$ This concept is derived from data showing that microalbuminuria is associated with a greater transcapillary escape rate of albumin, i.e. with greater microvascular permeability ${ }^{28}$ and from data showing that microalbuminuria is strongly associated with risk of cardiovascular disease, that this association cannot be explained by conventional risk factors, and that changes in microalbuminuria are paralleled by changes in cardiovascular risk (reviewed elsewhere ${ }^{39}$ ).

\section{MIRCOVASCULAR VASOMOTION}

Microvascular vasomotion, i.e. rhythmic changes in (pre-capillary) arteriolar diameter, is thought to be an important component of microvascular function. ${ }^{14}$ In fact, these rhythmic oscillations regulate microvascular flow distribution so that various tissue regions are intermittently perfused. ${ }^{14,40}$ Thus, vasomotion may be an important component of microcirculatory function by ensuring optimal delivery of nutrients and oxygen to tissue and regulating local hydraulic resistance. ${ }^{14,41,42}$ Different mechanisms are thought to contribute to vasomotion: the activity of the vascular endothelium, neurogenic activity, myogenic activity of vascular smooth muscle cells, respiration, and cardiac contraction frequency. ${ }^{19,43-45}$ The rhythmic changes in arteriolar diameter caused by vasomotion produce periodical fluctuations of flow known as microvascular flowmotion, which can easily be assessed using laser-Doppler flowmetry. ${ }^{41}$

\section{MICROVASCULAR DYSFUNCTION: A CAUSE OF INSULIN RESISTANCE}

Insulin resistance is typically defined as decreased sensitivity and/or responsiveness to the metabolic actions of insulin, which results in impaired glucose disposal. ${ }^{5,6,46,47}$ In muscle cells, activation of the phosphatidylinositol-kinase (PI3K) pathway leads to translocation of glucose transporter-4 (GLUT-4) to the cell membrane, which activates the downstream pathways of glucose metabolism. ${ }^{5,6,46-48}$ The translocation of GLUT-4 is believed to be the rate-limiting step for insulin-mediated glucose uptake in muscle. ${ }^{48,49}$ Several studies demonstrated that inappropriate fat accumulation in muscle cells or the release of inflammatory cytokines by fat cells may affect this pathway. ${ }^{48,50,51}$ This process is referred 
to as metabolic insulin resistance, and is widely accepted to precede the development of T2DM. ${ }^{10}$ Nevertheless, most studies investigating metabolic insulin resistance examined individuals with long-standing T2DM. ${ }^{52}$ These studies demonstrated that there are indeed defects in the insulin-signalling pathway in muscle cells in the diabetic state. ${ }^{19,53}$ However, an important and necessary step preceding translocation of GLUT-4 is the perfusion of the microvasculature within the skeletal muscle in order to deliver insulin and glucose to the muscle cells.

Since the 1990s, there has been an increasing interest in this precellular step, and it has become clear that the delivery of insulin and glucose to muscle tissue is regulated by insulin itself via direct effects on microvascular function that require activation of the insulin receptor on endothelial cells. ${ }^{6,47}$ Baron and colleagues ${ }^{54}$ first reported that insulin increases total blood flow in skeletal muscle, which is paralleled by an increase in insulinmediated glucose uptake. ${ }^{54,55}$ Although some studies have confirmed this vascular action of insulin ${ }^{56,57}$, most studies observed only insulin-mediated increases in total limb blood flow after using supra-physiological doses of insulin or after several hours of delay when physiological concentrations were used. ${ }^{58-60}$ Therefore, the physiological importance of insulin's ability to increase total blood flow remains controversial. ${ }^{6,19,59}$ However, besides these actions on resistance vessels, insulin can redirect blood flow in skeletal muscle from non-nutritive to nutritive capillary networks, without increasing total blood flow. This results in a net increase of the overall number of perfused nutritive capillary networks ${ }^{6}$, and thereby increases insulin-mediated glucose uptake by skeletal muscle. ${ }^{47,58}$ This process is referred to as functional (nutritive) capillary recruitment. Such capillary recruitment requires physiological concentrations of insulin and has a time course that accords well with the time course for insulin-mediated glucose uptake in skeletal muscle. ${ }^{46,59,61}$ In addition, this process has been shown to be endothelium-dependent, requiring activation of the PI3K pathway in the endothelial cell ${ }^{46}$, including the insulin receptor, insulin receptor substrate 1 (IRS-1), insulin receptor substrate 2 (IRS-2) ${ }^{62}$, phosphoinositide-dependent kinase 1 (PDK-1), and protein kinase B (Akt) (Fig. 1.1). ${ }^{46,48}$ In contrast to muscle cells, this activation does not result in translocation of GLUT-4 to the cell surface, but in the production of NO due to increased endothelial NO synthase (eNOS) activity (Fig. 1.1). ${ }^{46}$ Consequently, insulin-induced stimulation of endothelial cells leads to increased NO production, which stimulates capillary recruitment ${ }^{46}$ and transendothelial transport of insulin. ${ }^{63}$ In addition, however, insulin also has vasoconstrictor effects through the production of endothelin-1 (ET-1) through stimulation of the intracellular MAP kinase signalling (MAPK) pathway and extracellular signal-regulated kinase-1/2 (ERK1/2) (Fig. 1.1). ${ }^{46}$ In physiological conditions, when insulin binds to the insulin or insulin-like growth factor receptor on endothelial cells ${ }^{64}$, the net result usually favours NO production $^{6}$ and thus vasodilatation and capillary recruitment. 


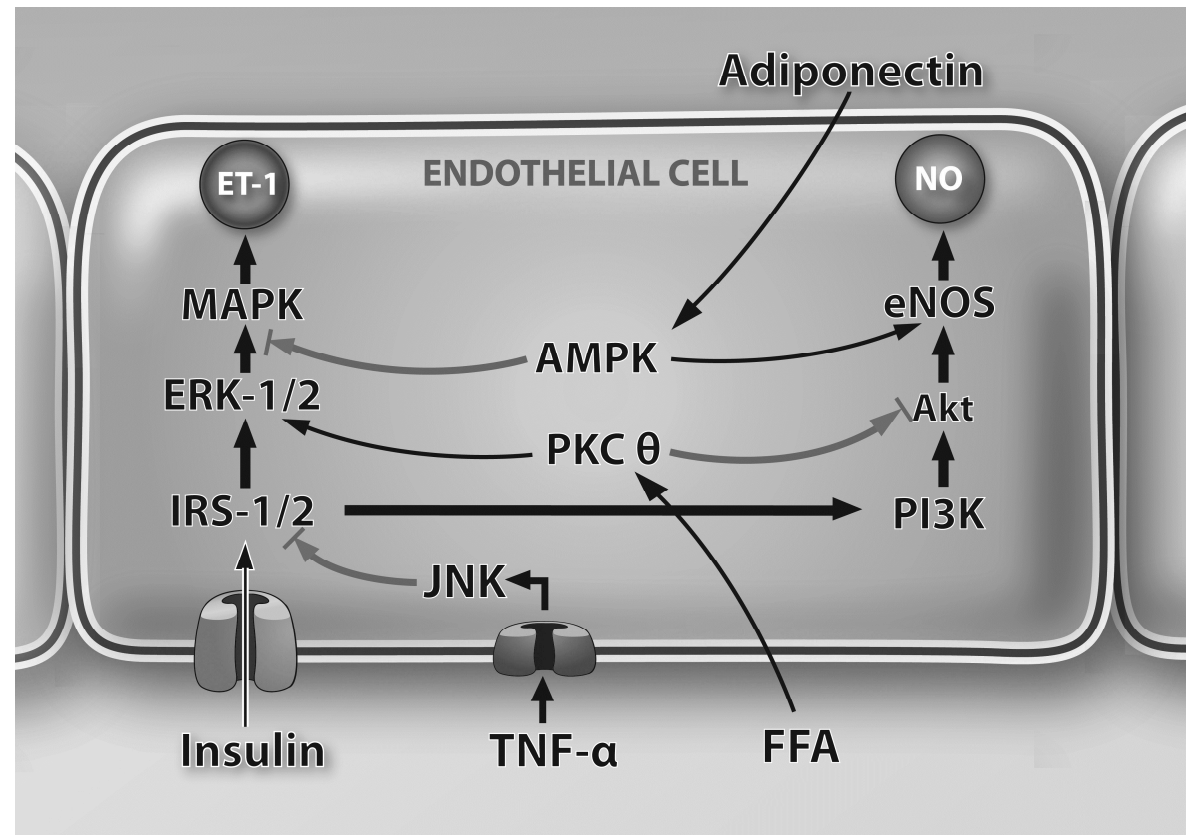

Figure 1.1. When insulin binds to the insulin receptor of endothelial cells, the PI3K and MAPK pathways in the endothelial cell are activated. These activations lead to the production of NO and ET-1, resulting in vasodilatation and vasoconstriction respectively. Normally, the net result usually favours NO production, resulting in a redirection of blood flow in skeletal muscle from non-nutritive capillaries to nutritive capillaries, thereby increasing insulin-mediated glucose uptake by skeletal muscle. In obesity, there is an increase in several circulating adipose tissue-derived factors, in particular FFA and TNF- $\alpha$, whereas the anti-inflammatory adipokine adiponectin is decreased. FFA and TNF- $\alpha$ affect the insulin signaling pathway in endothelial cells by the activation of PKC $\theta$ and JNK respectively. In addition, decreased adiponectin levels decrease AMPK phosphorylation. Accordingly, these endocrine factors are likely candidates to influence insulin signalling pathways (i.e. decreased PI3K activation and increased ERK-1/2 activation) in endothelial cells, thereby impairing insulin-mediated vasodilatation and capillary recruitment, and thus skeletal muscle glucose uptake. - , stimulation; inhibition; IRS-1/2, insulin receptor substrate 1/2; PI3K, phosphatidylinositol-kinase-dependent; Akt, protein kinase $B$; eNOS, endothelial nitric oxide synthase; NO, nitric oxide; ERK-1/2, extracellular signalregulatedkinase$1 / 2$; ET-1, endothelin-1; FFA, free fatty acids; TNF- $\alpha$, tumor necrosis factor- $\alpha$; JNK, intracellular enzyme c-Jun Nterminal kinase; PKC $\theta$, protein kinase $C$; AMPK, $5^{\prime}$ adenosine monophosphate-activated protein kinase

There now is substantial evidence, derived from both animal experiments and observations in humans, that this pathway is an important determinant of insulinmediated glucose uptake in muscle. Thus, Clark and colleagues ${ }^{40}$ were the first to report insulin-mediated capillary recruitment in skeletal muscle of the rat hind limb. In subsequent in vivo rat studies, the effect of insulin on capillary perfusion was confirmed. ${ }^{60,65,66}$ In human muscle, it was established that insulin increased microvascular blood volume. ${ }^{67,68}$ In addition, hyperinsulinaemia was shown to enhance skin postocclusive capillary recruitment and microvascular vasomotion. ${ }^{69,70}$ Moreover, capillary recruitment and acetylcholine-mediated vasodilatation of both skin and resistance 
arteries were strongly associated with insulin sensitivity. ${ }^{71-75}$ In further support of the physiological importance of insulin-mediated capillary recruitment, several studies have demonstrated that insulin-mediated capillary recruitment contributes to glucose disposal in skeletal muscle. ${ }^{12,58,61,62,68,76,77}$ In subsequent studies, it was established that approximately $40 \%$ of insulin-mediated glucose uptake by skeletal muscle can be attributed to capillary recruitment. ${ }^{61,78,79}$ In pathophysiological conditions, both obese Zucker rats ${ }^{80}$ and obese insulin-resistant humans ${ }^{12-14,67,71,77,81-86}$ are characterized by impaired capillary recruitment as well as impaired insulin-mediated glucose uptake by skeletal muscle in the basal state and during hyperinsulinaemia.

In accordance, accumulating evidence supports the hypothesis that microvascular dysfunction precedes and even predicts the development T2DM. First, studies which examined diet-induced insulin resistance in both vasculature and skeletal muscle demonstrated that microvascular endothelial dysfunction develops well before impaired insulin activation of PI3K in skeletal muscle. ${ }^{87,88}$ Second, a recent study demonstrated reduced insulin-mediated glucose uptake by skeletal muscle in tissue-specific knockout mice lacking IRS-2 in endothelial cells. ${ }^{62}$ Importantly, glucose uptake by isolated skeletal muscle from these mice was not impaired, indicating that microvascular endothelial dysfunction causes impaired insulin-mediated glucose uptake even while insulin signalling pathways in skeletal muscle cells are intact. ${ }^{62}$

In summary, these findings strongly support the hypothesis that microvascular dysfunction is a cause of insulin resistance, by affecting insulin-mediated glucose uptake by skeletal muscle through impaired capillary recruitment (Fig. 1.2). ${ }^{4-7}$ Subsequently, the hyperglycaemia and hyperinsulinaemia that evolve from metabolic insulin resistance can further impair endothelial dysfunction (and thus capillary recruitment) ${ }^{89-91}$ and glucose disposal $^{19}$, which results in a vicious circle (Fig. 1.2).

Importantly, by increasing peripheral vascular resistance, microvascular dysfunction can also contribute to the development of hypertension (Fig. 1.2), which suggests that microvascular dysfunction constitutes one of the links between insulin resistance and hypertension in the metabolic syndrome (reviewed elsewhere ${ }^{4-7}$ ). 


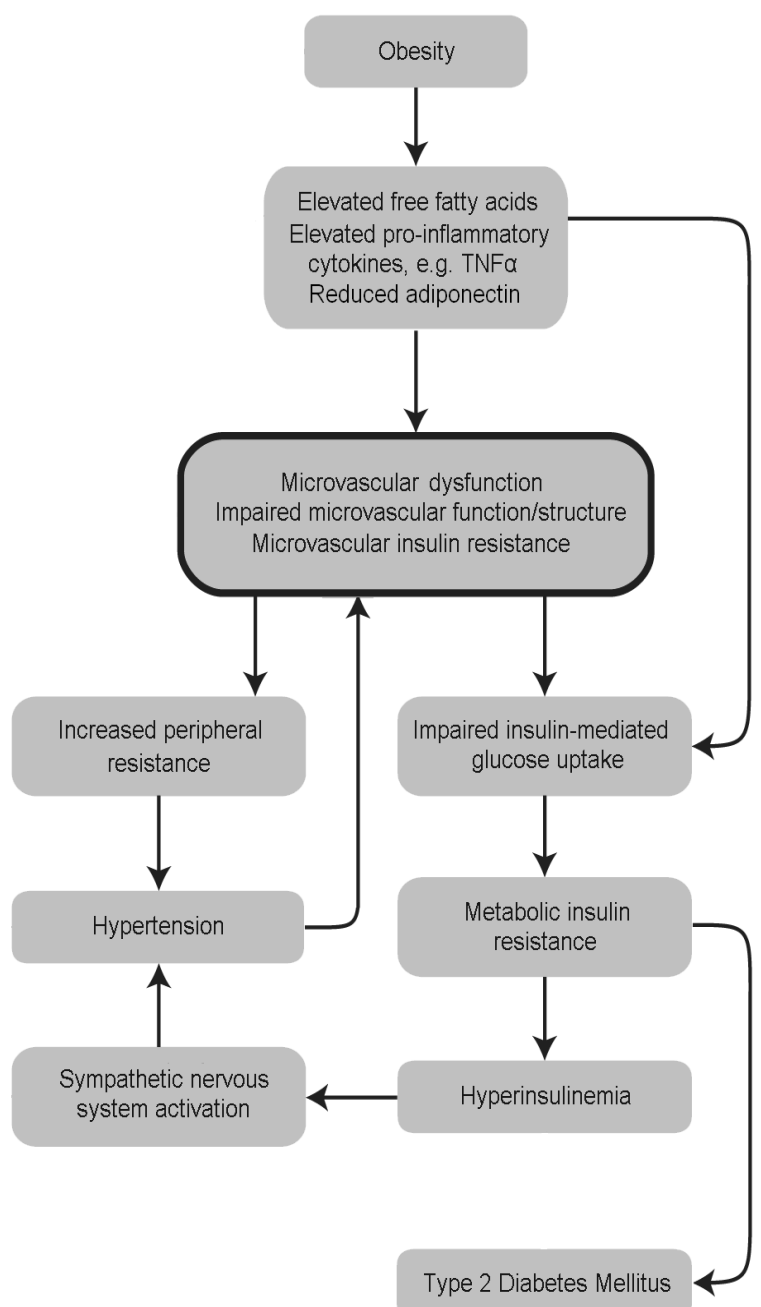

Figure 1.2. Hypothesis describing microvascular dysfunction as an intermediate step linking central obesity to insulin resistance (and, downstream, T2DM) and hypertension (adapted with permission from Jonk ${ }^{19}$ ). TNF- $\alpha$, tumor necrosis factor- $\alpha$

\section{OBESITY: A CAUSE OF MICROVASCULAR DYSFUNCTION}

Several mechanisms may be involved in the development of obesity-related microvascular dysfunction. In the following subsections the two main mechanisms will be discussed. 


\section{OBESITY-RELATED INTRACELLULAR SIGNALING}

We $\mathrm{e}^{12-14}$ and others ${ }^{15,16,67,92,93}$ have demonstrated that microvascular dysfunction is impaired in obesity and that microvascular dysfunction develops progressively along with an increase in adipose tissue. ${ }^{47,72,94}$ In obesity, insulin-mediated activation of the PI3K pathway in endothelial cells is selectively impaired while the insulin-mediated activation of ERK-1/2 is intact ${ }^{47,95}$, i.e., there is endothelial or microvascular insulin resistance with regard to insulin's vasodilator actions. For example, studies in diet-induced obesity in animals revealed blunted PI3K signalling pathways in endothelial cells through impaired insulin-mediated phosphorylation of $\mathrm{Akt}^{87,96,97}$ and $\mathrm{eNOS}^{62,87,96,98}$, whereas insulinmediated ET-1 expression was unchanged. ${ }^{62,98}$

Thus, obesity-related microvascular dysfunction is characterized by cellular defects in endothelial cells that influence the balance between vasodilatation and vasoconstriction. The selective impairment in endothelial cells may contribute importantly to obesity-related insulin resistance (Fig. 1.2).

\section{OBESITY-RELATED ENDOCRINE SIGNALING}

The close association between adipose tissue and microvascular functioning strongly suggests signalling pathways between adipose tissue and the microcirculation. ${ }^{6,47}$ Adipose tissue and in particular visceral adipose tissue cells secrete a variety of bioactive substances called adipokines. ${ }^{6,47}$ In obesity, there is an enhanced production of free fatty acids (FFAs), tumor necrosis factor (TNF)- $\alpha$, leptin, resistin, and several other inflammatory cytokines ${ }^{6,47}$, whereas the production of adiponectin, an anti-inflammatory adipokine, is reduced. $^{6,99}$

Several studies have demonstrated that systemic FFA infusion inhibits insulinmediated capillary recruitment ${ }^{86,100-102}$ and forearm blood flow responses ${ }^{103}$ with subsequent blunted insulin-mediated glucose uptake by skeletal muscle. ${ }^{100-102,104-108}$ Conversely, lowering FFA levels in obese subjects improved basal and insulin-mediated capillary recruitment in obese insulin-resistant individuals. ${ }^{86}$ FFA may induce insulin resistance through activation of protein kinase $C$ (PKC) $\theta$ which subsequently inhibits insulin-mediated phosphorylation of Akt and stimulates ERK-1/2 (Fig. 1.1). ${ }^{109}$

TNF- $\alpha$ inhibits both insulin-mediated capillary recruitment and insulin-mediated glucose uptake by skeletal muscle. ${ }^{94,110,111}$ TNF- $\alpha$ may induce endothelial insulin resistance trough activation of intracellular enzyme c-Jun $\mathrm{N}$-terminal kinase (JNK). ${ }^{112}$ JNK has been shown to regulate both whole-body insulin sensitivity and insulin-mediated cell signalling. ${ }^{47,113}$ Hence, activation of JNK impairs the PI3K pathway and stimulates the phosphorylation of ERK-1/2 in endothelial cells ${ }^{112,114}$, resulting in insulin-mediated 
vasoconstriction (Fig. 1.1). ${ }^{47}$ Conversely, a recent study found that specific inhibition of JNK in $d b / d b$ mice can restore the blunted insulin-mediated vasodilatation. ${ }^{115}$

Adiponectin has been shown to increase insulin sensitivity and improve vascular function. ${ }^{116}$ These beneficial effects are probably attributable to stimulation of $5^{\prime}$ adenosine monophosphate-activated protein kinase (AMPK) phosphorylation by adiponectin, which enhances insulin-mediated vasodilatation through increased eNOS phosphorylation and decreased ERK-1/2 stimulation (Fig. 1.1). ${ }^{117,118}$ In addition, adiponectin itself can reduce the production of proinflammatory cytokines, which has favourable effects of insulin-signalling pathways. ${ }^{5,119,120}$ In obesity, adiponectin levels are decreased, which is probably caused by TNF $\alpha$ and IL-6, as well as by other inflammatory mediators. $^{5,120,121}$

Another important system that has been suggested to be involved in microvascular functioning is the renin-angiotensin system (RAS). ${ }^{6}$ All the components of the RAS necessary to generate the vasoconstrictor angiotensin II (AngII) are expressed in human adipose tissue. ${ }^{6,122,123}$ In obese subjects there is enhanced activation of the RAS, which may directly relate to the mass of adipose tissue. ${ }^{6,124}$ Enhanced RAS activity may have detrimental effects on insulin-mediated skeletal muscle glucose uptake by 1) affecting insulin-mediated IRS-1 phosphorylation in endothelial cells ${ }^{125,126}$; 2) production of reactive oxygen species (ROS), which reduce NO bioavailability ${ }^{127,128}$; and 3) stimulation of the release of ET-1. ${ }^{129,130}$

In addition to the above, leptin and other cytokines and chemokines have also been implicated in the pathogenesis of endothelial or (micro)vascular insulin resistance (reviewed elsewhere ${ }^{5,120,131,132}$ ).

In summary, in obesity, there is an increase in several circulating adipose tissuederived factors, in particular FFA and TNF- $\alpha$, whereas the anti-inflammatory adipokine, adiponectin, is decreased. These endocrine factors are likely candidates to influence insulin signalling pathways in endothelial cells, thereby causing both impaired insulinmediated vasodilatation and impaired skeletal muscle glucose uptake (Fig. 1.1). ${ }^{6}$ Hence, these endocrine factors provide a potential link between obesity-related microcirculatory dysfunction and obesity-related insulin resistance (Fig. 1.2). ${ }^{6}$ In addition to these systemic endocrine effects, we and others have postulated a vasoregulatory role for local deposits of fat next to the microvasculature (i.e. perivascular adipose tissue, PVAT). ${ }^{6,47,133}$ Adipokines released by these fat cells may directly inhibit vasodilatory pathways locally, and thus have a local rather than a systemic vasoregulatory effect, which we named "vasocrine". $6,47,133$ A recent animal study demonstrated dramatic increases in PVAT in muscle of $d b / d b$ mice. In addition, these mice had a reduction in adiponectin release by PVAT and decreased insulin-mediated vasodilatation ${ }^{115}$, indicating that PVAT induces microvascular dysfunction by influencing insulin signalling and thereby insulin's microvascular effects. ${ }^{4}$ 


\section{CONCLUDING REMARKS}

Considerable evidence exists that microvascular dysfunction is a key feature in the development of obesity-related T2DM. Obesity is associated with microvascular dysfunction through alterations in endocrine and vasocrine signals that cause alterations in microvascular endothelial and skeletal muscle intracellular signalling. Microvascular dysfunction, in turn, may contribute to both the development of T2DM - by impairing the timely access of glucose and insulin to their target tissues (Fig. 1.2).

Importantly, it is generally accepted that T2DM causes clinically apparent diabetic microangiopathy including retinopathy, neuropathy, and nephropathy. ${ }^{8-10}$ Changes in microvascular function and structure underlie the pathogenesis of diabetic microangiopathy. ${ }^{134}$ In addition, T2DM is associated with organ damage in the heart and the brain, leading to heart failure, cognitive decline, and depression, ${ }^{135-137}$ which can occur even in the absence of clinically apparent diabetic microangiopathy. ${ }^{138,139}$ A potential explanation to explain such findings is that T2DM can be associated with microvascular dysfunction that is not detected by standard clinical examination. Therefore, it is possible to envisage a vicious circle of progressive microvascular dysfunction, caused by obesity, which contributes to the development of T2DM, which, in turn, contributes to a further deterioration of microvascular function, and, ultimately, to the development of structural microvascular changes and diabetic microangiopathy (Fig 1.3).

As microvascular vasomotion may be an important component of microcirculatory function - by ensuring optimal delivery of nutrients and oxygen to tissue and regulating local hydraulic resistance ${ }^{14,41,42}$-, an impaired vasomotion, initiated by obesity, may have negative effects on the delivery of nutrients and oxygen to tissue and local hydraulic resistance and thus microvascular functioning. This, in turn, may contribute to the development of T2DM (Fig. 1.3).

To date, most studies on the role of microvascular dysfunction in the development of obesity-related T2DM have been conducted in small groups of highly selected patients. For instance, in a study investigating microvascular function in obesity, lean subjects with a body mass index (BMI) $21.3 \pm 1.9 \mathrm{~kg} / \mathrm{m}^{2}$ were compared with obese subjects with a BMI of $38.8 \pm 7.0 \mathrm{~kg} / \mathrm{m}^{2}{ }^{12}$ In addition, evidence how microvascular dysfunction relates to general cardiovascular risk factors, such as cholesterol and smoking, is scarce. It is therefore necessary to investigate the (longitudinal) associations of obesity, T2DM, and other cardiovascular risk factors with microvascular dysfunction with an epidemiological approach. An epidemiological approach has several advantages over small-scale experimental studies, since 1) it enables investigation of relatively unbiased associations (i.e., without selection bias and without [or with proper adjustment for] confounding), 2) it enables assessment of multiple exposures and multiple outcomes, and 3) longitudinal studies provide more information about the underlying associations. ${ }^{140}$ 


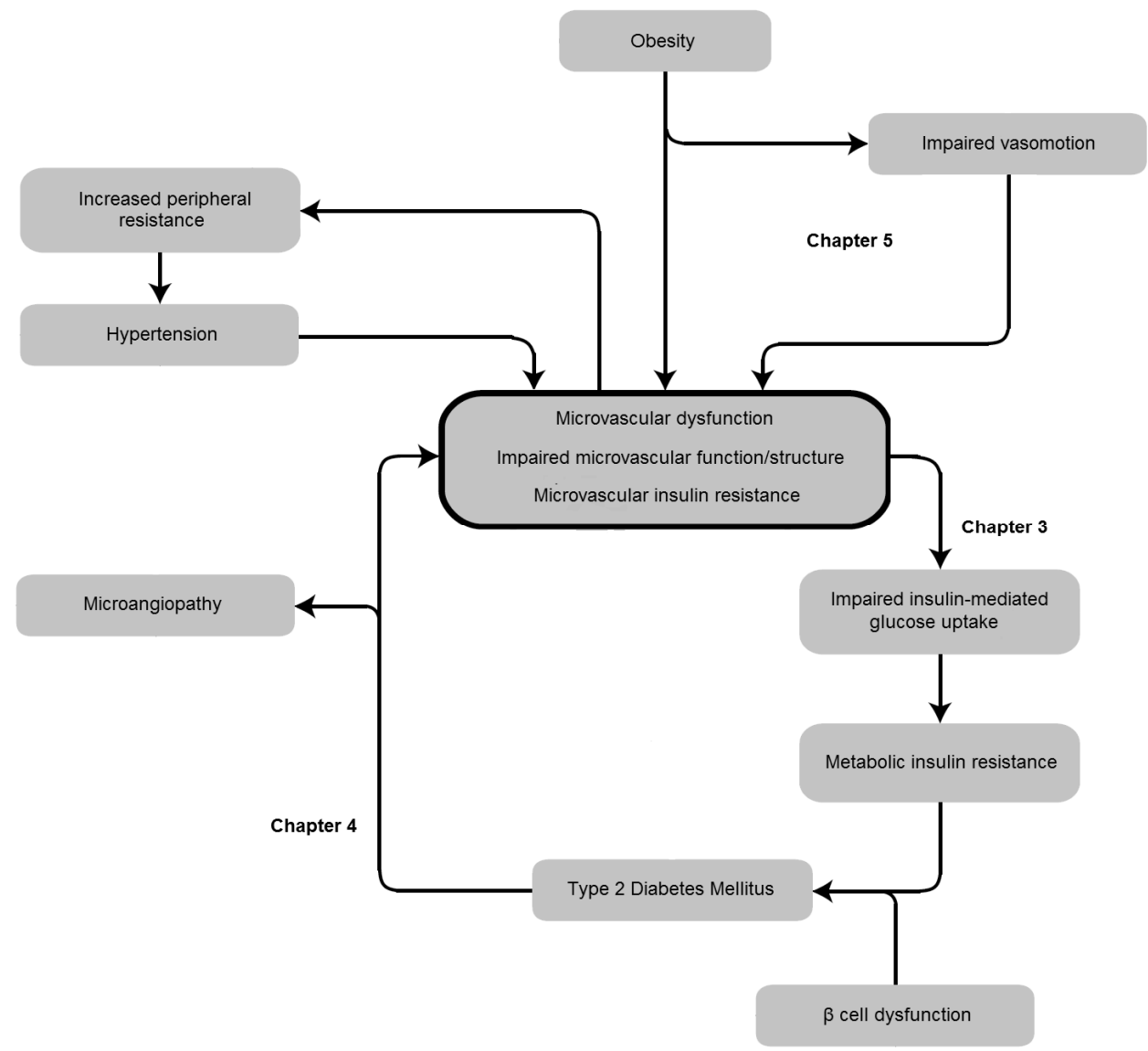

Figure 1.3. Hypothesis describing how microvascular dysfunction, initiated by obesity, contributes to the development of T2DM, which in turn, contributes to a further deterioration of microvascular function, and ultimately to the development of diabetic microangiopathy. In addition, impaired vasomotion, as an important component of microvascular function, may have negative effects on the delivery of nutrients and oxygen to tissues and on local hydraulic resistance and thus on microvascular functioning. 


\section{OUTLINE OF THE THESIS}

Since epidemiological evidence on the role of microvascular dysfunction in the development of T2DM is largely lacking, the general aim of this thesis was to investigate the associations of microvascular dysfunction with T2DM and long-term hyperglycaemia with an epidemiological approach. In chapter 2 we provide a detailed description of the concepts and techniques we used for the assessment of microvascular function. In general, assessment of microvascular function in specific vascular beds - especially the assessment of skin capillary density - is technically demanding and time-consuming, and is thus mostly used in relatively small-scale, experimental studies. Therefore, we first developed a semi-automatic method for the assessment of skin capillary density, which facilitates the use of skin capillaroscopy in large-scale studies. In chapter $\mathbf{2 . 3}$ we describe this new technique and present accuracy, reproducibility and efficiency results.

Since the early 2000s, a growing number of prospective studies have investigated the association between various estimates of microvascular dysfunction (e.g., in eye and kidney) with both incident impaired fasting glucose (IFG) and T2DM. In order to test the hypothesis that microvascular dysfunction is associated with incident IFG and T2DM, we conducted a systematic review and meta-analysis (chapter 3; Fig 1.3).

In order to test the hypothesis that changes in microvascular function and structure can be present in T2DM even in the absence of clinical evidence of microangiopathy, we investigated the cross-sectional association of T2DM and long-term hyperglycaemia with functional and structural capillary density in the skin (chapter 4; Fig. 1.3).

The periodical fluctuations of flow produced by vasomotion are known as microvascular flowmotion. Skin microvascular flowmotion (SMF) can easily be assessed using laser-Doppler flowmetry. ${ }^{41}$ In order to test the hypothesis that microvascular vasomotion (i.e., SMF) is altered in obesity, T2DM, and hypertension (Fig. 1.3), we investigated the cross-sectional associations of cardiovascular risk factors (i.e., age, sex, waist circumference, total-to-HDL cholesterol ratio, 24-h systolic blood pressure, and pack years of smoking) with SMF, which is described in chapter 5 (Fig. 1.3).

Finally, chapter 6 summarizes and discusses the results of the studies in this thesis and implications for future research. 


\section{REFERENCES}

1. Flegal KM, Carroll MD, Kit BK, Ogden CL. Prevalence of obesity and trends in the distribution of body mass index among US adults, 1999-2010. JAMA 2012;307:491-7.

2. Han TS, Feskens EJ, Lean ME, Seidell JC. Associations of body composition with type 2 diabetes mellitus. Diabet Med 1998;15:129-35.

3. Federation ID: Spreadsheet: prevalence estimated of diabetes mellitus (DM), 2010. Brussel, Belgium. International Diabetes Federation: IDF diabetes atlas, 2010.

4. de Boer MP, Meijer RI, Wijnstok NJ, Jonk AM, Houben AJ, Stehouwer CD, Smulders YM, Eringa EC, Serne EH. Microvascular dysfunction: a potential mechanism in the pathogenesis of obesity-associated insulin resistance and hypertension. Microcirculation 2012;19:5-18.

5. Houben AJ, Eringa EC, Jonk AM, Serne EH, Smulders YM, Stehouwer CD. Perivascular fat and the microcirculation: relevance to insulin resistance, diabetes, and cardiovascular disease. Curr Cardiovasc Risk Rep 2012;6:80-90.

6. Jonk AM, Houben AJ, de Jongh RT, Serne EH, Schaper NC, Stehouwer CD. Microvascular dysfunction in obesity: a potential mechanism in the pathogenesis of obesity-associated insulin resistance and hypertension. Physiology (Bethesda) 2007;22:252-60.

7. Levy BI, Schiffrin EL, Mourad JJ, Agostini D, Vicaut E, Safar ME, Struijker-Boudier HA. Impaired tissue perfusion: a pathology common to hypertension, obesity, and diabetes mellitus. Circulation 2008;118:96876.

8. Struijker Boudier HA, le Noble JL, Messing MW, Huijberts MS, le Noble FA, van Essen H. The microcirculation and hypertension. J Hypertens Suppl 1992;10:S147-56.

9. Tooke JE, Goh KL. Vascular function in Type 2 diabetes mellitus and pre-diabetes: the case for intrinsic endotheiopathy. Diabet Med 1999;16:710-5.

10. Schalkwijk CG, Stehouwer CD. Vascular complications in diabetes mellitus: the role of endothelial dysfunction. Clin Sci (Lond) 2005;109:143-59.

11. Levy BI, Ambrosio G, Pries AR, Struijker-Boudier HA. Microcirculation in hypertension: a new target for treatment? Circulation 2001;104:735-40.

12. de Jongh RT, Serne EH, IJzerman RG, de Vries G, Stehouwer CD. Impaired microvascular function in obesity: implications for obesity-associated microangiopathy, hypertension, and insulin resistance. Circulation 2004;109:2529-35.

13. Jonk AM, Houben AJ, Schaper NC, de Leeuw PW, Serne EH, Smulders YM, Stehouwer CD. Obesity is associated with impaired endothelial function in the postprandial state. Microvasc Res 2011;82:423-9.

14. Jonk AM, Houben AJ, Schaper NC, de Leeuw PW, Serne EH, Smulders YM, Stehouwer CD. Meal-related increases in microvascular vasomotion are impaired in obese individuals: a potential mechanism in the pathogenesis of obesity-related insulin resistance. Diabetes Care 2011;34 Suppl 2:S342-8.

15. Agapitov AV, Correia ML, Sinkey CA, Dopp JM, Haynes WG. Impaired skeletal muscle and skin microcirculatory function in human obesity. J Hypertens 2002;20:1401-5.

16. Keske MA, Clerk LH, Price WJ, Jahn LA, Barrett EJ. Obesity blunts microvascular recruitment in human forearm muscle after a mixed meal. Diabetes Care 2009;32:1672-7.

17. Verdant C, De Backer D. How monitoring of the microcirculation may help us at the bedside. Curr Opin Crit Care 2005;11:240-4.

18. Knotzer $\mathrm{H}$, Hasibeder WR. Microcirculatory function monitoring at the bedside--a view from the intensive care. Physiol Meas 2007;28:R65-86.

19. Jonk AM. Microvascular actions of insulin: studies on the interaction with angiotensin $I I$ and on the postprandial state. Amsterdam: GVO drukkers \& vormgevers B.V.; Ponsen \& Looijen, 2011.

20. Minson CT, Berry LT, Joyner MJ. Nitric oxide and neurally mediated regulation of skin blood flow during local heating. J Appl Physiol 2001;91:1619-26.

21. Serne EH, Gans RO, ter Maaten JC, Tangelder GJ, Donker AJ, Stehouwer CD. Impaired skin capillary recruitment in essential hypertension is caused by both functional and structural capillary rarefaction. Hypertension 2001;38:238-42.

22. Houben AJ, Stehouwer CD. Retinal microvascular abnormalities: can they predict future risk of hypertension? J Hypertens 2009;27:2346-8. 
23. Ikram MK, de Jong FJ, Vingerling JR, Witteman JC, Hofman A, Breteler MM, de Jong PT. Are retinal arteriolar or venular diameters associated with markers for cardiovascular disorders? The Rotterdam Study. Invest Ophthalmol Vis Sci 2004;45:2129-34.

24. Klein R, Sharrett AR, Klein BE, Chambless LE, Cooper LS, Hubbard LD, Evans G. Are retinal arteriolar abnormalities related to atherosclerosis?: the atherosclerosis risk in communities study. Arterioscler Thromb Vasc Biol 2000;20:1644-50.

25. Wong TY, Islam FM, Klein R, Klein BE, Cotch MF, Castro C, Sharrett AR, Shahar E. Retinal vascular caliber, cardiovascular risk factors, and inflammation: the multi-ethnic study of atherosclerosis (MESA). Invest Ophthalmol Vis Sci 2006;47:2341-50.

26. Wilkinson-Berka JL. Vasoactive factors and diabetic retinopathy: vascular endothelial growth factor, cycoloxygenase-2 and nitric oxide. Curr Pharm Des 2004;10:3331-48.

27. Delles C, Michelson G, Harazny J, Oehmer S, Hilgers KF, Schmieder RE. Impaired endothelial function of the retinal vasculature in hypertensive patients. Stroke 2004;35:1289-93.

28. Stehouwer CD. Is measurement of endothelial dysfunction clinically useful? Eur J Clin Invest 1999;29:459-61.

29. Kubes $P$, Kerfoot $S M$. Leukocyte recruitment in the microcirculation: the rolling paradigm revisited. News Physiol Sci 2001;16:76-80.

30. Stehouwer CD. Endothelial dysfunction in diabetic nephropathy: state of the art and potential significance for non-diabetic renal disease. Nephrol Dial Transplant 2004;19:778-81.

31. Stehouwer CD, Lambert J, Donker AJ, van Hinsbergh VW. Endothelial dysfunction and pathogenesis of diabetic angiopathy. Cardiovasc Res 1997;34:55-68.

32. Kasprzak JD, Klosinska M, Drozdz J. Clinical aspects of assessment of endothelial function. Pharmacol Rep 2006;58:33-40.

33. Schram MT, Stehouwer CD. Endothelial dysfunction, cellular adhesion molecules and the metabolic syndrome. Horm Metab Res 2005;37 Suppl 1:49-55.

34. Szmitko PE, Wang CH, Weisel RD, de Almeida JR, Anderson TJ, Verma S. New markers of inflammation and endothelial cell activation: Part I. Circulation 2003;108:1917-23.

35. Wolinsky H. A proposal linking clearance of circulating lipoproteins to tissue metabolic activity as a basis for understanding atherogenesis. Circ Res 1980;47:301-11.

36. Deckert T, Feldt-Rasmussen B, Borch-Johnsen K, Jensen T, Kofoed-Enevoldsen A. Albuminuria reflects widespread vascular damage. The Steno hypothesis. Diabetologia 1989;32:219-26.

37. Jensen T, Bjerre-Knudsen J, Feldt-Rasmussen B, Deckert T. Features of endothelial dysfunction in early diabetic nephropathy. Lancet 1989;1:461-3.

38. Ochodnicky $\mathrm{P}$, Henning RH, van Dokkum RP, de Zeeuw D. Microalbuminuria and endothelial dysfunction: emerging targets for primary prevention of end-organ damage. J Cardiovasc Pharmacol 2006;47 Suppl 2:S151-62.

39. Stehouwer CD, Smulders YM. Microalbuminuria and risk for cardiovascular disease: Analysis of potential mechanisms. J Am Soc Nephrol 2006;17:2106-11.

40. Rattigan S, Clark MG, Barrett EJ. Hemodynamic actions of insulin in rat skeletal muscle: evidence for capillary recruitment. Diabetes 1997;46:1381-8.

41. Aalkjaer C, Boedtkjer D, Matchkov V. Vasomotion - what is currently thought? Acta Physiol (Oxf) 2011;202:253-69.

42. Intaglietta M. Vasomotion and flowmotion: physiological mechanisms and clinical evidence. Vascular Medicine 1990;1:101-12.

43. Kvandal P, Landsverk SA, Bernjak A, Stefanovska A, Kvernmo HD, Kirkeboen KA. Low-frequency oscillations of the laser Doppler perfusion signal in human skin. Microvasc Res 2006;72:120-7.

44. Kvandal P, Stefanovska A, Veber M, Kvernmo HD, Kirkeboen KA. Regulation of human cutaneous circulation evaluated by laser Doppler flowmetry, iontophoresis, and spectral analysis: importance of nitric oxide and prostaglandines. Microvasc Res 2003;65:160-71.

45. Stefanovska A, Bracic M, Kvernmo HD. Wavelet analysis of oscillations in the peripheral blood circulation measured by laser Doppler technique. IEEE Trans Biomed Eng 1999;46:1230-9.

46. Kim JA, Montagnani M, Koh KK, Quon MJ. Reciprocal relationships between insulin resistance and endothelial dysfunction: molecular and pathophysiological mechanisms. Circulation 2006;113:1888-904.

47. Serne EH, de Jongh RT, Eringa EC, RG IJ, Stehouwer CD. Microvascular dysfunction: a potential pathophysiological role in the metabolic syndrome. Hypertension 2007;50:204-11.

48. Shulman GI. Cellular mechanisms of insulin resistance. J Clin Invest 2000;106:171-6. 
49. Shulman GI. Unraveling the cellular mechanism of insulin resistance in humans: new insights from magnetic resonance spectroscopy. Physiology (Bethesda) 2004;19:183-90.

50. Hotamisligil GS. Inflammation and metabolic disorders. Nature 2006;444:860-7.

51. Savage DB, Petersen KF, Shulman GI. Disordered lipid metabolism and the pathogenesis of insulin resistance. Physiol Rev 2007;87:507-20.

52. Karlsson HK, Zierath JR. Insulin signaling and glucose transport in insulin resistant human skeletal muscle. Cell Biochem Biophys 2007;48:103-13.

53. Taubes G. Insulin resistance. Prosperity's plague. Science 2009;325:256-60.

54. Laakso M, Edelman SV, Brechtel G, Baron AD. Decreased effect of insulin to stimulate skeletal muscle blood flow in obese man. A novel mechanism for insulin resistance. J Clin Invest 1990;85:1844-52.

55. Baron AD, Steinberg $H$, Brechtel $G$, Johnson A. Skeletal muscle blood flow independently modulates insulinmediated glucose uptake. Am J Physiol 1994;266:E248-53.

56. de Haan CH, van Dielen FM, Houben AJ, de Leeuw PW, Huvers FC, De Mey JG, Wolffenbuttel BH, Schaper NC. Peripheral blood flow and noradrenaline responsiveness: the effect of physiological hyperinsulinemia. Cardiovasc Res 1997;34:192-8.

57. Tack CJ, Lutterman JA, Vervoort G, Thien T, Smits P. Activation of the sodium-potassium pump contributes to insulin-induced vasodilation in humans. Hypertension 1996;28:426-32.

58. Clark MG, Wallis MG, Barrett EJ, Vincent MA, Richards SM, Clerk LH, Rattigan S. Blood flow and muscle metabolism: a focus on insulin action. Am J Physiol Endocrinol Metab 2003;284:E241-58.

59. Yki-Jarvinen $\mathrm{H}$, Utriainen T. Insulin-induced vasodilatation: physiology or pharmacology? Diabetologia 1998;41:369-79.

60. Zhang L, Vincent MA, Richards SM, Clerk LH, Rattigan S, Clark MG, Barrett EJ. Insulin sensitivity of muscle capillary recruitment in vivo. Diabetes 2004;53:447-53.

61. Vincent MA, Clerk LH, Lindner JR, Klibanov AL, Clark MG, Rattigan S, Barrett EJ. Microvascular recruitment is an early insulin effect that regulates skeletal muscle glucose uptake in vivo. Diabetes 2004; 53: 1418-23.

62. Kubota T, Kubota N, Kumagai H, Yamaguchi S, Kozono H, Takahashi T, Inoue M, Itoh S, Takamoto I, Sasako T, Kumagai K, Kawai T, Hashimoto S, Kobayashi T, Sato M, Tokuyama K, Nishimura S, Tsunoda M, Ide T, Murakami K, Yamazaki T, Ezaki O, Kawamura K, Masuda H, Moroi M, Sugi K, Oike Y, Shimokawa H, Yanagihara N, Tsutsui M, Terauchi Y, Tobe K, Nagai R, Kamata K, Inoue K, Kodama T, Ueki K, Kadowaki T. Impaired insulin signaling in endothelial cells reduces insulin-induced glucose uptake by skeletal muscle. Cell Metab 2011;13:294-307.

63. Wang $H$, Wang $A X$, Barrett EJ. Insulin-induced endothelial cell cortical actin filament remodeling: a requirement for trans-endothelial insulin transport. Mol Endocrinol 2012;26:1327-38.

64. Johansson GS, Chisalita SI, Arnqvist HJ. Human microvascular endothelial cells are sensitive to IGF-I but resistant to insulin at the receptor level. Mol Cell Endocrinol 2008;296:58-63.

65. Clark AD, Barrett EJ, Rattigan S, Wallis MG, Clark MG. Insulin stimulates laser Doppler signal by rat muscle in vivo, consistent with nutritive flow recruitment. Clin Sci (Lond) 2001;100:283-90.

66. Vincent MA, Dawson D, Clark AD, Lindner JR, Rattigan S, Clark MG, Barrett EJ. Skeletal muscle microvascular recruitment by physiological hyperinsulinemia precedes increases in total blood flow. Diabetes 2002;51:428.

67. Clerk LH, Vincent MA, Jahn LA, Liu Z, Lindner JR, Barrett EJ. Obesity blunts insulin-mediated microvascular recruitment in human forearm muscle. Diabetes 2006;55:1436-42.

68. Coggins M, Lindner J, Rattigan S, Jahn L, Fasy E, Kaul S, Barrett E. Physiologic hyperinsulinemia enhances human skeletal muscle perfusion by capillary recruitment. Diabetes 2001;50:2682-90.

69. de Jongh RT, Clark AD, RG IJ, Serne EH, de Vries G, Stehouwer CD. Physiological hyperinsulinaemia increases intramuscular microvascular reactive hyperaemia and vasomotion in healthy volunteers. Diabetologia 2004;47:978-86.

70. Serne EH, Gans RO, ter Maaten JC, ter Wee PM, Donker AJ, Stehouwer CD. Capillary recruitment is impaired in essential hypertension and relates to insulin's metabolic and vascular actions. Cardiovasc Res 2001;49:161-8.

71. Francischetti EA, Tibirica E, da Silva EG, Rodrigues E, Celoria BM, de Abreu VG. Skin capillary density and microvascular reactivity in obese subjects with and without metabolic syndrome. Microvasc Res 2011;81:325-30.

72. Serne EH, Stehouwer CD, ter Maaten JC, ter Wee PM, Rauwerda JA, Donker AJ, Gans RO. Microvascular function relates to insulin sensitivity and blood pressure in normal subjects. Circulation 1999;99:896-902. 
73. Grassi G, Seravalle G, Scopelliti F, Dell'Oro R, Fattori L, Quarti-Trevano F, Brambilla G, Schiffrin EL, Mancia G. Structural and functional alterations of subcutaneous small resistance arteries in severe human obesity. Obesity (Silver Spring) 2010;18:92-8.

74. Lampinen $\mathrm{KH}$, Ronnback M, Groop PH, Kaaja RJ. A relationship between insulin sensitivity and vasodilation in women with a history of preeclamptic pregnancy. Hypertension 2008;52:394-401.

75. Clough GF, L'Esperance V, Turzyniecka M, Walter L, Chipperfield AJ, Gamble J, Krentz AJ, Byrne CD. Functional dilator capacity is independently associated with insulin sensitivity and age in central obesity and is not improved by high dose statin treatment. Microcirculation 2011;18:74-84.

76. Vincent MA, Clerk LH, Rattigan S, Clark MG, Barrett EJ. Active role for the vasculature in the delivery of insulin to skeletal muscle. Clin Exp Pharmacol Physiol 2005;32:302-7.

77. Serne EH, IJzerman RG, Gans RO, Nijveldt R, De Vries G, Evertz R, Donker AJ, Stehouwer CD. Direct evidence for insulin-induced capillary recruitment in skin of healthy subjects during physiological hyperinsulinemia. Diabetes 2002;51:1515-22.

78. Newman JM, Dwyer RM, St-Pierre P, Richards SM, Clark MG, Rattigan S. Decreased microvascular vasomotion and myogenic response in rat skeletal muscle in association with acute insulin resistance. J Physiol 2009;587:2579-88.

79. Vincent MA, Barrett EJ, Lindner JR, Clark MG, Rattigan S. Inhibiting NOS blocks microvascular recruitment and blunts muscle glucose uptake in response to insulin. Am J Physiol Endocrinol Metab 2003; 285: E123-9.

80. Wallis MG, Wheatley CM, Rattigan S, Barrett EJ, Clark AD, Clark MG. Insulin-mediated hemodynamic changes are impaired in muscle of Zucker obese rats. Diabetes 2002;51:3492-8.

81. Han KA, Patel Y, Lteif AA, Chisholm R, Mather KJ. Contributions of dysglycaemia, obesity, and insulin resistance to impaired endothelium-dependent vasodilation in humans. Diabetes Metab Res Rev 2011;27:354-61.

82. de Jongh RT, Serne EH, RG IJ, de Vries G, Stehouwer CD. Impaired microvascular function in obesity: implications for obesity-associated microangiopathy, hypertension, and insulin resistance. Circulation 2004;109:2529-35.

83. de Jongh RT, Serne EH, RG IJ, Jorstad HT, Stehouwer CD. Impaired local microvascular vasodilatory effects of insulin and reduced skin microvascular vasomotion in obese women. Microvasc Res 2008;75:256-62.

84. Ketel IJ, Serne EH, Ijzerman RG, Korsen TJ, Twisk JW, Hompes PG, Smulders YM, Homburg R, Vorstermans L, Stehouwer CD, Lambalk CB. Insulin-induced capillary recruitment is impaired in both lean and obese women with PCOS. Hum Reprod 2011;26:3130-7.

85. Ketel IJ, Stehouwer CD, Serne EH, Korsen TJ, Hompes PG, Smulders YM, de Jongh RT, Homburg R, Lambalk $\mathrm{CB}$. Obese but not normal-weight women with polycystic ovary syndrome are characterized by metabolic and microvascular insulin resistance. J Clin Endocrinol Metab 2008;93:3365-72.

86. de Jongh RT, Serne EH, ljzerman RG, de Vries G, Stehouwer CD. Free fatty acid levels modulate microvascular function: relevance for obesity-associated insulin resistance, hypertension, and microangiopathy. Diabetes 2004;53:2873-82.

87. Kim F, Pham M, Maloney E, Rizzo NO, Morton GJ, Wisse BE, Kirk EA, Chait A, Schwartz MW. Vascular inflammation, insulin resistance, and reduced nitric oxide production precede the onset of peripheral insulin resistance. Arterioscler Thromb Vasc Biol 2008;28:1982-8.

88. Bonner JS, Lantier L, Hasenour CM, James FD, Bracy DP, Wasserman DH. Muscle-specific vascular endothelial growth factor deletion induces muscle capillary rarefaction creating muscle insulin resistance. Diabetes 2013;62:572-80.

89. Chittari MV, McTernan P, Bawazeer N, Constantinides K, Ciotola M, O'Hare JP, Kumar S, Ceriello A. Impact of acute hyperglycaemia on endothelial function and retinal vascular reactivity in patients with Type 2 diabetes. Diabet Med 2011;28:450-4.

90. Giugliano D, Marfella R, Coppola L, Verrazzo G, Acampora R, Giunta R, Nappo F, Lucarelli C, D'Onofrio F. Vascular effects of acute hyperglycemia in humans are reversed by L-arginine. Evidence for reduced availability of nitric oxide during hyperglycemia. Circulation 1997;95:1783-90.

91. Watanabe K, Oba K, Suzuki T, Ouchi M, Suzuki K, Futami-Suda S, Sekimizu K, Yamamoto N, Nakano H. Oral glucose loading attenuates endothelial function in normal individual. Eur J Clin Invest 2011;41:465-73.

92. Steinberg HO, Chaker $H$, Leaming $R$, Johnson A, Brechtel $G$, Baron AD. Obesity/Insulin resistance is associated with endothelial dysfunction. Implications for the syndrome of insulin resistance. J Clin Invest 1996;47:310-13. 
93. Costa RR, Villela NR, Souza MG, Boa BC, Cyrino FZ, Silva SV, Lisboa PC, Moura EG, Barja-Fidalgo TC, Bouskela $\mathrm{E}$. High fat diet induces central obesity, insulin resistance and microvascular dysfunction in hamsters. Microvasc Res 2011;82:416-22.

94. de Jongh RT, Ijzerman RG, Serne EH, Voordouw JJ, Yudkin JS, de Waal HA, Stehouwer CD, van Weissenbruch $\mathrm{MM}$. Visceral and truncal subcutaneous adipose tissue are associated with impaired capillary recruitment in healthy individuals. J Clin Endocrinol Metab 2006;91:5100-6.

95. Jiang ZY, Lin YW, Clemont A, Feener EP, Hein KD, Igarashi M, Yamauchi T, White MF, King GL. Characterization of selective resistance to insulin signaling in the vasculature of obese Zucker (fa/fa) rats. J Clin Invest 1999;104:447-57.

96. Rizzo NO, Maloney E, Pham M, Luttrell I, Wessells H, Tateya S, Daum G, Handa P, Schwartz MW, Kim F. Reduced NO-cGMP signaling contributes to vascular inflammation and insulin resistance induced by high-fat feeding. Arterioscler Thromb Vasc Biol 2010;30:758-65.

97. Tsuchiya K, Sakai H, Suzuki N, Iwashima F, Yoshimoto T, Shichiri M, Hirata Y. Chronic blockade of nitric oxide synthesis reduces adiposity and improves insulin resistance in high fat-induced obese mice. Endocrinology 2007;148:4548-56.

98. Eringa EC, Stehouwer CD, Roos MH, Westerhof N, Sipkema P. Selective resistance to vasoactive effects of insulin in muscle resistance arteries of obese Zucker ( $\mathrm{fa} / \mathrm{fa}$ ) rats. Am J Physiol Endocrinol Metab 2007;293:E1134-9.

99. Arita Y, Kihara S, Ouchi N, Takahashi M, Maeda K, Miyagawa J, Hotta K, Shimomura I, Nakamura T, Miyaoka K, Kuriyama H, Nishida M, Yamashita S, Okubo K, Matsubara K, Muraguchi M, Ohmoto Y, Funahashi T, Matsuzawa Y. Paradoxical decrease of an adipose-specific protein, adiponectin, in obesity. Biochem Biophys Res Commun 1999;257:79-83.

100. Liu J, Jahn LA, Fowler DE, Barrett EJ, Cao W, Liu Z. Free fatty acids induce insulin resistance in both cardiac and skeletal muscle microvasculature in humans. J Clin Endocrinol Metab 2011;96:438-46.

101. Liu Z, Liu J, Jahn LA, Fowler DE, Barrett EJ. Infusing lipid raises plasma free fatty acids and induces insulin resistance in muscle microvasculature. J Clin Endocrinol Metab 2009;94:3543-9.

102. Clerk LH, Rattigan S, Clark MG. Lipid infusion impairs physiologic insulin-mediated capillary recruitment and muscle glucose uptake in vivo. Diabetes 2002;51:1138-45.

103. Watanabe S, Tagawa T, Yamakawa K, Shimabukuro M, Ueda S. Inhibition of the renin-angiotensin system prevents free fatty acid-induced acute endothelial dysfunction in humans. Arterioscler Thromb Vasc Biol 2005;25:2376-80.

104. Chai W, Liu J, Jahn LA, Fowler DE, Barrett EJ, Liu Z. Salsalate attenuates free fatty acid-induced microvascular and metabolic insulin resistance in humans. Diabetes Care 2011;34:1634-8.

105. Li H, Bao Y, Zhang X, Yu Y. Free fatty acids induce endothelial dysfunction and activate protein kinase $C$ and nuclear factor-kappaB pathway in rat aorta. Int J Cardiol 2011;152:218-24.

106. Steinberg HO, Paradisi G, Hook G, Crowder K, Cronin J, Baron AD. Free fatty acid elevation impairs insulinmediated vasodilation and nitric oxide production. Diabetes 2000;49:1231-8.

107. Steinberg HO, Tarshoby M, Monestel R, Hook G, Cronin J, Johnson A, Bayazeed B, Baron AD. Elevated circulating free fatty acid levels impair endothelium-dependent vasodilation. J Clin Invest 1997;100:1230-9.

108. Inyard AC, Chong DG, Klibanov AL, Barrett EJ. Muscle contraction, but not insulin, increases microvascular blood volume in the presence of free fatty acid-induced insulin resistance. Diabetes 2009;58:2457-63.

109. Bakker W, Sipkema P, Stehouwer CD, Serne EH, Smulders YM, van Hinsbergh VW, Eringa EC. Protein kinase C theta activation induces insulin-mediated constriction of muscle resistance arteries. Diabetes 2008;57:70613.

110. Youd JM, Rattigan S, Clark MG. Acute impairment of insulin-mediated capillary recruitment and glucose uptake in rat skeletal muscle in vivo by TNF-alpha. Diabetes 2000;49:1904-9.

111.Zhang L, Wheatley CM, Richards SM, Barrett EJ, Clark MG, Rattigan S. TNF-alpha acutely inhibits vascular effects of physiological but not high insulin or contraction. Am J Physiol Endocrinol Metab 2003; 285: E65460.

112. Eringa EC, Stehouwer CD, Walburg K, Clark AD, van Nieuw Amerongen GP, Westerhof N, Sipkema P. Physiological concentrations of insulin induce endothelin-dependent vasoconstriction of skeletal muscle resistance arteries in the presence of tumor necrosis factor-alpha dependence on c-Jun N-terminal kinase. Arterioscler Thromb Vasc Biol 2006;26:274-80.

113. Hirosumi J, Tuncman G, Chang L, Gorgun CZ, Uysal KT, Maeda K, Karin M, Hotamisligil GS. A central role for JNK in obesity and insulin resistance. Nature 2002;420:333-6. 
114. Li G, Barrett EJ, Barrett MO, Cao W, Liu Z. Tumor necrosis factor-alpha induces insulin resistance in endothelial cells via a p38 mitogen-activated protein kinase-dependent pathway. Endocrinology 2007; 148:3356-63.

115. Meijer RI, Bakker W, Alta CL, Sipkema P, Yudkin JS, Viollet B, Richter EA, Smulders YM, van Hinsbergh VW, Serne EH, Eringa EC. Perivascular adipose tissue control of insulin-induced vasoreactivity in muscle is impaired in db/db mice. Diabetes 2013;62:590-8.

116. Koenig W, Khuseyinova N, Baumert J, Meisinger C, Lowel H. Serum concentrations of adiponectin and risk of type 2 diabetes mellitus and coronary heart disease in apparently healthy middle-aged men: results from the 18-year follow-up of a large cohort from southern Germany. J Am Coll Cardiol 2006;48:1369-77.

117. Chen H, Montagnani M, Funahashi T, Shimomura I, Quon MJ. Adiponectin stimulates production of nitric oxide in vascular endothelial cells. J Biol Chem 2003;278:45021-6.

118. Zheng Q, Yuan Y, Yi W, Lau WB, Wang Y, Wang X, Sun Y, Lopez BL, Christopher TA, Peterson JM, Wong GW, Yu S, Yi D, Ma XL. C1q/TNF-related proteins, a family of novel adipokines, induce vascular relaxation through the adiponectin receptor-1/AMPK/eNOS/nitric oxide signaling pathway. Arterioscler Thromb Vasc Biol 2011;31:2616-23.

119. Luo N, Liu J, Chung BH, Yang Q, Klein RL, Garvey WT, Fu Y. Macrophage adiponectin expression improves insulin sensitivity and protects against inflammation and atherosclerosis. Diabetes 2010;59:791-9.

120. Meijer RI, Serne EH, Smulders YM, van Hinsbergh VW, Yudkin JS, Eringa EC. Perivascular adipose tissue and its role in type 2 diabetes and cardiovascular disease. Curr Diab Rep 2011;11:211-7.

121. Tilg $\mathrm{H}$, Moschen AR. Adipocytokines: mediators linking adipose tissue, inflammation and immunity. Nat Rev Immunol 2006;6:772-83.

122. Karlsson C, Lindell K, Ottosson M, Sjostrom L, Carlsson B, Carlsson LM. Human adipose tissue expresses angiotensinogen and enzymes required for its conversion to angiotensin II. J Clin Endocrinol Metab 1998;83:3925-9.

123. Schling $P$, Mallow $H$, Trindl A, Loffler G. Evidence for a local renin angiotensin system in primary cultured human preadipocytes. Int J Obes Relat Metab Disord 1999;23:336-41.

124. Rahmouni K, Mark AL, Haynes WG, Sigmund CD. Adipose depot-specific modulation of angiotensinogen gene expression in diet-induced obesity. Am J Physiol Endocrinol Metab 2004;286:E891-5.

125. Andreozzi F, Laratta E, Sciacqua A, Perticone F, Sesti G. Angiotensin II impairs the insulin signaling pathway promoting production of nitric oxide by inducing phosphorylation of insulin receptor substrate-1 on Ser312 and Ser616 in human umbilical vein endothelial cells. Circ Res 2004;94:1211-8.

126. Velloso LA, Folli F, Sun XJ, White MF, Saad MJ, Kahn CR. Cross-talk between the insulin and angiotensin signaling systems. Proc Natl Acad Sci U S A 1996;93:12490-5.

127. Rajagopalan S, Kurz S, Munzel T, Tarpey M, Freeman BA, Griendling KK, Harrison DG. Angiotensin IImediated hypertension in the rat increases vascular superoxide production via membrane NADH/NADPH oxidase activation. Contribution to alterations of vasomotor tone. J Clin Invest 1996;97:1916-23.

128. Zhou MS, Schulman IH, Raij L. Role of angiotensin II and oxidative stress in vascular insulin resistance linked to hypertension. Am J Physiol Heart Circ Physiol 2009;296:H833-9.

129. Hong HJ, Chan P, Liu JC, Juan SH, Huang MT, Lin JG, Cheng TH. Angiotensin II induces endothelin-1 gene expression via extracellular signal-regulated kinase pathway in rat aortic smooth muscle cells. Cardiovasc Res 2004;61:159-68.

130. Imai T, Hirata Y, Emori T, Yanagisawa M, Masaki T, Marumo F. Induction of endothelin-1 gene by angiotensin and vasopressin in endothelial cells. Hypertension 1992;19:753-7.

131. Bakker W, Eringa EC, Sipkema P, van Hinsbergh VW. Endothelial dysfunction and diabetes: roles of hyperglycemia, impaired insulin signaling and obesity. Cell Tissue Res 2009;335:165-89.

132. Eringa EC, Bakker W, van Hinsbergh VW. Paracrine regulation of vascular tone, inflammation and insulin sensitivity by perivascular adipose tissue. Vascul Pharmacol 2012;56:204-9.

133. Yudkin JS, Eringa $E$, Stehouwer CD. "Vasocrine" signalling from perivascular fat: a mechanism linking insulin resistance to vascular disease. Lancet 2005;365:1817-20.

134. Tooke JE, Morris SJ, Shore AC. Microvascular functional abnormalities in diabetes: the role of the endothelium. Diabetes Res Clin Pract 1996;31:S127-32.

135. Lustman PJ, Griffith LS, Gavard JA, Clouse RE. Depression in adults with diabetes. Diabetes Care 1992;15:1631-9.

136. McMurray JJ, Gerstein HC, Holman RR, Pfeffer MA. Heart failure: a cardiovascular outcome in diabetes that can no longer be ignored. Lancet Diabetes Endocrinol 2014;2:843-51. 
137. Spauwen PJ, Kohler S, Verhey FR, Stehouwer CD, van Boxtel MP. Effects of type 2 diabetes on 12-year cognitive change: results from the Maastricht Aging Study. Diabetes Care 2013;36:1554-61.

138. Houben AJ, Beljaars JH, Hofstra L, Kroon AA, De Leeuw PW. Microvascular abnormalities in chronic heart failure: a cross-sectional analysis. Microcirculation 2003;10:471-8.

139. Wong TY, Klein R, Sharrett AR, Duncan BB, Couper DJ, Tielsch JM, Klein BE, Hubbard LD. Retinal arteriolar narrowing and risk of coronary heart disease in men and women. The atherosclerosis risk in communities study. JAMA 2002;287:1153-9.

140. Rothman KJ, Greenland S, Lash TL. Modern Epidemiology. Vol 3rd ed. Philidelphia: Lippincott Williams \& Wilkins, 2008. 



\section{Chapter 2.1}

Study population 


\section{STUDY POPULATION}

In chapters 4 and $\mathbf{5}$ of this thesis we used data from The Maastricht Study, an ongoing observational prospective population-based cohort study. ${ }^{1}$ The study focuses on the aetiology and pathophysiology of type 2 diabetes (T2DM), its classic complications (cardiovascular disease, nephropathy, neuropathy, and retinopathy) and its emerging comorbidities (e.g., cognitive decline, depression, and gastrointestinal, respiratory and musculoskeletal diseases), as well as on the development of chronic diseases in the general population.

Eligible for participation were all individuals aged between 40 and 75 years and living in the southern part of the Netherlands (municipalities of Maastricht, EijsdenMargraten, Meerssen and Valkenburg). Participants were recruited through mass media campaigns and from the municipal registries and the regional Diabetes Patient Registry via mailings. For reasons of efficiency, the study population is enriched with T2DM participants to increase the statistical power to identify any potential contrasts between individuals with and without T2DM.

The examinations of each participant were performed within a time window of three months. Extensive phenotyping is performed by trained research assistants, according to standardized protocols, during three to four 4-hour visits to the Maastricht Study research centre. The study has been approved by the institutional medical ethical committee (NL31329.068.10) and the Netherlands Health Council under the Dutch "Law for Population Studies" (Permit 131088-105234-PG). All participants gave written informed consent.

The present thesis includes cross-sectional data from the first 866 participants, who completed the baseline survey between November 2010 and March 2012. Of the 866 participants included, 473 (54.6\%) were men, 140 (16.2\%) had an impaired glucose metabolism (IGM; defined as having either impaired fasting glucose [IFG] or impaired glucose tolerance [IGT]), 253 (29.2\%) had T2DM, 397 (45.8\%) had hypertension (based on office blood pressure measurements), 152 (17.6\%) had a prior cardiovascular event, and 140 (16.2\%) were current smokers. Mean age was $59.8 \pm 8.5$ years, mean body mass index was $27.3 \pm 4.5 \mathrm{~kg} / \mathrm{m}^{2}$, mean serum high-density lipoprotein (HDL) cholesterol was $1.3 \pm$ $0.4 \mathrm{mmol} / \mathrm{L}$, mean serum low-density lipoprotein ( $L D L$ ) cholesterol was $3.3 \pm 1.1 \mathrm{mmol} / \mathrm{L}$, and median serum triglycerides were 1.2 [interquartile range $0.9-1.8$ ] $\mathrm{mmol} / \mathrm{L}$. 


\section{REFERENCES}

1. Schram MT, Sep SJ, Kallen van der CJ, Dagnelie PC, Koster A, Schaper NC, Henry RM, Stehouwer CD. The Maastricht Study: an extensive phenotyping study on determinants of type 2 diabetes, its complications and its comorbidities. Eur J Epidemiol 2014;29:439-51. 



\section{Chapter

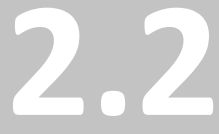

Assessment of microvascular function

Adapted from

Response to comment on: Semi-automatic assessment of skin capillary density: proof of principle and validation Dennis M. J. Muris, Ed H.B.M. Gronenschild, Miranda T. Schram, Ümit Karaça, Coen D.A. Stehouwer, Alfons J.H.M. Houben 


\section{METHODS USED TO STUDY THE MICROVASCULATURE}

In the Maastricht Study we used two different methods to study skin microvasculature; 1) laser Doppler flowmetry with Fourier analysis of the laser Doppler signal and 2) capillaroscopy. All participants were asked to refrain from smoking and caffeine 3 hours before the measurements. A light meal (breakfast and (or) lunch) low in fat content was allowed prior to the start of the microvascular measurements. The measurements were performed in a quiet, temperature-controlled room $\left(T=24^{\circ} \mathrm{C}\right)$ with participants in supine position. In the following subsections we provide a detailed description of the measurement techniques performed in the Maastricht Study.

\section{LASER DOPPLER FLOWMETRY}

\section{TECHNIQUE}

Laser Doppler flowmetry (LDF) is a non-invasive technique which allows continuous monitoring of the dynamic variation in microvascular perfusion in the skin. The technique is based on the emission of a beam of laser light carried by a fibre-optic probe. The light penetrates the skin and a fraction of the light is backscattered by moving erythrocytes and also partly absorbed by the tissue being studied. Light which is backscattered from moving erythrocytes undergoes a shift in frequency proportional to their velocity, according to the Doppler principle, while light hitting static objects is unchanged. The magnitude and frequency distribution of these changes in wavelength are directly related to the number and velocity of the blood cells in the sample volume. The information is picked up by a returning fibre, converted into an electronic signal and analysed. A limitation of LDF is that researchers cannot be sure what volume of tissue is being measured. Thus, rather than perfusion being measured quantitatively (e.g., $\mathrm{mL} / \mathrm{min} / 100$ gram tissue), it is expressed as blood flow in arbitrary perfusion units (PU). PU is the product of the velocity and concentration of moving red blood cells. ${ }^{1}$

The measuring depth depends on tissue properties such as the structure and density of the capillary beds, pigmentation, and oxygenation. It also depends on the wavelength of the laser light, and on the distance between the sending and receiving fibres in the laser Doppler probe. In the present thesis, a thermostatic laser Doppler probe (PF 457, Perimed, Stockholm, Sweden) was used with a measuring depth in the order of 
0.5 - 1.0 millimetre. The LDF signals from the skin will therefore reflect perfusion in predominantly arterioles and venules $^{2}$ (derived from http://www.perimedinstruments.com/support/theory/laser-doppler).

\section{SKIN MICROVASCULAR FLOWMOTION}

Skin microvascular flowmotion (SMF) can easily be assessed using laser-Doppler flowmetry. In order to perform SMF measurements, cutaneous blood perfusion was measured by means of a laser Doppler system (Periflux 5000, Perimed, Stockholm, Sweden), equipped with a thermostatic laser Doppler probe (PF 457; Perimed, Stockholm, Sweden) at the dorsal side of the wrist of the left hand. Since flowmotion has predominantly been observed in participants with a skin temperature above $29.3^{\circ} \mathrm{C}^{3}$, the laser Doppler probe was set at $30^{\circ} \mathrm{C}$. The LDF output was recorded for 25 minutes with a sample rate of $32 \mathrm{~Hz}$, which gives a semi quantitative assessment of skin microvascular blood perfusion expressed in arbitrary PU.

A fast-Fourier transform algorithm was performed by means of Perisoft dedicated software (PSW version 2.50; Perimed) to measure the power density of the LDF oscillations. The frequency spectrum between 0.01 and $1.6 \mathrm{~Hz}$ was divided into five SMF components: 1) endothelial, $0.01-0.02 \mathrm{~Hz} ; 2$ ) neurogenic, $0.02-0.06 \mathrm{~Hz} ; 3)$ myogenic, $0.06-0.15 \mathrm{~Hz}$; 4) respiratory, $0.15-0.40 \mathrm{~Hz}$; and 5) heartbeat, $0.40-1.60 \mathrm{~Hz} .{ }^{4}$ In addition, total SMF energy was obtained by the sum of the power density values of the total frequency spectrum.

\section{SKIN CAPILLAROSCOPY}

Intravital skin capillaroscopy is a dynamic method to directly visualize perfused nutritive capillaries in human skin. Skin capillaroscopy without dyes depends on the presence of red blood cells inside capillaries for their identification. Skin capillaries were visualized in the skin of the dorsal phalanges of the third and fourth finger of the right hand by use of a digital video microscope $\left(\right.$ Capiscope $^{\circledR}$, KK Technology, Honiton UK, http://www.kktechnology.com) with a system magnification of 100x. Capillaries were visualized $\sim 4.5 \mathrm{~mm}$ proximal to the terminal row of capillaries in the middle of the nailfold, where capillaries run perpendicularly to the skin. In this visual field, the investigator selected a region of interest (ROI) of a square millimetre of skin. Subsequently, capillaries with eye-catching morphological features were kept on the same spot in the visual field (marked by a dot on the monitor) to ensure that capillary density was measured in exactly 
the same visual field during the entire experiment. ${ }^{5}$ Capillary density was measured under three conditions. First, we measured baseline capillary density, defined as the number of continuously erythrocyte-perfused capillaries per square millimetre of skin. The number of baseline capillaries was counted during a 15-second period. During this period, only continuously perfused capillaries were counted (Fig. 2.2.1A). Second, we used postocclusive reactive hyperaemia after 4 minutes of arterial occlusion to assess functional capillary reserve capacity (capillary recruitment during peak reactive hyperaemia (PRH)) (Fig. 2.2.1B). For the assessment of reactive hyperaemia, a miniature cuff (Digit cuff, Hokanson, Inc., Bellevue, WA, USA) was applied on the base of the investigated finger and inflated to suprasystolic pressure $(\sim 260 \mathrm{mmHg})$. After 4 minutes of arterial occlusion the cuff was released. The commonly used occlusion of 4 minutes ${ }^{6,7}$ is expected to cause vasodilatation through both the mechanism of myogenic vasodilatation and metabolic vasodilatory stimuli. ${ }^{8}$ Directly after release of the cuff, all (continuously and intermittently) perfused capillaries were counted for 15 seconds (Fig. 2.2.1B). Third, we applied venous congestion, with the cuff inflated to $60 \mathrm{mmHg}$ for 2 minutes, to expose the maximal number of capillaries (i.e., structural capillary density). Capillaries during venous congestion were counted in the last 60 -second recordings, by counting all (continuously and intermittently) perfused capillaries for 15 seconds. Venous congestion increases venous back pressure, which allows passive trapping of red blood cells in non-perfused and intermittently perfused capillaries, thereby enhancing the visualization of capillaries filled with red blood cells (i.e., allows visualization of the maximal number of skin capillaries). ${ }^{7,9}$ Nevertheless, it is not clear how the true maximal capillary density should be assessed, ${ }^{6}$ as we recently demonstrated that hyperinsulinaemia significantly increases capillary density during venous congestion. ${ }^{6,7,9}$ All procedures were performed on two separate fingers, and the mean of both measurements was used for analyses.

Capillaries were counted with a semi-automatic image analysis application (described in chapter 2.3) by two investigators who were both masked to the characteristics of the participants. Both investigators counted approximately half of the participants. 
A.

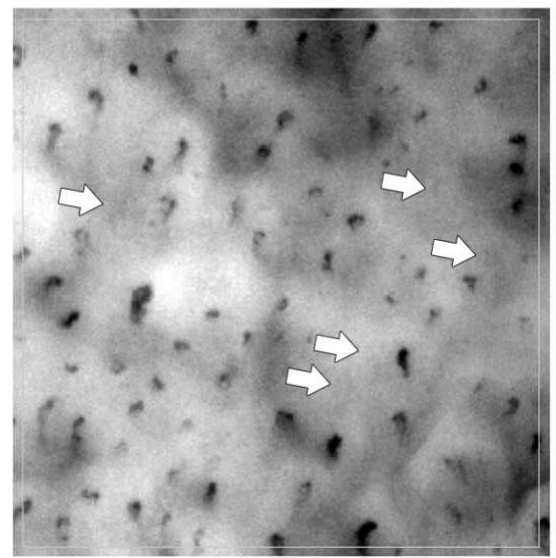

B.

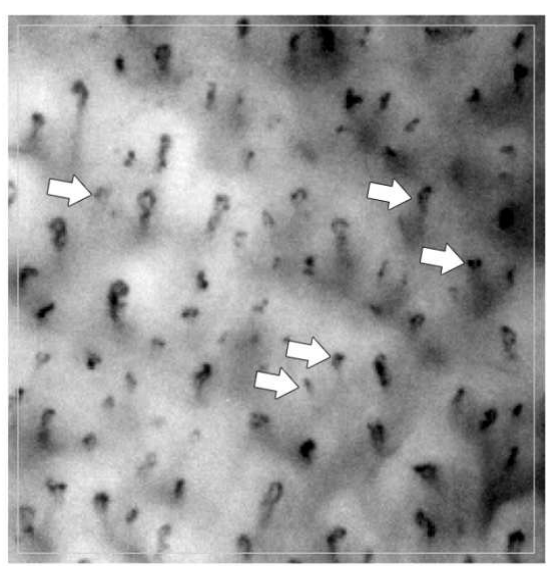

Figure 2.2.1. Microscopic images in exactly the same visual field ( $1 \mathrm{~mm}^{2}$ of skin). A. Baseline capillary density. B. Capillary recruitment after peak reactive hyperaemia. The white arrows represent examples of non-perfused capillaries under baseline conditions (A) that are recruited during post-occlusive reactive hyperaemia (B). 


\section{REFERENCES}

1. Braverman IM, Schechner JS, Silverman DG, Keh-Yen A. Topographic mapping of the cutaneous microcirculation using two outputs of laser-Doppler flowmetry: flux and the concentration of moving blood cells. Microvasc Res 1992;44:33-48.

2. Kvandal P, Landsverk SA, Bernjak A, Stefanovska A, Kvernmo HD, Kirkeboen KA. Low-frequency oscillations of the laser Doppler perfusion signal in human skin. Microvasc Res 2006;72:120-7.

3. Thorn $\mathrm{CE}$, Kyte $\mathrm{H}$, Slaff DW, Shore AC. An association between vasomotion and oxygen extraction. Am J Physiol Heart Circ Physiol 2011;301:H442-9.

4. Stefanovska A, Bracic M, Kvernmo HD. Wavelet analysis of oscillations in the peripheral blood circulation measured by laser Doppler technique. IEEE Trans Biomed Eng 1999;46:1230-9.

5. Jonk AM, Houben AJ, Schaper NC, de Leeuw PW, Serne EH, Smulders YM, Stehouwer CD. Acute angiotensin II receptor blockade improves insulin-induced microvascular function in hypertensive individuals. Microvasc Res 2011;82:77-83.

6. Jonk AM, Houben AJ, Schaper NC, de Leeuw PW, Serne EH, Smulders YM, Stehouwer CD. Angiotensin II enhances insulin-stimulated whole-body glucose disposal but impairs insulin-induced capillary recruitment in healthy volunteers. J Clin Endocrinol Metab 2010;95:3901-8.

7. Serne EH, Gans RO, ter Maaten JC, Tangelder GJ, Donker AJ, Stehouwer CD. Impaired skin capillary recruitment in essential hypertension is caused by both functional and structural capillary rarefaction. Hypertension 2001;38:238-42.

8. Johnson PC, Burton KS, Henrich $\mathrm{H}$, Henrich U. Effect of occlusion duration on reactive hyperemia in sartorius muscle capillaries. Am J Physiol 1976;230:715-9.

9. Antonios TF, Rattray FE, Singer DR, Markandu ND, Mortimer PS, MacGregor GA. Maximization of skin capillaries during intravital video-microscopy in essential hypertension: comparison between venous congestion, reactive hyperaemia and core heat load tests. Clin Sci (Lond) 1999;97:523-8. 


\section{Chapter $\mathbf{2 . 3}$}

Semi-automatic assessment of skin capillary

density: proof of principle and validation

Dennis M. J. Muris* and Ed H.B.M. Gronenschild*, Miranda T. Schram, Ümit Karaça, Coen D.A. Stehouwer, Alfons J.H.M. Houben

Microvasc Res 2013;90:192-8

* Both authors contributed equally 


\section{ABSTRACT}

\section{Background}

Skin capillary density and recruitment have been proven to be relevant measures of microvascular function. Unfortunately, the assessment of skin capillary density from movie files is very timeconsuming, since this is done manually. This impedes the use of this technique in large-scale studies. We aimed to develop a (semi-)automated assessment of skin capillary density.

\section{Methods}

CapiAna (Capillary Analysis) is a newly developed semi-automatic image analysis application. The technique involves four steps: 1) movement correction, 2) selection of the frame range and positioning of the region of interest (ROI), 3) automatic detection of capillaries, and 4) manual correction of detected capillaries. To gain insight into the performance of the technique, skin capillary density was measured in twenty participants (ten women; mean age 56.2 [42 - 72] years). To investigate the agreement between CapiAna and the classic manual counting procedure, we used weighted Deming regression and Bland-Altman analysis. In addition, intra- and inter-observer coefficients of variation (CVs), and differences in analysis time were assessed.

\section{Results}

We found a good agreement between CapiAna and the classic manual method, with a Pearson's correlation coefficient $(r)$ of $0.95(P<0.001)$ and a Deming regression coefficient of $1.01(95 \% \mathrm{Cl}$ : $0.91 ; 1.10)$. In addition, we found no significant differences between the two methods, with an intercept of the Deming regression of $1.75(-6.04 ; 9.54)$, while the Bland-Altman analysis showed a mean difference (bias) of $2.0(-13.5 ; 18.4)$ capillaries $/ \mathrm{mm}^{2}$. The intra- and inter-observer CVs of CapiAna were $2.5 \%$ and $5.6 \%$ respectively, while for the classic manual counting procedure these were $3.2 \%$ and $7.2 \%$, respectively. Finally, the analysis time for CapiAna ranged between $25-35$ minutes versus $80-95$ minutes for the manual counting procedure.

\section{Conclusion}

We have developed a semi-automatic image analysis application (CapiAna) for the assessment of skin capillary density, which agrees well with the classic manual counting procedure, is time-saving, and has a better reproducibility as compared to the classic manual counting procedure. As a result, the use of skin capillaroscopy is feasible in large-scale studies, which importantly extends the possibilities to perform microcirculation research in humans. 


\section{INTRODUCTION}

It is increasingly being recognized that microvascular dysfunction may be a key feature in the development of both obesity-related hypertension and insulin resistance. ${ }^{1-3}$ In fact, several studies have shown the relevance of microvascular effects of insulin ${ }^{4,5}$ and their role in whole body glucose uptake. ${ }^{6,7}$ The skin is a unique site allowing simple and reproducible assessment of capillary density and capillary recruitment. Specifically, the skin is the only site available in humans allowing direct, non-invasive visualization of capillaries at rest and during provocative stimuli. In addition, the cutaneous microcirculation is considered a representative vascular bed to examine generalized systemic microvascular dysfunction. ${ }^{8}$ Importantly, with regard to specific effects on insulin, several studies have demonstrated comparable metabolic ${ }^{9}$ and vascular effects ${ }^{7,10}$ of insulin in muscle and skin. Moreover, it has been demonstrated that the (systemic) effects of obesity and free fatty acids on insulin-mediated microvascular recruitment in muscle ${ }^{10,11}$ can be reproduced in skin. ${ }^{12,13}$ These data strongly suggests that vascular responses observed in skin parallel those in muscle, and thus that measurement of the skin microvasculature is an important tool for the assessment of microvascular function.

Skin capillaroscopy is often used to study the skin microvasculature. ${ }^{4,14}$ Unfortunately, the analysis of skin capillary density from movie files is done manually, and thus is very time-consuming. This impedes the use of this technique in large-scale investigations. Hence, an automated assessment of skin capillary density would facilitate the use of capillary microscopy in larger studies.

We developed a semi-automatic method for the assessment of skin capillary density, i.e. an image analysis application named CapiAna (Capillary Analysis). The purpose of this report is to describe this new technique and to present accuracy, reproducibility and efficiency results.

\section{METHODS}

\section{SUBJECTS}

Twenty Caucasian subjects (ten women; mean age 56.2 [42 - 72] years) participated in this study. These subjects were selected from the Maastricht Study (http://themaastrichtstudy.com), a large-scale cohort study. To ensure that we tested the 
agreement and reproducibility across a wide range of capillary densities, these subjects were selected based on their (baseline) skin capillary densities. All participants gave informed consent. The Maastricht Study protocol was approved by the local ethics committee (NL31329.068.10) and performed in accordance with the Declaration of Helsinki.

\section{SKIN CAPILLAROSCOPY}

In the present study, skin capillaries were visualized in the skin of the dorsal phalanges of the third and fourth finger of the right hand by use of a digital video microscope (Capiscope ${ }^{\circledR}$, KK Technology, Honiton UK, http://www.kktechnology.com) with a system magnification of $100 \times$. Capillaries were visualized $\sim 4.5 \mathrm{~mm}$ proximal to the terminal row of capillaries in the middle of the nailfold, where capillaries run perpendicularly to the skin. In this visual field, the investigator selected a region of interest (ROI) of a square millimetre of skin. Subsequently, capillaries with eye-catching morphological features were kept on the same spot in the visual field (marked by a dot on the monitor) to ensure that capillary density was measured in exactly the same visual field during the entire experiment. ${ }^{15}$ Capillary density was measured under three conditions. First, we measured baseline capillary density, defined as the number of continuously erythrocyte-perfused capillaries per square millimetre of skin. Second, we used post-occlusive reactive hyperaemia after 4 minutes of arterial occlusion to assess functional capillary reserve capacity (capillary recruitment during peak reactive hyperaemia (PRH)). For the assessment of reactive hyperaemia, a miniature cuff (Digit cuff, Hokanson, Inc., Bellevue, WA, USA) was applied on the base of the investigated finger and inflated to suprasystolic pressure ( $260 \mathrm{mmHg}$ ). Third, we applied venous congestion, with the cuff inflated to 60 $\mathrm{mmHg}$ for 2 minutes, to expose the maximal number of capillaries. All procedures were performed on two separate fingers, and the mean of both measurements was used for analyses. Between conditions, a resting interval of 5 minutes was used.

\section{AUTOMATIC METHOD}

CapiAna is a software application to detect capillaries semi-automatically in a sequence of uncompressed monochrome images (frames) captured by the Capiscope. It comprises a series of image processing steps which will be described in detail below. Only minimal user interaction is required. 


\section{DATA ACQUISITION}

The Capiscope captures image data at a rate of 25 frames per second. Each frame measures $640 \times 480$ pixels with 256 grey levels per pixel. The uncompressed raw data were transferred to the PC for subsequent processing.

\section{DETERMINATION OF POSITION SHIFTS}

The first step was the determination of the position shifts caused by the movements (mainly due to respiration) of the finger during image acquisition. We used a technique based on phase shifts in the Fourier domain, which was shown to be more accurate than for instance cross-correlation. ${ }^{16}$ For this purpose, within a centrally located square of $256 \times 256$ pixels, an edge enhancement filter (Prewitt) followed by a Fourier transformation was applied to each frame of the full frame sequence. In the Fourier domain, the phase shift image between each frame and the first frame was derived. The position of the maximum intensity corresponded to the position shift of each frame with respect to the first frame. Note that by this method, the position shifts were always derived in integer precision. The assessed sequence of position shifts for all frames was smoothed by a median filter, independently in the $X$ and $Y$ directions. This sequence was saved to disk for later use. If a position shift was found too large, the corresponding frame was marked invalid because it contained too much movement blurring. Such invalid frames were not taken into account in the subsequent analysis.

\section{FRAME RANGE SELECTION}

By looping through the frame sequence, the user can inspect the quality and select manually the range of contiguous frames that will be used for the detection of the capillaries. The time duration of this episode was generally on the order of 16 seconds, corresponding to 400 frames.

\section{ROI POSITIONING}

The second manual interaction was the positioning of a squared ROI measuring $1 \times 1 \mathrm{~mm}^{2}$ ( $248 \times 248$ pixels). Its size in pixels was determined previously by calibration measurements using a ruler (resulting in a resolution of $4.03 \mu$ per pixel). Only within this ROI will the detection take place. The position shifts derived in the previous step were 
applied to this ROI so that for each frame the same area was being analysed, as if the ROI was fixed to the skin of the finger.

\section{DETECTION OF CAPILLARIES}

The actual detection of the capillaries was data-driven and based on a combination of grey-level and morphological filtering, and took information of all the selected frames into account. There were several reasons for this approach. The images were far from being uniform in intensity (due to the positions of the LED lights fixed to the microscopic device), making techniques solely based on intensity thresholding rather useless. Furthermore, the fact that during baseline measurements some capillaries were not perfused continuously impeded the use of correlation techniques. Finally, the application of adaptive filtering techniques did not make sense because the shape of a capillary was not the same for all capillaries, both within a frame and between frames.

Because the number of capillaries present in each frame varied during time, we noted that splitting the selected frame range into $N$ intervals of 100 frames each resulted in a more robust detection. The intervals were contiguous without any overlap, except for the last one in case the number of selected frames, $N F$, was not a multiple of 100 . For each interval, $k$, so-called seed points were derived, as follows (Fig. 2.3.2). A minimumintensity image was built from the frames after correction of the position shifts and highpass filtered to remove the non-uniform background. Next, the resulting image was binarized between 0 and the median intensity and then morphologically dilated. This result was called HPImage ${ }^{k}$, where superscript $k$ refers to the $k$-th interval. In addition, a variance image was built from the frames, as follows. Each frame was corrected for the position shift and then a random position shift was applied to it. We used a uniformly random number generator (called "Random3" in Numerical Recipes in $\mathrm{C}^{17}$ ) with an amplitude of 3 pixels, a value which was derived empirically to produce the best results. For each pixel, the variance in intensity through the 100 frames was computed. This variance image was binarized between the 90 percentile and maximum intensity value and then morphologically dilated. This result was called Varlmage ${ }^{k}$. In both binarized images, objects could be identified where an object was defined as a set of linked (neighbouring) white pixels. Finally, only the intersecting objects from both images were kept (called Objlmage ${ }^{k}$ ) and objects smaller than 10 pixels were removed as these were considered spurious. The top-left position of each object within the squared ROI was determined and these positions constituted the set of initial seed points, $\left\{I S_{i}^{k}, i=1-L^{k}\right\}$. Note that all positions were corrected for position shifts. It was found that the combination of such a minimum-intensity image and variance image improved the robustness of the technique. 


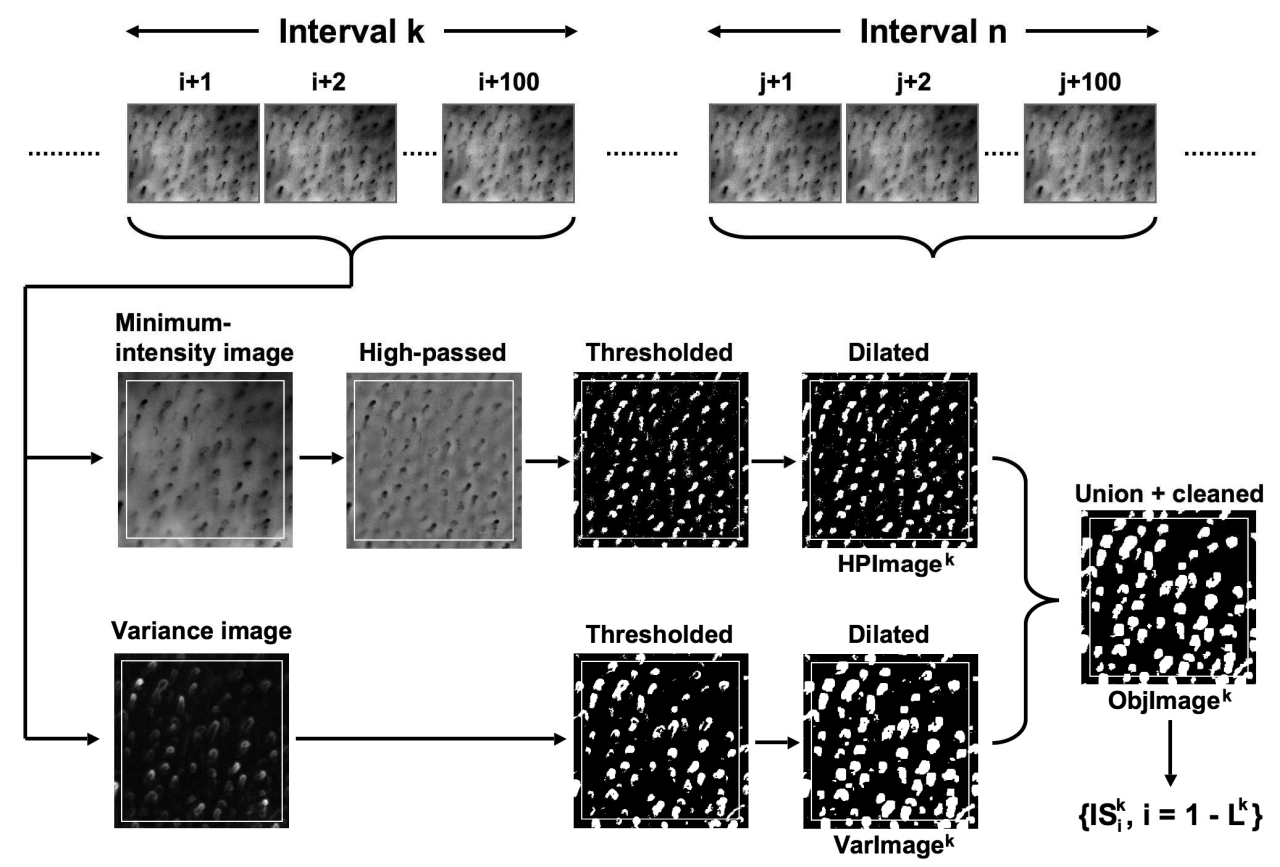

Figure 2.3.2. Illustration of the procedure to derive the initial seed points (estimated positions of the capillaries). The selected $N F$ frames were split into $N$ contiguous intervals of 100 frames each. For each interval, a minimumintensity image and variance image was derived and processed separately, resulting into binarized images, called HPImage $^{k}$ and VarImage ${ }^{k}$, respectively, where superscript $k$ refers to the $k$-th interval. In these binarized images, so-called objects were present, where an object was defined as a set of linked (neighboring) white pixels. Both images were combined into a single image by retaining only the objects which were intersecting and by subsequently removing objects which were smaller than 10 pixels in size. The resulting image was called Objlmage $^{\mathrm{k}}$ and the set of initial seed points $\left\{I S_{i}^{k}, i=1-L^{k}\right\}$ was constituted by the top-left positions of all $L^{k}$ objects inside the ROI (white rectangle). Note that for each interval a different set of initial seed points was derived.

After processing all the $N$ intervals of 100 frames in this way we ended up with $N$ sets of initial seed points. Note that the number of seed points in each interval $\left(=L^{k}\right)$ may differ. These sets of positions were merged and subsequently pruned, i.e., only positions that were different were kept. The result was a set of final seed positions, $\left\{S_{i}, i=1-N L\right\}$, with $N L=\left\lfloor\left(\sum_{k} L^{k}\right)-N_{e q}\right\rfloor$, where $N_{\text {eq }}$ is the number of removed equal positions (Fig. 2.3.3). A seed point derived by this procedure represented an initial guess of the position of a capillary in all NF frames. 


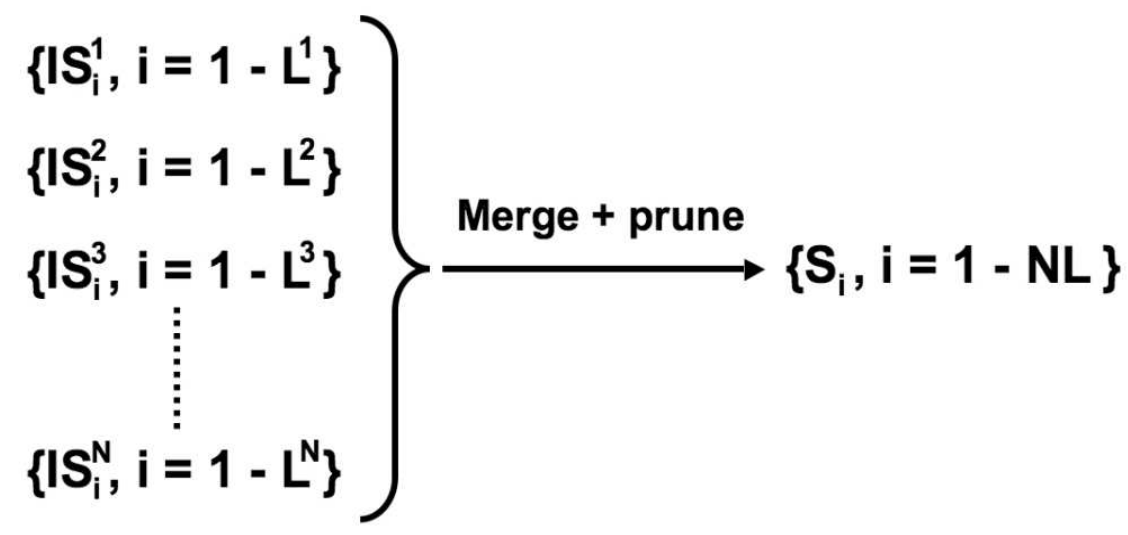

Figure 2.3.3. The determination of the final set of seed points. The set of initial seed points $\left\{I S_{i}^{k}, i=1-L^{k}\right\}$ for each $k$-th interval $(k=1-N)$ were combined into a single set and pruned, i.e., only positions that were different were kept.

For each of the $N$ intervals, a number of operations were needed to find out if a seed point really represented a capillary and to prevent multiple counting since seed points may be very near each other and thus referring to the same capillary. Of note, this additional processing was required only because the selected frame range was split into $N$ subsequent intervals of 100 frames. First, it was checked if a seed point was located in one of the objects in Objlmage ${ }^{k}$ since a seed point derived in interval $n$ may be different from a seed point derived in interval $m \neq n$. If so, then for each of the 100 frames in the $k$-th interval the position with the minimum intensity for pixels within this object was derived and added to the initial list of positions of capillaries (Fig. 2.3.4). If the above check failed, an invalid position was added for each of the pertaining 100 frames. After all the $N$ intervals were processed, a two-dimensional list of initial positions, $I P_{\mathrm{ij}}$, existed, all having a correspondence with one of the seed points. In other words, each seed point $S_{i}$ was associated with a list of $N F$ initial positions, $\left\{I P_{i j}, j=1-N F\right\}$. For each $i$, this list was smoothed by taking the average over all NF frames, excluding invalid positions. The result was a list of average positions, $\left\{A P_{i}, i=1-N L\right\}$ (Fig. 2.3.5).

Because seed points from different intervals were integrated and thus may be located close to each other, we had to make sure that each seed point would correspond to a unique final capillary. To this end, average positions which were close to each other were replaced by their average, resulting in the final set of $N C$ unique capillary positions, $\left\{P_{i}, i=1-N C\right\}$ (Fig. 2.3.5). For display purposes, this one-dimensional list was extended to a two-dimensional list (NC $\times$ NF) by copying these positions to each frame and applying the position shifts. 


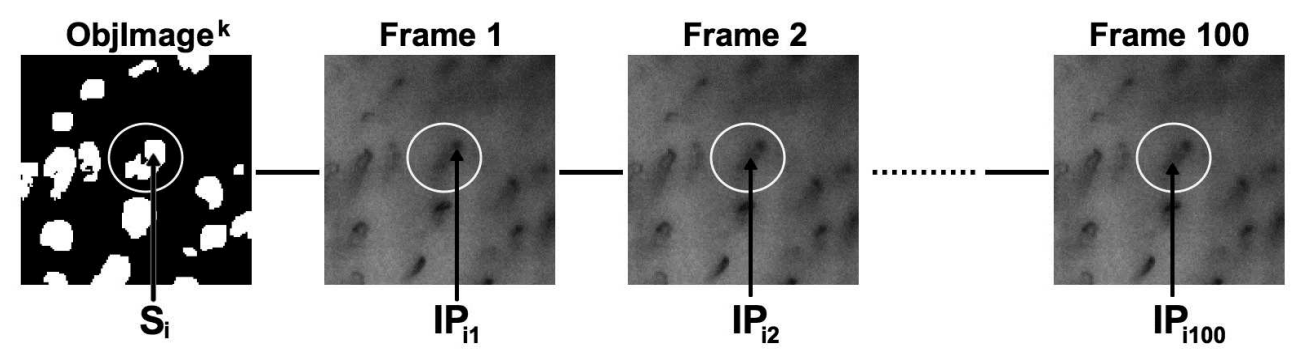

Figure 2.3.4. The promotion of a final seed point $S_{i}$ to an initial capillary position $I P_{\mathrm{ij}}$ in each of the 100 frames in the $k$-th interval. If a seed point was located in one of the objects in Objlmage ${ }^{k}$ then the initial capillary position was set to the position of the minimum intensity of pixels within this object in each frame. If a seed point was not within any object then invalid positions were inserted instead. After processing all $N$ intervals, each seed point was associated with NF initial capillary positions.

\section{OUTPUT}

The final capillary positions were shown as crosses superimposed on the displayed frame in either white or black colour, where white indicated that a capillary was detected in all frames (continuously perfused) and black if this was not the case (Fig. 2.3.6). Because of the fact that the positions were averaged over all frames and that to each position the position shift was added, the crosses moved in near synchrony with the movements of the finger during movie display of the frame sequence. The user is offered the ability to add or remove positions or to change white into black capillaries or vice versa, if necessary. All manual editing is indicated by a different appearance of a position on the monitor.

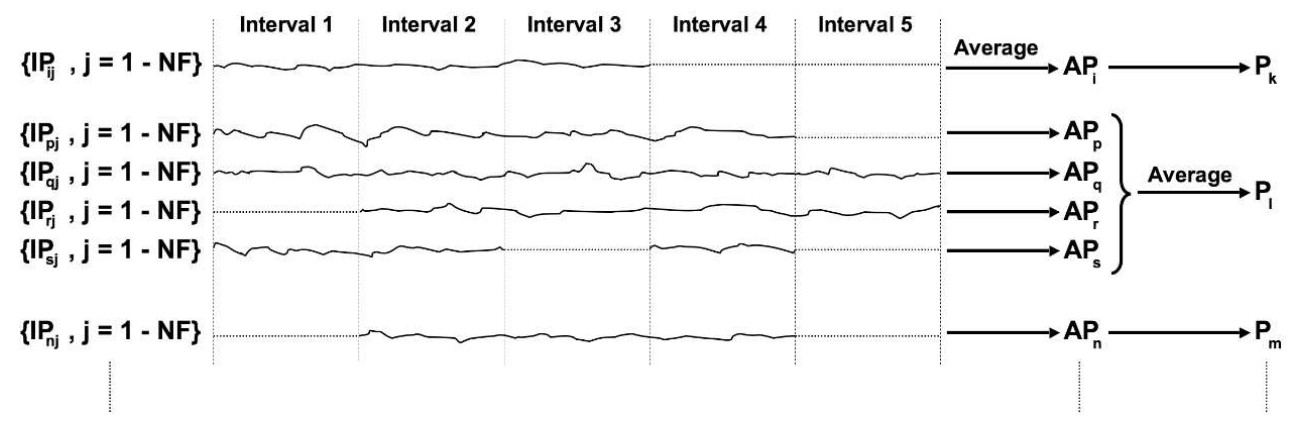

Figure 2.3.5. The conversion of an initial to a final capillary position. The list of NF initial positions associated with seed point $S_{i}$ was smoothed by taking the average $A P_{j}$. Because seed points could be located close together, so could the averaged positions. Therefore, averaged positions which were near each other were replaced by their average, e.g., the final capillary position $P_{l}$. In all other cases the final capillary position was taken equal to the averaged position, e.g., $P_{k}$ and $P_{m}$. Note that for readability we have considered only 5 intervals to illustrate this process. Dashed lines indicate invalid positions (associated seed point was outside any object in Objlmage). 


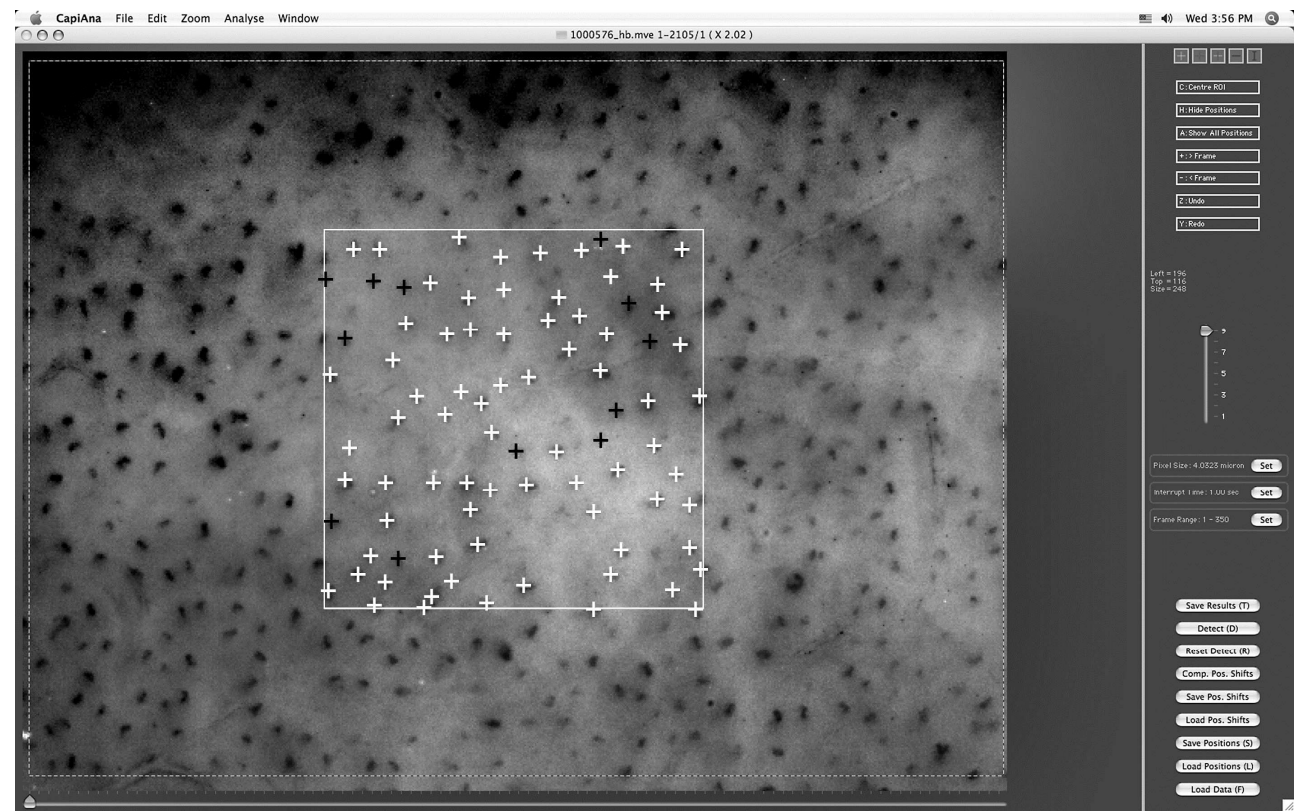

Figure 2.3.6. Screenshot of the display window of CapiAna. The main part shows the captured contrast enhanced data. Superimposed are the results of the automatic detection of the capillaries. White crosses denote capillaries which are detected in all selected frames, i.e., continuously perfused. Black crosses indicate intermittently perfused capillaries. The white rectangle represents the $1 \times 1 \mathrm{~mm}^{2} \mathrm{ROI}$. The dashed line shows the allowable area in which the ROI can be positioned such that it will never be outside the image borders due to the finger movements. At the bottom, a scrollbar is provided to be able to quickly navigate through the frames. At the right various tools and buttons are presented. For instance, the five small rectangles at the top are used for manual corrections. With the small scrollbar the user can change the frame rate at which the frames are displayed in movie mode. Also the frame range can be selected by pressing the lower "Set" button. Finally, the row of large buttons at the bottom enables the user to load and save data and results or to reset or start the detection.

The positions and, in addition, a text file with a summary of the results can be saved to disk. This summary includes a list of the number of detected capillaries in each frame (also differentiated into white and black), and the total number of capillaries present in the whole frame sequence, differentiated into the different categories, such as white, black, manually added white or black, and manually changed from white into black.

\section{PRACTICAL CONSIDERATIONS}

For our research, measurements were carried out typically during three different conditions: 1) baseline; 2) capillary recruitment $\mathrm{PRH}$; 3) capillary density during venous congestion. To be able to properly analyse the data, it is important to position the square$\mathrm{mm} \mathrm{ROI}$ at the same location of the finger for each of the three corresponding measurements. This was done by making use of three instances of CapiAna. By minimizing 
and moving the three display windows next to each other on the monitor, it allowed easy identification of similar ROIs.

\section{SEMI-AUTOMATIC AND MANUAL COUNTING PROCEDURE}

One single experienced investigator (D.M.J.M.) assessed capillary density of the three conditions (i.e. baseline capillary density, capillary recruitment PRH, and capillary density during venous congestion) with 1) the semi-automatic image analysis application (CapiAna) and 2) the classic manual counting procedure. The analysis time of both counting procedures was recorded.

For the semi-automatic counting procedure, we assessed the number of capillaries from a running movie file using CapiAna which involved four steps: 1) movement correction, 2) selection of the frame range and positioning of the ROI, 3) automatic detection of capillaries located in this ROI and frame range, and 4) manual correction of detected capillaries.

For the manual counting procedure, we manually counted the number of capillaries, which has been described in detailed elsewhere. ${ }^{14,15}$ Briefly, capillaries were counted using the naked eye from a freeze-framed reproduction of the movie-file and from the running movie-file, when it was uncertain whether a capillary was present or not.

The investigator determined capillary density for the two methods at exactly the same frame range and ROI after a minimum of two weeks. The number of capillaries at baseline, directly after release of the cuff, and during venous congestion was counted for 16 seconds (i.e., 400 frames). The mean of both measurements at the two fingers was used for analyses.

\section{STATISTICAL ANALYSIS}

\section{METHOD COMPARISON AND AGREEMENT}

We used the Paired-samples t-test to study the differences in capillary density between the semi-automatic image analysis application (CapiAna) and the manual counting procedure. To investigate agreement between the methods, capillary densities as determined by CapiAna and the manual counting procedure were compared by use of Pearson's correlation and weighted Deming regression. By the latter analysis, the regression coefficient and intercept between the methods were assessed (i.e., proportional bias and constant bias, respectively). When two methods produce equivalent results the regression coefficient will be one and the intercept will be zero, resulting in the 
equation $y=x .^{18}$ This statistical technique for method comparison is superior to simple linear regression by taking into account the error in both the dependent and independent variables. ${ }^{18,19}$ A Bland-Altman plot was used to investigate levels of agreement between the methods. We assessed the mean difference (bias) and $95 \% \mathrm{Cl}$ (limits of agreement). ${ }^{20}$

\section{REPRODUCIBILITY}

To establish reproducibility, we calculated the intra- and inter-observer coefficients of variation (CV), defined as the SD divided by the mean of the differences, multiplied by 100 . For the intra-observer CV, grader 1 (D.M.J.M.) counted the number of capillaries for the three conditions with CapiAna and repeated this semi-automatic counting procedure after a minimum of two weeks. For the inter-observer CV, a second experienced investigator (Ü.K., grader 2) counted the number of capillaries for the three conditions with CapiAna in exactly the same ROI and frame range as grader 1 .

All analyses were performed with the use of the Statistical Package for Social Sciences (IBM, version 20.0, Chicago, Illinois, USA), except weighted Deming regression, which was analysed using the Analyse-It software (Analyse-it Software Ltd, Leeds, UK) for Microsoft Excel (Microsoft Corporation, Washington, USA). A $P$ value less than 0.05 was considered statistically significant.

\section{RESULTS}

Table 2.3.1 shows the capillary densities as measured with CapiAna and the manual counting procedure. The capillary density during baseline, capillary recruitment $\mathrm{PRH}$, and capillary density during venous congestion did not significantly differ between CapiAna and the manual counting procedure, although baseline capillary density derived with CapiAna was borderline significantly $(P=0.06)$ higher as compared to the manual counting procedure. 
Table 2.3.1. Capillary densities as determined by the semi-automatic image analysis application (CapiAna) and the manual procedure

\begin{tabular}{|c|c|c|c|c|}
\hline & $\begin{array}{l}\text { Capillary } \\
\text { density } \\
\text { CapiAna }\end{array}$ & $\begin{array}{c}\text { Capillary } \\
\text { density manual } \\
\text { counting } \\
\text { procedure }\end{array}$ & $\begin{array}{l}\text { Difference } \\
\text { between } \\
\text { methods }\end{array}$ & $P$-value \\
\hline Baseline $\left(\mathrm{n} / \mathrm{mm}^{2}\right)$ & $67.5 \pm 25.7$ & $63.0 \pm 22.6$ & $4.5(-9.3 ; 0.3)$ & 0.06 \\
\hline Capillary recruitment PRH $\left(\mathrm{n} / \mathrm{mm}^{2}\right)$ & $87.4 \pm 21.9$ & $86.6 \pm 22.9$ & $0.9(-4.3 ; 2.6)$ & 0.61 \\
\hline $\begin{array}{l}\text { Capillary density during venous congestion } \\
\left(\mathrm{n} / \mathrm{mm}^{2}\right)\end{array}$ & $95.2 \pm 24.4$ & $93.3 \pm 23.8$ & $1.9(-4.8 ; 1.0)$ & 0.19 \\
\hline
\end{tabular}

Data are means \pm SD or means (lower and upper limit). $\mathrm{n} / \mathrm{mm}^{2}$, number of capillaries per square millimetre of finger skin. $\mathrm{PRH}$, peak reactive hyperaemia

We found a Pearson's correlation coefficient $(r)$ of $0.95(P<0.001)$. The Deming regression coefficient was $1.01(95 \% \mathrm{Cl}: 0.91 ; 1.10 ; P=0.86)$ with an intercept of 1.75 (6.04; 9.54; $P=0.65$ ) (Fig. 2.3.7). In addition, the Bland-Altman analysis showed a mean difference (bias) of $2.0(-13.5 ; 18.4)$ capillaries $/ \mathrm{mm}^{2}$ (Fig. 2.3.8). The results indicate that CapiAna and the classic manual method are in good agreement (i.e., the equation $y=$ $1.01 x+1.75$ was not significantly different from the equation $y=x$ (Fig. 2.3.7) with no significant differences between the methods (Fig. 2.3.8).

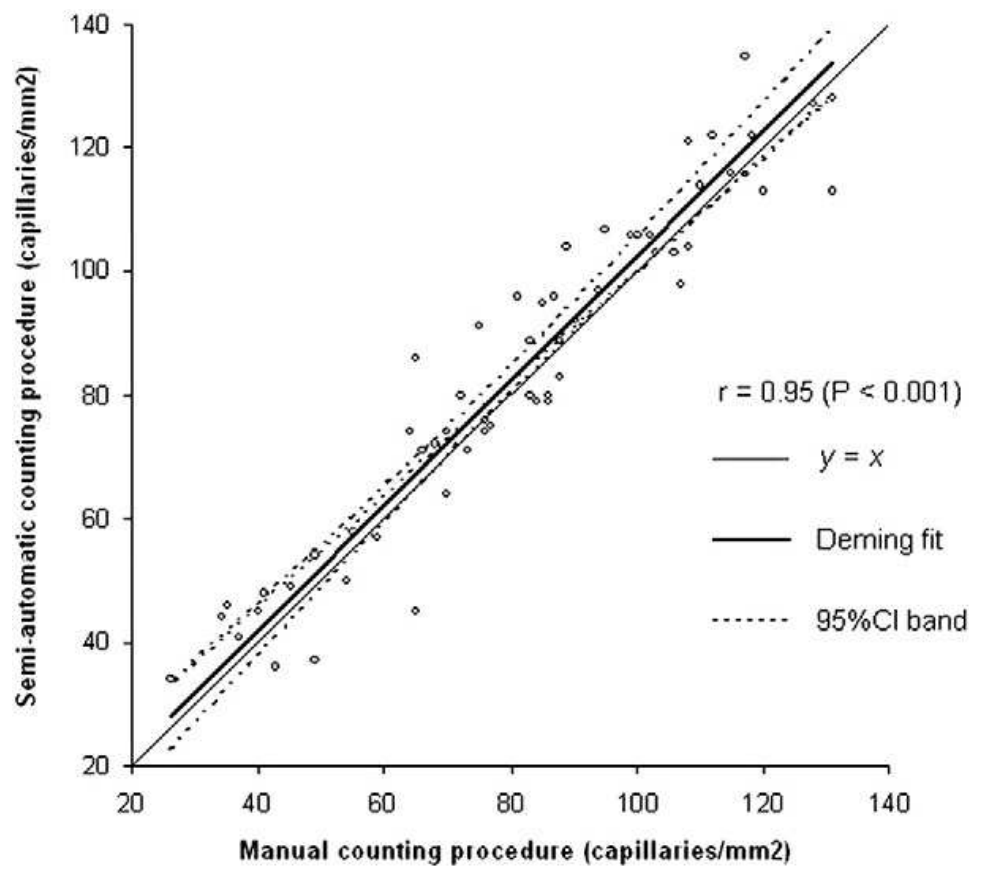

Figure 2.3.7. Comparison of capillary densities between CapiAna (semi-automatic counting procedure) and the manual counting procedure by weighted Deming regression. Regression coefficient $1.01(0.91 ; 1.10)$; intercept $1.75(-6.04 ; 9.54)$. 


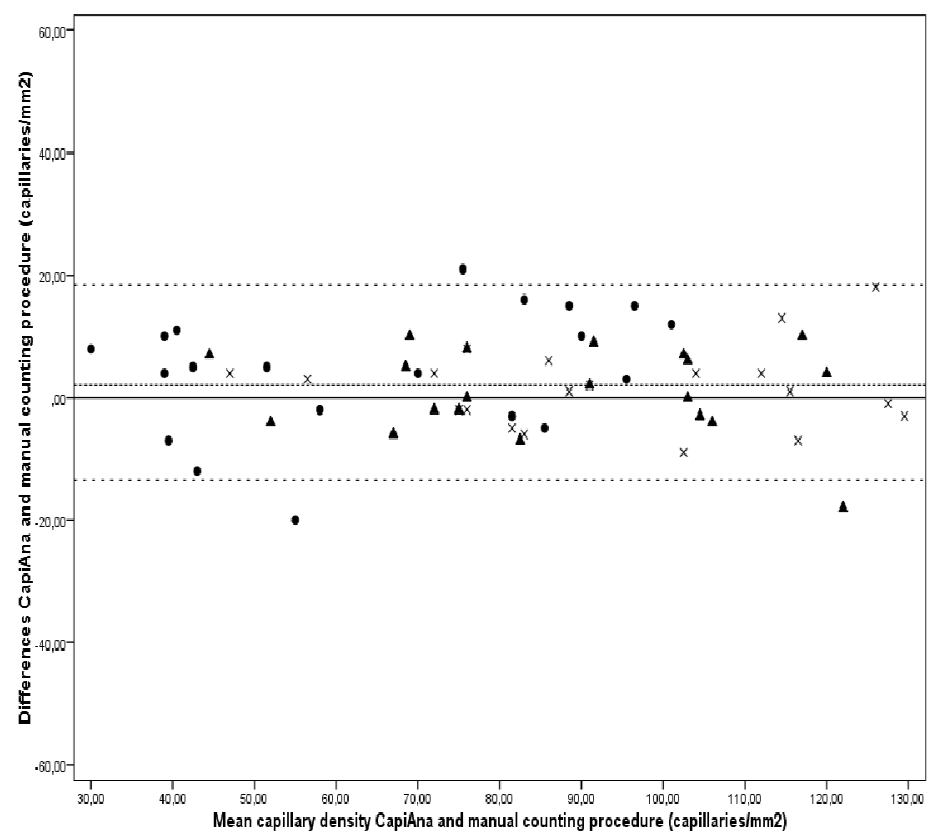

Figure 2.3.8. Bland-Altman plot of the differences between CapiAna (semi-automatic counting procedure) and the manual counting procedure. $\bullet$ baseline, $\boldsymbol{\Delta}$ capillary recruitment PRH, $\mathbf{x}$ capillary density during venous congestion.

The reproducibility of CapiAna is presented in Table 2.3.2. The semi-automatically derived capillary density for the three conditions was highly reproducible by the same rater with a CV of $2.5 \%$ (ranging from 1.7 to 3.5\%). The inter-observer CV for the three conditions was $5.6 \%$ (ranging from 4.9 to $6.6 \%$ ). In addition, intra- and inter-observer CVs for the manual counting procedure for the three conditions were $3.2 \%$ (ranging from 1.8 to $4.5 \%$ ) and $7.2 \%$ (ranging from 6.8 to $8.0 \%$ ) respectively as reported elsewhere. ${ }^{21}$

Table 2.3.2. Reproducibility of the semi-automatic image analysis application (CapiAna)

\begin{tabular}{lccc}
\hline & $\begin{array}{c}\text { Intra-observer } \\
\text { variability }\end{array}$ & & $\begin{array}{c}\text { Inter-observer } \\
\text { variability }\end{array}$ \\
\cline { 2 - 3 } & $\begin{array}{c}\text { Coefficient } \\
\text { of Variation (\%) }\end{array}$ & $\begin{array}{c}\text { Coefficient } \\
\text { of Variation (\%) }\end{array}$ \\
\hline Baseline & 3.5 & 6.6 \\
Capillary recruitment PRH & 1.7 & 5.4 \\
Capillary density during venous congestion & 2.2 & 4.9 \\
Overall & 2.5 & 5.6 \\
\hline
\end{tabular}

$\mathrm{PRH}$, peak reactive hyperaemia 
The complete analysis time for CapiAna (i.e., assessment of capillary density of the three conditions for two fingers) ranged from 25 to 35 minutes, while for the manual counting procedure this ranged from 80 to 95 minutes.

\section{DISCUSSION}

We have developed a semi-automatic image analysis application (CapiAna) for the assessment of skin capillary density, which 1) is in agreement with the manual counting procedure; 2) has a better reproducibility as compared to the manual counting procedure and 3 ) is intrinsically faster as compared to the manual counting procedure, with time savings of approximately 60 minutes per subject. As a result, skin capillaroscopy can be more easily applied in large-scale studies.

The automatic detection steps of CapiAna may potentially introduce systematic errors. Firstly, once a seed point is located in one of the objects then this is promoted to a capillary in all the corresponding 100 frames, irrespective of the presence or absence of a capillary. This may generate false-positive detections. Indeed, the capillary density derived with CapiAna was slightly higher as compared to the capillary density derived with the manual counting procedure. Nevertheless, we found no significant differences between these methods. Work is in progress to make detection on a frame-to-frame basis feasible. Secondly, optimal exposure is a prerequisite for a successful detection of the capillaries. Consequently, poor quality images (i.e., images with low contrast) need a higher extent of manual corrections. However, non-uniform intensity has only limited impact, ensured by the use of a high-pass filter. Thirdly, out-of-focus effects occurring at the borders of the visual field may impair the automatic detection. Generally, the ROI was positioned in the centre of the image, minimizing these effects. However, if the ROI could not be positioned optimally, out-of-focus capillaries could be included. This may generate false-negative detections. Yet, the detection turned out to be robust against these effects and only severe out-of-focus capillaries failed to be detected. Considering the limitations of these automatic detection steps, we concluded that manual correction of the detected capillaries is required.

The manual steps (i.e., selection of the frame range and positioning of the ROI and manual correction of detected capillaries) in CapiAna may introduce random errors and may therefore yield the largest contribution to the intra- and inter-observer variabilities. Nevertheless, CapiAna is a highly reproducible method. More precisely, CapiAna has a better reproducibility than the manual counting procedure; intra-observer CVs were $2.5 \%$ as compared to $3.2 \%$ and inter-observer $\mathrm{CVs}$ were $5.6 \%$ as compared to $7.2 \%{ }^{21}$ In addition, intra- and inter-observer CVs of CapiAna are better as compared to the CVs 
described in literature $\left(4.5 \%\right.$ and $10.1 \%$ respectively $\left.{ }^{14}\right)$. Thus, these data suggest that random errors in CapiAna are smaller than in the manual counting procedure.

CapiAna turned out to be an accurate method as compared to the manual counting procedure, i.e. there were no significant structural differences between the two methods. However, we only included twenty subjects for this study; therefore, a lack of power should be taken into consideration when interpreting these results. Nevertheless, the $95 \% \mathrm{Cl}$ of the mean difference - as demonstrated with the Bland-Altman analysis - has an acceptable range of approximately $\pm 20 \%$. In addition, we found no evidence for systematic errors between CapiAna and the manual counting procedure over the wide range of capillary densities studied. These observations strengthen the conclusion that CapiAna is in good agreement with the manual counting procedure. Hence, CapiAna can be used for a wide range of capillary densities and thus for the investigation of the skin microcirculation in health and disease.

CapiAna facilitates the use of skin capillaroscopy in microvascular research, since the method is shown to be equivalent to and interchangeable with the manual counting procedure with an intrinsically large reduction in analysis time. Microvascular dysfunction may constitute one of the links between insulin resistance and hypertension in the metabolic syndrome. ${ }^{1-3}$ The skin is the only site available in humans allowing direct noninvasive visualization of capillaries at rest and during provocative stimuli. In addition, the cutaneous microcirculation is considered a representative vascular bed to examine the mechanism of generalized systemic microvascular dysfunction. ${ }^{8}$ Therefore, it is important to facilitate the use of skin capillaroscopy and with CapiAna this has become feasible.

In conclusion, we have developed a semi-automatic image analysis application, named CapiAna, for the assessment of skin capillary density, which is in agreement with the manual counting procedure, has a better reproducibility as compared to the classic manual counting procedure and is time-saving. As a result, skin capillaroscopy can be used in large-scale studies, which facilitates investigation of the microcirculation in health and disease. 


\section{REFERENCES}

1. Houben AJ, Eringa EC, Jonk AM, Serne EH, Smulders YM, Stehouwer CD. Perivascular fat and the microcirculation: relevance to insulin resistance, diabetes, and cardiovascular disease. Curr Cardiovasc Risk Rep 2012;6:80-90.

2. Jonk AM, Houben AJ, de Jongh RT, Serne EH, Schaper NC, Stehouwer CD. Microvascular dysfunction in obesity: a potential mechanism in the pathogenesis of obesity-associated insulin resistance and hypertension. Physiology (Bethesda) 2007;22:252-60.

3. Muris DM, Houben AJ, Schram MT, Stehouwer CD. Microvascular dysfunction: An emerging pathway in the pathogenesis of obesity-related insulin resistance. Rev Endocr Metab Disord 2013;14:29-38.

4. Jonk AM, Houben AJ, Schaper NC, de Leeuw PW, Serne EH, Smulders YM, Stehouwer CD. Angiotensin II enhances insulin-stimulated whole-body glucose disposal but impairs insulin-induced capillary recruitment in healthy volunteers. J Clin Endocrinol Metab 2010;95:3901-8.

5. Serne EH, IJzerman RG, Gans RO, Nijveldt R, De Vries G, Evertz R, Donker AJ, Stehouwer CD. Direct evidence for insulin-induced capillary recruitment in skin of healthy subjects during physiological hyperinsulinemia. Diabetes 2002;51:1515-22.

6. Kubota T, Kubota N, Kumagai H, Yamaguchi S, Kozono H, Takahashi T, Inoue M, Itoh S, Takamoto I, Sasako T, Kumagai K, Kawai T, Hashimoto S, Kobayashi T, Sato M, Tokuyama K, Nishimura S, Tsunoda M, Ide T, Murakami K, Yamazaki T, Ezaki O, Kawamura K, Masuda H, Moroi M, Sugi K, Oike Y, Shimokawa H, Yanagihara N, Tsutsui M, Terauchi Y, Tobe K, Nagai R, Kamata K, Inoue K, Kodama T, Ueki K, Kadowaki T. Impaired insulin signaling in endothelial cells reduces insulin-induced glucose uptake by skeletal muscle. Cell Metab 2011;13:294-307.

7. Meijer RI, de Boer MP, Groen MR, Eringa EC, Rattigan S, Barrett EJ, Smulders YM, Serne EH. Insulin-induced microvascular recruitment in skin and muscle are related and both are associated with whole body glucose uptake. Microcirculation 2012;19:494-500.

8. Holowatz LA, Thompson-Torgerson CS, Kenney WL. The human cutaneous circulation as a model of generalized microvascular function. J Appl Physiol 2008;105:370-2.

9. Lang $\mathrm{CH}$. Rates and tissue sites of noninsulin- and insulin-mediated glucose uptake in diabetic rats. Proc Soc Exp Biol Med 1992;199:81-7.

10. Clerk LH, Vincent MA, Jahn LA, Liu Z, Lindner JR, Barrett EJ. Obesity blunts insulin-mediated microvascular recruitment in human forearm muscle. Diabetes 2006;55:1436-42.

11. Liu Z, Liu J, Jahn LA, Fowler DE, Barrett EJ. Infusing lipid raises plasma free fatty acids and induces insulin resistance in muscle microvasculature. J Clin Endocrinol Metab 2009;94:3543-9.

12. de Jongh RT, Serne EH, ljzerman RG, de Vries G, Stehouwer CD. Free fatty acid levels modulate microvascular function: relevance for obesity-associated insulin resistance, hypertension, and microangiopathy. Diabetes 2004;53:2873-82.

13. de Jongh RT, Serne EH, IJzerman RG, de Vries G, Stehouwer CD. Impaired microvascular function in obesity: implications for obesity-associated microangiopathy, hypertension, and insulin resistance. Circulation 2004;109:2529-35.

14. Serne EH, Stehouwer CD, ter Maaten JC, ter Wee PM, Rauwerda JA, Donker AJ, Gans RO. Microvascular function relates to insulin sensitivity and blood pressure in normal subjects. Circulation 1999; 99: 896-902.

15. Jonk AM, Houben AJ, Schaper NC, de Leeuw PW, Serne EH, Smulders YM, Stehouwer CD. Acute angiotensin II receptor blockade improves insulin-induced microvascular function in hypertensive individuals. Microvasc Res 2011;82:77-83.

16. Giele EL, de Priester JA, Blom JA, den Boer JA, van Engelshoven JM, Hasman A, Geerlings M. Movement correction of the kidney in dynamic MRI scans using FFT phase difference movement detection. J Magn Reson Imaging 2001;14:741-9.

17. Press WH, Flannery BP, Teukolsky SA, Vetterling WT. Numerical Recipes in C. Cambridge University Press; New York, 1989.

18. Martin RF. General deming regression for estimating systematic bias and its confidence interval in methodcomparison studies. Clin Chem 2000;46:100-4.

19. van Bussel BC, Ferreira I, van de Waarenburg MP, van Greevenbroek MM, van der Kallen CJ, Henry RM, Feskens EJ, Stehouwer CD, Schalkwijk CG. Multiple inflammatory biomarker detection in a prospective cohort study: a cross-validation between well-established single-biomarker techniques and an electrochemiluminescense-based multi-array platform. PLoS One 2013;8:e58576. 
20. Bland JM, Altman DG. Statistical methods for assessing agreement between two methods of clinical measurement. Lancet 1986;1:307-10.

21. Jonk AM, Houben AJ, Schaper NC, de Leeuw PW, Serne EH, Smulders YM, Stehouwer CD. Obesity is associated with impaired endothelial function in the postprandial state. Microvasc Res 2011; 82: 423-9.

22. Schram MT, Sep SJ, Kallen van der CJ, Dagnelie PC, Koster A, Schaper NC, Henry RM, Stehouwer CD. The Maastricht Study: an extensive phenotyping study on determinants of type 2 diabetes, its complications and its comorbidities. Eur J Epidemiol 2014;29:439-51.

23. Antonios TF, Rattray FE, Singer DR, Markandu ND, Mortimer PS, MacGregor GA. Maximization of skin capillaries during intravital video-microscopy in essential hypertension: comparison between venous congestion, reactive hyperaemia and core heat load tests. Clin Sci (Lond) 1999;97:523-8.

24. Serne EH, Gans RO, ter Maaten JC, Tangelder GJ, Donker AJ, Stehouwer CD. Impaired skin capillary recruitment in essential hypertension is caused by both functional and structural capillary rarefaction. Hypertension 2001;38:238-42. 


\section{Chapter 3}

Microvascular dysfunction is associated with a

higher incidence of type 2 diabetes mellitus: a

systematic review and meta-analysis

Dennis M. J. Muris, Alfons J.H.M. Houben, Miranda T. Schram, Coen D.A. Stehouwer 


\section{ABSTRACT}

\section{Background}

Recent data support the hypothesis that microvascular dysfunction may be a potential mechanism in the development of insulin resistance. We examined the association of microvascular dysfunction with incident type 2 diabetes mellitus (T2DM) and impaired glucose metabolism by reviewing the literature and conducting a meta-analysis of longitudinal studies on this topic.

\section{Methods}

We searched MEDLINE and EMBASE for articles published up to October 2011. Prospective cohort studies that focused on microvascular measurements in participants free of T2DM at baseline were included. Pooled relative risks (RR) were calculated using random effects models.

\section{Results}

Thirteen studies met the inclusion criteria for this meta-analysis. These studies focused on T2DM and/or impaired fasting glucose (IFG), not on impaired glucose tolerance. The pooled RR for incident T2DM (3846 cases) was 1.25 [95\% Cl: 1.15; 1.36] per 1SD greater microvascular dysfunction when all estimates of microvascular dysfunction were combined. In analyses of single estimates of microvascular dysfunction, the pooled RR for incident T2DM was 1.49 [1.36; 1.64] per 1SD higher plasma sE-selectin levels; 1.21 [1.11; 1.31] per 1SD higher plasma sICAM-1 levels; 1.48 [1.03; 2.12$]$ per 1SD lower response to acetylcholine-mediated peripheral vascular reactivity; 1.18 [1.08; 1.29 ] per 1SD lower retinal arteriole-to-venule ratio; and 1.43 [1.33; 1.54] per 1 logarithmically transformed unit higher albumin-to-creatinine ratio. In addition, the pooled RR for incident IFG (409 cases) was 1.15 [1.01; 1.31] per 1SD greater retinal venular diameters.

\section{Conclusion}

These data indicate that various estimates of microvascular dysfunction were associated with incident T2DM and, possibly, IFG, suggesting a role for the microcirculation in the pathogenesis of T2DM. 


\section{INTRODUCTION}

Insulin resistance and beta cell dysfunction are key features of the pathophysiology of type 2 diabetes mellitus (T2DM), the prevalence of which is rapidly increasing. Central obesity and low physical activity, in turn, are main underlying causes of insulin resistance. $\mathrm{We}^{1}$ and others ${ }^{2}$ have recently advanced the hypothesis that microvascular dysfunction, by impairing the timely access of glucose and insulin to their target tissues, is an additional cause of insulin resistance. In addition, microvascular dysfunction may function as an intermediate step linking central obesity, low physical activity, and chronic, low-grade inflammation to insulin resistance (Fig. 1.2). ${ }^{3}$

There is substantial evidence in support of this hypothesis. For example, it has been demonstrated that insulin can redirect blood flow in skeletal muscle from non-nutritive capillaries to nutritive capillaries and thereby increase insulin-mediated glucose uptake without increasing total blood flow. ${ }^{4}$ This process, so-called capillary recruitment, is impaired in insulin-resistant individuals. ${ }^{5,6}$ In addition, experimental studies have demonstrated impairments in glucose disposal after blocking insulin-mediated capillary recruitment ${ }^{7}$, suggesting that microvascular dysfunction directly affects insulin-mediated glucose disposal. It is not clear, however, whether there is consistent prospective evidence to support this hypothesis, although, since the early 2000s, a growing number of prospective studies have investigated the association between various estimates of microvascular dysfunction and incident T2DM and impaired fasting glucose (IFG).

In view of these considerations, we conducted a systematic review and meta-analysis of these prospective studies to investigate whether microvascular dysfunction is associated with incident T2DM and IFG in population-based settings

\section{METHODS}

\section{SEARCH STRATEGY}

We conducted a search in MEDLINE and EMBASE for studies published from inception (1977) to October 2011. We considered four types of estimates of microvascular function. First, we included plasma markers of endothelial dysfunction, defined as markers that are synthesized to an important extent by the endothelium (regardless of whether they are also synthesized by other cell types), including soluble E-selectin (sE-selectin), soluble 
intercellular adhesion molecule-1 (sICAM-1), soluble vascular cell adhesion molecule-1 (sVCAM-1), and von Willebrand factor (VWF). ${ }^{8}$ Higher concentrations of these markers are associated with cardiovascular disease ${ }^{9}$ and are thought to be derived mainly from microcirculatory endothelium ${ }^{10}$, which makes it plausible that higher concentrations of these markers reflect greater microvascular endothelial dysfunction. Second, we included assessment of skin and muscle microcirculation (by capillaroscopy and laser-Doppler fluxmetry, and plethysmography, respectively), with lower responses reflecting microcirculatory dysfunction. Third, we included retinal diameters, as evaluated by retinal photography. We defined greater venular diameters and both lower arteriolar diameters and lower arteriole-to-venule ratios (AVRs) as markers of microvascular dysfunction, as greater retinal venular diameters are associated with atherosclerosis, inflammation, and cholesterol levels, and both lower AVRs and generalized arteriolar narrowing are associated with incident cardiovascular disease. ${ }^{11}$ Finally, we included microalbuminuria, which is thought to reflect a generalized increase in endothelial permeability. ${ }^{8}$ Therefore, higher values of urinary albumin excretion (UAE; expressed as albumin-to-creatinine ratio (ACR) or as urinary albumin excretion per time) is thought to reflect greater microvascular endothelial dysfunction.

To identify the studies of interest, we used the following terms: plasma markers of endothelial dysfunction (sE-selectin, sICAM-1, sVCAM-1, VWF); peripheral vascular reactivity (forearm blood flow, plethysmography, acetylcholine, sodium nitroprusside, LNMMA); skin microvascular endothelium-dependent or -independent reactivity (iontophoresis, intracutaneous injection, acetylcholine, sodium nitroprusside, L-NMMA); capillary density (capillary density, capillary recruitment, capillaroscopy, capillaries); retinal diameters (retinal vessels, arteriovenous ratio, AVR, venular diameter, arteriolar diameter, retinal arteriolar diameter); microalbuminuria (microalbuminuria, macroalbuminuria, albuminuria, ACR, UAE). These search strategies were combined with the terms (risk of) diabetes, glucose tolerance, cohort, follow-up, longitudinal. The search was limited to studies within humans and to studies written in English. Finally, we examined the reference lists of the selected papers to find other relevant articles.

\section{SELECTION CRITERIA AND DATA EXTRACTION}

Three authors (D.M.J.M., A.J.H.M.H., and M.T.S.) independently selected articles. Prospective cohort studies that measured microvascular function in participants free of T2DM at baseline were included. First, titles and abstracts of the retrieved studies were scanned and excluded if they were clearly irrelevant. After the title and abstract selection, the full text of the included articles was read to identify whether the studies met the prespecified inclusion criteria. After the selection procedure, the following data were 
extracted: characteristics of the study population, number of participants without T2DM at baseline, incident cases of T2DM or IFG, mean follow-up, definition of T2DM or IFG, the crude and adjusted odds ratios (OR), relative risks (RR) or hazard ratios (HR) with $95 \%$ confidence intervals $(95 \% \mathrm{Cl})$, confounding variables included in the analyses and the incidence and cumulative incidence of T2DM and IFG. When these data were missing, the principal investigator of the selected study was contacted for further information. If the investigator could not provide the requested information or did not respond, the available data were used.

\section{STATISTICAL ANALYSIS}

\section{INCIDENCES AND CUMULATIVE INCIDENCES}

When incidence data were not presented in the original article, cases per 1000 personyears and cumulative incidences were calculated. We used the following formulas: cases per 1000 person-years $=[($ T2DM or IFG cases/person-years $) * 1000]$, person-years = [participants*follow-up time], and cumulative incidence $=[(T 2 D M$ or IFG cases/controls)*100\%]. If the person-years were not specified in the article, T2DM or IFG cases were set at half of the duration of the follow-up.

\section{STATISTICAL ANALYSIS FOR THE META-ANALYSIS}

The meta-analysis was performed by use of RevMan $5^{12}$, using the generic inverse variance method with a random effects model. One standard deviation (1SD) difference of the independent variable in the fully adjusted models was used to estimate the pooled RRs and $95 \% \mathrm{Cl}$. The pooled effect sizes were estimated by calculating the logarithm of the RR and the standard error. In this analysis, larger studies with smaller standard errors have a greater weight than smaller studies with larger standard errors. A forest plot was made to show the pooled RRs and $95 \% \mathrm{Cls}$. We assumed that the populations in the different studies share the same underlying distribution of the microvascular markers. Therefore different SDs of the microvascular markers are likely to be the result of measurements errors, and risk per 1SD can be compared without conversion. ${ }^{13}$ Heterogeneity was assessed visually by forest plots, by means of Cochran's $Q$ test, of which the null hypothesis assumes homogeneity ${ }^{14}$, and by $I^{2}$ statistics, which indicates the percentage of variability across trials that is explained by heterogeneity rather than chance. ${ }^{15}$

Because of the highly skewed distribution, the continuous variables ACR and UAE were logarithmically transformed, and results on the association of microalbuminuria with 
incident T2DM are expressed per logarithmically transformed unit higher ACR or UAE. All logarithmic transformations were to the base $e$.

\section{RESULTS}

\section{STUDY SELECTION AND CHARACTERISTICS}

The literature search resulted in 2,722 articles (Fig. 3.1). After title, abstract and full text selection, twenty three articles were found that investigated the association of plasma markers of endothelial dysfunction $(n=11)$, peripheral vascular reactivity $(n=1)$, retinal diameters $(n=5)$, and microalbuminuria $(n=6)$, respectively, with incident T2DM and/or IFG. These studies focused on T2DM and/or IFG, not on IGT. We did not find any articles that prospectively investigated the association of skin microvascular endotheliumdependent or -independent reactivity and capillary density or recruitment with IGM or T2DM.

Table 3.1 shows the characteristics of the selected studies. All articles were published in English after 1994. We found 15 prospective population-based cohort studies ${ }^{16-30}$, three prospective nested case-control studies ${ }^{31-33}$ and five prospective case-cohort studies ${ }^{34-38}$. The studies examined mainly Caucasian participants from Europe, USA, and Australia. As expected, subjects who developed T2DM during follow-up were slightly older and had a higher body mass index (BMI) at baseline. In addition $10.2-70.2 \%$ of the subjects had hypertension at baseline and $9.3-72.6 \%$ of the subjects were current smokers. The follow-up time of the studies ranged from 2.6 to 12 years. The included studies used different measures to diagnose T2DM and IFG, mainly based on the ADA (1997 and 2003) and WHO (1985 and 2006) criteria. Most studies compared incident T2DM to a combined sample of non-T2DM and incident IFG. Two studies ${ }^{20,21}$ compared incident T2DM and IFG to non-T2DM.

Plasma samples of sE-selectin, sVCAM-1, sICAM-1 and VWF were analyzed by use of ELISAs. Peripheral vascular reactivity was assessed by a dose-response curve to intraarterial infusion of acetylcholine $\left(7.5,15\right.$ and $\left.30 \mu \mathrm{g}^{*} \mathrm{~mL}^{-1} * \mathrm{~min}^{-1}\right) .{ }^{25}$ Retinal diameters were evaluated offline by the use of fundus photos (Retinal Analysis; Optimate, Madison, WI). ACR or UAE were calculated to determine microalbuminuria. Five studies assessed microalbuminuria in a morning fasting spot urine sample ${ }^{18,19,23,27,33}$, while one study assessed microalbuminuria by use of two $24-\mathrm{h}$ urine collections. ${ }^{16}$ 


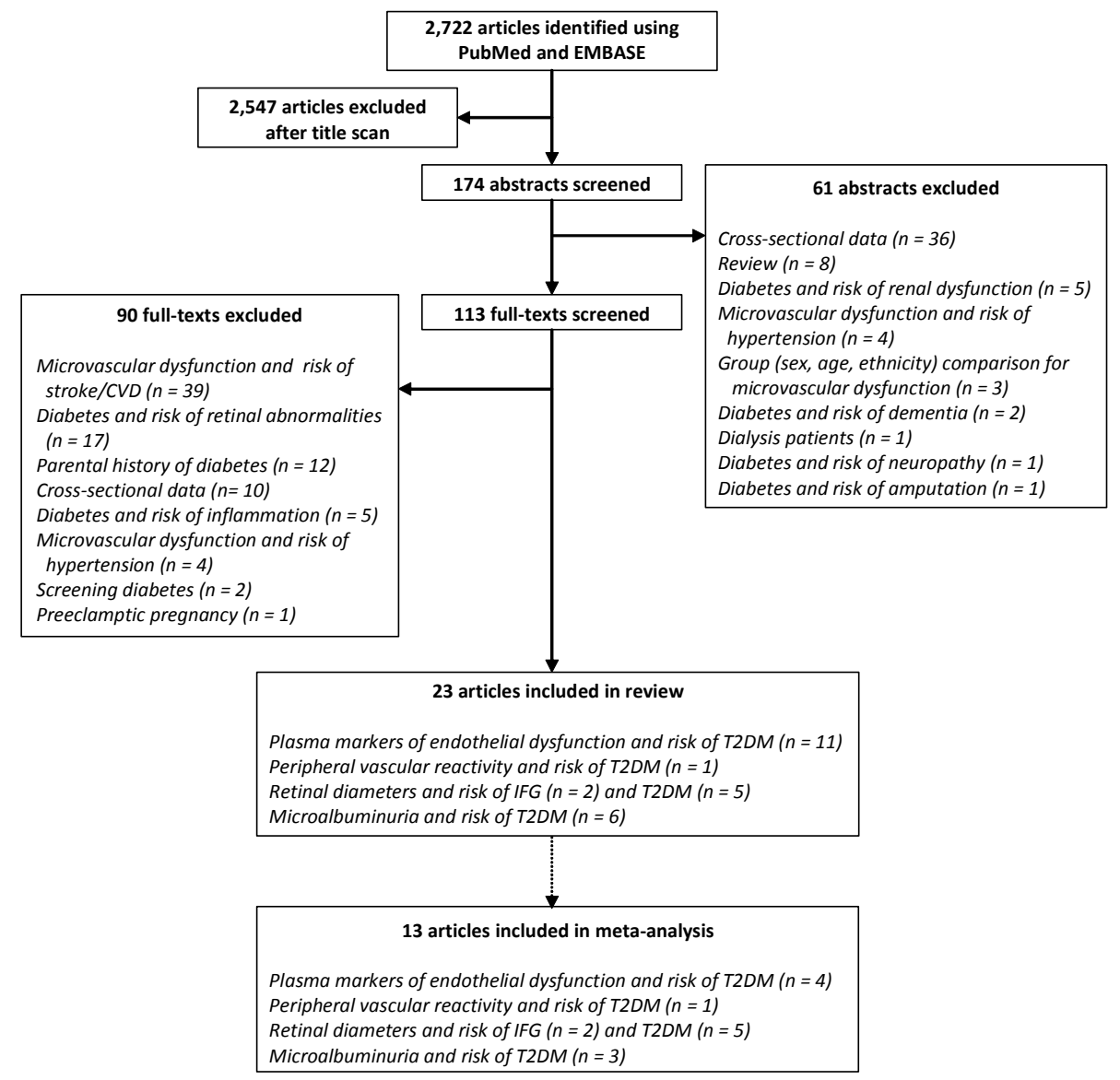

Figure 3.1. Literature selection

\section{MICROVASCULAR DYSFUNCTION AND RISK OF T2DM}

Eleven studies ${ }^{17,22,26,28,31,32,34-38}$ investigated the association of microvascular dysfunction as measured by plasma markers of endothelial dysfunction and incident T2DM. Table 3.2 shows a higher incidence of T2DM at higher levels of SE-selectin, sICAM-1 and VWF at baseline. Only the Western New York Study ${ }^{37}$ showed a lower incidence of T2DM at a higher level of sICAM-1 at baseline. Table 3.3 illustrates the associations of plasma markers of endothelial dysfunction with incident T2DM, comparing the upper to the lower tertile/quartile. Plasma markers of sE-selectin, sICAM-1, SVCAM-1, and VWF were positively and significantly associated with incident T2DM. After adjustment for confounders, including age, sex, race, and body composition, sE-selectin and sICAM-1 remained associated with incident T2DM, with RRs ranging from 1.34 [0.91; 1.99] to 4.61 $[2.85 ; 7.46]$ and from $1.03[0.64 ; 1.67]$ to $1.84[1.26 ; 2.69]$ respectively. 
Table 3.1. Characteristics of selected studies

\begin{tabular}{|c|c|c|c|c|c|c|c|c|c|c|c|c|c|}
\hline \multirow[t]{3}{*}{ Study } & \multirow[t]{3}{*}{ Etnicity } & \multicolumn{2}{|c|}{$\begin{array}{c}\text { Age study } \\
\text { population } \\
\text { (years) }\end{array}$} & \multicolumn{2}{|c|}{$\begin{array}{c}\text { BMI } \\
(\mathrm{kg} / \mathrm{m} 2)\end{array}$} & \multicolumn{2}{|c|}{$\begin{array}{l}\text { Hypertension } \\
\text { (\%) }\end{array}$} & \multicolumn{2}{|c|}{$\begin{array}{c}\text { Current } \\
\text { smokers } \\
(\%)\end{array}$} & \multirow{3}{*}{$\begin{array}{c}\text { Number of } \\
\text { participants } \\
\text { without } \\
\text { diabetes at } \\
\text { baseline }\end{array}$} & \multirow{3}{*}{$\begin{array}{l}\text { Incident } \\
\text { cases of } \\
\text { diabetes/ } \\
\text { IFG }\end{array}$} & \multirow{3}{*}{$\begin{array}{l}\text { Mean } \\
\text { follow-up } \\
\text { (years) }\end{array}$} & \multirow[t]{3}{*}{ Definitions of IFG or diabetes } \\
\hline & & \multicolumn{8}{|c|}{ Developed T2DM } & & & & \\
\hline & & Yes & No & Yes & No & Yes & No & Yes & No & & & & \\
\hline \multicolumn{14}{|c|}{ Plasma markers of endothelial dysfunction } \\
\hline The ARIC Study* ${ }^{17}$ & $\begin{array}{l}\text { Caucasians (78\%) } \\
\text { and African- } \\
\text { Americans (22\%) }\end{array}$ & \multicolumn{2}{|c|}{54} & \multicolumn{2}{|c|}{26.4} & \multicolumn{2}{|c|}{30} & \multicolumn{2}{|c|}{25} & 12330 & 1335 & 7 & $\begin{array}{l}\text { ADA guidelines } \\
\text { Use of antidiabetic medication } \\
\text { Physicians diagnosis }\end{array}$ \\
\hline $\begin{array}{l}\text { The Framingham } \\
\text { offspring study* } 22\end{array}$ & $\begin{array}{l}\text { Primarily } \\
\text { Caucasians }\end{array}$ & \multicolumn{2}{|c|}{54} & \multicolumn{2}{|c|}{25.3} & \multicolumn{2}{|c|}{38.6} & \multicolumn{2}{|c|}{18.5} & 2924 & 153 & 7 & $\begin{array}{l}\text { ADA guidelines } \\
\text { Use of antidiabetic medication }\end{array}$ \\
\hline $\begin{array}{l}\text { The British regional } \\
\text { heart study*28}\end{array}$ & Caucasians & 68 & 69 & 29.7 & 26.6 & \multicolumn{2}{|c|}{ NA } & \multicolumn{2}{|r|}{13.3} & 3562 & 162 & 7 & $\begin{array}{l}\text { WHO guidelines } \\
\text { Physicians diagnosis }\end{array}$ \\
\hline $\begin{array}{l}\text { The prospective } \\
\text { study of pravastatin } \\
\text { in the elderly at risk* }{ }^{26}\end{array}$ & Caucasians & 75 & 75 & 26.5 & 28.8 & 70.2 & 61.9 & 22.3 & 29.0 & 4945 & 292 & 3.2 & $\begin{array}{l}\text { ADA guidelines } \\
\text { Self-reported history }\end{array}$ \\
\hline The ARIC Study ${ }^{\dagger} 35$ & $\begin{array}{l}\text { Caucasians } \\
\text { and African- } \\
\text { Americans }\end{array}$ & 54 & 53 & 30.5 & 26.8 & 40.5 & 23.6 & 19.8 & 21.9 & 1153 & 581 & 9 & $\begin{array}{l}\text { ADA guidelines } \\
\text { Use of antidiabetic medication } \\
\text { Physicians diagnosis }\end{array}$ \\
\hline $\begin{array}{l}\text { The women's health } \\
\text { initiative observational } \\
\text { study }^{\ddagger 32}\end{array}$ & $\begin{array}{l}\text { Caucasians, } \\
\text { Blacks, } \\
\text { Hispanics and } \\
\text { Asian/Pacific } \\
\text { Islanders }\end{array}$ & 64 & 64 & 33 & 26 & & NA & \multicolumn{2}{|c|}{ NA } & 3782 & 1584 & $5.9^{\S}$ & $\begin{array}{l}\text { Use of antidiabetic medication } \\
\text { Self-reported history }\end{array}$ \\
\hline $\begin{array}{l}\text { The nurses' health } \\
\text { study }^{\ddagger 31}\end{array}$ & $\begin{array}{l}\text { Primarily } \\
\text { Caucasian }\end{array}$ & 56 & 56 & 30.2 & 26.2 & & NA & 14.0 & 13.4 & 1522 & 737 & 10 & $\begin{array}{l}\text { ADA guidelines } \\
\text { Use of antidiabetic medication }\end{array}$ \\
\hline $\begin{array}{l}\text { The MONICA and } \\
\text { KORA study }^{+38}\end{array}$ & Caucasians & 56 & 52 & 29.7 & 27.1 & 65.8 & 43.9 & 35.1 & 29.4 & 2244 & 532 & 12 & $\begin{array}{l}\text { Physicians diagnosis } \\
\text { Self-reported history }\end{array}$ \\
\hline $\begin{array}{l}\text { The Western New } \\
\text { York study }{ }^{+37}\end{array}$ & $\begin{array}{l}\text { Primarily } \\
\text { Caucasians }\end{array}$ & 58 & 60 & 32.2 & 29.5 & 55.9 & 35.1 & 19.7 & 10.8 & 219 & 61 & 5.9 & ADA guidelines \\
\hline $\begin{array}{l}\text { Longitudinal health } \\
\text { study in Pima } \\
\text { Indians }^{+36}\end{array}$ & Pima Indians & 33 & 32 & 36.3 & 36.3 & & NA & & & 142 & 71 & $4.6^{\|} 6.8^{\pi}$ & WHO guidelines \\
\hline
\end{tabular}


Table 3.1. Continued

\begin{tabular}{|c|c|c|c|c|c|c|c|c|c|c|c|c|c|}
\hline \multirow[t]{3}{*}{ Study } & \multirow[t]{3}{*}{ Etnicity } & \multicolumn{2}{|c|}{$\begin{array}{c}\text { Age study } \\
\text { population } \\
\text { (years) }\end{array}$} & \multicolumn{2}{|c|}{$\begin{array}{c}\text { BMI } \\
(\mathrm{kg} / \mathrm{m} 2)\end{array}$} & \multicolumn{2}{|c|}{$\begin{array}{l}\text { Hypertension } \\
\text { (\%) }\end{array}$} & \multicolumn{2}{|c|}{$\begin{array}{c}\text { Current } \\
\text { smokers } \\
(\%) \\
\end{array}$} & \multirow{3}{*}{$\begin{array}{l}\text { Number of } \\
\text { participants } \\
\text { without } \\
\text { diabetes at } \\
\text { baseline }\end{array}$} & \multirow{3}{*}{$\begin{array}{l}\text { Incident } \\
\text { cases of } \\
\text { diabetes/ } \\
\text { IFG }\end{array}$} & \multirow{3}{*}{$\begin{array}{l}\text { Mean } \\
\text { follow-up } \\
\text { (years) }\end{array}$} & \multirow[t]{3}{*}{ Definitions of IFG or diabetes } \\
\hline & & \multicolumn{8}{|c|}{ Developed T2DM } & & & & \\
\hline & & Yes & No & Yes & No & Yes & No & Yes & No & & & & \\
\hline $\begin{array}{l}\text { The MONICA and } \\
\text { KORA Study }{ }^{+34}\end{array}$ & Caucasians & 57 & 52 & 30.3 & 26.7 & 69.5 & 39.5 & 23.9 & 23.3 & 1846 & 436 & 10.5 & $\begin{array}{l}\text { Physicians diagnosis } \\
\text { Self-reported history }\end{array}$ \\
\hline \multicolumn{14}{|c|}{ Peripheral vascular reactivity } \\
\hline Perticone, 2008* 25 & Caucasians ${ }^{\#}$ & 50 & 48 & 27.6 & 27.5 & 100 & 100 & 14 & 19 & 400 & 44 & 4.5 & $\begin{array}{l}\text { ADA guidelines } \\
\text { Use of antidiabetic medication }\end{array}$ \\
\hline \multicolumn{14}{|l|}{ Retinal diameters } \\
\hline $\begin{array}{l}\text { The Rotterdam } \\
\text { study* } 20\end{array}$ & Caucasians & \multicolumn{2}{|c|}{65} & \multicolumn{2}{|c|}{26.2} & \multicolumn{2}{|c|}{ NA } & \multicolumn{2}{|c|}{21.8} & 2309 & $118 / 305$ & 6.4 & $\begin{array}{l}\text { ADA guidelines } \\
\text { Use of antidiabetic medication }\end{array}$ \\
\hline $\begin{array}{l}\text { The blue mountains } \\
\text { eye study* }{ }^{21}\end{array}$ & Caucasians & \multicolumn{2}{|c|}{ NA } & \multicolumn{2}{|c|}{ NA } & \multicolumn{2}{|r|}{ NA } & \multicolumn{2}{|c|}{ NA } & 2123 & $165 / 104$ & 10 & $\begin{array}{l}\text { ADA guidelines } \\
\text { Physicians diagnosis }\end{array}$ \\
\hline The AusDiab study* ${ }^{24}$ & Caucasians & 58 & 56 & 30.2 & 27.5 & 55.7 & 44.2 & 12.4 & 8.8 & 803 & 108 & 4.98 & $\begin{array}{l}\text { WHO guidelines } \\
\text { Use of antidiabetic medication }\end{array}$ \\
\hline The ARIC Study* 29 & $\begin{array}{l}\text { Caucasians } \\
(82.9 \%) \\
\text { and African- } \\
\text { Americans } \\
(17.1 \%)\end{array}$ & \multicolumn{2}{|c|}{59} & \multicolumn{2}{|c|}{27.9} & \multicolumn{2}{|r|}{ NA } & \multicolumn{2}{|c|}{16.6} & 7993 & 291 & $3.5^{\S}$ & $\begin{array}{l}\text { ADA guidelines } \\
\text { Use of antidiabetic medication } \\
\text { Physicians diagnosis }\end{array}$ \\
\hline $\begin{array}{l}\text { The beaver dam } \\
\text { eye study* } 30\end{array}$ & Caucasians & \multicolumn{2}{|c|}{50} & \multicolumn{2}{|c|}{28.7} & \multicolumn{2}{|r|}{ NA } & \multicolumn{2}{|c|}{ NA } & 3251 & 249 & 10 & $\begin{array}{l}\text { Postload plasma glucose } \\
>11.1 \mathrm{mmol} / \mathrm{L} \\
\text { Use of antidiabetic medication } \\
\text { or diet therapy } \\
\text { Physicians diagnosis }\end{array}$ \\
\hline
\end{tabular}




\begin{tabular}{|c|c|c|c|c|c|c|c|c|c|c|c|c|c|}
\hline \multirow[t]{3}{*}{ Study } & \multirow[t]{3}{*}{ Etnicity } & \multicolumn{2}{|c|}{$\begin{array}{c}\text { Age study } \\
\text { population } \\
\text { (years) }\end{array}$} & \multicolumn{2}{|c|}{$\begin{array}{c}\text { BMI } \\
(\mathrm{kg} / \mathrm{m} 2)\end{array}$} & \multicolumn{2}{|c|}{$\begin{array}{l}\text { Hypertension } \\
\text { (\%) }\end{array}$} & \multicolumn{2}{|c|}{$\begin{array}{c}\text { Current } \\
\text { smokers } \\
(\%)\end{array}$} & \multirow{3}{*}{$\begin{array}{l}\text { Number of } \\
\text { participants } \\
\text { without } \\
\text { diabetes at } \\
\text { baseline }\end{array}$} & \multirow{3}{*}{$\begin{array}{c}\text { Incident } \\
\text { cases of } \\
\text { diabetes/ } \\
\text { IFG }\end{array}$} & \multirow{3}{*}{$\begin{array}{c}\text { Mean } \\
\text { follow-up } \\
\text { (years) }\end{array}$} & \multirow[t]{3}{*}{ Definitions of IFG or diabetes } \\
\hline & & \multicolumn{8}{|c|}{ Developed T2DM } & & & & \\
\hline & & Yes & No & Yes & No & Yes & No & Yes & No & & & & \\
\hline \multicolumn{14}{|l|}{ Microalbuminuria } \\
\hline $\begin{array}{l}\text { The strong heart } \\
\text { study*27 }\end{array}$ & $\begin{array}{l}\text { American } \\
\text { Indians** }\end{array}$ & \multicolumn{2}{|c|}{56} & 31.5 & 30.1 & 32.6 & 34.2 & 30.4 & 38.5 & 1079 & 391 & $7.8^{\S}$ & ADA guidelines \\
\hline The DESIR study* ${ }^{19}$ & Caucasians & \multicolumn{2}{|c|}{47} & 24.0 & 25.3 & 29.4 & 42.0 & 13.3 & 26.3 & 3842 & 171 & 9 & $\begin{array}{l}\text { ADA guidelines } \\
\text { Use of antidiabetic medication }\end{array}$ \\
\hline Wang, $2006^{\ddagger 33}$ & Aboriginals & 36 & 36 & 26.7 & 26.2 & \multicolumn{2}{|c|}{ NA } & 72.6 & 66.7 & 234 & 117 & 11 & WHO guidelines \\
\hline $\begin{array}{l}\text { The PREVEND } \\
\text { study* }{ }^{16}\end{array}$ & Caucasians & 57 & 49 & 29.6 & 25.8 & 25.4 & 10.2 & \multicolumn{2}{|c|}{ NA } & 5654 & 185 & 4.2 & $\begin{array}{l}\text { ADA guidelines } \\
\text { Use of antidiabetic medication }\end{array}$ \\
\hline $\begin{array}{l}\text { Diabetes prevention } \\
\text { program* }{ }^{18}\end{array}$ & All races** & \multicolumn{2}{|c|}{50} & \multicolumn{2}{|c|}{33} & & NA & \multicolumn{2}{|c|}{7.9} & 3188 & 674 & $3.2^{\S}$ & $\begin{array}{l}\text { ADA guidelines } \\
\text { WHO guidelines }\end{array}$ \\
\hline Mykkanen, $1994 *{ }^{23}$ & Caucasians & \multicolumn{2}{|c|}{69} & \multicolumn{2}{|c|}{27.4} & & 9.7 & \multicolumn{2}{|c|}{10.0} & 891 & 92 & 3.5 & $\begin{array}{l}\text { WHO guidelines } \\
\text { Physicians diagnosis }^{++}\end{array}$ \\
\hline
\end{tabular}

\footnotetext{
Population-based cohort study

${ }^{\dagger}$ Case-cohort study

${ }^{\ddagger}$ Nested-case cohort study

${ }^{\S}$ Follow-up described in median

"Mean follow-up for control subjects

१ Mean follow-up for case subjects

\# Hypertension at baseline

** Prediabetes at baseline

${ }^{+\dagger}$ Definition of Non-Insulin-Dependent Diabetes Mellitus (NIDDM)

NA not applicable, not described in article
}

ACR (Urinary Albumin to Creatinine Ratio): milligrams of albumin per gram of creatinine. ACR: $30-300 \mathrm{mg} / \mathrm{day}=$ microalbuminuria

UAE (Urinary Albumin Excretion): milligrams albumin per litre urine. UAE: $20-200 \mathrm{mg} / \mathrm{L}=$ microalbuminuria

ADA (American Diabetes Association) guidelines: incident IFG if fasting glucose values reach 6.1-7.0 mmol/L. Incident T2DM if fasting glucose values reach $\geq 7.0 \mathrm{mmol} / \mathrm{L}$

WHO (World Health Organization) guidelines: incident IFG if fasting glucose values reach 6.1-6.9 mmol/L. Incident T2DM if fasting glucose values reach $\geq 7.0 \mathrm{mmol} / \mathrm{L}$ 
Table 3.2. Incidence and cumulative incidence of T2DM per tertile/quartile higher/lower plasma markers of endothelial dysfunction, retinal diameters, and microalbuminuria

\begin{tabular}{|c|c|c|c|c|c|c|c|}
\hline Study & Risk Marker & $\begin{array}{l}\text { Range/ } \\
\text { median }\end{array}$ & $\begin{array}{l}\text { Participants } \\
\text { (n) }\end{array}$ & $\begin{array}{l}\text { T2DM cases } \\
\text { (n) }\end{array}$ & $\begin{array}{l}\text { Person } \\
\text { years }\end{array}$ & $\begin{array}{l}\text { Cases per } 1000 \\
\text { person years }\end{array}$ & Cumulative incidence (\%) \\
\hline \multicolumn{8}{|c|}{ Plasma markers of endothelial dysfunction } \\
\hline \multirow[t]{18}{*}{ The MONICA and KORA study ${ }^{38}$} & sE-selectin* ${ }^{\lambda}$ & 36.4 & 368 & 60 & 4056 & 14.8 & 16.3 \\
\hline & & 55.9 & 389 & 80 & 4188 & 19.1 & 20.6 \\
\hline & & 82.0 & 455 & 170 & 4440 & 38.3 & 37.4 \\
\hline & sE-selectin*O & 30.0 & 323 & 42 & 3624 & 11.6 & 13.0 \\
\hline & & 47.9 & 328 & 57 & 3594 & 15.9 & 17.4 \\
\hline & & 71.3 & 381 & 123 & 3834 & 32.1 & 32.3 \\
\hline & sICAM-1* $\hat{\sigma}$ & 539.1 & 389 & 78 & 4200 & 18.6 & 20.1 \\
\hline & & 753.6 & 386 & 82 & 4140 & 19.8 & 21.2 \\
\hline & & 1034.0 & 437 & 150 & 4344 & 34.5 & 34.4 \\
\hline & sICAM-1*0 & 506.2 & 328 & 50 & 3636 & 13.8 & 15.2 \\
\hline & & 690.7 & 341 & 69 & 3678 & 18.8 & 20.2 \\
\hline & & 940.0 & 363 & 103 & 3738 & 27.6 & 28.4 \\
\hline & $\mathrm{vWF}^{+} \mathrm{C}^{\prime}$ & 59.5 & 140 & 31 & 1494 & 20.7 & 22.1 \\
\hline & & 110.9 & 155 & 53 & 1542 & 34.4 & 34.2 \\
\hline & & 183.4 & 104 & 43 & 990 & 43.4 & 41.3 \\
\hline & $\mathrm{vWF}^{\dagger+}$ & 65.6 & 107 & 20 & 1164 & 17.2 & 18.7 \\
\hline & & 117.2 & 109 & 18 & 1200 & 15.0 & 16.5 \\
\hline & & 181.0 & 116 & 26 & 1236 & 21.0 & 22.4 \\
\hline \multirow{6}{*}{$\begin{array}{l}\text { The Western New } \\
\text { York Study }{ }^{37}\end{array}$} & sE-selectin* & & 63 & 10 & 342 & 29.2 & 15.9 \\
\hline & & NA & 71 & 18 & 366 & 49.2 & 25.4 \\
\hline & & & 84 & 32 & 401 & 79.8 & 38.1 \\
\hline & sICAM-1* & & 74 & 22 & 372 & 59.2 & 29.7 \\
\hline & & NA & 75 & 20 & 384 & 52.2 & 26.7 \\
\hline & & & 70 & 18 & 360 & 50.0 & 25.7 \\
\hline \multirow{4}{*}{$\begin{array}{l}\text { The Framingham } \\
\text { offspring study }{ }^{22}\end{array}$} & $\mathrm{vWF}^{\dagger}$ & & & & & 4.4 & \\
\hline & & $N A$ & 2924 & 153 & 19664 & 7.4 & NA \\
\hline & & NA & 2924 & 153 & 19664 & 8.8 & NA \\
\hline & & & & & & 10.2 & \\
\hline
\end{tabular}


Table 3.2. Continued

\begin{tabular}{|c|c|c|c|c|c|c|c|}
\hline Study & Risk Marker & $\begin{array}{l}\text { Range/ } \\
\text { median }\end{array}$ & $\begin{array}{l}\text { Participants } \\
\text { (n) }\end{array}$ & $\begin{array}{l}\text { T2DM cases } \\
\text { (n) }\end{array}$ & $\begin{array}{c}\text { Person } \\
\text { years }\end{array}$ & $\begin{array}{c}\text { Cases per } 1000 \\
\text { person years }\end{array}$ & Cumulative incidence (\%) \\
\hline \multirow{3}{*}{$\begin{array}{l}\text { The British regional } \\
\text { heart study }{ }^{28}\end{array}$} & $\mathrm{vWF}^{\ddagger}$ & $<115$ & & & & 5.8 & \\
\hline & & $115-155$ & 3562 & 162 & 24934 & 6.1 & NA \\
\hline & & $>155$ & & & & 8.4 & \\
\hline \multicolumn{8}{|l|}{ Retinal diameters } \\
\hline \multirow[t]{6}{*}{ The AusDiab study ${ }^{24}$} & Venular diameter ${ }^{\pi}$ & $\leq 196$ & 264 & 38 & 1225 & 31 & 14.4 \\
\hline & & $196-216$ & 287 & 39 & 1338 & 29.1 & 13.6 \\
\hline & & $\geq 216$ & 252 & 31 & 1183 & 26.2 & 12.3 \\
\hline & Arteriolar diameter ${ }^{\pi}$ & $\leq 167$ & 254 & 42 & 1165 & 36.1 & 16.5 \\
\hline & & $167-188$ & 301 & 41 & 1403 & 29.2 & 13.6 \\
\hline & & $\geq 188$ & 248 & 25 & 1178 & 21.2 & 10.1 \\
\hline \multirow[t]{4}{*}{ The ARIC study ${ }^{29}$} & Avratio** & $0.57-0.79$ & 1998 & 104 & 6811 & 15.3 & 5.2 \\
\hline & & $0.80-0.84$ & 1998 & 79 & 6855 & 11.5 & 4,0 \\
\hline & & $0.85-0.90$ & 1999 & 61 & 6890 & 8.9 & 3.1 \\
\hline & & $0.91-1.12$ & 1998 & 47 & 6911 & 6.8 & 2.4 \\
\hline \multirow{12}{*}{$\begin{array}{c}\text { The beaver dam } \\
\text { eye study }\end{array}$} & Venular diameter ${ }^{\Uparrow}$ & $166.4-227.4$ & 802 & 59 & 7725 & 7.6 & 7.4 \\
\hline & & $227.5-242.3$ & 814 & 61 & 7835 & 7.8 & 7.5 \\
\hline & & $242.4-257.6$ & 821 & 60 & 7910 & 7.6 & 7.3 \\
\hline & & $257.7-357.8$ & 814 & 69 & 7795 & 8.9 & 8.5 \\
\hline & Arteriolar diameter ${ }^{\natural}$ & $103.2-163$ & 808 & 87 & 7645 & 11.4 & 10.8 \\
\hline & & $163.1-171.8$ & 819 & 68 & 7850 & 8.7 & 8.3 \\
\hline & & 171.9-182.9 & 814 & 55 & 7865 & 7.0 & 6.9 \\
\hline & & $183-229.4$ & 810 & 39 & 7905 & 4.9 & 4.8 \\
\hline & Avratio** & $0.50-0.67$ & 801 & 87 & 7575 & 11.5 & 10.9 \\
\hline & & $0.68-0.71$ & 822 & 69 & 7875 & 8.8 & 8.4 \\
\hline & & $0.72-0.75$ & 818 & 54 & 7910 & 6.8 & 6.6 \\
\hline & & $0.76-1.04$ & 810 & 39 & 7905 & 4.9 & 4.8 \\
\hline
\end{tabular}


Table 3.2. Continued

\begin{tabular}{|c|c|c|c|c|c|c|c|}
\hline Study & Risk Marker & $\begin{array}{l}\text { Range/ } \\
\text { median }\end{array}$ & $\begin{array}{l}\text { Participants } \\
\text { (n) }\end{array}$ & $\begin{array}{l}\text { T2DM cases } \\
\text { (n) }\end{array}$ & $\begin{array}{c}\text { Person } \\
\text { years }\end{array}$ & $\begin{array}{c}\text { Cases per } 1000 \\
\text { person years }\end{array}$ & Cumulative incidence (\%) \\
\hline \multicolumn{8}{|l|}{ Microalbuminuria } \\
\hline \multirow[t]{3}{*}{ The PREVEND study ${ }^{16}$} & $U A E^{\S}$ & $<15$ & 4031 & 87 & & & 2.2 \\
\hline & & $15-30$ & 762 & 33 & NA & NA & 4.3 \\
\hline & & $>30$ & 682 & 56 & & & 8.2 \\
\hline \multirow[t]{5}{*}{ Wang, $2006^{33}$} & Microalbuminuria & Absent & 85 & 32 & 407 & 78.6 & 37.6 \\
\hline & & Present & 75 & 42 & 319 & 131.8 & 56.0 \\
\hline & $A C R^{\|}$ & & 66 & 22 & 325 & 67.8 & 33.3 \\
\hline & & NA & 67 & 35 & 292 & 119.8 & 52.2 \\
\hline & & & 101 & 60 & 419 & 143.2 & 59.4 \\
\hline \multirow{2}{*}{$\begin{array}{l}\text { The strong heart } \\
\text { study }^{27}\end{array}$} & Microalbuminuria & Absent & 959 & 335 & 4670 & 62.4 & 34.9 \\
\hline & & Present & 120 & 56 & 543 & 101.0 & 46.7 \\
\hline \multicolumn{8}{|c|}{ Marker described in $\mathrm{ng} / \mathrm{mL}$} \\
\hline \multicolumn{8}{|c|}{${ }^{+}$Marker described \% control } \\
\hline \multicolumn{8}{|c|}{${ }^{\ddagger}$ Marker described in IU/dL } \\
\hline \multicolumn{8}{|c|}{${ }^{\S}$ Marker described in $\mathrm{mg} / 24 \mathrm{~h}$} \\
\hline \multicolumn{8}{|c|}{$\|$ Marker described in $\mathrm{mg} / \mathrm{mmol}$} \\
\hline \multicolumn{8}{|c|}{ " Marker described in $\mu \mathrm{m}$} \\
\hline \multicolumn{8}{|c|}{${ }^{* *}$ Marker described in units } \\
\hline \multicolumn{8}{|c|}{ NA not applicable, not described in article } \\
\hline \multicolumn{8}{|l|}{ Incidences in men } \\
\hline Incidences in women & & & & & & & \\
\hline
\end{tabular}


Table 3.3. Unadjusted and fully adjusted associations of plasma markers of endothelial dysfunction, peripheral vascular reactivity, retinal diameters, and microalbuminuria with T2DM and IFG

\begin{tabular}{|c|c|c|c|c|c|c|}
\hline Study & Risk marker & $\begin{array}{l}\text { Crude IFG } \\
\text { risk }\end{array}$ & $\begin{array}{c}\text { Crude T2DM } \\
\text { risk }\end{array}$ & $\begin{array}{l}\text { Fully adjusted } \\
\text { IFG risk }\end{array}$ & $\begin{array}{c}\text { Fully adjusted T2DM } \\
\text { risk } \\
\end{array}$ & Adjustment for confounders ${ }^{\mathrm{e}}$ \\
\hline \multicolumn{7}{|c|}{ Plasma markers of endothelial dysfunction } \\
\hline The ARIC Study ${ }^{17}$ & vWF & NA & 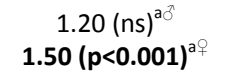 & NA & $\begin{array}{l}0.95(\mathrm{~ns})^{\mathrm{a} \mathrm{o}^{\mathrm{j}}} \\
1.30(\mathrm{~ns})^{\mathrm{a}+}\end{array}$ & $\begin{array}{l}1,3,4,6,8,9,10,15,16,19,21 \\
22,26\end{array}$ \\
\hline $\begin{array}{l}\text { The Framingham } \\
\text { offspring study }{ }^{22}\end{array}$ & vWF & NA & $1.40(1.12-1.77)^{b^{+}}$ & NA & $1.33(1.03-1.72)^{b^{+}}$ & $\begin{array}{l}2,7,9,10,11,13,14,16 \\
19,21,24,27,28,29,30,31\end{array}$ \\
\hline $\begin{array}{l}\text { The British regional } \\
\text { heart study }\end{array}$ & vWF & NA & $1.39(0.94-2.03)^{b}$ & NA & $1.01(0.67-1.53)^{b}$ & $\begin{array}{l}1,2,5,7,9,10,11,16,33 \\
34,35,36\end{array}$ \\
\hline $\begin{array}{l}\text { The prospective } \\
\text { study of pravastatin } \\
\text { in the elderly at risk }\end{array}$ & sICAM-1 & NA & $1.60(1.14-2.25)^{\mathrm{c \ddagger}}$ & NA & $1.84(1.26-2.69)^{c \ddagger}$ & $\begin{array}{l}1,2,6,13,14,19,20,21,22 \\
27\end{array}$ \\
\hline The ARIC study ${ }^{35}$ & sICAM-1 & NA & $1.91(1.45-2.50)^{c}$ & NA & $1.50(1.02-2.23)^{c}$ & $1,2,3,4,7,15,19,21,22,27$ \\
\hline \multirow{3}{*}{$\begin{array}{l}\text { The women's health } \\
\text { initiative observational } \\
\text { study }^{32}\end{array}$} & sE-selectin & \multirow{3}{*}{ NA } & $5.48(4.33-6.94)^{b}$ & \multirow{3}{*}{ NA } & $2.89(2.11-3.96)^{b}$ & \multirow[t]{3}{*}{$1,3,4,6,9,10,11,16,29,37,38$} \\
\hline & sVCAM-1 & & $2.05(1.62-2.59)^{b}$ & & $1.05(0.74-1.50)^{b+x}$ & \\
\hline & sICAM-1 & & $3.32(2.67-4.11)^{b+}$ & & $1.85(1.35-2.52)^{b+}$ & \\
\hline \multirow{3}{*}{$\begin{array}{l}\text { The nurses' health } \\
\text { study }^{31}\end{array}$} & sE-selectin & & $7.50(5.05-11.14)^{b+}$ & \multirow{3}{*}{ NA } & $4.61(2.85-7.46)^{b+}$ & \multirow[t]{3}{*}{$1,3,6,9,10,11,16,22,27,29,39$} \\
\hline & sVCAM-1 & NA & $1.54(1.10-2.15)^{b+9}$ & & $0.64(0.41-1.00)^{b+}$ & \\
\hline & sICAM-1 & & $4.29(2.95-6.23)^{b}$ & & $1.75(1.05-2.92)^{\mathrm{b} /+}$ & \\
\hline \multirow{6}{*}{$\begin{array}{l}\text { The MONICA and } \\
\text { KORA study }^{38}\end{array}$} & \multirow[t]{2}{*}{ sE-selectin } & & $3.01(2.18-4.17)^{c}$ & \multirow{6}{*}{ NA } & $2.63(1.79-3.88)^{c^{n}}$ & \multirow[t]{6}{*}{$1,4,6,9,10,11,13,16,19,21,27$} \\
\hline & & & $3.29(2.25-4.83)^{\mathrm{c} q}$ & & $1.71(1.07-2.75)^{\mathrm{c} q}$ & \\
\hline & \multirow[t]{2}{*}{ sICAM-1 } & & $2.16(1.59-2.93)^{c}$ & & $1.32(0.89-1.96)^{\mathrm{c} \mathrm{c}^{2}}$ & \\
\hline & & NA & $2.24(1.55-3.25)^{\mathrm{c} P}$ & & $1.03(0.64-1.67)^{\mathrm{c} P}$ & \\
\hline & \multirow[t]{2}{*}{$v W F$} & & $1.43(0.85-2.40)^{\mathrm{c}}$ & & $0.87(0.44-1.74)^{\mathrm{c}}$ & \\
\hline & & & $1.31(0.69-2.49)^{\mathrm{c}+}$ & & $1.10(0.42-2.90)^{\mathrm{c} P}$ & \\
\hline \multirow{2}{*}{$\begin{array}{l}\text { The Western New } \\
\text { York study }{ }^{37}\end{array}$} & sE-selectin & & $3.39(1.47-7.83)^{b}$ & \multirow{2}{*}{ NA } & $2.77(1.13-6.79)^{b}$ & \multirow[t]{2}{*}{$1,2,3,6,10,11,16,22,40$} \\
\hline & sICAM-1 & NA & $0.88(0.42-1.87)^{b}$ & & NA & \\
\hline \multirow{4}{*}{$\begin{array}{l}\text { Longitudinal health } \\
\text { study in Pima } \\
\text { Indians }^{36}\end{array}$} & sE-selectin & & $1.12(0.82-1.55)^{d}$ & \multirow{4}{*}{ NA } & $1.34(0.91-1.99)^{d}$ & \multirow[t]{4}{*}{$1,7,22,23,41,42$} \\
\hline & sVCAM-1 & & $0.70(n s)^{d q}$ & & 0.90 (ns) ${ }^{\mathrm{d} \pi}$ & \\
\hline & sICAM-1 & NA & $0.70(\mathrm{~ns})^{\mathrm{d} q}$ & & $0.80(\mathrm{~ns})^{\mathrm{d} q}$ & \\
\hline & vWF & & $0.67(0.45-1.00)^{d}$ & & $0.73(0.46-1.16)^{d}$ & \\
\hline
\end{tabular}




\begin{tabular}{|c|c|c|c|c|c|c|}
\hline Study & Risk marker & $\begin{array}{l}\text { Crude IFG } \\
\text { risk }\end{array}$ & $\begin{array}{l}\text { Crude T2DM } \\
\text { risk }\end{array}$ & $\begin{array}{l}\text { Fully adjusted } \\
\text { IFG risk }\end{array}$ & $\begin{array}{l}\text { Fully adjusted T2DM } \\
\text { risk }\end{array}$ & Adjustment for confounders ${ }^{e}$ \\
\hline The MONICA and & sE-selectin & \multirow{2}{*}{ NA } & $1.80(p<0.001)^{c * T}$ & & $1.60(p<0.001)^{c * \pi}$ & $1,2,4,6,9,10,11,13,16,18,19$ \\
\hline KORA study ${ }^{34}$ & sICAM-1 & & $1.45(p<0.001)^{\mathrm{c} * \pi}$ & NA & $1.30(p=0.031)^{c * \pi}$ & \\
\hline \multicolumn{7}{|c|}{ Peripheral vascular reactivity } \\
\hline Perticone, $2008^{25}$ & $\begin{array}{l}\text { Acetylcholine- } \\
\text { stimulated } \\
\text { forearm blood } \\
\text { flow }\end{array}$ & NA & $1.47(1.16-1.85)^{\mathrm{c}^{* *}}$ & NA & $1.30(1.01-1.64)^{\mathrm{c}^{* *}}$ & $1,2,6,10,13,18,22,23,24,27$ \\
\hline \multicolumn{7}{|l|}{ Retinal diameters } \\
\hline \multirow{3}{*}{$\begin{array}{l}\text { The Rotterdam } \\
\text { study }{ }^{20}\end{array}$} & AVratio & NA & NA & $1.93(1.35-2.77)^{a}$ & $1.80(1.05-3.08)^{a}$ & \multirow{3}{*}{$\begin{array}{l}1,2,6,10,13,14,18,19,27,38 \\
46\end{array}$} \\
\hline & Venular diameter & NA & NA & $1.46(1.02-2.08)^{a}$ & $1.41(0.83-2.38)^{a}$ & \\
\hline & Arteriolar diameter & NA & NA & $1.17(0.82-1.66)^{a}$ & $1.29(0.73-2.28)^{\mathrm{a}}$ & \\
\hline \multirow{2}{*}{$\begin{array}{l}\text { The blue mountains } \\
\text { eye study }\end{array}$} & Venular diameter & $1.28(1.04-1.59)^{\mathrm{a} *}$ & $1.26(1.06-1.50)^{\mathrm{a} *}$ & $1.16(0.91-1.47)^{\mathrm{a} *}$ & $1.06(0.87-1.29)^{\mathrm{a} *}$ & \multirow[t]{2}{*}{$1,2,6,10,11,13,16,19,22,32$} \\
\hline & Arteriolar diameter & $0.96(0.77-1.18)^{a} *$ & $1.06(0.89-1.26)^{\mathrm{a} *}$ & $1.02(0.80-1.30)^{\mathrm{a} *}$ & $1.07(0.88-1.30)^{a} *$ & \\
\hline \multirow[t]{2}{*}{ The AusDiab study ${ }^{24}$} & Venular diameter & & $1.11(0.61-2.01)^{\mathrm{a}}$ & \multirow{2}{*}{ NA } & $0.82(0.40-1.69)^{a}$ & \multirow{2}{*}{$\begin{array}{l}1,2,5,6,7,9,10,13,15,16,19 \\
21,22,23,28,47,48\end{array}$} \\
\hline & Arteriolar diameter & NA & $2.14(1.13-4.05)^{a}$ & & $2.21(1.02-4.80)^{a}$ & \\
\hline The ARIC study ${ }^{29}$ & AVratio & NA & $2.76(1.67-4.58)^{a}$ & NA & $1.92(1.10-3.36)^{a}$ & $\begin{array}{l}1,2,3,4,5,6,8,9,10,11,15,16 \\
18,19,21,22,23\end{array}$ \\
\hline \multirow{3}{*}{$\begin{array}{l}\text { The beaver dam } \\
\text { eye study }\end{array}$} & AVratio & & $1.71(1.17-2.51)^{b}$ & \multirow{3}{*}{ NA } & $1.53(1.03-2.27)^{b}$ & \multirow{3}{*}{$\begin{array}{l}1,2,9,10,11,13,14,18,19,22 \\
41\end{array}$} \\
\hline & Venular diameter & NA & $1.10(0.71-1.43)^{b}$ & & $1.03(0.73-1.46)^{b}$ & \\
\hline & Arteriolar diameter & & $1.67(1.14-2.46)^{b}$ & & $1.47(0.99-2.18)^{b}$ & \\
\hline \multicolumn{7}{|l|}{ Microalbuminuria } \\
\hline $\begin{array}{l}\text { The strong heart } \\
\text { study }{ }^{27}\end{array}$ & $A C R$ & NA & NA & NA & $1.46(1.08-1.98)^{c \S}$ & $1,2,6,7,9,10,16,43$ \\
\hline The DESIR study ${ }^{19}$ & UAE & NA & $2.28(1.39-3.73)^{c}$ & NA & $2.12(1.76-9.54)^{c}$ & $\begin{array}{l}1,6,9,10,15,16,22,23,24,26 \\
27,28,33,44\end{array}$ \\
\hline \multirow[t]{2}{*}{ Wang, $2006^{33}$} & $A C R$ & \multirow{2}{*}{ NA } & $2.22(1.11-4.48)^{b}$ & \multirow{2}{*}{ NA } & $2.36(1.01-5.50)^{b}$ & \multirow[t]{2}{*}{$1,6,18,22,27$} \\
\hline & Microalbuminuria & & $2.22(1.15-4.29)^{b \S}$ & & $1.90(0.88-4.06)^{b \S}$ & \\
\hline $\begin{array}{l}\text { The PREVEND } \\
\text { study }{ }^{16}\end{array}$ & UAE & NA & $1.59(1.42-1.79)^{b}$ & NA & $1.53(1.25-1.88)^{b}$ & $\begin{array}{l}1,2,7,13,14,16,17,19,21,22 \\
23,27,31,32\end{array}$ \\
\hline
\end{tabular}


Table 3.3. Continued

\begin{tabular}{|c|c|c|c|c|c|c|}
\hline Study & Risk marker & $\begin{array}{l}\text { Crude IFG } \\
\text { risk }\end{array}$ & $\begin{array}{l}\text { Crude T2DM } \\
\text { risk }\end{array}$ & $\begin{array}{l}\text { Fully adjusted } \\
\text { IFG risk }\end{array}$ & $\begin{array}{c}\text { Fully adjusted T2DM } \\
\text { risk }\end{array}$ & Adjustment for confounders ${ }^{\mathrm{e}}$ \\
\hline $\begin{array}{l}\text { Diabetes prevention } \\
\text { program }{ }^{18}\end{array}$ & $A C R$ & NA & $1.07(1.00-1.10)^{c / \mid}$ & NA & $0.98(0.91-1.06)^{c \|}$ & $1,2,3,9,45$ \\
\hline Mykkanen, $1994^{23}$ & ACR & NA & $1.76(1.07-2.90)^{\mathrm{b} \S}$ & NA & $1.40(0.82-2.39)^{b \S}$ & 1,2 \\
\hline
\end{tabular}

IFG and T2DM risk were calculated by comparison of the upper and lower tertile/quartile, unless otherwise indicated. The fully adjusted models were extracted from the articles

${ }^{a}$ Odds Ratio

${ }^{\mathrm{b}}$ Relative Risk

${ }^{\mathrm{c}}$ Hazard Ratio

'Incidence Rate Ratio

e 1 , age; 2 , sex; 3 , race; 4, study center; 5 , education; 6 , body mass index; 7, waist circumference; 8 , waist-to-hip ratio; 9 , physical activity; 10 , smoking; 11 , alcohol consumption; 13 , systolic blood pressure; 14, diastolic blood pressure; 15 , hypertension; 16, family history of diabetes; 17 , family histroy of cardiovascular disease; 18 , total cholesterol; 19, HDL cholesterol; 20, LDL cholesterol; 21, triglycerides; 22, fasting glucose; 23, fasting insulin; 24, HOMA-IR; 25, social class; 26, fibrinogen; 27, CRP; 28, IFG, IGT; 29, postmenopausal hormone therapy; 30, use of aspirin; 31, blood pressure therapy; 32, cholesterol lowering medication; 33, history of cardiovascular disease; 34, use of statins; 35, adiponectin; 36, IL-6; 37, time of blood draw; 38, follow-up time; 39, diet score; 40, year of baseline visit; 41, HbA1c; 42, 2-h glucose levels; 43 , albuminuria; 44 , leucocytes; 45 , weight loss; 46 , carotid plaque score; 47 , retinopathy; 48 , microalbumin-to-creatinine ratio

* Risk IFG and T2DM per 1SD change in risk marker

${ }^{\dagger}$ Risk T2DM per IQR higher level of vWF

${ }^{\ddagger}$ Risk T2DM per 1 unit higher log[sICAM-1]

$\S$ (Micro)albuminuria absent versus present

" Risk diabetes with every doubling of ACR

" No exact data, risks estimated from figure

${ }^{* *}$ Risk diabetes per $100 \%$ lower vasodilatory response to acetylcholine

NA not applicable, effect on incident IFG not investigated

ns effect not significant

${ }^{\hat{A}}$ Association in men

${ }^{+}$Association in women 
One study investigated the association of peripheral vascular reactivity with incident T2DM. ${ }^{25}$ An attenuated endothelium-dependent vasoreactivity response was significantly associated with incident T2DM; the association remained present after adjustment for age, sex, BMI, smoking, systolic blood pressure (SBP), total cholesterol, fasting glucose, fasting insulin, HOMA-IR, and C-reactive protein (CRP) (HR, 1.30 [1.01; 1.64]).

Five studies assessed the relationship between retinal diameters and incident T2DM. $^{20,21,24,29,30}$ Table 3.2 shows a higher incidence of T2DM with smaller baseline arteriolar diameters and AVR. In contrast, venular diameters were not significantly associated with the incidence of T2DM. Table 3.3 illustrates that lower AVRs were significantly associated with incident T2DM in all three studies ${ }^{20,29,30}$, with RRs ranging from 1.53 [1.03; 2.27] to 1.92 [1.10; 3.36]. No significant associations were found between either venular or arteriolar diameters and the development of T2DM, except in the AusDiab Study ${ }^{24}$, which showed a significant association for arteriolar diameters (OR, 2.21 [1.02; 4.80]). All studies adjusted for age, sex, smoking, SBP and fasting plasma glucose levels. The studies additionally adjusted for ethnicity, study centre, BMI, waist circumference, physical activity, alcohol consumption, diastolic blood pressure (DBP), hypertension, family history of diabetes, total cholesterol, HDL cholesterol, fasting insulin levels, IFG/IGT, cholesterol-lowering medication, follow-up time, HbA1c, carotid plaque score, retinopathy, and $A C R$, although not all studies used the same variables in the fully adjusted models (Table 3.3).

Six studies investigated the association between microalbuminuria with incident T2DM. ${ }^{16,18,19,23,27,33}$ The incidence of T2DM was higher at higher levels of UAE and ACR, or in presence of microalbuminuria at baseline (Table 3.2). In addition, all six studies showed that the presence of microalbuminuria was significantly associated with incident T2DM. After adjustment for potential confounders, the associations remained present in five studies, with RRs ranging from 1.40 [0.82; 2.39] to 2.36 [1.01; 5.50], although studies adjusted for different variables in the analyses (Table 3.3 ).

\section{META-ANALYSIS}

With regard to plasma markers, two studies ${ }^{34,36}$ presented their results in figures and, therefore, did not report exact relative risks. Five studies presented their data in units that we could not transform into SDs (either tertiles ${ }^{28,35,37,38}$ or quintiles ${ }^{31}$ ). The remaining four studies $^{22,26,32,36}$ were included in the meta-analysis. With regard to peripheral vascular reactivity, only one study ${ }^{25}$ was available (Fig. 3.2). With regard to retinal diameters, all five studies ${ }^{20,21,24,29,30}$ were included in the meta-analysis and are presented in Figure 3.2. 
With regard to microalbuminuria, three studies presented $\mathrm{UAE}^{16}$ and $A C R^{18,33}$ as a continuous variable. These studies are presented in Figure 3.2.

Figure 3.2 shows that 1 SD greater microvascular dysfunction was associated with a $25 \%(15 ; 36 \%)$ higher incidence of T2DM. In addition, 1SD higher levels of plasma markers of endothelial function were associated with a $21 \%(5 ; 39 \%)$ higher incidence of T2DM. In analyses of single estimates of microvascular dysfunction, 1SD higher levels of sE-selectin and sICAM-1 were significantly associated with a $49 \%(36 ; 64 \%)$ and $21 \%(11$; $31 \%)$ higher incidence of T2DM, respectively. sVCAM-1 (2\% (-9; 16\%)) and VWF (15\% (-9; $44 \%)$ ) were not significantly associated with incident T2DM. One SD lower vasodilatory response to acetylcholine was associated with a $48 \%$ (3; 102\%) higher incidence of T2DM. In addition, 1SD lower AVR was associated with an 18\% (8; 29\%) higher incidence of T2DM. Greater venular diameters and 1SD lower arteriolar diameters were positively, but not significantly, associated with a $6 \%(-3 ; 15 \%)$ and $8 \%(-4 ; 22 \%)$ higher incidence of T2DM, respectively. Finally, one logarithmically transformed unit higher UAE or ACR was associated with a $43 \%(33 ; 54 \%)$ higher incidence of T2DM.

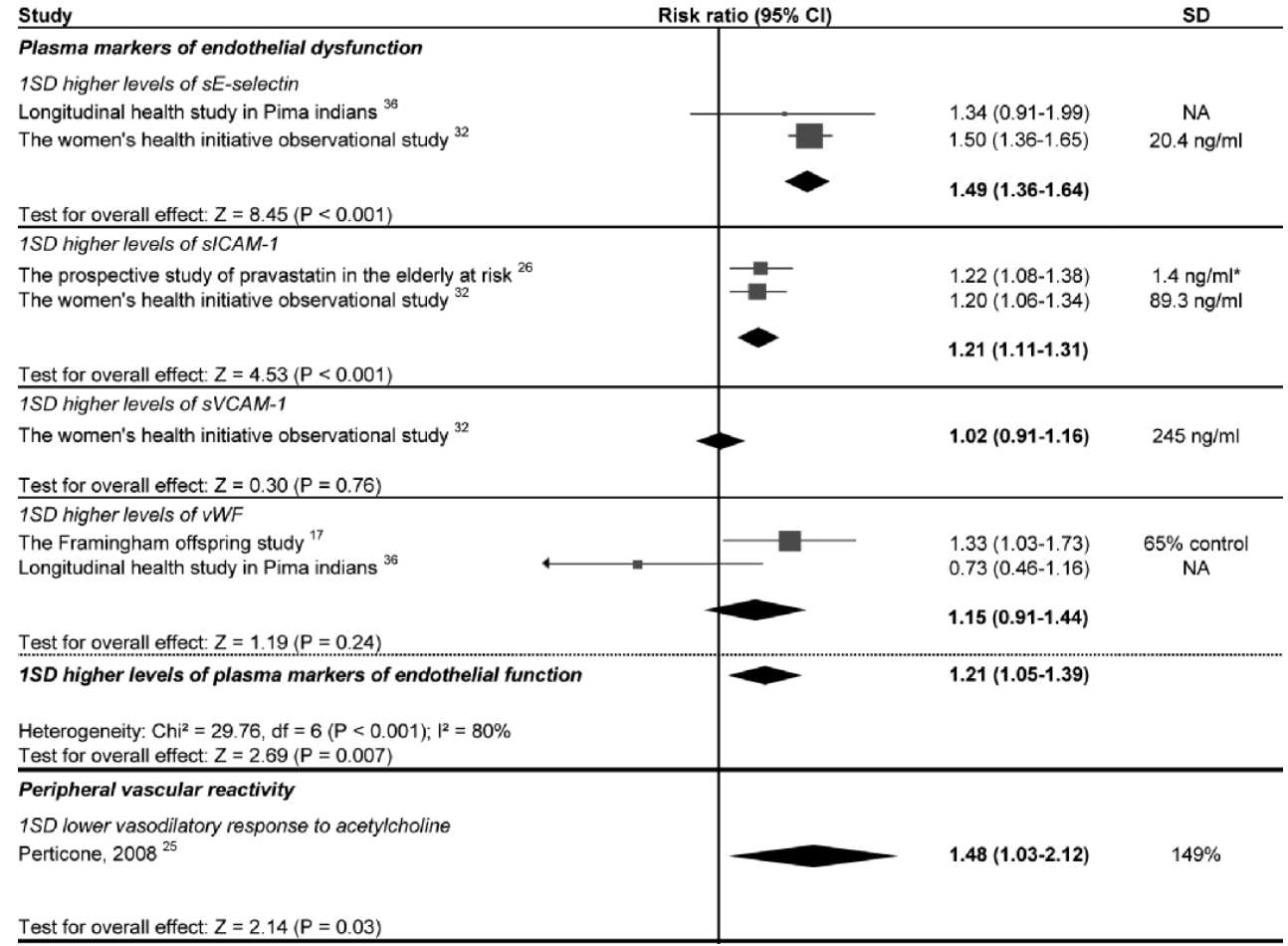

Continued

Figure 3.2. Forest plot showing the relative risk (RR) and $95 \% \mathrm{Cl}$ for each study and the pooled $\mathrm{RR}$ and $95 \% \mathrm{Cl}$ for risk of type 2 diabetes mellitus. 


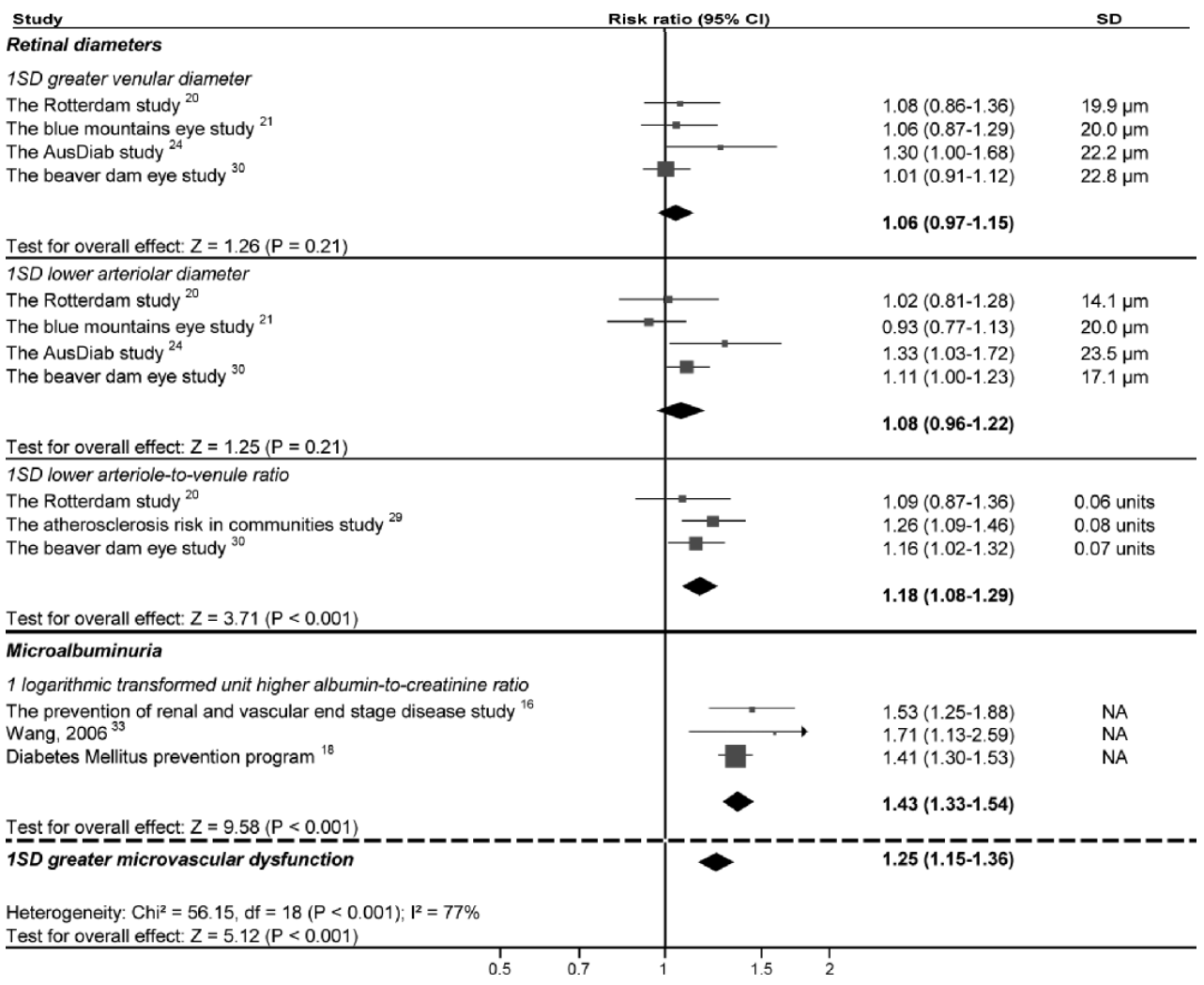

Figure 3.2. Continued. * Geometric SD. sE-selectin, soluble E-selectin; sICAM-1, soluble intercellular adhesion molecule-1; sVCAM-1, soluble vascular cell adhesion molecule-1; vWF, von Willebrand factor; NA, not applicable or not described in article.

\section{MICROVASCULAR DYSFUNCTION AND RISK OF IFG}

Two studies, the Rotterdam Study ${ }^{20}$ and the Blue Mountains Eye Study ${ }^{21}$, investigated the relationship between microvascular dysfunction as measured by retinal diameters and incident IFG. These studies did not specify cumulative incidences per tertile/quartile. Table 3.3 illustrates the associations of retinal diameters with incident IFG, comparing the upper to the lower tertile/quartile. The Rotterdam Study ${ }^{20}$ showed a significant association between both larger venular diameters (OR, 1.46 [95\% Cl: 1.02; 2.08]) and smaller AVR (OR, 1.93 [1.35; 2.77]), and the development of IFG. The Blue Mountains Eye Study ${ }^{21}$ showed a positive association between larger venular diameters (OR, 1.16 [0.91; 1.47]) and the development of IFG. Both studies adjusted for age, sex, body mass index, smoking, systolic blood pressure and HDL cholesterol. The Rotterdam Study ${ }^{20}$ additionally adjusted for diastolic blood pressure, total cholesterol, CRP, follow-up time, and carotid 
plaque score. In contrast, the Blue Mountains Eye Study ${ }^{21}$ additionally adjusted for alcohol consumption, family history of diabetes, fasting plasma glucose levels, and cholesterol lowering medication.

\section{META-ANALYSIS}

One SD greater venular diameters were associated with a $15 \%(1 ; 31 \%)$ higher incidence of IFG (Fig. 3.3). Arteriolar diameter was not associated with incident IFG. The Rotterdam Study $^{20}$ also showed that 1SD lower AVR was associated with a $14 \%(-2 ; 32 \%)$ higher incidence of IFG.

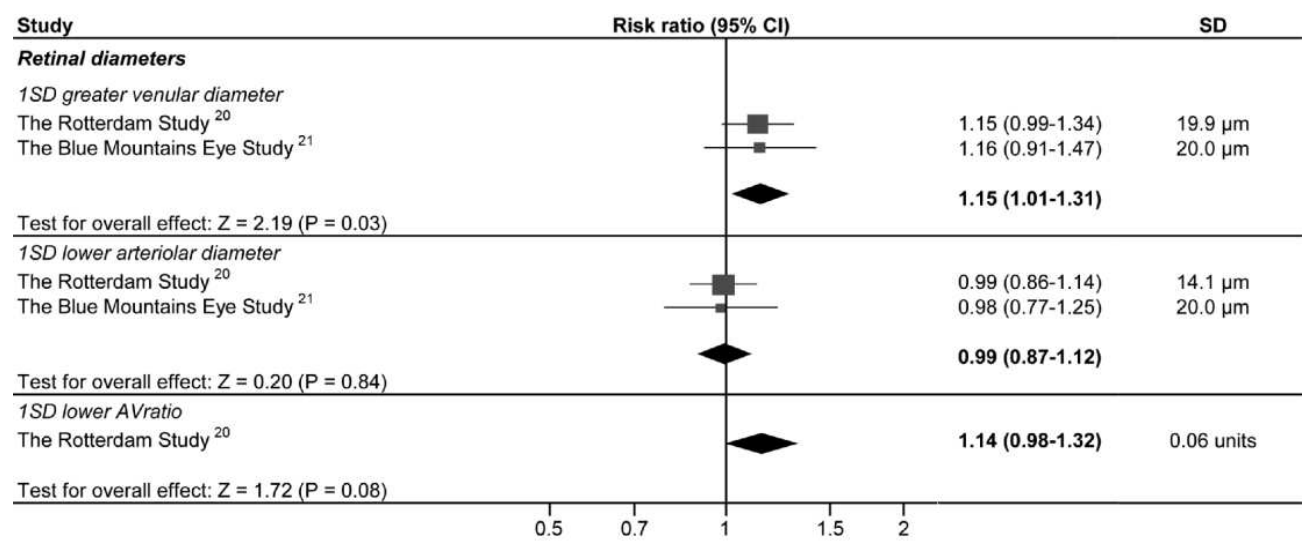

Figure 3.3. Forest plot showing the relative risks (RR) and $95 \% \mathrm{Cl}$ for each study and the pooled $\mathrm{RR}$ and $95 \% \mathrm{Cl}$ for risk of impaired fasting glucose.

\section{DISCUSSION}

This study represents the first systematic overview regarding microvascular dysfunction as a risk factor for incident T2DM and IFG. This review had two main findings. First, several markers of microvascular dysfunction, including plasma markers, peripheral vascular reactivity, AVR, and microalbuminuria were associated with incident T2DM. Second, greater venular diameters were associated with incident IFG. These findings are consistent with the hypothesis that microvascular dysfunction is causally linked with T2DM.

Our meta-analysis confirms that microvascular dysfunction was associated with a $10-49 \%$ higher incidence of T2DM and an $8-15 \%$ higher incidence of IFG. Several mechanisms, not mutually exclusive, may explain the association between microvascular 
dysfunction with both T2DM and IFG. First, one underlying mechanism is likely to involve the concept that insulin normally can redirect blood flow in skeletal muscle from nonnutritive capillaries to nutritive capillaries and thereby increase insulin-mediated glucose uptake without increasing total blood flow ${ }^{39}$, and that these processes are impaired in states of microvascular dysfunction, such as obesity, low physical activity, and chronic, low-grade inflammation. ${ }^{3}$ Notably, specific inhibition of insulin-mediated microvascular effects has been shown to cause a $30-40 \%$ reduction in glucose disposal. ${ }^{7}$ Second, it has been suggested that (pancreatic) microvascular endothelial dysfunction causes apoptosis of beta cells in the pancreas. ${ }^{40}$ This process decreases insulin secretory capacity and thus may lead to hyperglycemia, which, in addition, can further impair endothelial (microvascular) function, thus leading to a vicious cycle that may play a crucial role in the development of T2DM. ${ }^{40}$

Our analysis demonstrated consistent positive associations across all markers of microvascular endothelial dysfunction used. An important assumption in this reasoning is that these markers are valid indicators of microvascular endothelial dysfunction. ${ }^{41}$ The endothelium is a key regulator of permeability, vascular tone, and haemostasis. Thus, endothelial dysfunction can be manifested as increased microvascular permeability and impaired balance between vasodilatation and vasoconstriction, as well as between thrombotic and antithrombotic properties. ${ }^{8}$ Likewise, plasma markers of endothelial dysfunction, peripheral vascular reactivity, retinal diameters, and microalbuminuria may reflect different manifestations of these disturbances of the microvascular endothelium. First, E-selectin, ICAM-1, and VCAM-1 are thought to increase endothelial permeability to leucocytes, initiated by rolling and endothelial adhesion ${ }^{8}$, and their soluble forms are thought to reflect the concentration of membrane-bound adhesion molecules on the endothelium. ${ }^{42}$ In addition, vWF is thought to increase prothrombotic and procoagulant activity. ${ }^{8}$ These markers are synthesized by endothelial cells ${ }^{8}$, and the microvascular endothelium, with its large surface area and production capacity (i.e., the microvasculature covers $98 \%$ of the total vascular surface area ${ }^{43}$ ), is likely to be the most important determinant of these plasma concentrations. ${ }^{8}$ In addition, according to a previously described concept, endothelial dysfunction in large arteries is paralleled by endothelial dysfunction in resistance vessels that contributes to the development of T2DM. $^{44}$ For these reasons, it is plausible that higher circulating concentrations of these markers reflect microvascular endothelial dysfunction. Second, acetylcholine is an endothelium-dependent vasodilator due to the release of NO and the production of prostaglandins and endothelium-derived hyperpolarizing factor (EDHF). ${ }^{45}$ Consequently, a lower response in the peripheral microvasculature following stimulation with acetylcholine suggests a defect in the release of NO, EDHF and/or prostaglandins, and thus impaired endothelium-dependent vasodilatation. Third, retinal venular dilation and retinal arteriolar narrowing have been associated with endothelial dysfunction. ${ }^{46,47}$ Hence, both 
alterations may represent a directly microvascular phenotype of endothelial dysfunction. ${ }^{48}$ In addition, it has been hypothesized that higher intraluminal retinal venular diameters reflect a disrupted endothelial surface layer and thereby increase leukocyte adhesion. ${ }^{11}$ This assumption is in line with our meta-analysis, which suggests an association between higher venular diameters and incident IFG. However, due to the use of static fundus photos it is uncertain whether retinal diameters reflect structural or functional microvascular changes. Fourth, microalbuminuria is considered to reflect various aspects of endothelial dysfunction in many vascular beds. ${ }^{8}$ This concept is derived from data showing that microalbuminuria is associated with a greater transcapillary escape rate of albumin, i.e., with greater microvascular permeability ${ }^{8}$ and from data showing that microalbuminuria is strongly associated with risk of cardiovascular disease, that this association cannot be explained by conventional risk factors, and that changes in microalbuminuria are paralleled by changes in cardiovascular risk (reviewed elsewhere ${ }^{49}$ ).

Strengths of our study include its systematic approach and the evaluation of population-based studies. In order to identify all studies that assessed the association of microvascular dysfunction with both T2DM and IFG, we extensively searched MEDLINE and EMBASE. Given the fact that we searched for relatively large population-based studies, it seems unlikely that these studies will have been published and not identified by our search. Therefore, it is likely that we retrieved all published data. All studies included in this systematic review adjusted for multiple confounders, which makes it unlikely that residual confounding may have influenced the results, although we cannot completely exclude this. In contrast, overcorrection may have occurred, as microvascular dysfunction may link central obesity, low physical activity, and chronic, low-grade inflammation to insulin resistance, and be an intermediate step in the pathophysiologic process. ${ }^{3}$ Adjustment for these factors could therefore result in an underestimation of the actual association. In fact, some studies ${ }^{17,37,38}$ specifically adjusted for BMI, and were able to quantify the exact influence of adjusting for BMI and/or waist-to-hip ratio (WHR) (Table 3.4). Interestingly, the significant associations between SICAM- $^{37,38}, \mathrm{VWF}^{17}$, and $\mathrm{sE}-$ selectin $^{37,38}$ with incident T2DM decreased after adjustment for BMI and/or WHR. As adjustment for BMI and/or WHR may be an over adjustment, we conclude that the reported risks possibly underestimate the true risk for incident T2DM associated with microvascular dysfunction. Another important issue to address is whether the association is different among different subgroups (i.e., whether there is effect modification). Three studies included in this systematic review demonstrated significant associations between microvascular dysfunction with incident T2DM in the general population group as well as obese $^{31}$, inflammation ${ }^{32}$, and hypertensive ${ }^{30}$ population groups. In addition, at every level of increasing $\mathrm{BMI}^{31}, \mathrm{CRP}^{32}$, and blood pressure ${ }^{30}$ there was a stepwise increase in the association of markers of microvascular dysfunction with incident T2DM. Taken together, these studies suggest that there are significant associations between microvascular 
dysfunction and incident T2DM in all populations groups, with stronger associations in the obese, inflammation, and hypertensive groups. However, other studies included in this review did not investigate effect modification. Therefore, we cannot definitively conclude that the association is stronger in obese or hypertensive individuals, or at higher levels of inflammation.

Table 3.4 Associations between plasma markers of endothelial dysfunction with T2DM before and after correction for BMI

\begin{tabular}{|c|c|c|c|}
\hline Study & Risk Marker & $\begin{array}{l}\text { T2DM risk without } \\
\text { adjustment for BMI }\end{array}$ & $\begin{array}{l}\text { T2DM risk with } \\
\text { adjustment for BMI }\end{array}$ \\
\hline \multicolumn{4}{|c|}{ Plasma markers of endothelial dysfunction } \\
\hline The MONICA and KORA study ${ }^{38}$ & sE-selectin & $3.44(2.46-4.83)^{\mathrm{c}}$ & $3.01(2.18-4.17)^{\mathrm{C}}$ \\
\hline The Western New York study ${ }^{37}$ & & $3.18(1.32-7.64)^{b+}$ & $2.77(1.13-6.79)^{b}$ \\
\hline The MONICA and KORA study ${ }^{38}$ & sICAM-1 & $1.98(1.33-2.95)^{\mathrm{c}+*}$ & $1.24(0.80-1.91)^{\mathrm{c}+}$ \\
\hline The ARIC study ${ }^{17}$ & vWF & $1.40(p<0.01)^{a} \ddagger$ & $1.30(\mathrm{~ns})^{\mathrm{a}+}$ \\
\hline \multicolumn{4}{|c|}{ T2DM risk was calculated by comparison of the upper and lower tertile/quartile. } \\
\hline \multicolumn{4}{|l|}{${ }^{\text {a }}$ Odds Ratio } \\
\hline \multicolumn{4}{|l|}{${ }^{\mathrm{b}}$ Relative Risk } \\
\hline \multicolumn{4}{|l|}{${ }^{\mathrm{c}}$ Hazard Ratio } \\
\hline \multicolumn{4}{|c|}{ * Model adjusted for age and follow-up time } \\
\hline \multicolumn{4}{|c|}{$\begin{array}{l}\text { † Model adjusted for age, sex, race, smoking, alcohol consumption, family history of diabetes, fasting glucose, } \\
\text { year of baseline visit }\end{array}$} \\
\hline \multirow{2}{*}{\multicolumn{4}{|c|}{$\begin{array}{l}\text { ‡ Model adjusted for age, sex, race, study centre, physical activity, smoking, family history of diabetes, fasting } \\
\text { glucose and fibrinogen }\end{array}$}} \\
\hline & & & \\
\hline \multicolumn{4}{|l|}{ ns not significant } \\
\hline \multicolumn{4}{|l|}{ Association in men } \\
\hline${ }^{\circ}$ Association in women & & & \\
\hline
\end{tabular}

The studies included in this review had several limitations. First, because most studies examined mainly Caucasians (Table 3.1), the results of our meta-analysis are not necessarily valid for other ethnicities. For instance, the Longitudinal Health Study ${ }^{36}$ examined very obese Pima Indians, who had higher sE-selectin levels as compared to other studies ${ }^{31,32,34,37,38}$, and found no significant associations between plasma markers of endothelial dysfunction and T2DM. The authors concluded that the substantially higher plasma levels might reduce the power to detect an effect of such markers. ${ }^{36}$ However, ethnic differences (e.g., different population risks) may also explain the variations in T2DM risk. On the other hand, the Women's Health Initiative Observational Study ${ }^{32}$ showed no major differences between ethnic groups with respect to plasma markers of endothelial dysfunction. In addition, the MONICA and KORA Study ${ }^{38}$ demonstrated no clear differences between men and women (Table 3.2 and Table 3.3). Second, power problems could explain the lack of significant results in some studies. Mykkänen et al. ${ }^{23}$ examined 92 incident T2DM cases and demonstrated a positive, but non-significant relationship between microalbuminuria and incident T2DM, which suggests a lack of power. In contrast, other studies that did demonstrate significant associations ${ }^{16,19,27,33}$ included 
between 117 and 391 cases of incident T2DM (Table 3.1). Third, different methods for the assessment of microalbuminuria were used. The PREVEND Study ${ }^{16}$ assessed microalbuminuria by use of the mean of two 24-h urine collections (the accepted standard), while other studies ${ }^{18,19,23,27,33}$ used less precise morning urine samples. Although morning urine samples are a good screening test for albuminuria ${ }^{50}$, its lesser precision may have resulted in less strong associations with wider confidence intervals.

Our meta-analysis had some additional limitations. First, the concept that high plasma levels of endothelial dysfunction reflect endothelial dysfunction requires that endothelial cells are the major source of the plasma markers and that higher plasma levels are caused more by increased synthesis than by decreased clearance. ${ }^{8,41}$ Indeed, sEselectin is exclusively synthesized by endothelial cells ${ }^{51}$, which may explain the strong association between sE-selectin and incident T2DM. In addition, in T2DM, higher plasma VWF levels are determined by synthesis rather than clearance. ${ }^{52}$ However, sICAM-1, sVCAM-1, and VWF are expressed by several other cell types. ${ }^{51}$ Furthermore, except for VWF there is no information on the clearance of these markers. Consequently, the validity of these assumptions remains uncertain. ${ }^{8,41}$ Second, we acknowledge the limited availability of prospective studies that could be included in analyses of single estimates of microvascular dysfunction. Due to this low number we could not formally test for heterogeneity ${ }^{53}$ and we could not perform meta-regression analyses. As a consequence, we cannot exclude statistical heterogeneity, although all Cls overlapped (Fig. 3.2 and 3.3). Third, microvascular function is strongly tissue-dependent. ${ }^{54}$ In this systematic overview, we searched for all available prospective population-based studies that focused on any marker of microvascular function. Probably because of the difficulties of microvascular measurements in population-based studies, we only found studies investigating the microcirculation in skin, eye, and kidney. On the one hand, this could limit the generalisability of the data, because the association of microvascular dysfunction and incident T2DM may be tissue-specific (e.g., be limited to skeletal muscle microcirculation). On the other hand, the meta-analysis in fact demonstrated that all markers of microvascular dysfunction (skin, eye as well as kidney) are associated with incident T2DM. This suggests that microvascular function in quite different tissues does have common properties, a notion supported by other data. For example, it has been demonstrated that skeletal muscle microvascular dysfunction was associated with brain microvascular damage among individuals with hypertension. ${ }^{55}$

This systematic review underscores the importance of microvascular dysfunction in the pathogenesis of T2DM. However, this systematic review cannot prove any causal relationship. Therefore, more studies are needed to investigate this. These findings may contribute to more precise assessment of risk of T2DM. In addition, unravelling how microvascular dysfunction is determined and how it leads to T2DM may lead to new treatment targets as well as to a better understanding of why certain existing treatments 
are associated with decreased risk of developing T2DM (i.e., angiotensin converting enzyme- (ACE-)inhibitors, angiotensin receptor blockers (ARBs), and physical activity).

In conclusion, we demonstrated that microvascular dysfunction, assessed by use of different methods, was associated with incident T2DM and even IFG. Our findings are consistent with the hypothesis that microvascular dysfunction is causally linked with T2DM. 


\section{REFERENCES}

1. Jonk AM, Houben AJ, Schaper NC, et al. Angiotensin II enhances insulin-stimulated whole-body glucose disposal but impairs insulin-induced capillary recruitment in healthy volunteers. J Clin Endocrinol Metab. 2010;95:3901-8.

2. Liu Z, Liu J, Jahn LA, Fowler DE, Barrett EJ. Infusing lipid raises plasma free fatty acids and induces insulin resistance in muscle microvasculature. J Clin Endocrinol Metab. 2009;94:3543-9.

3. Jonk AM, Houben AJ, de Jongh RT, Serne EH, Schaper NC, Stehouwer CD. Microvascular dysfunction in obesity: a potential mechanism in the pathogenesis of obesity-associated insulin resistance and hypertension. Physiology (Bethesda). 2007;22:252-60.

4. Rattigan S, Clark MG, Barrett EJ. Hemodynamic actions of insulin in rat skeletal muscle: evidence for capillary recruitment. Diabetes. 1997;46:1381-8.

5. Czernichow S, Greenfield JR, Galan $P$, et al. Microvascular dysfunction in healthy insulin-sensitive overweight individuals. J Hypertens. 2010;28:325-32.

6. Tack CJ, Ong MK, Lutterman JA, Smits P. Insulin-induced vasodilatation and endothelial function in obesity/insulin resistance. Effects of troglitazone. Diabetologia. 1998;41:569-76.

7. Vincent MA, Barrett EJ, Lindner JR, Clark MG, Rattigan S. Inhibiting NOS blocks microvascular recruitment and blunts muscle glucose uptake in response to insulin. Am J Physiol Endocrinol Metab. 2003;285:E123-9.

8. Stehouwer CD. Is measurement of endothelial dysfunction clinically useful? Eur J Clin Invest. 1999;29:45961.

9. de Jager J, Dekker JM, Kooy A, et al. Endothelial dysfunction and low-grade inflammation explain much of the excess cardiovascular mortality in individuals with type 2 diabetes: the Hoorn Study. Arterioscler Thromb Vasc Biol. 2006;26:1086-93.

10. To SS, Newman PM, Hyland VJ, Robinson BG, Schrieber L. Regulation of adhesion molecule expression by human synovial microvascular endothelial cells in vitro. Arthritis Rheum. Mar 1996;39(3):467-77.

11. Ikram MK, de Jong FJ, Vingerling JR, et al. Are retinal arteriolar or venular diameters associated with markers for cardiovascular disorders? The Rotterdam Study. Invest Ophthalmol Vis Sci. 2004;45:2129-34.

12. Review Manager (RevMan) [Computer program]. Version 5.0. Copenhagen: The Nordic Cochrane Centre. The Cochrane Collaboration, 2008.

13. Lorenz MW, Markus HS, Bots ML, Rosvall M, Sitzer M. Prediction of clinical cardiovascular events with carotid intima-media thickness: a systematic review and meta-analysis. Circulation. 2007;115:459-67.

14. Egger M, Smith GD, Altman DG. Systematic reviews in health care. Meta-analysis in context. BMJ. 2001: Chapter 15.

15. Higgins JP, Thompson SG, Deeks JJ, Altman DG. Measuring inconsistency in meta-analyses. BMJ. 2003;327:557-60.

16. Brantsma AH, Bakker SJ, Hillege HL, de Zeeuw D, de Jong PE, Gansevoort RT. Urinary albumin excretion and its relation with C-reactive protein and the metabolic syndrome in the prediction of type 2 diabetes. Diabetes Care. 2005;28:2525-30.

17. Duncan BB, Schmidt MI, Offenbacher S, Wu KK, Savage PJ, Heiss G. Factor VIII and other hemostasis variables are related to incident diabetes in adults. The Atherosclerosis Risk in Communities (ARIC) Study. Diabetes Care. 1999;22:767-72.

18. Friedman AN, Marrero D, Ma Y, et al. Value of urinary albumin-to-creatinine ratio as a predictor of type 2 diabetes in pre-diabetic individuals. Diabetes Care. 2008;31:2344-8.

19. Halimi JM, Bonnet F, Lange C, Balkau B, Tichet J, Marre M. Urinary albumin excretion is a risk factor for diabetes mellitus in men, independently of initial metabolic profile and development of insulin resistance. The DESIR Study. Journal of Hypertension. 2008;26:2198-206.

20. Ikram MK, Janssen JA, Roos AM, et al. Retinal vessel diameters and risk of impaired fasting glucose or diabetes: the Rotterdam study. Diabetes. 2006;55:506-510.

21. Kifley A, Wang JJ, Cugati S, Wong TY, Mitchell P. Retinal vascular caliber and the long-term risk of diabetes and impaired fasting glucose: the Blue Mountains Eye Study. Microcirculation. 2008;15:373-7.

22. Meigs JB, O'Donnell C J, Tofler GH, et al. Hemostatic markers of endothelial dysfunction and risk of incident type 2 diabetes: the Framingham Offspring Study. Diabetes. 2006;55:530-7.

23. Mykkänen L, Haffner SM, Kuusisto J, Pyorala K, Laakso M. Microalbuminuria precedes the development of NIDDM. Diabetes. 1994;43:552-7. 
24. Nguyen TT, Wang JJ, Islam FM, et al. Retinal arteriolar narrowing predicts incidence of diabetes: the Australian Diabetes, Obesity and Lifestyle (AusDiab) Study. Diabetes. 2008;57:536-9.

25. Perticone F, Maio R, Sciacqua $A$, et al. Endothelial dysfunction and c-reactive protein are risk factors for diabetes in essential hypertension. Diabetes. 2008;57:167-71.

26. Sattar N, Murray HM, Welsh P, et al. Are elevated circulating intercellular adhesion molecule 1 levels more strongly predictive of diabetes than vascular risk? Outcome of a prospective study in the elderly. Diabetologia. 2009;52:235-39.

27. Wang H, Shara NM, Calhoun D, Umans JG, Lee ET, Howard BV. Incidence rates and predictors of diabetes in those with prediabetes: the Strong Heart Study. Diabetes Metab Res Rev. 2010;26:378-85.

28. Wannamethee SG, Sattar N, Rumley A, Whincup PH, Lennon L, Lowe GD. Tissue plasminogen activator, von Willebrand factor, and risk of type 2 diabetes in older men. Diabetes Care. 2008;31:995-1000.

29. Wong TY, Klein R, Sharrett AR, et al. Retinal arteriolar narrowing and risk of diabetes mellitus in middle-aged persons. JAMA. 2002;287:2528-33.

30. Wong TY, Shankar A, Klein R, Klein BE, Hubbard LD. Retinal arteriolar narrowing, hypertension, and subsequent risk of diabetes mellitus. Arch Intern Med. 2005;165:1060-5.

31. Meigs JB, Hu FB, Rifai N, Manson JE. Biomarkers of endothelial dysfunction and risk of type 2 diabetes mellitus. JAMA. 2004;291:1978-86.

32. Song $Y$, Manson JE, Tinker $L$, et al. Circulating levels of endothelial adhesion molecules and risk of diabetes in an ethnically diverse cohort of women. Diabetes. 2007;56:1898-904.

33. Wang Z, Hoy WE. Albuminuria as a marker of the risk of developing type 2 diabetes in non-diabetic Aboriginal Australians. International Journal of Epidemiology. 2006;35:1331-5.

34. Herder C, Baumert J, Zierer A, et al. Immunological and cardiometabolic risk factors in the prediction of type 2 diabetes and coronary events: MONICA/KORA Augsburg case-cohort study. PLoS One. 2011;6:e19852.

35. Hoogeveen RC, Ballantyne $\mathrm{CM}$, Bang $\mathrm{H}$, et al. Circulating oxidised low-density lipoprotein and intercellular adhesion molecule-1 and risk of type 2 diabetes mellitus: the atherosclerosis risk in communities study. Diabetologia. 2007;50:36-42.

36. Krakoff J, Funahashi T, Stehouwer CD, et al. Inflammatory markers, adiponectin, and risk of type 2 diabetes in the Pima Indian. Diabetes Care. 2003;26:1745-51.

37. Stranges S, Rafalson LB, Dmochowski J, et al. Additional contribution of emerging risk factors to the prediction of the risk of type 2 diabetes: evidence from the Western New York study. Obesity (Silver Spring). 2008;16:1370-6.

38. Thorand B, Baumert J, Chambless L, et al. Elevated markers of endothelial dysfunction predict type 2 diabetes mellitus in middle-aged men and women from the general population. Arterioscler Thromb Vasc Biol. 2006;26:398-405.

39. Clark MG, Wallis MG, Barrett EJ, et al. Blood flow and muscle metabolism: a focus on insulin action. Am J Physiol Endocrinol Metab. 2003;284:E241-58.

40. Tal MG. Type 2 diabetes: Microvascular ischemia of pancreatic islets? Med Hypotheses. 2009;73:357-358.

41. de Jager J, Kooy $A$, Lehert $P$, et al. Effects of short-term treatment with metformin on markers of endothelial function and inflammatory activity in type 2 diabetes mellitus: a randomized, placebo-controlled trial. J Intern Med. 2005;257:100-9.

42. Heyl W, Handt S, Reister F, Gehlen J, Mittermayer C, Rath W. The role of soluble adhesion molecules in evaluating endothelial cell activation in preeclampsia. Am J Obstet Gynecol. 1999;180:68-72.

43. Wolinsky H. A proposal linking clearance of circulating lipoproteins to tissue metabolic activity as a basis for understanding atherogenesis. Circ Res. 1980;47:301-11.

44. Pinkney JH, Stehouwer CD, Coppack SW, Yudkin JS. Endothelial dysfunction: cause of the insulin resistance syndrome. Diabetes. 1997;46 Suppl 2:S9-13.

45. Rubanyi GM. Endothelium-derived relaxing and contracting factors. J Cell Biochem. 1991;46:27-36.

46. Klein $\mathrm{R}$, Sharrett $A R$, Klein $B E$, et al. Are retinal arteriolar abnormalities related to atherosclerosis?: The Atherosclerosis Risk in Communities Study. Arterioscler Thromb Vasc Biol. 2000;20:1644-50.

47. Wilkinson-Berka JL. Vasoactive factors and diabetic retinopathy: vascular endothelial growth factor, cycoloxygenase-2 and nitric oxide. Curr Pharm Des. 2004;10(27):3331-48.

48. Liew G, Wang JJ, Mitchell $P$, Wong TY. Retinal vascular imaging: a new tool in microvascular disease research. Circ Cardiovasc Imaging. Sep 2008;1(2):156-61.

49. Stehouwer CD, Smulders YM. Microalbuminuria and risk for cardiovascular disease: Analysis of potential mechanisms. J Am Soc Nephrol. 2006;17:2106-11. 
50. Houlihan CA, Tsalamandris C, Akdeniz A, Jerums G. Albumin to creatinine ratio: a screening test with limitations. Am J Kidney Dis. 2002;39:1183-9.

51. Price DT, Loscalzo J. Cellular adhesion molecules and atherogenesis. Am J Med. 1999;107:85-97.

52. Vischer UM, Emeis JJ, Bilo HJ, et al. von Willebrand factor (vWf) as a plasma marker of endothelial activation in diabetes: improved reliability with parallel determination of the vWf propeptide (vWf:AgII). Thromb Haemost. Dec 1998;80(6):1002-7.

53. Schriger DL, Altman DG, Vetter JA, Heafner T, Moher D. Forest plots in reports of systematic reviews: a crosssectional study reviewing current practice. Int J Epidemiol. 2010;39:421-9.

54. Knotzer $\mathrm{H}$, Hasibeder WR. Microcirculatory function monitoring at the bedside--a view from the intensive care. Physiol Meas. 2007;28:R65-86.

55. Greenstein AS, Paranthaman R, Burns A, et al. Cerebrovascular damage in late-life depression is associated with structural and functional abnormalities of subcutaneous small arteries. Hypertension. 2010;56:734-40. 


\title{
Chapter 4
}

Type 2 diabetes mellitus and hyperglycaemia are

\author{
associated with microvascular dysfunction: the
}

\author{
Maastricht Study
}

Dennis M.J. Muris, Alfons J.H.M. Houben, Ümit Karaça, Nicolaas C. Schaper, Ronald M.A. Henry, Carla J.H. van der Kallen, Simone J.S. Sep, Annemarie Koster, Pieter C. Dagnelie, Coen D.A. Stehouwer, Miranda T. Schram 


\section{ABSTRACT}

\section{Background}

T2DM is associated with organ damage in the heart and the brain which can occur even in the absence of clinically apparent diabetic macro- and microangiopathy. A potential explanation to explain such findings is that T2DM can be associated with microvascular dysfunction that is not detected by standard clinical examination. We therefore investigated, in an observational population-based cohort study, whether T2DM status and long-term hyperglycaemia are independently associated with functional and structural capillary density. In particular, we investigated whether these associations are present even before clinically apparent diabetic microangiopathy has developed.

\section{Methods}

Using intravital videomicroscopy, we measured skin baseline capillary density, functional capillary density, and structural capillary density in 641 participants ( $n=223$ with T2DM). In addition, we selected, for additional analyses, a population ( $n=355 ; n=90$ with T2DM) free of clinically apparent diabetic microangiopathy. We used multiple linear regression analyses to investigate the associations of T2DM and HbA1c with skin capillary density values. Associations were adjusted for age, sex, waist circumference, total-to-HDL cholesterol ratio, triglycerides, systolic blood pressure, diastolic blood pressure, smoking, prior CVD, and anti-hypertensive, and lipid lowering medication.

\section{Results}

After adjustment for potential confounders, T2DM was associated with a significantly greater baseline capillary density ( $\beta 6.3$ [95\% Cl: $2.3 ; 10.3]$ capillaries $\left./ \mathrm{mm}^{2} ; P<0.001\right)$ and with a significantly lower relative functional and structural capillary density $(\beta-14.1[-20.6 ;-7.6] \% ; P<0.001$ and $\beta-13.8$ $[-20.1 ;-6.0] \% ; P<0.001$, respectively). In addition, $\mathrm{HbA1C}$ was significantly associated with a lower functional capillary density $(\beta-3.3[-6.0 ;-0.1] \% ; P=0.04)$, after adjustment for potential confounders. HbA1c was not associated with baseline capillary density and structural capillary density. Finally, additional adjustment for glomerular filtration rate, (micro-)albuminuria, and vibration perception threshold did not materially change these associations. In addition, analyses excluding T2DM patients with microangiopathy gave similar results.

\section{Conclusion}

T2DM is associated with increased baseline skin capillary density and with decreased relative functional and structural capillary densities. In addition, hyperglycaemia as estimated by HbA1c is associated with impaired functional capillary densities. Importantly, analyses excluding T2DM patients with microangiopathy gave similar results, suggesting that T2DM is associated with functional as well as structural capillary rarefaction, even in the absence of clinically apparent microangiopathy. 


\section{INTRODUCTION}

The prevalence of type 2 diabetes mellitus (T2DM) is increasing worldwide and has reached epidemic proportions in Western society. ${ }^{1}$ It is generally accepted that T2DM causes clinically apparent diabetic microangiopathy including retinopathy, neuropathy, and nephropathy. ${ }^{2-4}$ Changes in microvascular function and structure underlie the pathogenesis of diabetic microangiopathy. ${ }^{5}$ These changes may, in turn, be the consequence of hyperglycaemia, as it has been demonstrated that hyperglycaemia plays an important role in the pathogenesis of microvascular dysfunction ${ }^{6}$ and, ultimately, diabetic microangiopathy. ${ }^{7}$ In addition, T2DM is associated with organ damage in the heart and the brain, leading to heart failure, cognitive decline, and depression, ${ }^{8-10}$ which can occur even in the absence of clinically apparent diabetic macro- and microangiopathy. ${ }^{11,12}$ A potential explanation to explain such findings is that T2DM can be associated with microvascular dysfunction that is not detected by standard clinical examination.

In this regard, the skin is a unique site allowing simple and reproducible assessment of capillary density with the use of skin capillaroscopy. Specifically, the skin is the only site available in humans allowing direct, non-invasive visualization of capillaries at rest and during provocative stimuli, such as reactive hyperaemia and venous congestion. ${ }^{13}$ Capillary recruitment during reactive hyperaemia is thought to reflect functional capillary density. ${ }^{14}$ Indeed, skin capillaries in the resting state are thought to work on a 'rota system' (i.e., some are temporarily perfused, whereas others are temporarily shut down), and capillaries intermittently perfused in the resting state seem to be an important functional reserve that can be recruited during post-occlusive reactive hyperaemia. ${ }^{14,15}$ On the other hand, capillary density during venous congestion is thought to reflect structural capillary density. ${ }^{14}$ Indeed, venous congestion increases venous back pressure, which allows passive trapping of red blood cells in non-perfused and intermittently perfused capillaries, thereby enhancing the visualization of capillaries filled with red blood cells (i.e., allows visualization of the maximal number of skin capillaries). ${ }^{14,15}$

Unfortunately, assessment of skin capillary density is technically demanding and time-consuming, and is thus mostly used in relatively small-scale, experimental studies. ${ }^{16}$ Data comparing skin microvascular function in people with versus without T2DM are therefore limited. ${ }^{17,18}$ Recently, we developed a semi-automatic method for the assessment of skin capillary density, which facilitates the use of skin capillaroscopy in large-scale studies. ${ }^{13}$

In view of these considerations, we investigated whether T2DM status and longterm hyperglycaemia are independently associated with functional and structural capillary 
density in an observational population-based cohort study. In particular, we investigated whether these associations are present even before clinically apparent diabetic microangiopathy has developed.

\section{METHODS}

\section{STUDY POPULATION}

In this study, we used data from The Maastricht Study, an observational prospective population-based cohort study. The rationale and methodology have been described previously. ${ }^{19}$ In brief, the study focuses on the aetiology, pathophysiology, complications and comorbidities of T2DM and is characterized by an extensive phenotyping approach. Eligible for participation were all individuals aged between 40 and 75 years and living in the southern part of the Netherlands. Participants were recruited through mass media campaigns and from the municipal registries and the regional Diabetes Patient Registry via mailings. Recruitment was stratified according to known T2DM status for reasons of efficiency. The present report includes cross-sectional data from the first 866 participants, who completed the baseline survey between November 2010 and March 2012. The examinations of each participant were performed within a time window of three months. The study has been approved by the institutional medical ethical committee (NL31329.068.10) and the Netherlands Health Council under the Dutch "Law for Population Studies" (Permit 131088-105234-PG). All participants gave written informed consent.

\section{SKIN CAPILLAROSCOPY}

All participants were asked to refrain from smoking and caffeine three hours before the measurements. A light meal (breakfast and (or) lunch), low in fat content, was allowed prior to the start of the measurements. Skin capillaroscopy measurements were performed in a quiet, temperature-controlled room $\left(T=24^{\circ} \mathrm{C}\right)$ with participants in supine position, as previously described. ${ }^{13}$

Briefly, a digital videomicroscope (Capiscope, KK Technology, Honiton UK) was used to record capillaries in the dorsal skin of the distal phalanges of the right-hand third and fourth finger. Capillaries were visualised $4.5 \mathrm{~mm}$ proximal to the terminal row of capillaries in the middle of the nailfold, after which a region of interest of $1 \mathrm{~mm}^{2}$ skin area 
was selected. Capillary density (mean of two fields) was measured under three conditions. First, we measured baseline capillary density, defined as the number of continuously erythrocyte-perfused capillaries per square millimetre of skin. Capillaries at baseline were counted for 15 seconds. Second, capillary recruitment after 4 minutes of arterial occlusion was measured. Directly after release of the cuff, all (continuously and intermittently) perfused capillaries were counted for 15 seconds. Finally, capillary density during 2 minutes of venous congestion was examined, by counting all (continuously and intermittently) perfused capillaries for 15 seconds. For analysis, we used absolute numbers of capillaries at baseline, after arterial occlusion, and during venous congestion. In addition, we used percentage capillary recruitment and percentage capillary density during venous congestion (((capillary recruitment or capillary density during venous congestion - baseline capillary density) / baseline capillary density) * 100\%). These measures are thought to reflect functional and/or structural capillary reserve capacity. ${ }^{14,15}$ The number of continuously perfused capillaries within the region of interest was counted with a semi-automatic image analysis application (CapiAna) by two investigators (D.M.J.M. and Ü.K.) who were both blinded to the characteristics of the participants. As described elsewhere, the intra- and inter-observer variability was $2.5 \%$ and $5.6 \%$, respectively. ${ }^{13}$

\section{GLUCOSE METABOLISM STATUS}

To determine glucose metabolism, all participants (except those who used insulin) underwent a standardized 2-h 75g oral glucose tolerance test (OGTT) after an overnight fast. For safety reasons, participants with a fasting glucose level above $11.0 \mathrm{mmol} / \mathrm{L}$, as determined by a finger prick, did not undergo the OGTT. For these individuals $(n=13)$, fasting glucose level and information about their use of diabetes medication were used to determine glucose metabolism status. Glucose metabolism was defined according to the WHO 2006 criteria into normal glucose metabolism (NGM) and T2DM. ${ }^{20}$

\section{COVARIATES}

Medical history, history of cardiovascular disease (CVD), medication use, and smoking behaviour were assessed by questionnaire. ${ }^{19}$ We determined weight, height, waist circumference, body mass index (BMI), HbA1c, glucose levels, total and high-density lipoprotein (HDL) cholesterol, triglycerides, office blood pressure, and ambulatory blood pressure as described elsewhere. ${ }^{19}$ GFR was estimated using the CKD-EPI equation based on both serum creatinine and serum cystatin $\mathrm{C}^{21}$ Serum creatinine was measured with a Jaffé method traceable to isotope dilution mass spectrometry (Beckman Synchron LX20, Beckman Coulter Inc., Brea, USA). Serum cystatin C was measured with a particle- 
enhanced immunoturbidimetric assay standardised against ERM-DA471/IFCC reference material (Roche Cobas 8000, F. Hoffman-La Roche Ltd, Basel, Switzerland).

\section{ASSESSMENT OF MICROALBUMINURIA}

To assess urinary albumin excretion, participants were requested to collect two 24-hour urine collections. Urinary albumin concentration was measured with a standard immunoturbidimetric assay by an automatic analyser (Beckman Synchron LX20, Beckman Coulter Inc., Brea, USA) and multiplied by collection volume to obtain the 24-hour urinary albumin excretion. A urinary albumin concentration below the detection limit of the assay ( $2 \mathrm{mg} / \mathrm{L}$ ) was set at $1.5 \mathrm{mg} / \mathrm{L}$ before multiplying by collection volume. Only urine collections with a collection time between 20 and 28 hours were considered valid. If needed, urinary albumin excretion was extrapolated to a 24-hours' excretion. Microalbuminuria was defined as a urinary albumin excretion of 30-300 mg per 24 hours whereas macroalbuminuria was defined as a urinary albumin excretion of $>300 \mathrm{mg}$ per 24 hours. ${ }^{22}$ These definitions were based on one $(n=12.2 \%)$, or, when available $(n=87.8 \%)$, the average of two 24-hour urine collections.

\section{ASSESSMENT OF SENSORY NEUROPATHY}

Vibration perception threshold (VPT) was measured as a marker of peripheral neuropathy. VPT was assessed using a hand-held neurothesiometer (Horwell Scientific Laboratory Supplies, Nottingham, UK). After a test procedure on the subject's elbow, VPT was tested 3 times at the distal phalanx of the hallux of the right and left foot. The minimum VPT at which the subject was aware of vibration sensation was recorded to the nearest $0.5 \mathrm{~V}$, starting from $0.0 \mathrm{~V}$ with increasing stimulation. The mean of the three measurements for the least sensitive foot was used in further analyses. ${ }^{23,24}$ Peripheral sensory neuropathy (PSN) was defined as VPT $\geq 25 \mathrm{~V}^{24}$

\section{STATISTICAL ANALYSIS}

All analyses were performed with the use of the Statistical Package for Social Sciences (IBM, version 20.0, Chicago, Illinois, USA). Comparisons of baseline characteristics between groups were made using Student's t-test for continuous variables and $\chi^{2}$ test for discrete variables. We used multiple linear regression analysis to investigate the associations of both T2DM and $\mathrm{HbA1c}$ with skin capillary density values. These associations were adjusted for age, sex, waist circumference, total-to-HDL cholesterol 
ratio, triglycerides, systolic blood pressure (SBP), diastolic blood pressure (DBP), smoking (yes/no), prior CVD (yes/no), anti-hypertensive medication, lipid-modifying medication use (yes/no), eGFR, (micro)albuminuria (yes/no), and VPT to assess potential confounding by these factors. Variables with a skewed distribution were log transformed before analyses.

\section{RESULTS}

From the initial 866 participants included in this study, participants with T1DM were excluded $(n=4)$ and 469 participants with NGM and 253 with T2DM were included in the analyses. Of these 722 participants, capillaroscopy data were available in 686 participants; missing data were due to device failure $(n=36)$. Complete data on all other (potentially confounding) variables were available in 641 participants. Data were missing on prior CVD status $(n=30)$, cholesterol levels $(n=7)$, smoking status $(n=4)$, waist circumference $(n=$ 3 ), and office blood pressure (BP) measurements ( $n=1)$. In addition, we selected, for additional analyses, a population ( $n=355$ with complete data; $n=90$ with T2DM) free of clinically apparent diabetic microangiopathy (i.e., no nephropathy [eGFR $<90$ $\mathrm{ml} / \mathrm{min} / 1.73 \mathrm{~m}^{2}$ and/or (micro-)albuminuria] and neuropathy [PSN $\geq 25 \mathrm{~V}$ ]; data on retinopathy were lacking due to logistical reasons).

\section{GENERAL CHARACTERISTICS}

General characteristics of the study population are shown in Table 4.1, stratified according to NGM and T2DM status. As expected, participants with T2DM had an adverse cardiometabolic risk profile. Table 4.1 shows that participants with T2DM had a greater baseline capillary density and a lower capillary recruitment, both in absolute terms as well as in percentages, as compared with participants with NGM. Capillary density during venous congestion in absolute terms was not significantly different between the two groups; however participants with T2DM had a lower percentage capillary density during venous congestion as compared with participants with NGM (Table 4.1). 
Table 4.1. General characteristics

\begin{tabular}{|c|c|c|c|c|c|c|}
\hline \multirow[b]{3}{*}{ Characteristic } & \multicolumn{3}{|c|}{ Study population } & \multicolumn{3}{|c|}{ Subpopulation without microangiopathy } \\
\hline & NGM & T2DM & & NGM & T2DM & \\
\hline & $N=418$ & $\mathbf{N}=\mathbf{2 2 3}$ & P-value & $N=265$ & $\mathbf{N}=90$ & $P$-value \\
\hline Age (years) & $57.0 \pm 8.5$ & $63.5 \pm 7.2$ & $<0.001$ & $54.1 \pm 8.2$ & $60.1 \pm 7.4$ & $<0.001$ \\
\hline Sex (men) & $189(45.2)$ & $157(70.4)$ & $<0.001$ & 111 (41.9) & $61(67.8)$ & $<0.001$ \\
\hline \multicolumn{7}{|l|}{ BMI categories } \\
\hline Normal weight $\left(\mathrm{BMI}<25 \mathrm{~kg} / \mathrm{m}^{2}\right)$ & $189(45.2)$ & $27(12.1)$ & $<0.001$ & $132(49.8)$ & $14(15.6)$ & $<0.001$ \\
\hline Overweight (BMI $\geq 25-<30 \mathrm{~kg} / \mathrm{m}^{2}$ ) & $180(43.1)$ & $103(46.2)$ & $<0.001$ & $105(39.6)$ & $48(53.3)$ & $<0.001$ \\
\hline Obese $\left(\mathrm{BMI} \geq 30 \mathrm{~kg} / \mathrm{m}^{2}\right)$ & $49(11.7)$ & $93(41.7)$ & $<0.001$ & $28(10.6)$ & $28(31.1)$ & $<0.001$ \\
\hline \multicolumn{7}{|l|}{ Waist circumference $(\mathrm{cm})$} \\
\hline Men & $97.2 \pm 9.7$ & $107.3 \pm 12.1$ & $<0.001$ & $96.1 \pm 9.5$ & $105.5 \pm 10.7$ & $<0.001$ \\
\hline Women & $87.2 \pm 11.0$ & $103.0 \pm 14.8$ & $<0.001$ & $86.0 \pm 11.3$ & $96.9 \pm 12.8$ & $<0.001$ \\
\hline HbA1c (\%) & $5.6 \pm 0.3$ & $6.9 \pm 0.9$ & $<0.001$ & $5.6 \pm 0.3$ & $6.9 \pm 0.9$ & $<0.001$ \\
\hline Fasting plasma glucose (mmol/L) & $5.2 \pm 0.4$ & $7.7 \pm 1.7$ & $<0.001$ & $5.2 \pm 0.4$ & $8.0 \pm 1.8$ & $<0.001$ \\
\hline Total cholesterol (mmol/L) & $5.5 \pm 1.1$ & $4.5 \pm 1.1$ & $<0.001$ & $5.5 \pm 1.1$ & $4.5 \pm 1.1$ & $<0.001$ \\
\hline LDL-cholesterol (mmol/L) & $3.6 \pm 1.0$ & $2.6 \pm 0.9$ & $<0.001$ & $3.5 \pm 1.0$ & $2.6 \pm 1.0$ & $<0.001$ \\
\hline Total-to-HDL cholesterol ratio & $4.1 \pm 1.3$ & $4.3 \pm 1.2$ & 0.09 & $4.0 \pm 1.2$ & $4.0 \pm 1.2$ & 0.77 \\
\hline Triglycerides (mmol/L) & $1.0[0.7-1.5]$ & $1.6[1.1-2.3]$ & $<0.001$ & $0.9[0.7-1.3]$ & $1.5[1.1-2.1]$ & $<0.001$ \\
\hline Office SBP (mmHg) & $132 \pm 18$ & $147 \pm 19$ & $<0.001$ & $130 \pm 17$ & $146 \pm 18$ & $<0.001$ \\
\hline Office DBP (mmHg) & $75 \pm 10$ & $79 \pm 10$ & $<0.001$ & $75 \pm 10$ & $80 \pm 10$ & $<0.001$ \\
\hline 24-h SBP (mmHg) & $117 \pm 11$ & $124 \pm 13$ & $<0.001$ & $116 \pm 11$ & $125 \pm 12$ & $<0.001$ \\
\hline 24-h DBP (mmHg) & $74 \pm 7$ & $74 \pm 7$ & 0.74 & $74 \pm 7$ & $76 \pm 6$ & 0.03 \\
\hline Heart rate (bpm) (based on office measurements) & $66 \pm 9$ & $71 \pm 13$ & $<0.001$ & $67 \pm 9$ & $72 \pm 13$ & $<0.001$ \\
\hline
\end{tabular}


Table 4.1. Continued

\begin{tabular}{|c|c|c|c|c|c|c|}
\hline \multirow[b]{3}{*}{ Characteristic } & \multicolumn{3}{|c|}{ Study population } & \multicolumn{3}{|c|}{ Subpopulation without microangiopathy } \\
\hline & NGM & T2DM & & NGM & T2DM & \\
\hline & $N=418$ & $N=223$ & $P$-value & $N=265$ & $N=90$ & $P$-value \\
\hline $\mathrm{GFR}_{\mathrm{MDRD}}\left(\mathrm{ml} / \mathrm{min} / 1.73 \mathrm{~m}^{2}\right)$ & $92.8 \pm 14.9$ & $83.8 \pm 19.3$ & $<0.001$ & $102.6 \pm 8.3$ & $102.0 \pm 9.2$ & 0.59 \\
\hline Microalbuminuria & $12(2.8)$ & 40 (17.9) & $<0.001$ & $0(0)$ & $0(0)$ & - \\
\hline Macroalbuminuria & $4(1.0)$ & $3(1.3)$ & 0.68 & $0(0)$ & $0(0)$ & - \\
\hline Peripheral sensory neuropathy & $21(5.0)$ & $39(17.5)$ & $<0.001$ & $0(0)$ & $0(0)$ & - \\
\hline \multicolumn{7}{|l|}{ Smoking } \\
\hline Never & $150(35.9)$ & $49(22.0)$ & $<0.001$ & $103(38.9)$ & $23(25.6)$ & $<0.001$ \\
\hline Former & $198(47.4)$ & $141(63.2)$ & $<0.001$ & $120(45.3)$ & $57(63.3)$ & $<0.001$ \\
\hline Current & $70(16.7)$ & $33(14.8)$ & 0.03 & $42(15.8)$ & $10(11.1)$ & $<0.001$ \\
\hline Prior CVD & $48(11.5)$ & $70(31.4)$ & $<0.001$ & $18(6.8)$ & $21(23.3)$ & $<0.001$ \\
\hline Hypertension & $169(40.4)$ & $192(86.1)$ & $<0.001$ & $89(33.6)$ & $73(81.1)$ & $<0.001$ \\
\hline Diabetes medication use & $0(0)$ & $174(78.0)$ & $<0.001$ & $0(0)$ & $66(73.3)$ & $<0.001$ \\
\hline Anti-hypertensive medication use & $92(22.0)$ & $158(70.9)$ & $<0.001$ & $44(16.6)$ & $54(60.0)$ & $<0.001$ \\
\hline Baseline capillary density $\left(\mathrm{n} / \mathrm{mm}^{2}\right)$ & $72.2 \pm 17.1$ & $77.6 \pm 18.0$ & $<0.001$ & $72.5 \pm 17.3$ & $75.8 \pm 16.8$ & 0.12 \\
\hline Capillary recruitment $\left(\mathrm{n} / \mathrm{mm}^{2}\right)$ & $104.6 \pm 16.8$ & $102.3 \pm 18.8$ & 0.11 & $104.5 \pm 17.5$ & $97.8 \pm 18.7$ & 0.01 \\
\hline Capillary recruitment (\%) & $49.3 \pm 29.9$ & $35.0 \pm 24.9$ & $<0.001$ & $49.0 \pm 29.9$ & $32.1 \pm 25.7$ & $<0.001$ \\
\hline Capillary density during venous congestion $\left(\mathrm{n} / \mathrm{mm}^{2}\right)$ & $104.5 \pm 17.1$ & $102.2 \pm 19.0$ & 0.12 & $104.8 \pm 17.5$ & $99.0 \pm 19.1$ & 0.01 \\
\hline Capillary density during venous congestion (\%) & $49.5 \pm 32.0$ & $35.1 \pm 25.9$ & $<0.001$ & $49.9 \pm 32.6$ & $34.1 \pm 28.2$ & $<0.001$ \\
\hline
\end{tabular}

Data are presented as mean \pm SD, median [inter-quartile ranges], or number (percentages). 
Results were generally similar in the subpopulation without microangiopathy (Table 4.1), except that the difference, between the NGM and T2DM groups, in baseline capillary density was not statistically significant.

Table 4.2. Associations of type 2 diabetes mellitus with skin capillary density values

\begin{tabular}{|c|c|c|}
\hline & $\beta(95 \% \mathrm{Cl})$ & $P$-value \\
\hline \multicolumn{3}{|c|}{ Baseline capillary density $\left(\mathrm{n} / \mathrm{mm}^{2}\right)$} \\
\hline Crude & $5.4(2.6 ; 8.2)$ & $<0.001$ \\
\hline Model 2 & $6.3(2.3 ; 10.3)$ & $<0.001$ \\
\hline Model 3 & $5.8(1.8 ; 9.9)$ & 0.01 \\
\hline \multicolumn{3}{|c|}{ Capillary recruitment $\left(\mathrm{n} / \mathrm{mm}^{2}\right)$} \\
\hline Crude & $-2.3(-5.1 ; 0.6)$ & 0.11 \\
\hline Model 2 & $-1.1(-5.1 ; 2.9)$ & 0.58 \\
\hline Model 3 & $-1.0(-5.1 ; 3.1)$ & 0.63 \\
\hline \multicolumn{3}{|c|}{ Capillary recruitment (\%-point) } \\
\hline Crude & $-14.3(-18.9 ;-9.7)$ & $<0.001$ \\
\hline Model 2 & $-14.1(-20.6 ;-7.6)$ & $<0.001$ \\
\hline Model 3 & $-13.0(-19.6 ;-6.4)$ & $<0.001$ \\
\hline \multicolumn{3}{|c|}{ Capillary density during venous congestion $\left(\mathrm{n} / \mathrm{mm}^{2}\right)$} \\
\hline Crude & $-2.4(-5.3 ; 0.5)$ & 0.12 \\
\hline Model 2 & $-0.6(-4.6 ; 3.5)$ & 0.79 \\
\hline Model 3 & $-0.7(-4.8 ; 3.5)$ & 0.76 \\
\hline \multicolumn{3}{|c|}{ Capillary density during venous congestion (\%-point) } \\
\hline Crude & $-14.7(-19.6 ;-9.8)$ & $<0.001$ \\
\hline Model 2 & $-13.8(-20.8 ;-6.9)$ & $<0.001$ \\
\hline Model 3 & $-13.1(-20.1 ;-6.0)$ & $<0.001$ \\
\hline
\end{tabular}

Coefficients were obtained with linear regression analyses and indicate the difference in skin capillary density between individuals without versus with type 2 diabetes.

Crude: unadjusted model.

Model 2: adjusted for age, sex, waist circumference, total-to-HDL cholesterol ratio, triglycerides, systolic blood pressure, diastolic blood pressure, smoking (never, former, current), prior cardiovascular event (yes/no), antihypertensive, and lipid-modifying medication use (yes/no).

Model 3: model 2 + additional adjustment for eGFR, (micro-)albumuria (yes/no), and VPT.

\section{T2DM AND SKIN CAPILLARY DENSITY VALUES}

After adjustment for potential confounders, T2DM was associated with a significantly greater baseline capillary density $(\beta 6.3$ [95\% $\mathrm{Cl}: 2.3 ; 10.3]$ capillaries $/ \mathrm{mm}^{2} ; P<0.001$; Table 4.2: model 2 ), but not with differences in capillary recruitment and capillary density during venous congestion in absolute terms, both in the crude model $(\beta-2.3[-5.1 ; 0.6]$ capillaries $/ \mathrm{mm}^{2} ; P=0.12$ and $\beta-2.4[-5.3 ; 0.5]$ capillaries $/ \mathrm{mm}^{2} ; P=0.11$, respectively; Table 4.2: crude), and after adjustment for potential confounders $(\beta-1.1[-5.1 ; 2.9]$ capillaries $/ \mathrm{mm}^{2} ; P=0.58$ and $\beta-0.6(-4.6 ; 3.5)$ capillaries $/ \mathrm{mm}^{2} ; P=0.79$, respectively; Table 4.2: model 2). However, after adjustment for potential confounders, T2DM was associated with a significantly lower percentage capillary recruitment and capillary density during venous congestion $(\beta-14.1[-20.6 ;-7.6] \% ; P<0.001$ and $\beta-13.8[-20.8 ;-6.9] \% ; P<$ 
0.001; Table 4.2: model 2). Additional adjustment for eGFR, (micro-)albuminuria, and VPT did not materially change these associations (Table 4.2: model 3).

\section{HYPERGLYCAEMIA AND SKIN CAPILLARY DENSITY VALUES}

HbA1c was not associated with baseline capillary density, either in crude analysis or after adjustment for potential confounders (Table 4.3). However, after adjustment for potential confounders, $\mathrm{HbA} 1 \mathrm{c}$ was significantly inversely associated with capillary recruitment $(\beta$ $2.3[-4.3 ;-0.4]$ capillaries $/ \mathrm{mm}^{2} ; P=0.02$ ), but not with capillary density during venous congestion ( $\beta-1.6[-3.6 ; 0.4]$ capillaries $/ \mathrm{mm}^{2} ; P=0.12$ ) in absolute terms (Table 4.3). Finally, after adjustment for potential confounders, HbA1c was significantly inversely associated with percentage capillary recruitment $(\beta-3.3[-6.5 ;-0.1] \% ; P=0.04)$, but not with percentage capillary density during venous congestion $(\beta-2.6[-6.0 ; 0.8] \% ; P=0.14$; Table 4.3). Additional adjustment for eGFR, (micro-)albuminuria, and VPT did not materially change these associations (Table 4.2: model 3).

Table 4.3. Associations of $\mathrm{HbA1c}$ with skin capillary density values

\begin{tabular}{|c|c|c|}
\hline & $\beta(95 \% \mathrm{Cl})$ & $P$-value \\
\hline \multicolumn{3}{|c|}{ Baseline capillary density $\left(\mathrm{n} / \mathrm{mm}^{2}\right)$} \\
\hline Crude & $1.2(-0.4 ; 2.8)$ & 0.14 \\
\hline Model 2 & $0.1(-1.9 ; 2.1)$ & 0.93 \\
\hline Model 3 & $-0.3(-2.5 ; 1.8)$ & 0.76 \\
\hline \multicolumn{3}{|c|}{ Capillary recruitment $\left(\mathrm{n} / \mathrm{mm}^{2}\right)$} \\
\hline Crude & $-2.1(-3.7 ;-0.6)$ & 0.01 \\
\hline Model 2 & $-2.3(-4.3 ;-0.4)$ & 0.02 \\
\hline Model 3 & $-2.5(-4.6 ;-0.4)$ & 0.02 \\
\hline \multicolumn{3}{|c|}{ Capillary recruitment (\%-point) } \\
\hline Crude & $-5.4(-8.0 ;-2.9)$ & $<0.001$ \\
\hline Model 2 & $-3.3(-6.5 ;-0.1)$ & 0.04 \\
\hline Model 3 & $-3.0(-6.0 ;-0.1)$ & 0.04 \\
\hline \multicolumn{3}{|c|}{ Capillary density during venous congestion $\left(\mathrm{n} / \mathrm{mm}^{2}\right)$} \\
\hline Crude & $-1.9(-3.5 ;-0.3)$ & 0.02 \\
\hline Model 2 & $-1.6(-3.6 ; 0.4)$ & 0.12 \\
\hline Model 3 & $-1.7(-3.8 ; 0.4)$ & 0.12 \\
\hline \multicolumn{3}{|c|}{ Capillary density during venous congestion (\%-point) } \\
\hline Crude & $-5.3(-8.0 ;-2.5)$ & $<0.001$ \\
\hline Model 2 & $-2.6(-6.0 ; 0.8)$ & 0.14 \\
\hline Model 3 & $-1.7(-5.5 ; 1.9)$ & 0.35 \\
\hline
\end{tabular}

Coefficients were obtained with linear regression analyses and indicate the difference in skin capillary density values per \% higher HbA1c.

Crude: unadjusted model.

Model 2: adjusted for age, sex, waist circumference, total-to-HDL cholesterol ratio, triglycerides, systolic blood pressure, diastolic blood pressure, smoking (never, former, current), prior cardiovascular event (yes/no), antihypertensive, and lipid-modifying medication use (yes/no).

Model 3: model 2 + additional adjustment for eGFR, (micro-)albumuria (yes/no), and VPT. 


\section{ADDITIONAL ANALYSES}

Firstly, analyses excluding participants with microangiopathy gave similar results with regard to the associations of T2DM and $\mathrm{HbA1C}$ with skin capillary density values (data not shown), except that the association of T2DM with absolute numbers of capillaries at baseline was attenuated $\left(\beta 4.7[-1.1 ; 10.5]\right.$ capillaries $\left./ \mathrm{mm}^{2} ; P=0.11\right)$. Secondly, analyses excluding participants with an eGFR $<60 \mathrm{ml} / \mathrm{min} / 1.73 \mathrm{~m}^{2}$ instead of $<90 \mathrm{ml} / \mathrm{min} / 1.73 \mathrm{~m}^{2}$ gave similar results (data not shown). Thirdly, when capillary recruitment was expressed as delta capillary recruitment (capillary recruitment PRH - baseline capillary density) instead of percentage, analyses gave similar results (data not shown). Fourthly, adjustment for 24-h ambulatory SBP and DBP (instead of office SBP and office DBP) also gave similar results (data not shown). Fifthly, the associations between skin capillary density values and T2DM were not significantly different between women and men (i.e., baseline capillary density $[P=0.15]$, capillary recruitment $[P=0.24]$, and capillary density during venous congestion $[P=0.77]$, respectively). In addition, the associations between skin capillary density values and $\mathrm{HbA1c}$ were also not significantly different between women and men (i.e., baseline capillary density $[P=0.51]$, capillary recruitment $[P=0.92]$, and capillary density during venous congestion $[P=0.41]$, respectively). Sixthly, additional adjustment for clock time of skin capillaroscopy measurement (to adjust for diurnal influences) and time from light meal until skin capillaroscopy measurement (to adjust for light meal influences) again gave similar results (data not shown). Finally, additional adjustment of the association of T2DM with skin capillary density values for HbA1c or vice versa also gave similar results except that the association of $\mathrm{HbA1c}$ with capillary recruitment was attenuated after additional adjustment for T2DM $(\beta 1.5[-2.5 ; 5.5] \% ; P=$ 0.46 ; other data not shown). Since T2DM and $\mathrm{HbA} 1 \mathrm{c}$ may be a part of the same causal pathway linking hyperglycaemia with capillary density, we consider these mutual adjustments of T2DM and HbA1c an overcorrection. ${ }^{25}$

\section{DISCUSSION}

This study demonstrates that T2DM is associated with higher baseline skin capillary density and lower relative functional and structural capillary densities. In addition, longterm hyperglycaemia, as measured by $\mathrm{HbA1c}$, is associated with a lower functional capillary density. Furthermore, additional adjustment for eGFR, (micro-)albuminuria, and VPT as well as analyses excluding T2DM patients with microangiopathy gave similar results, suggesting that T2DM is associated with functional as well as structural capillary rarefaction even before clinically apparent microangiopathy (i.e., nephropathy and 
neuropathy) has developed. Similarly, long-term hyperglycaemia was associated with functional capillary rarefaction, even before the presence of clinically apparent diabetic microangiopathy.

The greater baseline capillary density values in participants with T2DM were somewhat unexpected. These higher levels could not be explained by the larger number of men in the diabetes group (70\% compared to $45 \%$ in the NGM group), as we adjusted analyses for sex differences. In addition, effect modification was ruled out by interaction analysis (i.e., these associations were not different in men as compared to women). Therefore, other mechanisms may explain the enhanced baseline capillary density values. Firstly, T2DM is characterized by high plasma fasting insulin levels ${ }^{26,27}$ and we recently demonstrated that hyperinsulinaemia significantly increases baseline capillary density. ${ }^{28,29}$ However, the microvascular actions of insulin are impaired in individuals with insulin resistance ${ }^{30,31}$ so this explanation appears unlikely. Alternatively, the enhanced baseline capillary density values may be the consequence of microvascular hyperperfusion, as demonstrated in participants with T1DM. ${ }^{32}$ Indeed, in the first years after the onset of diabetes, blood flow has been found to be increased in several organs and tissues. ${ }^{33,34}$ This increased capillary blood flow may contribute to functional microvascular changes, which in turn, may contribute to the development of structural microvascular changes, and ultimately microangiopathy (i.e., the haemodynamic hypothesis). ${ }^{35}$

Thus, T2DM appears associated with capillary hyperperfusion in the resting state and a relatively impaired functional and structural capillary recruitment capacity. This is in line with a recent study that demonstrated decreased functional densities in participants with T2DM. $^{18}$ Such functional microvascular changes associated with T2DM may contribute to the development of structural microvascular changes, and ultimately, clinical microangiopathy. ${ }^{35}$ Capillaries that are intermittently perfused in the resting state may be an important reserve that can be recruited after arterial occlusion. ${ }^{15}$ Therefore, the lower relative functional capillary recruitment in T2DM may be due to a greater number of intermittently perfused baseline capillaries in the resting state. Whether this abnormality reflects the functional consequence of a structural absence of capillaries is unclear. On the one hand, the absolute capillary density after venous occlusion (which is thought to reflect maximal density) was not clearly decreased in T2DM. On the other hand, we cannot fully exclude that this result was due to insufficient power; in addition, it is not clear how the true maximal capillary density should be assessed ${ }^{28}$, as we recently demonstrated that hyperinsulinaemia significantly increases capillary density during venous congestion. ${ }^{14,15,28}$

It is important to note that microvascular dysfunction may function as an intermediate step linking central obesity, low physical activity, and chronic low-grade inflammation to insulin resistance. ${ }^{16}$ Indeed, we have recently demonstrated that, among individuals with normal glucose metabolism, microvascular dysfunction is associated with a $25 \%$ higher incidence of $\mathrm{T}^{2 \mathrm{DM}}{ }^{36}$ Thus it is possible to envisage a vicious cycle of 
progressive microvascular dysfunction, initiated by obesity, which contributes to the development of T2DM, which, in turn, contributes to a further deterioration of microvascular function, and, ultimately, to the development structural microvascular changes and diabetic microangiopathy.

We demonstrated that $\mathrm{HbA} 1 \mathrm{c}$ is associated with decreased functional capillary densities, but not with structural capillary rarefaction. There was also no significant association with baseline capillary density. Several large scale studies demonstrated that hyperglycaemia plays an important role in the pathogenesis of microvascular complications, $^{37-39}$ and associations of estimates of hyperglycaemia with microvascular function and structure are thus to be expected. However, our findings suggest that the associations of $\mathrm{HbA} 1 \mathrm{C}$ and T2DM on the one hand and microvascular function and structure on the other show subtle differences, which is consistent with a model in which microvascular changes in part precede the occurrence of hyperglycaemia and thus cannot be caused by it. Alternatively, consequences of hyperglycaemia, such as the formation of advanced glycation endproducts that are poorly reflected by $\mathrm{HbA1c}$ may play a role. ${ }^{6,40}$ Indeed, recent studies have demonstrated that increased AGE levels in diabetes patients are associated with microangiopathy. ${ }^{41,42}$

This study had some limitations. Firstly, the present work is cross-sectional in nature and therefore it is not possible to distinguish between cause and effect. Hence, further large-scale (longitudinal) studies in this area are needed. Secondly, observational studies such as the Maastricht Study do not allow invasive measurements (i.e., we studied microcirculation in skin and not in relevant organs such as muscle, the kidney, the heart, or the brain). Nevertheless, several studies have demonstrated comparable metabolic ${ }^{43}$ and vascular effects in skin and muscle, ${ }^{44}$ and skin microcirculation is thought to be a valid model for the microcirculation in general. ${ }^{45}$ Thirdly, $77 \%$ of all participants fully complied with the smoking, caffeine, and meal instructions before microcirculatory measurements, and $23 \%$ did not. However, when analyses were restricted to fully compliant participants, results were essentially unchanged. Fourthly, we did not assess microvascular changes in individuals with impaired glucose metabolism, i.e., prediabetes. Finally, data on retinopathy were lacking, and our conclusions on T2DM without clinically apparent microangiopathy are thus limited by this fact.

In conclusion, T2DM is associated with increased baseline skin capillary densities and with decreased relative functional and structural capillary densities. In addition, hyperglycaemia as estimated by $\mathrm{HbA1c}$ is associated with impaired functional capillary recruitment. Importantly, analyses excluding T2DM patients with microangiopathy gave similar results, suggesting that T2DM is associated with functional as well as structural capillary rarefaction, even in the absence of clinically apparent microangiopathy. 


\section{REFERENCES}

1. Federation ID: Spreadsheet: prevalence estimated of diabetes mellitus (DM), 2010. Brussel, Belgium. International Diabetes Federation: IDF diabetes atlas, 2010.

2. Struijker Boudier HA, le Noble JL, Messing MW, Huijberts MS, le Noble FA, van Essen H. The microcirculation and hypertension. J Hypertens Suppl 1992;10:S147-56.

3. Tooke JE, Goh KL. Vascular function in Type 2 diabetes mellitus and pre-diabetes: the case for intrinsic endotheiopathy. Diabet Med 1999;16:710-5.

4. Schalkwijk CG, Stehouwer CD. Vascular complications in diabetes mellitus: the role of endothelial dysfunction. Clin Sci (Lond) 2005;109:143-59.

5. Tooke JE, Morris SJ, Shore AC. Microvascular functional abnormalities in diabetes: the role of the endothelium. Diabetes Res Clin Pract 1996; 31:S127-32.

6. Brouwers O, Niessen PM, Haenen G, Miyata T, Brownlee M, Stehouwer CD, De Mey JG, Schalkwijk CG. Hyperglycaemia-induced impairment of endothelium-dependent vasorelaxation in rat mesenteric arteries is mediated by intracellular methylglyoxal levels in a pathway dependent on oxidative stress. Diabetologia 2010;53:989-1000.

7. Intensive blood-glucose control with sulphonylureas or insulin compared with conventional treatment and risk of complications in patients with type 2 diabetes (UKPDS 33). UK Prospective Diabetes Study (UKPDS) Group. Lancet 1998; 352: 837-53.

8. Lustman PJ, Griffith LS, Gavard JA, Clouse RE. Depression in adults with diabetes. Diabetes Care 1992;15:1631-9.

9. McMurray JJ, Gerstein HC, Holman RR, Pfeffer MA. Heart failure: a cardiovascular outcome in diabetes that can no longer be ignored. The lancet. Diabetes \& endocrinology 2014;2:843-51.

10. Spauwen PJ, Kohler S, Verhey FR, Stehouwer CD, van Boxtel MP. Effects of type 2 diabetes on 12-year cognitive change: results from the Maastricht Aging Study. Diabetes Care 2013;36:1554-61.

11. Houben AJ, Beljaars JH, Hofstra L, Kroon AA, De Leeuw PW. Microvascular abnormalities in chronic heart failure: a cross-sectional analysis. Microcirculation 2003;10:471-8.

12. Wong TY, Klein R, Sharrett AR, Duncan BB, Couper DJ, Tielsch JM, Klein BE, Hubbard LD. Retinal arteriolar narrowing and risk of coronary heart disease in men and women. The Atherosclerosis Risk in Communities Study. JAMA 2002;287:1153-9.

13. Gronenschild EH, Muris DM, Schram MT, Karaca U, Stehouwer CD, Houben AJ. Semi-automatic assessment of skin capillary density: Proof of principle and validation. Microvasc Res 2013;90:192-8.

14. Antonios TF, Rattray FE, Singer DR, Markandu ND, Mortimer PS, MacGregor GA. Maximization of skin capillaries during intravital video-microscopy in essential hypertension: comparison between venous congestion, reactive hyperaemia and core heat load tests. Clin Sci (Lond) 1999;97:523-8.

15. Serne EH, Gans RO, ter Maaten JC, Tangelder GJ, Donker AJ, Stehouwer CD. Impaired skin capillary recruitment in essential hypertension is caused by both functional and structural capillary rarefaction. Hypertension 2001;38:238-42.

16. Muris DM, Houben AJ, Schram MT, Stehouwer CD. Microvascular dysfunction: An emerging pathway in the pathogenesis of obesity-related insulin resistance. Rev Endocr Metab Disord 2013;14:29-38.

17. Jaap AJ, Shore AC, Stockman AJ, Tooke JE. Skin capillary density in subjects with impaired glucose tolerance and patients with type 2 diabetes. Diabet Med 1996;13:160-4.

18. van Genugten RE, Serne EH, Heymans MW, van Raalte $\mathrm{DH}$, Diamant M. Postprandial microvascular function deteriorates in parallel with gradual worsening of insulin sensitivity and glucose tolerance in men with the metabolic syndrome or type 2 diabetes. Diabetologia 2013;56:583-7.

19. Schram MT, Sep SJ, Kallen van der CJ, Dagnelie PC, Koster A, Schaper NC, Henry RM, Stehouwer CD. The Maastricht Study: an extensive phenotyping study on determinants of type 2 diabetes, its complications and its comorbidities. Eur J Epidemiol 2014;29:439-51.

20. WHO. Definition and Diagnosis of diabetes mellitus and intermediate hyperglycemia. www.who.int/diabetes/publications/Definition\%20and\%20diagnosis\%20of\%20diabetes_new.pdf, 2006.

21. Inker LA, Schmid CH, Tighiouart H, Eckfeldt JH, Feldman HI, Greene T, Kusek JW, Manzi J, Van Lente F, Zhang $\mathrm{YL}$, Coresh J, Levey AS, Investigators C-E. Estimating glomerular filtration rate from serum creatinine and cystatin C. N Engl J Med 2012;367:20-9.

22. National Kidney F. K/DOQI clinical practice guidelines for chronic kidney disease: evaluation, classification, and stratification. Am J Kidney Dis 2002;39:S1-266. 
23. Boulton AJ, Malik RA, Arezzo JC, Sosenko JM. Diabetic somatic neuropathies. Diabetes Care 2004;27:145886.

24. Karvestedt L, Martensson E, Grill V, Elofsson S, von Wendt G, Hamsten A, Brismar K. Peripheral sensory neuropathy associates with micro- or macroangiopathy: results from a population-based study of type 2 diabetic patients in Sweden. Diabetes Care 2009;32:317-22.

25. Rothman KJ, Greenland S, Lash TL. Modern Epidemiology. Vol 3rd ed. Philidelphia: Lippincott Williams \& Wilkins, 2008.

26. Abdul-Ghani MA, Jenkinson CP, Richardson DK, Tripathy D, DeFronzo RA. Insulin secretion and action in subjects with impaired fasting glucose and impaired glucose tolerance: results from the Veterans Administration Genetic Epidemiology Study. Diabetes 2006;55:1430-5.

27. Weyer C, Bogardus C, Mott DM, Pratley RE. The natural history of insulin secretory dysfunction and insulin resistance in the pathogenesis of type 2 diabetes mellitus. J Clin Invest 1999;104:787-94.

28. Jonk AM, Houben AJ, Schaper NC, de Leeuw PW, Serne EH, Smulders YM, Stehouwer CD. Angiotensin II enhances insulin-stimulated whole-body glucose disposal but impairs insulin-induced capillary recruitment in healthy volunteers. J Clin Endocrinol Metab 2010;95:3901-8.

29. Jonk AM, Houben AJ, Schaper NC, de Leeuw PW, Serne EH, Smulders YM, Stehouwer CD. Acute angiotensin II receptor blockade improves insulin-induced microvascular function in hypertensive individuals. Microvasc Res 2011;82:77-83.

30. Clerk LH, Vincent MA, Jahn LA, Liu Z, Lindner JR, Barrett EJ. Obesity blunts insulin-mediated microvascular recruitment in human forearm muscle. Diabetes 2006;55:1436-42.

31. Han KA, Patel Y, Lteif AA, Chisholm R, Mather KJ. Contributions of dysglycaemia, obesity, and insulin resistance to impaired endothelium-dependent vasodilation in humans. Diabetes Metab Res Rev 2011;27:354-61.

32. Houben AJ, Schaper NC, Slaaf DW, Tangelder GJ, Nieuwenhuijzen Kruseman AC. Skin blood cell flux in insulin-dependent diabetic subjects in relation to retinopathy or incipient nephropathy. Eur J Clin Invest 1992;22:67-72.

33. Haggendal E, Steen B, Svanborg A. Blood flow in subcutaneous fat tissue in patients with diabetes mellitus. Acta medica Scandinavica 1970;187:49-53.

34. Kohner EM, Hamilton AM, Saunders SJ, Sutcliffe BA, Bulpitt CJ. The retinal blood flow in diabetes. Diabetologia 1975;11:27-33.

35. Tooke JE. Microvascular haemodynamics in diabetes mellitus. Clin Sci (Lond) 1986;70:119-25.

36. Muris DM, Houben AJ, Schram MT, Stehouwer CD. Microvascular Dysfunction Is Associated With a Higher Incidence of Type 2 Diabetes Mellitus: A Systematic Review and Meta-Analysis. Arterioscler Thromb Vasc Biol 2012;32:3082-94.

37. The effect of intensive treatment of diabetes on the development and progression of long-term complications in insulin-dependent diabetes mellitus. The Diabetes Control and Complications Trial Research Group. N Engl J Med 1993;329:977-86.

38. United Kingdom Prospective Diabetes Study (UKPDS). 13: Relative efficacy of randomly allocated diet, sulphonylurea, insulin, or metformin in patients with newly diagnosed non-insulin dependent diabetes followed for three years. BMJ 1995;310:83-8.

39. Stratton IM, Adler AI, Neil HA, Matthews DR, Manley SE, Cull CA, Hadden D, Turner RC, Holman RR. Association of glycaemia with macrovascular and microvascular complications of type 2 diabetes (UKPDS 35): prospective observational study. BMJ 2000;321:405-12.

40. Brownlee M. Biochemistry and molecular cell biology of diabetic complications. Nature 2001; 414: 813-20.

41. Fosmark DS, Torjesen PA, Kilhovd BK, Berg TJ, Sandvik L, Hanssen KF, Agardh CD, Agardh E. Increased serum levels of the specific advanced glycation end product methylglyoxal-derived hydroimidazolone are associated with retinopathy in patients with type 2 diabetes mellitus. Metabolism 2006;55:232-6.

42. Mostafa AA, Randell EW, Vasdev SC, Gill VD, Han Y, Gadag V, Raouf AA, El Said H. Plasma protein advanced glycation end products, carboxymethyl cysteine, and carboxyethyl cysteine, are elevated and related to nephropathy in patients with diabetes. Mol Cell Biochem 2007;302:35-42.

43. Lang $\mathrm{CH}$. Rates and tissue sites of noninsulin- and insulin-mediated glucose uptake in diabetic rats. Proc Soc Exp Biol Med 1992;199:81-7.

44. Meijer RI, De Boer MP, Groen MR, Eringa EC, Rattigan S, Barrett EJ, Smulders YM, Serne EH. Insulin-induced microvascular recruitment in skin and muscle are related and both are associated with whole-body glucose uptake. Microcirculation 2012;19:494-500. 
45. Holowatz LA, Thompson-Torgerson CS, Kenney WL. The human cutaneous circulation as a model of generalized microvascular function. J Appl Physiol 2008;105:370-2. 



\section{Chapter 5}

\section{Age, waist circumference, and blood pressure are}

associated with skin microvascular flow motion:

The Maastricht Study

Dennis M.J. Muris, Alfons J.H.M. Houben, Abraham A. Kroon, Ronald M.A. Henry, Carla J.H. van der Kallen, Simone J.S. Sep, Annemarie Koster, Pieter C. Dagnelie, Miranda T. Schram, Coen D.A. Stehouwer 


\section{ABSTRACT}

\section{Background}

Skin microvascular flow motion (SMF) - blood flow fluctuation attributed to the rhythmic contraction and dilation of arterioles - is thought to be an important component of the microcirculation, by ensuring optimal delivery of nutrients and oxygen to tissue and regulating local hydraulic resistance. There is some evidence that SMF is altered in obesity, T2DM, and hypertension. Nevertheless, most studies of SMF have been conducted in highly selected patient groups, and evidence how SMF relates to other cardiovascular risk factors is scarce. Therefore, the aim of the present study was to examine in a population-based setting which cardiovascular risk factors are associated with SMF.

\section{Methods}

We measured SMF in 506 participants of the Maastricht Study without prior cardiovascular event. SMF was investigated using Fourier transform analysis of skin laser Doppler flowmetry at rest within five frequency intervals in the 0.01-1.6 Hz spectral range. The associations with SMF of the cardiovascular risk factors age, sex, waist circumference, total-to-HDL cholesterol, fasting plasma glucose, 24-h systolic blood pressure (SBP), and cigarette smoking were analyzed by use of multiple linear regression analysis.

\section{Results}

Per 1SD higher age, waist circumference and $24-\mathrm{h} \mathrm{SBP}$, SMF was 0.16 SD higher $(95 \% \mathrm{Cl}: 0.07 ; 0.25$; $P<0.001),-0.14$ SD lower $(-0.25 ;-0.04 ; P=0.01)$, and 0.16 SD higher $(0.07 ; 0.26 ; P<0.001)$, respectively, in fully adjusted analyses. We found no significant associations of sex, fasting plasma glucose levels, total-to-HDL cholesterol ratio, or pack years of smoking with SMF.

\section{Conclusion}

Age and 24-h SBP are directly, and waist circumference is inversely associated with skin microvascular flow motion in the general population. The exact mechanisms underlying these findings remain elusive. We hypothesize that flow motion may be an important component of the microcirculation by ensuring optimal delivery of nutrients and oxygen to tissue and regulating local hydraulic resistance under physiological conditions, but also under pathophysiological conditions when microcirculatory perfusion is reduced, such as occurs with ageing and higher blood pressure. In addition, obesity may result in an impaired flow motion with negative effects on the delivery of nutrients and oxygen to tissue and local hydraulic resistance. 


\section{INTRODUCTION}

Microvascular vasomotion, i.e. rhythmic changes in (pre-capillary) arteriolar diameter, is thought to be an important component of microvascular function. ${ }^{1}$ In fact, these rhythmic oscillations regulate microvascular flow distribution so that various tissue regions are intermittently perfused. ${ }^{1,2}$ Indeed, theoretical and experimental studies demonstrate that an increase in vasomotion can increase total blood flow by $40-60 \% .^{3,4}$ In addition, when active and passive vessels with the same average diameter are compared, active vessels have a lower vascular resistance (according to Poiseuille's law) ${ }^{5,6}$; i.e., vasomotion decreases arterial pressure by $20 \%{ }^{7}$ Thus, vasomotion may be an important component of the microcirculation by ensuring optimal delivery of nutrients and oxygen to tissue and regulating local hydraulic resistance (i.e., resistance of the microcirculatory bed to blood flow). ${ }^{1,5,8}$ The rhythmic changes in arteriolar diameter caused by vasomotion produce periodical fluctuations of flow known as microvascular flow motion. ${ }^{8}$ Skin microvascular flow motion (SMF) can easily be assessed using laser-Doppler flowmetry. In vivo measurements of SMF show a broad spectrum of oscillation frequencies, with highfrequency oscillations originating from the cardiac and respiratory cycles, and lowfrequency oscillations origination from endothelial, neurogenic, and myogenic cycle. ${ }^{8-10}$

Central obesity and a sedentary lifestyle are important causes of type 2 diabetes mellitus (T2DM) and hypertension, respectively. ${ }^{11}$ However, how obesity leads to T2DM and hypertension is incompletely understood. We and others have advanced the hypothesis that microvascular dysfunction may contribute both to the development of T2DM - by impairing the timely access of glucose and insulin to their target tissues - and to the development of hypertension - by increasing vascular resistance. ${ }^{12}$ In addition, it has been suggested that obesity is a primary cause of microvascular dysfunction. ${ }^{13}$ Therefore, microvascular dysfunction may be an intermediate step linking central obesity to T2DM and hypertension. ${ }^{14}$

There is some evidence supporting the hypothesis that SMF, as an important component of microvascular function, is altered in obesity, T2DM, and hypertension. ${ }^{1,15-18}$ Nevertheless, most studies on SMF have been conducted in small numbers of highly selected patients. Hence, whether the differences found in these studies can be translated to the general population is unknown. In addition, evidence on whether and to what extent SMF relates to other cardiovascular risk factors, such as smoking and cholesterol levels, is scarce. ${ }^{19}$

Therefore, the aim of the present study was to examine in a population-based setting which cardiovascular risk factors are associated with SMF. In addition, we 
investigated whether these associations are similar in a healthy subpopulation (free of obesity, hypertension, T2DM, and medication use).

\section{METHODS}

\section{STUDY POPULATION}

In this study, we used data from The Maastricht Study, an observational prospective population-based cohort study. The rationale and methodology have been described previously. ${ }^{20}$ In brief, the study focuses on the etiology, pathophysiology, complications and comorbidities of T2DM and is characterized by an extensive phenotyping approach. Eligible for participation were all individuals aged between 40 and 75 years and living in the southern part of the Netherlands. Participants were recruited through mass media campaigns and from the municipal registries and the regional Diabetes Patient Registry via mailings. Recruitment was stratified according to known T2DM status for reasons of efficiency. The present report includes cross-sectional data from the first 866 participants, who completed the baseline survey between November 2010 and March 2012. The examinations of each participant were performed within a time window of three months. The study has been approved by the institutional medical ethical committee (NL31329.068.10) and the Netherlands Health Council under the Dutch "Law for Population Studies" (Permit 131088-105234-PG). All participants gave written informed consent.

\section{SKIN MICROVASCULAR FLOW MOTION MEASUREMENTS}

All participants were asked to refrain from smoking and caffeine 3 hours before the measurements. A light meal (breakfast and (or) lunch), low in fat content, was allowed prior to the start of the measurements. Laser-Doppler flowmetry (LDF) measurements were performed in a quiet, climate-controlled room $\left(T=24^{\circ} \mathrm{C}\right)$ with participants in supine position, as previously described. ${ }^{1}$

Cutaneous blood perfusion was measured by means of a laser-Doppler system (Periflux 5000, Perimed, Stockholm, Sweden), equipped with a thermostatic laser-Doppler probe (PF 457; Perimed, Stockholm, Sweden) at the dorsal side of the wrist of the left hand. Since flow motion has predominantly been observed in participants with a skin temperature above $29.3^{\circ} \mathrm{C}^{3}$ the laser-Doppler probe was set at $30^{\circ} \mathrm{C}$. The LDF output was recorded for 25 minutes with a sample rate of $32 \mathrm{~Hz}$, which gives a semi quantitative 
assessment of skin microvascular blood perfusion expressed in arbitrary perfusion units (i.e. the product of the velocity and concentration of moving red blood cells ${ }^{21}$ ). LDF measurements from the skin reflect perfusion in predominantly arterioles and venules. ${ }^{22}$

Fast-Fourier Transform algorithm was performed by means of Perisoft dedicated software (PSW version 2.50; Perimed) to measure the power density of the LDF oscillation. The frequency spectrum between 0.01 and $1.6 \mathrm{~Hz}$ was divided into five SMF components: 1) endothelial, $0.01-0.02 \mathrm{~Hz}$; 2) neurogenic, $0.02-0.06 \mathrm{~Hz}$; 3) myogenic, $0.06-0.15 \mathrm{~Hz}$; ) respiratory, $0.15-0.40 \mathrm{~Hz}$; and 5) heart beat, $0.40-1.60 \mathrm{~Hz} .{ }^{10}$ In addition, total SMF energy was obtained by the sum of the power density values of the total frequency spectrum.

\section{DEFINITION OF CARDIOVASCULAR RISK FACTORS}

Cardiovascular risk factors were adapted from the Framingham risk score ${ }^{23}$, and included: age, sex, waist circumference, fasting plasma glucose, total-to-high density lipoprotein (HDL) cholesterol ratio, 24-h systolic blood pressure (SBP), and pack years of smoking.

\section{MEASUREMENT OF CARDIOVASCULAR RISK FACTORS}

Medical history, history of cardiovascular disease, medication use, and smoking behavior were assessed by questionnaire. ${ }^{20}$ Weight, height, waist circumference, $\mathrm{HbA} 1 \mathrm{c}$, glucose levels, total and high-density lipoprotein (HDL) cholesterol, and triglycerides were determined as described elsewhere. ${ }^{20}$

To determine glucose metabolism, all participants (except those who used insulin) underwent a standardized $2-\mathrm{h} 75 \mathrm{~g}$ oral glucose tolerance test (OGTT) after an overnight fast. For safety reasons, participants with a fasting glucose level above 11.0 $\mathrm{mmol} / \mathrm{L}$, as determined by a finger prick, did not undergo the OGTT. For these individuals $(n=13)$, fasting glucose level and information about diabetes medication use were used to determine glucose metabolism status. Glucose metabolism was defined according to the WHO 2006 criteria into normal glucose tolerance (NGT), impaired fasting glucose (IFG), impaired glucose tolerance (IGT), and T2DM. ${ }^{24}$ Additionally, individuals without T1DM and on diabetes medication were considered as having T2DM. ${ }^{20}$

Ambulatory blood pressure was measured with ambulatory 24-hour BP monitoring (WatchBP O3, Microlife AG, Switzerland). Cuffs were applied to the participants' nondominant arm. Measurements were programmed for every 15 minutes during daytime (8 a.m. -11 p.m.) and every 30 minutes during the night (11 p.m. -8 a.m.), for a total of 24 hours. As quality criteria, mean 24-h BP measurements were only calculated if there were more than 14 valid measurements at daytime and more than 7 valid measurements at night, based on the recommendations of the British Hypertension 
Society. ${ }^{25}$ To classify blood pressure, we applied the guidelines as suggested by the Joint National Committee on Prevention, Detection, Evaluation, and Treatment of High Blood Pressure. $^{26}$ Hypertension was defined as $24-\mathrm{h}$ SBP $\geq 135 \mathrm{mmHg}, 24-\mathrm{h}$ diastolic blood pressure (DBP) $\geq 85 \mathrm{mmHg}$, and/or the use of antihypertensive medication.

Pack years of smoking was defined as one packet (20 cigarettes) per day, smoked over a course of 1 year.

\section{ASSESSMENT OF SENSORY NEUROPATHY}

Vibration perception threshold (VPT) was measured as a marker of peripheral neuropathy. VPT was assessed using a hand-held neurothesiometer (Horwell Scientific Laboratory Supplies, Nottingham, UK). After a test procedure on the subject's elbow, VPT was tested 3 times at the distal phalanx of the hallux of the right and left foot. The minimum VPT at which the subject was aware of vibration sensation was recorded to the nearest $0.5 \mathrm{~V}$, starting from $0.0 \mathrm{~V}$ with increasing stimulation. The mean of the three measurements for the least sensitive foot was used in further analyses. ${ }^{27,28}$ Peripheral sensory neuropathy (PSN) was defined as VPT $\geq 25 \mathrm{~V}^{28}$

\section{STATISTICAL ANALYSIS}

All statistical analyses were performed with the use of the Statistical Package for Social Sciences (IBM, version 20.0, Chicago, Illinois, USA). We used standardized multiple linear regression analysis to evaluate the association of cardiovascular risk factors with both total SMF energy and the energy contribution of the five SMF components. All associations were adjusted for the other cardiovascular risk factors and diabetes status. On the basis of an a priori sample size calculation ${ }^{29}$ with a small effect size $\left(f^{2}=0.03\right)$, we estimated that a sample size of approximately 485 participants was sufficient for our analysis. Finally, by design the study population was enriched with T2DM participants. Therefore, we investigated whether these associations differed by T2DM status by adding interaction terms in our models (i.e., the product of 1) the cardiovascular risk factor and 2) T2DM). Variables with a skewed distribution were log transformed for further analyses.

Data are expressed as standardized regression coefficients (sB) with their $95 \%$ confidence intervals $(95 \% \mathrm{Cl})$. A $P$ value less than 0.05 was considered statistically significant. 


\section{RESULTS}

From the initial 866 participants included in this study, we excluded four participants with T1DM. In the remaining 862 participants, LDF data were available in 746 participants; the reason for missing data was a defect LDF system $(n=78)$ and unsatisfactory LDF measurements (i.e., LDF recordings less than 10 minutes; $n=38$ ). In addition, to avoid treatment-induced changes in microvascular function, we excluded participants with a prior cardiovascular event $(n=152)$. In the remaining 594 participants, all variables were available in 506 participants. Data were missing on 24-h blood pressure (BP) measurements $(n=47)$, pack years of smoking $(n=36)$, cholesterol levels $(n=4)$, and waist circumference $(n=1)$ (Fig. 5.1). In addition, we selected a healthy subpopulation of participants who were free of: impaired glucose metabolism (IGM; defined as having either IFG or IGT) or T2DM; hypertension; glucose lowering medication, anti-hypertensive medication, and lipid modifying medication use; and $\mathrm{BMI} \geq 30 \mathrm{~kg} / \mathrm{m}^{2}$. Complete data for this healthy subpopulation were available in 193 participants (Fig. 5.1).

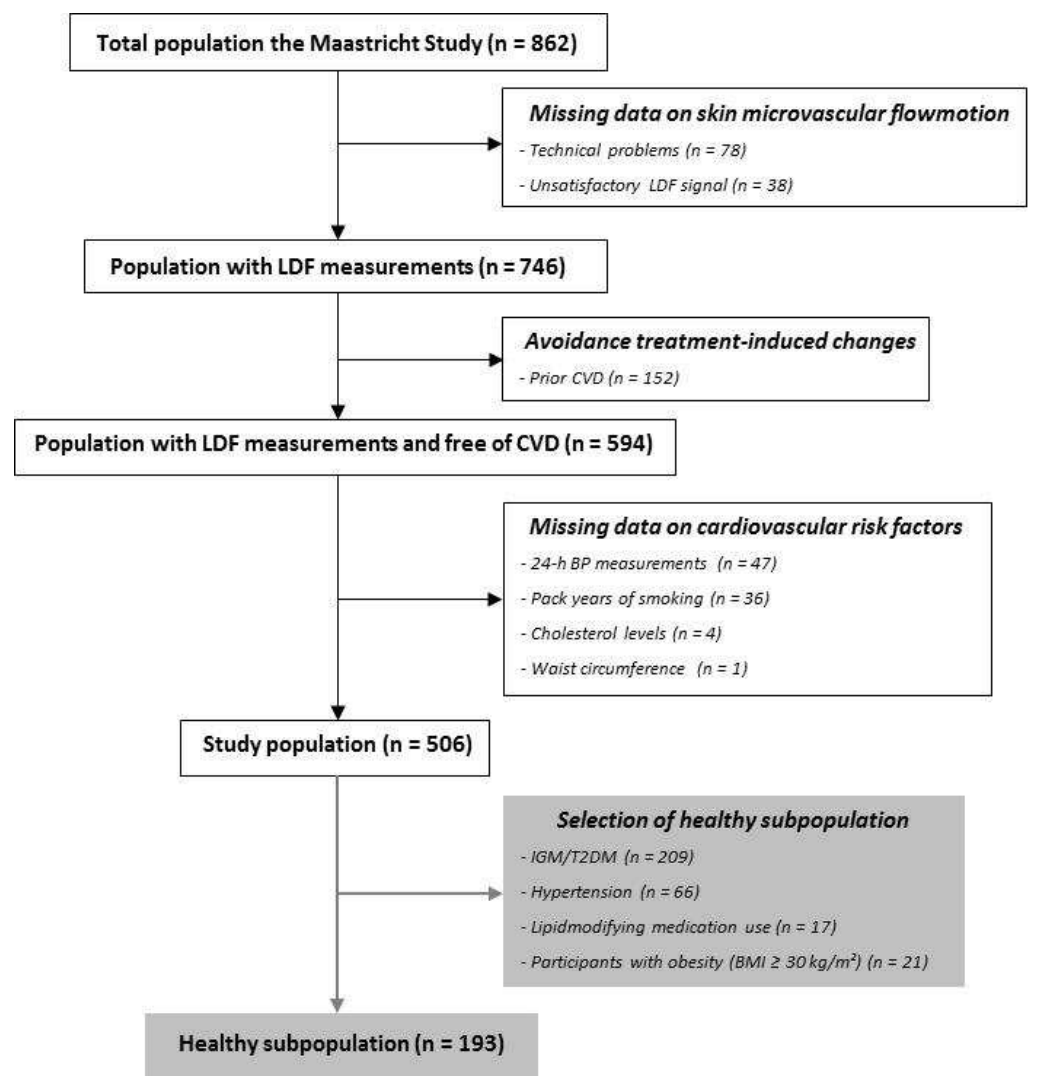

Figure 5.1. Flow diagram 
Table 5.1. General characteristics of the study population and the healthy subpopulation in total and according to tertiles of total skin microvascular flow motion energy

\begin{tabular}{|c|c|c|c|c|c|c|c|c|}
\hline \multirow[b]{2}{*}{ Characteristic } & \multicolumn{4}{|c|}{ Study population } & \multicolumn{4}{|c|}{ Healthy subpopulation } \\
\hline & Total & $T 1(n=168)$ & $T 2(n=169)$ & T3 (n = 169) & Total & $T 1(n=64)$ & $T 2(n=65)$ & $T 3(n=64)$ \\
\hline Age (years) & $58.8 \pm 8.5$ & $56.5 \pm 8.9$ & $59.3 \pm 8.0$ & $60.2 \pm 8.1$ & $55.6 \pm 8.5$ & $53.4 \pm 8.5$ & $56.2 \pm 8.7$ & $57.3 \pm 8.5$ \\
\hline Sex (men) & $260(51.4)$ & $85(50.6)$ & $88(52.1)$ & $87(51.5)$ & $80(41.5)$ & $26(40.6)$ & $27(41.5)$ & $27(42.2)$ \\
\hline \multicolumn{9}{|l|}{ BMI categories } \\
\hline Normal weight $\left(\mathrm{BMI}<25 \mathrm{~kg} / \mathrm{m}^{2}\right)$ & $171(33.8)$ & 57 (33.9) & $52(30.8)$ & $62(36.7)$ & $108(56.0)$ & $36(56.3)$ & $36(55.4)$ & $36(56.3)$ \\
\hline Overweight (BMI $\geq 25-<30 \mathrm{~kg} / \mathrm{m}^{2}$ ) & $243(48.0)$ & $83(49.4)$ & $80(47.3)$ & $80(47.3)$ & $85(44.0)$ & $28(43.8)$ & $29(44.6)$ & $28(43.8)$ \\
\hline Obese $\left(\mathrm{BMI} \geq 30 \mathrm{~kg} / \mathrm{m}^{2}\right)$ & $92(18.2)$ & $28(16.7)$ & 37 (21.9) & $27(16.0)$ & - & - & - & - \\
\hline \multicolumn{9}{|l|}{ Waist circumference } \\
\hline Men $(\mathrm{cm})$ & $100.3 \pm 10.5$ & $102.0 \pm 11.5$ & $99.7 \pm 9.8$ & $99.2 \pm 9.9$ & $94.1 \pm 7.4$ & $95.3 \pm 7.6$ & $94.0 \pm 7.8$ & $93.1 \pm 6.9$ \\
\hline Women $(\mathrm{cm})$ & $90.8 \pm 13.5$ & $91.7 \pm 15.8$ & $91.2 \pm 12.1$ & $89.4 \pm 12.4$ & $84.4 \pm 8.0$ & $85.1 \pm 7.7$ & $84.3 \pm 9.0$ & $83.9 \pm 9.0$ \\
\hline $\mathrm{HbA1c}(\%)$ & $5.9 \pm 0.8$ & $5.8 \pm 0.6$ & $5.9 \pm 0.6$ & $5.9 \pm 0.6$ & $5.5 \pm 0.3$ & $5.5 \pm 0.3$ & $5.5 \pm 0.4$ & $5.5 \pm 0.3$ \\
\hline Fasting plasma glucose (mmol/L) & $5.9 \pm 1.4$ & $5.6 \pm 1.3$ & $5.8 \pm 1.0$ & $5.9 \pm 1.1$ & $5.1 \pm 0.4$ & $5.1 \pm 0.4$ & $5.2 \pm 0.4$ & $5.1 \pm 0.4$ \\
\hline Total cholesterol (mmol/L) & $5.4 \pm 1.1$ & $5.5 \pm 1.0$ & $5.4 \pm 1.2$ & $5.5 \pm 1.1$ & $5.7 \pm 1.0$ & $5.6 \pm 0.9$ & $5.6 \pm 1.0$ & $5.7 \pm 1.1$ \\
\hline HDL-cholesterol (mmol/L) & $1.4 \pm 0.4$ & $1.4 \pm 0.4$ & $1.4 \pm 0.4$ & $1.4 \pm 0.4$ & $1.5 \pm 0.4$ & $1.5 \pm 0.4$ & $1.5 \pm 0.4$ & $1.5 \pm 0.4$ \\
\hline LDL-cholesterol (mmol/L) & $3.4 \pm 1.0$ & $3.5 \pm 0.9$ & $3.4 \pm 1.0$ & $3.5 \pm 1.0$ & $3.7 \pm 0.9$ & $3.7 \pm 0.8$ & $3.7 \pm 0.9$ & $3.8 \pm 1.0$ \\
\hline Total-to-HDL cholesterol ratio & $4.2 \pm 1.3$ & $4.4 \pm 1.5$ & $4.2 \pm 1.1$ & $4.1 \pm 1.3$ & $4.1 \pm 1.2$ & $4.0 \pm 1.2$ & $4.1 \pm 1.2$ & $4.0 \pm 1.2$ \\
\hline Triglycerides (mmol/L) & $1.2[0.8-1.7]$ & $1.2[0.8-1.7]$ & $1.3[0.9-1.8]$ & $1.2[0.8-1.7]$ & $1.0[0.7-1.3]$ & $0.9[0.7-1.2]$ & $1.0[0.7-1.5]$ & $1.0[0.7-1.3]$ \\
\hline 24-h SBP (mmHg) & $119 \pm 12$ & $116 \pm 11$ & $120 \pm 13$ & $120 \pm 12$ & $113 \pm 9$ & $110 \pm 9$ & $114 \pm 9$ & $115 \pm 10$ \\
\hline 24-h DBP (mmHg) & $74 \pm 7$ & $74 \pm 7$ & $75 \pm 7$ & $74 \pm 7$ & $72 \pm 6$ & $71 \pm 6$ & $73 \pm 6$ & $73 \pm 7$ \\
\hline 24-h MAP (mmHg) & $93 \pm 9$ & $91 \pm 8$ & $93 \pm 9$ & $93 \pm 9$ & $89 \pm 7$ & $87 \pm 7$ & $90 \pm 7$ & $90 \pm 8$ \\
\hline 24-h heart rate (bpm) & $70 \pm 9$ & $70 \pm 9$ & $71 \pm 8$ & $69 \pm 9$ & $69 \pm 8$ & $69 \pm 8$ & $69 \pm 8$ & $69 \pm 8$ \\
\hline \multicolumn{9}{|l|}{ Smoking } \\
\hline Never & $173(34.2)$ & $64(38.1)$ & $61(36.1)$ & $48(28.4)$ & $79(40.9)$ & $28(43.8)$ & $28(43.1)$ & $23(35.9)$ \\
\hline Former & $260(51.4)$ & $80(47.6)$ & $86(50.9)$ & $94(55.6)$ & $86(44.6)$ & $28(43.8)$ & $29(44.6)$ & $29(45.3)$ \\
\hline Current & $73(14.4)$ & $24(14.3)$ & $22(13.0)$ & $27(16.0)$ & $28(14.5)$ & $8(12.5)$ & $8(12.3)$ & $12(18.8)$ \\
\hline Pack years of smoking & $14.0[5.0-27.9]$ & $14.3[4.0-25.5]$ & $15.3[6.0-30.4]$ & $11.8[4.9-31.0]$ & $10.5[4.2-25.7]$ & $14.5[3.8-25.5]$ & $12.8[4.4-27.4]$ & $7.8[4.9-24.4]$ \\
\hline \multicolumn{9}{|l|}{ Glucose metabolism } \\
\hline NGM & $297(58.7)$ & $110(65.5)$ & $95(56.2)$ & $92(54.4)$ & $193(100)$ & $64(100)$ & $65(100)$ & $64(100)$ \\
\hline IGM & $89(17.6)$ & 25 (14.9) & $30(17.8)$ & $34(20.1)$ & - & - & - & - \\
\hline T2DM & $120(23.7)$ & $33(19.6)$ & $44(26.0)$ & $43(25.4)$ & - & - & - & - \\
\hline Hypertension & $189(37.4)$ & $61(36.3)$ & $70(41.4)$ & $58(34.4)$ & - & - & - & - \\
\hline Peripheral sensory neuropathy & $19(4.9)$ & $3(1.8)$ & $11(6.5)$ & $5(3.0)$ & $0(0)$ & $0(0)$ & $0(0)$ & $0(0)$ \\
\hline
\end{tabular}

Data are presented as means $\pm S D$, medians [inter-quartile ranges], or numbers (percentages) of the total group and according to tertiles (T1-T3) of total skin

microvascular flow motion energy. 


\section{GENERAL CHARACTERISTICS}

General characteristics of the study population are shown in Table 5.1. The study population included 260 (51.4\%) men, 73 (14.4\%) current smokers, 120 participants (23.7\%) with T2DM, and 189 participants (37.4\%) with hypertension. The healthy subpopulation included $80(41.4 \%)$ men and 28 (14.5\%) current smokers. In addition, Table 1 shows that, when compared with participants in the lowest tertile of SMF, those in the middle and highest tertiles had a higher age and higher BP-values. The median value of total SMF energy was 14.5 (inter-quartile range: $9.1-21.4$ ) in the study population and $13.6(7.8-22.1)$ in the healthy subpopulation (Table 5.2).

Table 5.2. Flow motion in the study population and the healthy subpopulation

\begin{tabular}{lcc}
\hline Characteristic & Study population & Healthy subpopulation \\
\hline Total skin microvascular flow motion energy (A.U.) & $14.5[9.1-21.4]$ & $13.6[7.8-22.1]$ \\
Energy contribution endothelial component (A.U.) & $0.9[0.5-1.4]$ & $0.9[0.5-1.4]$ \\
Energy contribution neurogenic component (A.U.) & $1.4[0.8-2.2]$ & $1.3[0.8-2.2]$ \\
Energy contribution myogenic component (A.U.) & $1.4[0.8-2.2]$ & $1.4[0.8-2.3]$ \\
Energy contribution respiratory component (A.U.) & $2.1[1.3-3.3]$ & $1.9[1.2-3.2]$ \\
Energy contribution heart beat component (A.U.) & $8.2[4.8-12.1]$ & $7.3[4.2-12.4]$ \\
\hline
\end{tabular}

Data are presented as medians [inter-quartile ranges]. A.U., arbitrary units

\section{ASSOCIATIONS OF AGE WITH TOTAL SKIN MICROVASCULAR FLOW MOTION ENERGY AND THE SKIN MICROVASCULAR FLOW MOTION COMPONENTS}

Age was associated with a higher total SMF energy; per standard deviation (SD) higher age (8.5 years) total SMF energy was 0.16 SD (95\% Cl: $0.07 ; 0.25 ; P<0.001$ ) higher (Fig. 5.2). Age was not significantly associated with the energy contribution of the endothelial, neurogenic, and myogenic component, but was associated with a higher energy contribution of the respiratory and heart beat component (sB 0.24 SD $[0.15 ; 0.33]$; $P<$ 0.001 and s6 0.20 SD [0.11; 0.29]; $P<0.001$, respectively) (Fig. 5.3). We found similar results when the frequency components were divided into a low $(0.01-0.15 \mathrm{~Hz})$ and high $(0.15-1.60 \mathrm{~Hz})$ frequency component; age was not significantly associated with the energy contribution of the low frequency component (s6 0.02 SD $[-0.08 ; 0.11] ; P=0.73$ ), but was associated with a higher energy contribution of the high frequency component (sB $0.21 \mathrm{SD}$ [0.12;0.30]; $P<0.001$ ). These results did not materially change when analyses were restricted to the healthy subpopulation (Fig. 5.4 and 5.5), although the association of a higher age with total SMF energy and the energy contribution of the heart beat 
component became somewhat weaker and borderline significant (s 0.13 SD [-0.02; $0.27] ; P=0.09$ and s6 0.13 SD $[-0.02 ; 0.28] ; P=0.09$, respectively).

Standardized $\beta(95 \% \mathrm{Cl})$

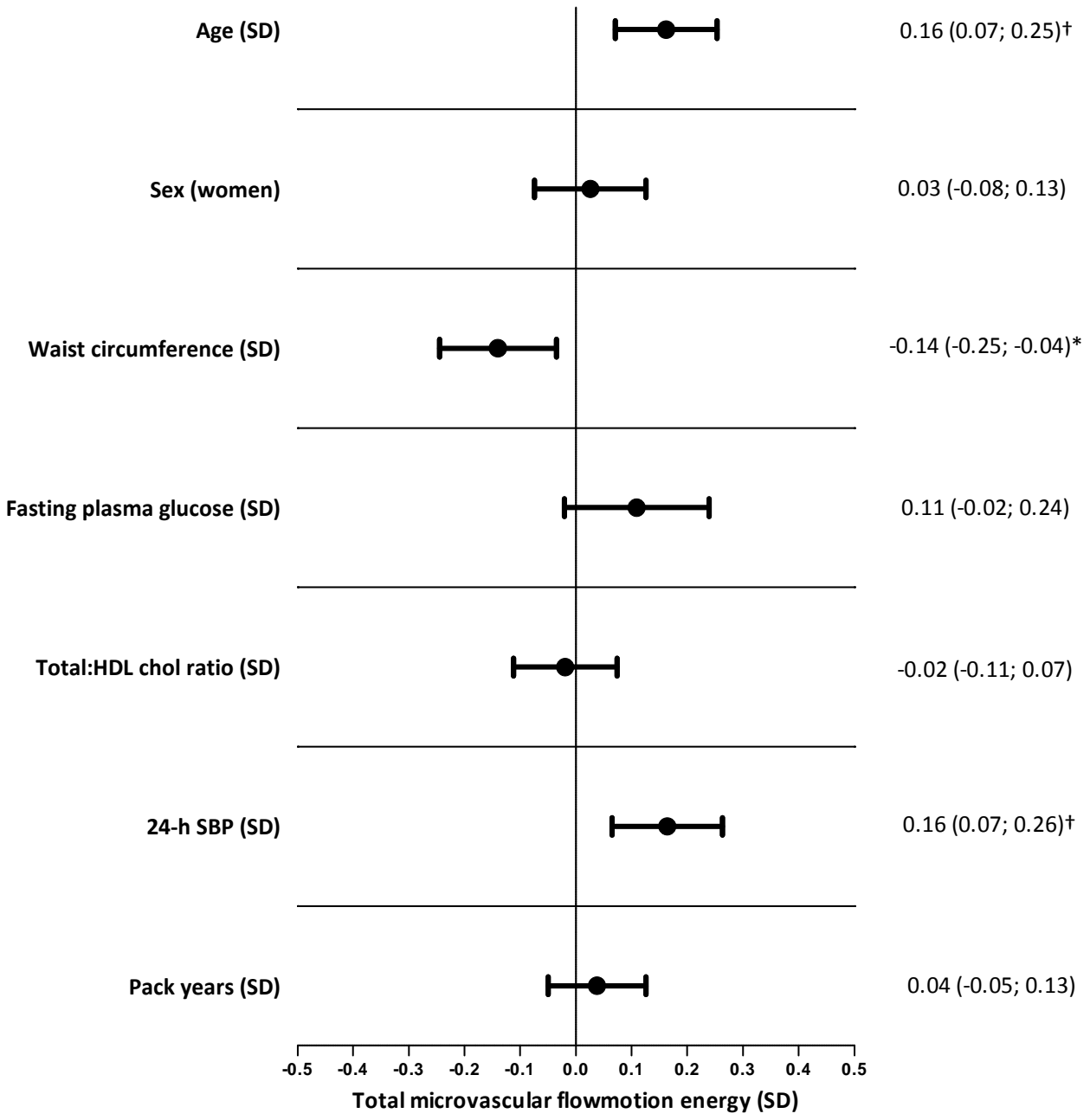

Figure 5.2. Associations between cardiovascular risk factors and total skin microvascular flow motion energy in the study population. Point estimates (standardized b) and $95 \% \mathrm{Cls}$ represent the change in total skin microvascular flow motion energy (in SD) per SD increase (or men vs. women) in the cardiovascular risk factor resulting from a fully adjusted multivariate regression model. $* P<0.05 ;+P<0.001$. SD, standard deviation; SBP, systolic blood pressure. 
Standardized $\beta(95 \% \mathrm{Cl})$

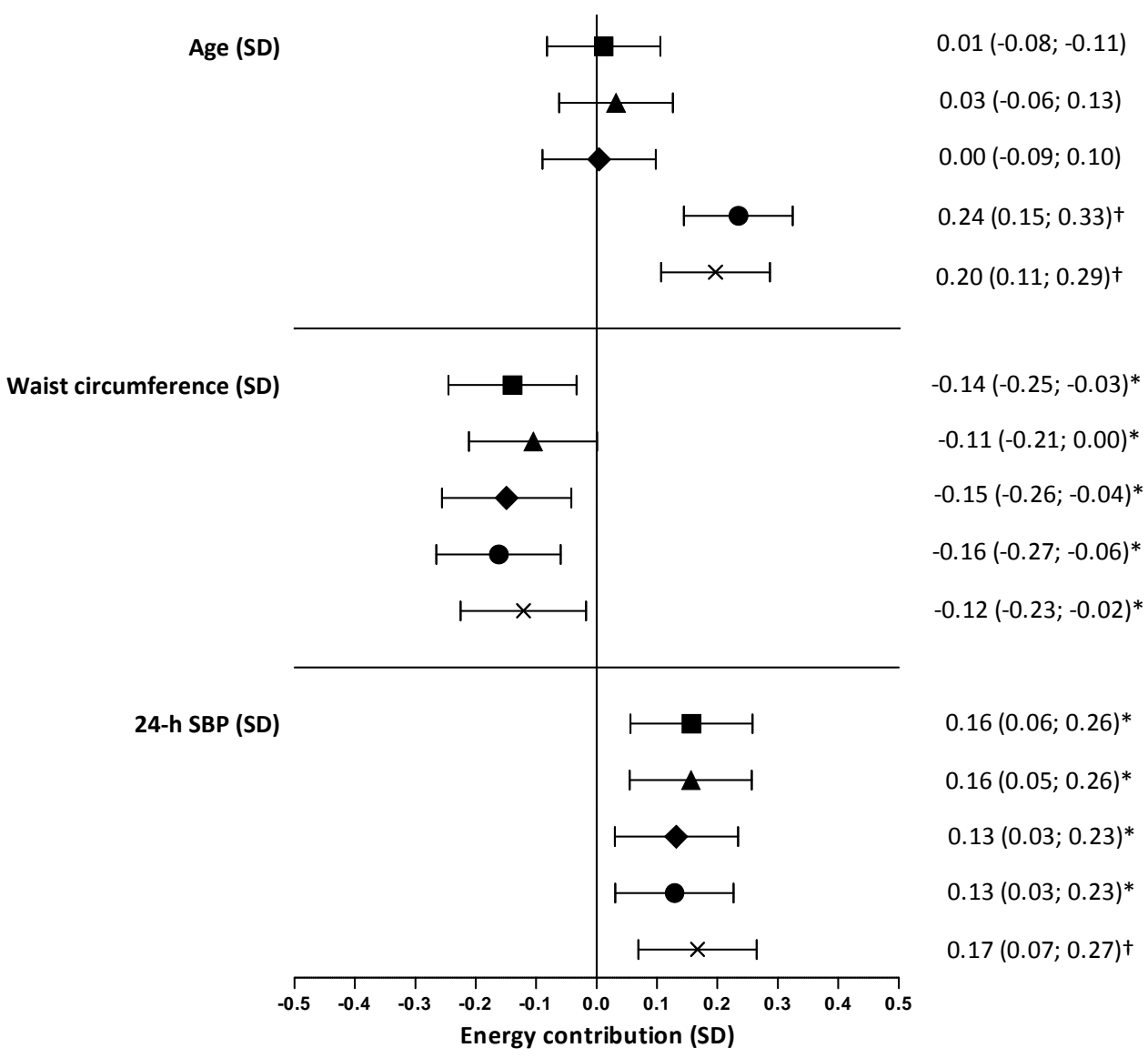

Figure 5.3. Associations between cardiovascular risk factors and the energy contribution of the different skin microvascular flow motion components in the study population. Point estimates (standardized 8 ) and $95 \% \mathrm{Cls}$ represent the change in the energy contribution of the frequency component (in SD) per SD increase in the cardiovascular risk factor resulting from a fully adjusted multivariate regression model. ${ }^{*} P<0.05 ;+P<0.001$. SD, standard deviation; SBP, systolic blood pressure. 
Standardized $\beta(95 \% \mathrm{Cl})$

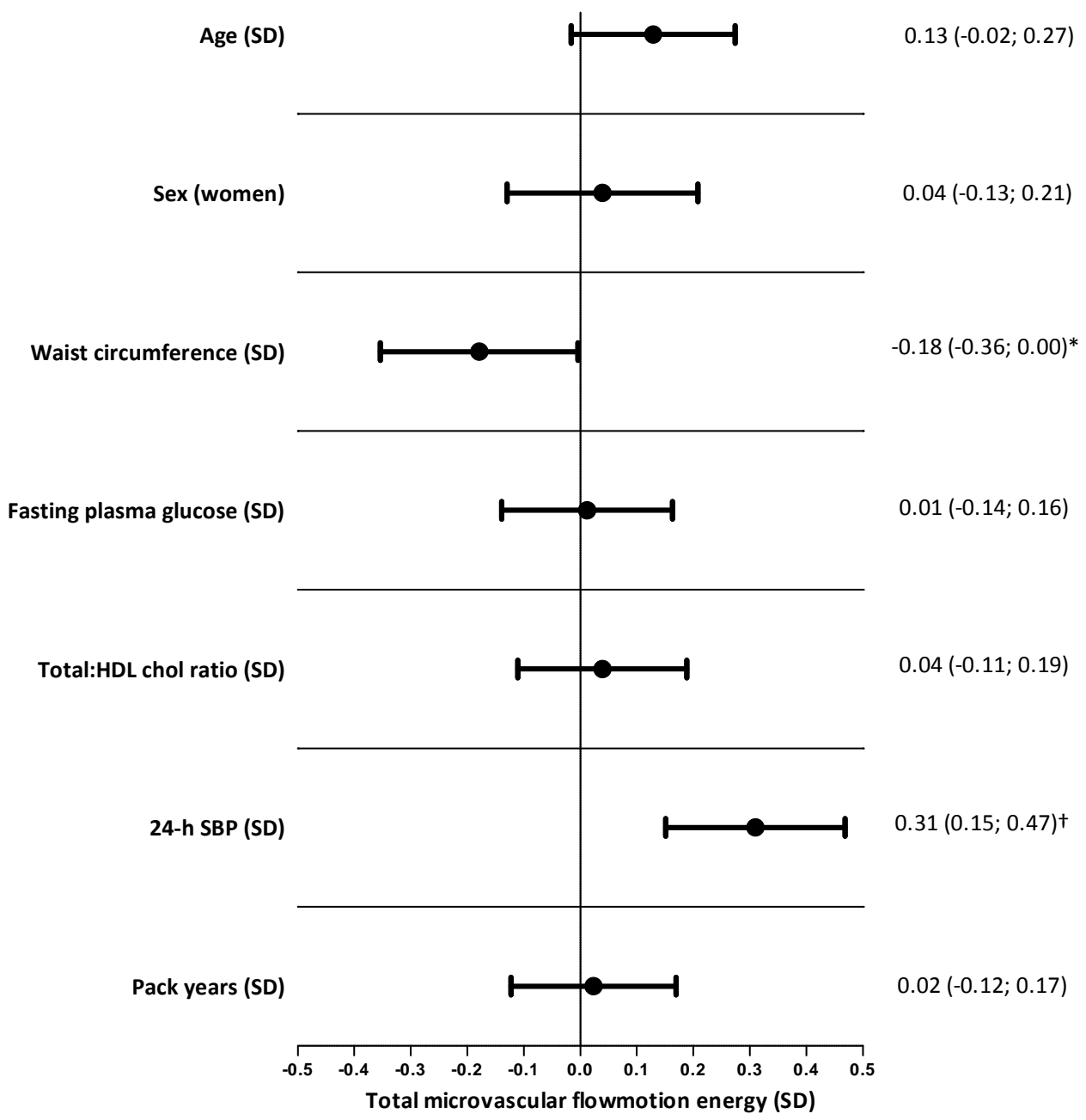

Figure 5.4. Associations between cardiovascular risk factors and total skin microvascular flow motion energy in the healthy subpopulation. Point estimates (standardized 6 ) and $95 \% \mathrm{Cls}$ represent the change in total skin microvascular flowmotion energy (in SD) per SD increase (or men vs. women) in the cardiovascular risk factor resulting from a fully adjusted multivariate regression model. ${ }^{*} P<0.05 ;+P<0.001$. SD, standard deviation; SBP, systolic blood pressure. 
Endothelial component

Neurogenic component

Myogenic component

Respiratory component

Heart beat component

Standardized $\beta(95 \% \mathrm{Cl})$

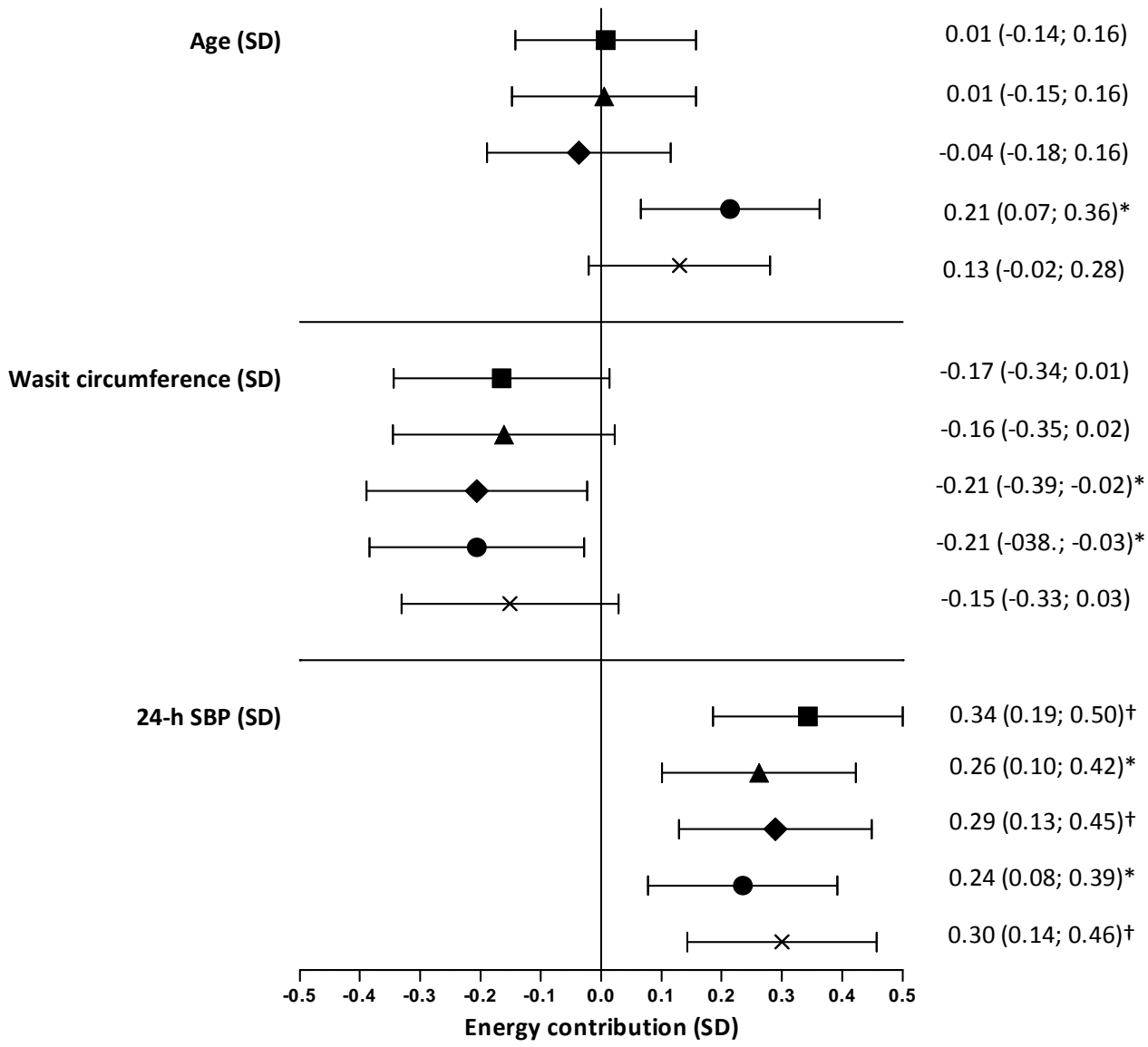

Figure 5.5. Associations between cardiovascular risk factors and the energy contribution of the different skin microvascular flow motion components in the healthy subpopulation. Point estimates (standardized 6 ) and $95 \% \mathrm{Cls}$ represent the change in the energy contribution of the frequency component (in SD) per SD increase in the cardiovascular risk factor resulting from a fully adjusted multivariate regression model. ${ }^{*} P<0.05$; $+P<$ 0.001. SD, standard deviation; SBP, systolic blood pressure. 


\section{ASSOCIATIONS OF WAIST CIRCUMFERENCE WITH TOTAL SKIN MICROVASCULAR FLOW MOTION ENERGY AND THE SKIN MICROVASCULAR FLOW MOTION COMPONENTS}

Waist circumference was associated with a lower total SMF energy; per SD higher waist circumference $(13.0 \mathrm{~cm})$ total SMF energy was -0.14 SD $(-0.25 ;-0.04 ; P=0.01)$ lower (Fig. 5.2). In addition, waist circumference was associated with a lower energy contribution of all the five frequency components (Fig. 5.3). We found similar results with the low and high frequency component; waist circumference was significantly associated with a lower energy contribution of the low as well as the high frequency component. Restriction of these analyses to the healthy subpopulation showed similar results (Fig. 5.4 and 5.5), although the association of a higher waist circumference with the energy contribution of the endothelial, neurogenic, and heart beat component became somewhat weaker and borderline significant (s $B-0.17$ SD $[-0.34 ; 0.01] ; P=0.07$, sB -0.16 SD $[-0.35 ; 0.02] ; P=0.09$, and $\mathrm{s} B-0.15$ SD $[-0.33 ; 0.03] ; P=0.10$, respectively).

\section{ASSOCIATIONS OF 24-H SBP WITH TOTAL SKIN MICROVASCULAR FLOW MOTION ENERGY AND THE SKIN MICROVASCULAR FLOW MOTION COMPONENTS}

24-h SBP was associated with a higher total SMF energy; per SD higher 24-h SBP (12 $\mathrm{mmHg}$ ) total SMF energy was 0.16 SD (0.07; 0.26; $P<0.001$ ) higher (Fig. 5.2). In addition, 24-h SBP was associated with a higher energy contribution of all the five frequency components (Fig. 5.3). We found similar results with the low and high frequency component; 24-h SBP was significantly associated with a higher energy contribution of the low as well as the high frequency component. Restriction of these analyses to the healthy subpopulation showed similar results (Fig. 5.4 and 5.5).

Analysis with 24-h DBP, MAP, or pulse pressure instead of 24-h SBP gave similar results, both in the study population and the analyses restricted to the healthy subpopulation (data not shown). 


\section{ASSOCIATIONS OF THE OTHER CARDIOVASCULAR RISK FACTORS WITH TOTAL SKIN MICROVASCULAR FLOW MOTION ENERGY AND THE SKIN MICROVASCULAR FLOW MOTION COMPONENTS}

We found no significant associations of sex, fasting plasma glucose levels, total-to-HDL cholesterol ratio, or pack years of smoking with total SMF energy, both in the study population (Fig. 5.2) and healthy subpopulation (Fig. 5.4). In addition, sex, fasting plasma glucose levels, total-to-HDL cholesterol ratio, or pack years of smoking were not associated with a higher or lower energy contribution of the five SMF components (data not shown).

Analysis with $\mathrm{HbA1c}$ or diagnostic measures of T2DM (i.e., T2DM (yes/no), T2DM and insulin use (yes/no), T2DM and peripheral neuropathy (yes/no)) instead of fasting plasma glucose did not result in significant associations either (data not shown). Nevertheless, participants with a T2DM duration $\geq 10$ years had a lower energy contribution of the endothelial component as compared to participants with a T2DM $<10$ years (s $8-0.23$ SD [$0.46 ;-0.01] ; P=0.04)$.

\section{ADDITIONAL ANALYSES}

First, the associations of the cardiovascular risk factors with both total SMF energy and the energy contribution of the components did not differ by diabetes status (data not shown). Second, the five SMF components can also be expressed in relative energy contributions. ${ }^{30}$ Analysis with the relative energy contribution instead of absolute energy contribution of the SMF components demonstrated that age was associated with a lower relative energy contribution of the endothelial, neurogenic, and myogenic components, but with a higher relative energy contribution of both the respiratory and the heart beat component. In addition, waist circumference and 24-h SBP were not associated with a higher or lower relative energy contribution of the five SMF components (data not shown). Third, additional adjustment for time of LDF measurements (to adjust for diurnal influences) and time from light meal till LDF measurements (to adjust for light meal influences) gave similar results (data not shown). Fourth, additional adjustment for glucose-lowering medication, antihypertensive medication, and lipid-modifying medication use in the study population gave similar results (data not shown). 


\section{DISCUSSION}

This study represents a comprehensive analysis of the associations of cardiovascular risk factors with SMF in a population-based sample. The study had two main findings. First, age and 24-h SBP were directly, and waist circumference was inversely associated with SMF after adjustment for the other cardiovascular risk factors, diabetes status, glucoselowering medication, antihypertensive medication, and lipid-modifying medication use. Second, these associations were similar both in the study population and in the healthy subpopulation. Importantly, the study population seems to be a representation of the source population in the study region (e.g., the prevalence of overweight, obesity, and hypertension was $48.0 \%, 18.2 \%$, and $37.4 \%$ respectively in our dataset as compared to $48.0 \%, 12.0 \%$, and $31.4 \%$ in the general Dutch population ${ }^{31,32}$ ). However, since the Maastricht Study focuses on the etiology, pathophysiology, complications and comorbidities of T2DM, recruitment was stratified according to known T2DM status for reasons of efficiency. ${ }^{20}$ Therefore, generalizability may be restricted to populations with similar profiles (i.e., with high prevalence's of T2DM). Nevertheless, restriction of these analyses to the healthy subpopulation (without IGM and T2DM) showed similar results, indicating that 1) these associations were not determined by IGM or T2DM and 2) these associations can be considered valid for the general population.

Our finding that age and 24-h SBP were directly and that waist circumference was inversely associated with total SMF energy is in line with previous studies. ${ }^{16,18,33,34}$ Nevertheless, the age-related increases in the respiratory and heart beat component, the waist circumference-related decreases, and the BP-related increases in all the five frequency components demonstrated in our study somewhat contrast with findings of other studies which demonstrated age-, obesity-, and hypertension-related alterations in the low frequency components. ${ }^{16,18,34}$ The explanation for these discrepancies is not entirely clear, but may be related to the fact that 1) we studied a larger group (i.e., we had more power to detect small differences) and 2) previous studies investigated a nonrandom sample of the population which could have introduced selection bias.

There is convincing evidence that the regulation of whole body and tissue metabolism and blood pressure by the microcirculation ${ }^{14}$ may be mediated, at least partly, via effects on flow motion under both physiological and pathophysiological conditions. ${ }^{1,8}$ Indeed, several studies demonstrated that insulin and meal ingestion stimulate microvascular flow motion, which is likely paralleled with an increased tissue perfusion and increased insulin-stimulated glucose uptake in skeletal muscle., ${ }^{1,35}$ In addition, experimental data demonstrated that rabbits with microvascular flow motion had a $20 \%$ lower arterial pressure as compared to rabbits without flow motion. ${ }^{7}$ Furthermore, tissue areas threatened by homeostatic and metabolic stress demonstrated enhanced flow motion. ${ }^{36}$ In addition, patients with mild peripheral arterial occlusive disease are 
characterized by enhanced flow motion. ${ }^{37}$ Interestingly, when these patients were divided into those exhibiting flow motion and those who did not, those with flow motion had significantly higher tissue oxygen levels than those patients without, despite similar blood flow. ${ }^{37}$ Thus, considering the suggested role of flow motion, we may suppose that the positive association of age and 24-h SBP with total SMF energy could represent an adaptive response to ageing and increased $\mathrm{BP}$, with beneficial effects on tissue perfusion and local hydraulic resistance. It should, however, be kept in mind that the positive associations of age and BP with SMF may reflect different aspects of microvascular function, which is reflected in the fact that we found positive associations of age with the high-frequency components and of BP with all frequency components. In addition, the negative association of waist circumference with total SMF energy could represent obesity-related disturbance of flow motion, with negative effects on the delivery of nutrients and oxygen to tissue and local hydraulic resistance, which is consistent with a role for microvascular dysfunction, specifically impaired SMF, in the development of obesity-related T2DM and hypertension. ${ }^{14}$

Theoretical and experimental evidence for the concept that flow motion increases with age as an adaptive response is lacking. Hence, it should be realized that the positive association of age with SMF might be the consequence of a thinner epidermis with increased age, resulting in a greater measuring depth and thus increased perfusion signals. Nevertheless, studies investigating the effect of ageing on epidermal thickness demonstrated conflicting results ${ }^{38,39}$, and therefore this concept remains controversial. In addition, increased perfusion signals due to a thinner epidermis would result in positive associations of all five frequency components. Here, we only demonstrated age-related increases of the respiratory and heart beat component, indicating that with ageing, there is a shift towards the contribution of the respiratory and heart beat component resulting in a, possibly adaptive, enhanced SMF.

With regard to $\mathrm{BP}$, several experimental and mathematical models demonstrated that during BP elevations arterioles are constricted and an oscillating network can transiently dilate these arterioles, thereby increasing tissue perfusion and alter local hydraulic resistance. ${ }^{40,41}$ Indeed, in the hamster microcirculation, vasoconstriction induced by $\mathrm{N}^{G}$-monomethyl-L-arginine (L-NMMA) caused a decrease in effective diameter and an increase in flow motion frequency. ${ }^{41}$ These experimental studies may support our positive association of BP with total SMF energy, indicating that flow motion may prevail over autoregulation during $\mathrm{BP}$ elevations. ${ }^{41}$ In relation to the possible mechanisms involved, we demonstrated BP-related increases in the energy contribution of all five frequency components. These findings suggest an improvement in the efficiency of all components of flow motion during BP elevation. ${ }^{18}$

With regard to waist circumference, there is convincing evidence that obesity is a primary cause of microvascular dysfunction ${ }^{13}$ and that microvascular dysfunction, in turn, 
may be an intermediate step linking obesity to T2DM and hypertension. ${ }^{14}$ In relation to the possible mechanisms involved, there is an increase in several circulating adipose tissue-derived factors in obesity, whereas the anti-inflammatory adipokine, adiponectin, is decreased. These endocrine factors are likely candidates to influence microvascular function and thus flow motion. ${ }^{1,14}$ Hence, the waist circumference-related decreases in the energy contribution of all five frequency components may reflect a decline in the efficiency of all the components of flow motion due to these endocrine factors. Interestingly, major weight loss in severely obese patients resulted in a full normalisation of flow motion ${ }^{33}$, suggesting a cause-effect relationship between obesity and impaired flow motion.

The lack of a significant association of fasting plasma glucose and other metabolic or diagnostic measures of T2DM with SMF was unexpected. Other studies suggested that humans with T1DM and T2DM are characterized by decreased flow motion patterns in the low-frequency oscillations. ${ }^{15,17}$ The explanation for this discrepancy is not entirely clear, but may be related to the fact that the participants with T2DM in our study had a shorter diabetes duration (median of 7.0 [inter-quartile range: $3.0-11.0$ ] years) than in the other study (mean of $17.1 \pm 2.3$ years). ${ }^{17}$ Indeed, in the current study, participants with a T2DM duration $\geq 10$ years had a decreased energy contribution of the endothelial component as compared to participants with a T2DM $<10$ years, suggesting that the altered patterns of flow motion as demonstrated in diabetes may be a complication of long-standing diabetes.

Sex, total-to-HDL ratio, and smoking are associated with macrovascular dysfunction. ${ }^{42}$ However, we could not confirm these associations with SMF. Interestingly, several other studies did not find significant associations of sex, cholesterol, and smoking with measures of microvascular function either (i.e., skin capillary recruitment ${ }^{43}$, and generalized retinal arteriolar narrowing and venular dilatation ${ }^{44,45}$ ), suggesting that these determinants are less important for microvascular as compared to macrovascular functioning.

The present study had some limitations. First, this study is cross-sectional in nature and therefore it is not possible to distinguish between cause and effect. Hence, further large-scale (longitudinal) studies in this area are needed. Second, observational studies like the Maastricht Study do not allow invasive measurements (i.e., we studied skin and not muscle microcirculation). Nevertheless, several studies have demonstrated comparable metabolic ${ }^{46}$ and vascular effects in skin and muscle. ${ }^{47}$ These studies strongly suggest that vascular responses observed in skin parallel those in muscle, and thus that measurement of the skin microvasculature is a valid tool for the assessment of microvascular function. ${ }^{48}$ Third, $86 \%$ of all participants complied with the smoking, caffeine, and meal instructions before SMF measurements. However, when analyses were restricted to these participants, results did not change. 
In conclusion, age and 24-h SBP are directly, and waist circumference is inversely associated with skin microvascular flow motion in the general population. The exact mechanisms underlying these findings remain elusive. We hypothesize that flow motion may be an important component of the microcirculation by ensuring optimal delivery of nutrients and oxygen to tissue and regulate local hydraulic resistance under physiological conditions, but also under pathophysiological conditions when microcirculatory perfusion is reduced, such as occurs with ageing and higher blood pressure. In addition, obesity may result in an impaired flow motion with negative effects on the delivery of nutrients and oxygen to tissue and local hydraulic resistance. 


\section{REFERENCES}

1. Jonk AM, Houben AJ, Schaper NC, de Leeuw PW, Serne EH, Smulders YM, Stehouwer CD. Meal-related increases in microvascular vasomotion are impaired in obese individuals: a potential mechanism in the pathogenesis of obesity-related insulin resistance. Diabetes Care 2011;34 Suppl 2:S342-8.

2. Rattigan S, Clark MG, Barrett EJ. Hemodynamic actions of insulin in rat skeletal muscle: evidence for capillary recruitment. Diabetes 1997;46:1381-8.

3. Thorn CE, Kyte $H$, Slaff DW, Shore AC. An association between vasomotion and oxygen extraction. Am J Physiol Heart Circ Physiol 2011;301:H442-9.

4. Ursino M, Cavalcanti S, Bertuglia S, Colantuoni A. Theoretical analysis of complex oscillations in multibranched microvascular networks. Microvasc Res 1996;51:229-49.

5. Intaglietta M. Vasomotion and flowmotion: physiological mechanisms and clinical evidence. Vascular Medicine 1990;1:101-12.

6. Slaaf DW, Vrielink HH, Tangelder GJ, Reneman RS. Effective diameter as a determinant of local vascular resistance in presence of vasomotion. Am J Physiol 1988;255:H1240-3.

7. Schmidt-Lucke C, Borgstrom P, Schmidt-Lucke JA. Low frequency flowmotion/(vasomotion) during pathophysiological conditions. Life Sci 2002;71:2713-28.

8. Aalkjaer C, Boedtkjer D, Matchkov V. Vasomotion - what is currently thought? Acta Physiol (Oxf) 2011;202:253-69.

9. Kvandal P, Stefanovska A, Veber M, Kvernmo HD, Kirkeboen KA. Regulation of human cutaneous circulation evaluated by laser Doppler flowmetry, iontophoresis, and spectral analysis: importance of nitric oxide and prostaglandines. Microvasc Res 2003;65:160-71.

10. Stefanovska A, Bracic M, Kvernmo HD. Wavelet analysis of oscillations in the peripheral blood circulation measured by laser Doppler technique. IEEE Trans Biomed Eng 1999;46:1230-9.

11. Manson JE, Nathan DM, Krolewski AS, Stampfer MJ, Willett WC, Hennekens CH. A prospective study of exercise and incidence of diabetes among US male physicians. JAMA 1992;268:63-7.

12. Muris DM, Houben AJ, Schram MT, Stehouwer CD. Microvascular dysfunction is associated with a higher incidence of type 2 diabetes mellitus: a systematic review and meta-analysis. Arterioscler Thromb Vasc Biol 2012;32:3082-94.

13. de Jongh RT, Serne EH, IJzerman RG, de Vries G, Stehouwer CD. Impaired microvascular function in obesity: implications for obesity-associated microangiopathy, hypertension, and insulin resistance. Circulation 2004;109:2529-35.

14. Muris DM, Houben AJ, Schram MT, Stehouwer CD. Microvascular dysfunction: An emerging pathway in the pathogenesis of obesity-related insulin resistance. Rev Endocr Metab Disord 2013;14:29-38.

15. Benbow SJ, Pryce DW, Noblett K, MacFarlane IA, Friedmann PS, Williams G. Flow motion in peripheral diabetic neuropathy. Clin Sci (Lond) 1995;88:191-6.

16. de Jongh RT, Serne EH, RG IJ, Jorstad HT, Stehouwer CD. Impaired local microvascular vasodilatory effects of insulin and reduced skin microvascular vasomotion in obese women. Microvasc Res 2008; 75: 256-62.

17. Stansberry KB, Shapiro SA, Hill MA, McNitt PM, Meyer MD, Vinik Al. Impaired peripheral vasomotion in diabetes. Diabetes Care 1996;19:715-21.

18. Rossi M, Bradbury A, Magagna A, Pesce M, Taddei S, Stefanovska A. Investigation of skin vasoreactivity and blood flow oscillations in hypertensive patients: effect of short-term antihypertensive treatment. J Hypertens 2011;29:1569-76.

19. Rossi M, Carpi A, Di Maria C, Galetta F, Santoro G. Absent post-ischemic increase of blood flowmotion in the cutaneous microcirculation of healthy chronic cigarette smokers. Clin Hemorheol Microcirc 2007;36:163-71.

20. Schram MT, Sep SJ, Kallen van der CJ, Dagnelie PC, Koster A, Schaper NC, Henry RM, Stehouwer CD. The Maastricht Study: an extensive phenotyping study on determinants of type 2 diabetes, its complications and its comorbidities. Eur J Epidemiol 2014;29:439-51.

21. Braverman IM, Schechner JS, Silverman DG, Keh-Yen A. Topographic mapping of the cutaneous microcirculation using two outputs of laser-Doppler flowmetry: flux and the concentration of moving blood cells. Microvasc Res 1992;44:33-48.

22. Kvandal P, Landsverk SA, Bernjak A, Stefanovska A, Kvernmo HD, Kirkeboen KA. Low-frequency oscillations of the laser Doppler perfusion signal in human skin. Microvasc Res 2006;72:120-7.

23. Pencina MJ, D'Agostino RB, Sr., Larson MG, Massaro JM, Vasan RS. Predicting the 30-year risk of cardiovascular disease: the framingham heart study. Circulation 2009;119:3078-84. 
24. WHO. Definition and Diagnosis of diabetes mellitus and intermediate hyperglycemia. www.who.int/diabetes/publications/Definition\%20and\%20diagnosis\%20of\%20diabetes_new.pdf, 2006.

25. O'Brien E, Coats A, Owens P, Petrie J, Padfield PL, Littler WA, de Swiet M, Mee F. Use and interpretation of ambulatory blood pressure monitoring: recommendations of the British hypertension society. BMJ 2000;320:1128-34.

26. Chobanian AV, Bakris GL, Black HR, Cushman WC, Green LA, Izzo JL, Jr., Jones DW, Materson BJ, Oparil S, Wright JT, Jr., Roccella EJ. Seventh report of the Joint National Committee on Prevention, Detection, Evaluation, and Treatment of High Blood Pressure. Hypertension 2003;42:1206-52.

27. Boulton AJ, Malik RA, Arezzo JC, Sosenko JM. Diabetic somatic neuropathies. Diabetes Care 2004;27:145886.

28. Karvestedt L, Martensson E, Grill V, Elofsson S, von Wendt G, Hamsten A, Brismar K. Peripheral sensory neuropathy associates with micro- or macroangiopathy: results from a population-based study of type 2 diabetic patients in Sweden. Diabetes Care 2009;32:317-22.

29. Soper DS. A-priori Sample Size Calculator for Multiple Regression [Software]. Available from http://www.danielsoper.com/statcalc, 2014.

30. Bracic M, Stefanovska A. Wavelet-based analysis of human blood-flow dynamics. Bull Math Biol 1998;60:919-35.

31. Bakel AM, Zantinge EM. Neemt het aantal mensen met overgewicht toe of af? In: Volksgezondheid Toekomst Verkenning, Nationaal Kompas Volksgezondheid. Bilthoven: RIVM, <http://www.nationaalkompas.nl> Nationaal Kompas Volksgezondheid\Determinanten\Persoonsgebonden \Overgewicht, 2013.

32. Blokstra A, Bakel AM. Hoeveel mensen hebben een verhoogde bloeddruk? . In: Volksgezondheid Toekomst Verkenning, Nationaal Kompas Volksgezondheid. Bilthoven: RIVM, <http://www.nationaalkompas.nl> Nationaal Kompas Volksgezondheid\Determinanten\Persoonsgebonden\Bloeddruk, 2012.

33. Rossi M, Nannipieri M, Anselmino M, Pesce M, Muscelli E, Santoro G, Ferrannini E. Skin vasodilator function and vasomotion in patients with morbid obesity: effects of gastric bypass surgery. Obes Surg 2011;21:87-94.

34. Tikhonova IV, Tankanag AV, Chemeris NK. Age-related changes of skin blood flow during postocclusive reactive hyperemia in human. Skin Res Technol 2013;19:e174-81.

35. Newman JM, Dwyer RM, St-Pierre P, Richards SM, Clark MG, Rattigan S. Decreased microvascular vasomotion and myogenic response in rat skeletal muscle in association with acute insulin resistance. J Physiol 2009;587:2579-88.

36. Bertuglia S, Colantuoni A, Coppini G, Intaglietta M. Hypoxia- or hyperoxia-induced changes in arteriolar vasomotion in skeletal muscle microcirculation. Am J Physiol 1991;260:H362-72.

37. Schmidt JA. Periodic Hemodynamics in Health and Disease. R.G. Landes Company, Georgetown 1996;

38. Branchet MC, Boisnic S, Frances C, Robert AM. Skin thickness changes in normal aging skin. Gerontology 1990;36:28-35.

39. Sandby-Moller J, Poulsen T, Wulf HC. Epidermal thickness at different body sites: relationship to age, gender, pigmentation, blood content, skin type and smoking habits. Acta Derm Venereol 2003;83:410-3.

40. Rucker M, Strobel O, Vollmar B, Roesken F, Menger MD. Vasomotion in critically perfused muscle protects adjacent tissues from capillary perfusion failure. Am J Physiol Heart Circ Physiol 2000;279:H550-8.

41. Ursino $M$, Colantuoni A, Bertuglia S. Vasomotion and blood flow regulation in hamster skeletal muscle microcirculation: A theoretical and experimental study. Microvasc Res 1998;56:233-52.

42. Iwamoto Y, Maruhashi T, Fujii Y, Idei N, Fujimura N, Mikami S, Kajikawa M, Matsumoto T, Kihara Y, Chayama K, Noma K, Nakashima A, Higashi Y. Intima-media thickness of brachial artery, vascular function, and cardiovascular risk factors. Arterioscler Thromb Vasc Biol 2012;32:2295-303.

43. IJzerman RG, de Jongh RT, Beijk MA, van Weissenbruch MM, Delemarre-van de Waal HA, Serne EH, Stehouwer $C D$. Individuals at increased coronary heart disease risk are characterized by an impaired microvascular function in skin. Eur J Clin Invest 2003;33:536-42.

44. Kawasaki R, Tielsch JM, Wang JJ, Wong TY, Mitchell P, Tano Y, Tominaga M, Oizumi T, Daimon M, Kato T, Kawata S, Kayama T, Yamashita $\mathrm{H}$. The metabolic syndrome and retinal microvascular signs in a Japanese population: the Funagata study. Br J Ophthalmol 2008;92:161-6.

45. Wong TY, Duncan BB, Golden SH, Klein R, Couper DJ, Klein BE, Hubbard LD, Sharrett AR, Schmidt MI. Associations between the metabolic syndrome and retinal microvascular signs: the Atherosclerosis Risk In Communities study. Invest Ophthalmol Vis Sci 2004;45:2949-54.

46. Lang $\mathrm{CH}$. Rates and tissue sites of noninsulin- and insulin-mediated glucose uptake in diabetic rats. Proc Soc Exp Biol Med 1992;199:81-7. 
47. Meijer RI, De Boer MP, Groen MR, Eringa EC, Rattigan S, Barrett EJ, Smulders YM, Serne EH. Insulin-induced microvascular recruitment in skin and muscle are related and both are associated with whole-body glucose uptake. Microcirculation 2012;19:494-500.

48. Gronenschild EH, Muris DM, Schram MT, Karaca U, Stehouwer CD, Houben AJ. Semi-automatic assessment of skin capillary density: Proof of principle and validation. Microvasc Res 2013;90:192-8. 


\section{GENERAL DISCUSSION}

Accumulating evidence supports the hypothesis that microvascular dysfunction precedes and even predicts the development of type 2 diabetes mellitus (T2DM). ${ }^{1-3}$ However, epidemiological and longitudinal evidence on this role of microvascular dysfunction is largely lacking. An epidemiological approach has several advantages over small-scale experimental studies, since 1) it enables investigation of relatively unbiased associations (i.e., without selection bias and without [or with proper adjustment for] confounding), 2) it enables assessment of multiple exposures and multiple outcomes, and 3) longitudinal studies provide more information about the underlying associations. ${ }^{4}$ The general aim of the research reported on in this thesis was therefore to investigate the associations of microvascular dysfunction with T2DM and long-term hyperglycaemia, using an epidemiological approach.

This final chapter first briefly summarizes the main findings of our studies and then discusses the most important methodological issues of the research underlying this thesis. Finally, it discusses the public health implications and proposes directions for future research.

\section{SUMMARY}

Chapter 1 summarized the current literature on microvascular dysfunction as an intermediate step linking central obesity to T2DM. Considerable evidence exists that microvascular dysfunction is a key feature in the development of obesity-related insulin resistance. Obesity is associated with microvascular dysfunction through alterations in endocrine and vasocrine signals that change intracellular signalling in microvascular endothelial and skeletal muscle cells. Microvascular dysfunction, in turn, may contribute to the development of T2DM - by impairing the timely access of glucose and insulin to their target tissues. ${ }^{5-7}$

The assessment of microvascular function in specific vascular beds - especially the assessment of skin capillary density - is technically demanding and time-consuming, and is thus mostly used in relatively small, experimental studies (chapter 2). In order to facilitate the use of skin capillaroscopy in large-scale studies we first developed a semiautomatic method for the assessment of skin capillary density. The study reported on in chapter $\mathbf{2 . 3}$ demonstrated that this semi-automatic image analysis application (CapiAna) 1) agrees well with the classic manual counting procedure, with no significant differences 
between the two methods, 2) has better reproducibility than the classic manual counting procedure and 3 ) is intrinsically faster than the manual counting procedure, with time savings of approximately 60 minutes per subject. This semi-automatic method facilitates the off-line analysis of skin capillary density.

In the systematic review discussed in chapter 3, we searched for all prospective studies available in the literature that investigated the association between microvascular dysfunction and incident T2DM and impaired fasting glucose (IFG). We found 23 articles that investigated the association of plasma markers of endothelial dysfunction $(n=11)$, peripheral vascular reactivity $(n=1)$, retinal diameters $(n=5)$, and microalbuminuria $(n=$ 6) with incident T2DM and/or IFG. Thirteen of these studies ${ }^{8-20}$ were included in a metaanalysis, which confirmed that microvascular dysfunction is associated with a $10 \%$ to $49 \%$ higher incidence of T2DM and an 8\% to 15\% higher incidence of IFG. These results indicate that various estimates of microvascular dysfunction are associated with incident T2DM and IFG, suggesting a role for the microcirculation in the pathogenesis of T2DM.

In chapter 4, we discussed the associations of T2DM status and long-term hyperglycaemia with functional and structural capillary density. We demonstrated that T2DM is associated with higher baseline skin capillary density and lower relative functional and structural capillary densities. In addition, long-term hyperglycaemia, as measured by $\mathrm{HbA1c}$, is associated with a lower functional capillary density. Analyses excluding T2DM patients with microangiopathy gave similar results, suggesting that T2DM is associated with functional as well as structural capillary rarefaction even before clinically apparent microangiopathy (i.e., nephropathy and neuropathy) has developed. Similarly, long-term hyperglycaemia was associated with functional capillary rarefaction, even before the presence of clinically apparent diabetic microangiopathy.

In the study discussed in chapter 5, we investigated the associations between skin microvascular flow motion (SMF) and the cardiovascular risk factors age, sex, waist circumference, total-to-HDL cholesterol, fasting plasma glucose, 24-h systolic blood pressure (SBP), and cigarette smoking. We demonstrated that age and 24-h SBP were positively associated with SMF, and that waist circumference was negatively associated with SMF, independent of other cardiovascular risk factors. More importantly, the associations remained similar in a healthy subpopulation, suggesting that these results can be considered valid for the general population.

In conclusion, using an epidemiological approach, we demonstrated a relationship between microvascular dysfunction and T2DM in the general population. Interpretation of these results suggests a vicious circle of progressive microvascular dysfunction, possibly initiated by obesity (chapter 1; Fig. 6.1), which contributes to the development of T2DM (chapter 3; Fig. 6.1), which, in turn, contributes to a further deterioration of microvascular function, and ultimately to the development of structural microvascular changes and diabetic microangiopathy (chapter 4; Fig. 6.1). In addition, 
microvascular vasomotion (resulting in flow motion) may be an important component of microvascular function, by ensuring optimal delivery of nutrients and oxygen to tissues and regulating local hydraulic resistance..$^{21-23}$ Impaired vasomotion, again initiated by obesity, may have negative effects on the delivery of nutrients and oxygen to tissues and on local hydraulic resistance, and thus on microvascular functioning. This, in turn, may contribute to the development of T2DM (chapter 5; Fig. 6.1).

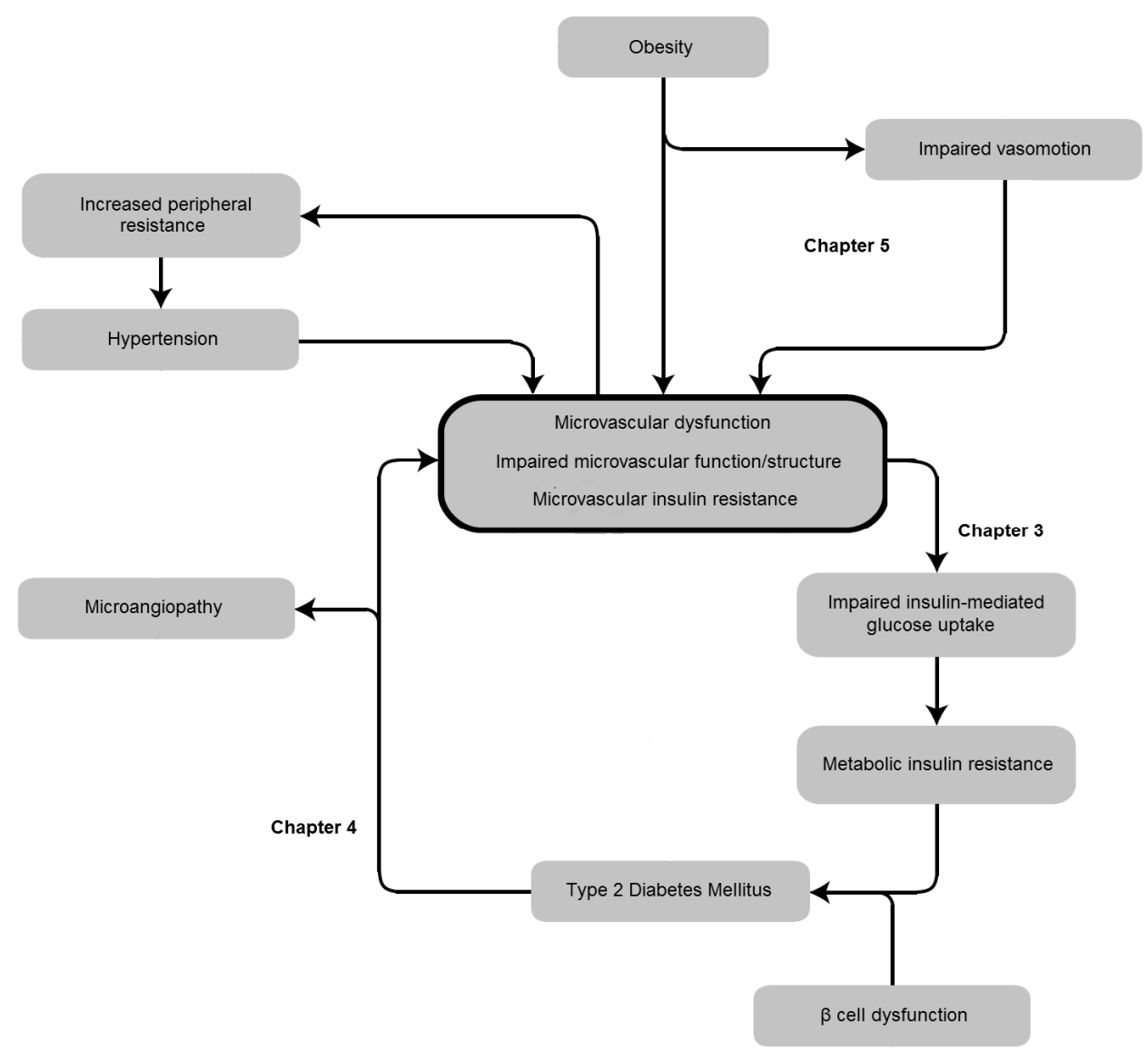

Figure 6.1. Hypothesis describing how microvascular dysfunction, initiated by obesity, contributes to the development of T2DM, which in turn, contributes to a further deterioration of microvascular function, and ultimately to the development of diabetic microangiopathy. In addition, impaired vasomotion, as an important component of microvascular function, may have negative effects on the delivery of nutrients and oxygen to tissues and on local hydraulic resistance and thus on microvascular functioning. 


\section{METHODOLOGICAL CONSIDERATIONS}

\section{EXTERNAL VALIDITY}

Most studies in this thesis (chapters 4 and 5) were conducted in the context of the Maastricht Study, an observational prospective population-based cohort study. ${ }^{24}$ Eligible for participation were all individuals aged between 40 and 75 years and living in the southern part of the Netherlands. Participants were recruited through mass media campaigns and from the municipal registries and the regional Diabetes Patient Registry via mailings. Since the Maastricht Study focuses on the etiology, pathophysiology, complications and comorbidities of T2DM, recruitment was stratified according to known T2DM status for reasons of efficiency. ${ }^{24}$ Therefore, generalizability may be restricted to populations with similar profiles (i.e., with high prevalence's of T2DM). Nevertheless, the associations presented in chapters $\mathbf{4}$ and $\mathbf{5}$ were similar for the study population, for the population without clinically apparent diabetic microangiopathy (chapter 4) and for the healthy subpopulation (chapter 5). In addition, several studies included in our systematic review (chapter 3) demonstrated significant associations between microvascular dysfunction and incident T2DM in the general population as well as in different ethnic groups, ${ }^{11}$ in men and women, ${ }^{26}$ and in obese, ${ }^{27}$ inflammation, ${ }^{11}$ and hypertensive ${ }^{17}$ population groups. Hence, the data presented in this thesis can be generalized to a large group of individuals.

\section{INTERNAL VALIDITY}

In observational studies, three sources of error, or bias, may influence the results, i.e., selection, information, and confounding bias. ${ }^{4}$ All of these types of bias might have influenced the results of the studies in the present thesis, so the impact of these biases needs to be discussed.

\section{SECECTION BIAS}

The potential sources of selection bias we considered for the studies in the present thesis were selective drop-out and selective non-response.

In longitudinal studies (chapter 3), selective drop-out of the unhealthiest participants often results in biased associations (i.e., attrition bias). For instance, of the initial 3699 participants at baseline in the Rotterdam Study, 947 (26\%) did not attend the 
follow-up. ${ }^{13}$ These participants were on average older, were more likely to be smokers, and had higher blood pressures and more plaques in the carotid arteries. ${ }^{13}$ Nevertheless, the retinal diameters (as a measure of microvascular function) did not differ for the participants not attending the follow-up. We therefore consider the risk of attrition bias in this, and the other studies presented in chapter 3 , to be low, and if any such bias existed, it would result in an underestimation of the associations presented, since these characteristics are associated with incident T2DM.

In the cross-sectional studies (chapters 4 and 5), the study population was enriched with T2DM participants to increase the statistical power for identifying any potential contrasts between individuals with and without T2DM. ${ }^{24}$ This might have led to selection bias. Nevertheless, the associations presented in chapter 5 did not differ with the diabetes status, indicating that the results of the Maastricht Study were probably not affected by selection bias. However, selective non-response may have occurred. For instance, participants with T2DM in the Maastricht Study were relatively healthy, with a median diabetes duration of 7.0 [inter-quartile range: 3.0 - 11.0] years and a low prevalence of diabetic complications. Hence, the inclusion of relatively healthy participants with T2DM may have led to underestimation of the associations. Indeed, several studies have demonstrated that humans with T1DM and T2DM are characterized by decreased skin microvascular flow motion patterns in the low-frequency oscillations. ${ }^{28,29}$ Unfortunately, we could not confirm a significant association of fasting plasma glucose and other metabolic or diagnostic measures of T2DM with skin microvascular flow motion (chapter 5). The explanation for this discrepancy is not entirely clear, but may be related to the fact that the participants with T2DM in our study had a shorter diabetes duration than those in the other study $\left(17.1 \pm 2.3\right.$ years). ${ }^{29}$ Indeed, participants with a T2DM duration $\geq 10$ years had a decreased energy contribution of the endothelial component as compared to participants with a T2DM $<10$ years (chapter 5 ).

In conclusion, both selective drop-out and selective non-response would have led to underestimation of the associations presented in the studies of this thesis. This may explain why we did not find some of the associations found in other studies. ${ }^{28,29}$

\section{INFORMATION BIAS}

Information bias results from errors in measuring determinants and outcome variables. ${ }^{4}$ There are two types of information bias, i.e., differential bias (systematic error) and nondifferential bias (random error). ${ }^{4}$ Differential bias results in either over- or underestimation of the associations under study if measurements error depends on risk factors exposure. ${ }^{4}$ Non-differential bias may result in underestimation of the associations under study. ${ }^{4}$ 
It seems unlikely that differential and non-differential bias have occurred in our studies. To avoid differential bias, all investigators in the Maastricht Study were blinded to the characteristics of the participants. In addition, the skin capillaroscopy (chapter 4) and skin microvascular flow motion (chapter 5 ) analyses were also performed by investigators who were blinded to the participants' characteristics. To avoid non-differential bias, all measurements were performed by trained research assistants, according to standardized protocols. In addition, skin capillaroscopy and skin microvascular flow motion have reasonable to good reliability, as shown in previous studies. ${ }^{30-32}$ More importantly, we developed a semi-automatic image analysis application to analyse skin capillary density, which has a better reproducibility than the classic manual counting procedure (chapter 2.3).

It is important to note that most studies similar to ours performed microvascular measurements under completely standardized conditions: i.e., after a $10 \mathrm{~h}$ fast, with subjects having abstained from drinking alcohol and smoking for a period of $24 \mathrm{~h}$, having abstained from exercise for a period of $48 \mathrm{~h}$, and being measured in the morning to avoid diurnal influences on microvascular function. ${ }^{31-33}$ Unfortunately, for logistic reasons (i.e., the use of an extensive phenotyping approach in the Maastricht Study ${ }^{24}$ ), we were not able to meet these conditions. To overcome this potential bias, all participants were asked to refrain from smoking and caffeine consumption three hours before the microvascular measurements. A light meal (breakfast and/or lunch), low in fat content, was allowed prior to the start of the microvascular measurements. In addition, we adjusted for the time at which the microvascular measurements took place (to adjust for diurnal influences) and the time that elapsed between the light meal and the microvascular measurements (to adjust for light meal influences). Fortunately, adjustment for these diurnal and light meal influences did not substantially change the results (chapters 4 and 5). Nor did the results change when analyses were restricted to the participants who complied with the smoking, caffeine, and meal instructions ( $77 \%$ chapter $4,86 \%$ chapter 5).

Finally, the interpretation of the flow motion data (chapter 5) is complicated and should therefore be pointed out. This technique, devised and predominantly used by the Stefanovska group, involves partitioning the laser Doppler flowmetry (LDF) oscillations (0.01 and $1.6 \mathrm{~Hz}$ ) into five SMF components: 1) endothelial, $0.01-0.02 \mathrm{~Hz} ; 2$ ) neurogenic, $0.02-0.06 \mathrm{~Hz}$; 3) myogenic, $0.06-0.15 \mathrm{~Hz}$; 4) respiratory, $0.15-0.40 \mathrm{~Hz}$; and 5) heartbeat, $0.40-1.60 \mathrm{~Hz}{ }^{34}$ Although there is some evidence that the frequencies around $0.01-0.15$ $\mathrm{Hz}$ are modulated by the endothelial, sympathetic, and myogenic activity, ${ }^{35-37}$ this evidence is mainly based on studies with relatively small patient groups ( $n<10)$. Hence, conclusions based on these frequency components should be interpreted with caution. Regardless of the question whether the low frequency components are modulated by endothelial, sympathetic, or myogenic activity, we demonstrated that total flow motion is 
positively associated with age and 24-h SBP and negatively with waist circumference (chapter 5). Studies like these will contribute to the debate whether flow motion is an important component of the microcirculation by ensuring optimal delivery of nutrients and oxygen to tissues and regulating local hydraulic resistance under physiological as well as pathophysiological conditions. ${ }^{21}$

\section{CONFOUNDING}

Confounding occurs when the effect of a variable of interest is affected or blurred by that of a third variable. ${ }^{38}$ To overcome this bias, we (chapters 4 and 5), and the studies included in the systematic review (chapter 3), adjusted for multiple confounders, which makes it unlikely that residual confounding has influenced the results. Nevertheless, bias due to residual confounding can never be excluded in observational studies. ${ }^{4}$

An important issue regarding the question whether to adjust for a potential confounder is whether the variable is believed to be part of the causal pathway between the determinant and outcome under study. ${ }^{4}$ For instance, since microvascular dysfunction may link central obesity to insulin resistance, adjustment for measures of central obesity (being part of the causal pathway) could result in an underestimation of the actual association. Interestingly, the associations of sICAM-1, ${ }^{26,39} \mathrm{VWF}^{40}$ and SE-selectin ${ }^{26,39}$ with incident T2DM became weaker after adjustment for body mass index (BMI), waist circumference, and/or waist-to-hip ratio (chapter 3 ).

In conclusion, since adjustment for BMI, waist circumference, and waist-to-hip ratio may represent overadjustment, we conclude that the associations reported in our thesis (chapters 3, 4, and 5) may represent underestimations of the true associations.

\section{CAUSALITY}

Given the cross-sectional design of the Maastricht Study, it is not possible to distinguish between cause and effect, and therefore conclusions about cause and effect from the studies in chapters $\mathbf{4}$ and $\mathbf{5}$ should be drawn with caution. The prospective cohort studies included in our meta-analysis (chapter 3 ) demonstrated that microvascular dysfunction is associated with a 10-49\% higher incidence of T2DM and an 8-15\% higher incidence of IFG. These longitudinal results suggest that the exposure continues its effect on the outcome throughout the longitudinal follow-up period, which favours causality. Nevertheless, it is important to note that the studies included in this meta-analysis are observational and that even longitudinal designs cannot prove causality. 
Regardless of the problem that the studies presented in this thesis cannot prove causality, accumulating experimental evidence supports the hypothesis that microvascular dysfunction precedes and even predicts the development of T2DM. ${ }^{1-3}$

\section{PUBLIC HEALTH IMPLICATIONS AND FUTURE DIRECTIONS}

T2DM currently affects an estimated 285 million people worldwide, with a further seven million people developing T2DM each year. ${ }^{25}$ In addition, the prevalence of obesity is increasing worldwide and has reached epidemic proportions in Western society. ${ }^{41}$ As adults with obesity have approximately 7 times higher odds of $\mathrm{T}^{2 \mathrm{DM}}{ }^{42}$ it is important to unravel the pathophysiology of obesity-related T2DM. Experimental evidence suggests that microvascular dysfunction may be an intermediate step linking central obesity to T2DM. $^{1-3}$ In the research project reported on in this thesis, we investigated the associations of obesity, T2DM, and other cardiovascular risk factors with microvascular dysfunction in a population-based setting.

The population-based studies discussed in this thesis are important because they provide further insight into the pathophysiology of obesity-related T2DM. Indeed, we demonstrated that microvascular dysfunction is associated with incident diabetes and prediabetes (chapter 3 ), and thus contributes to the translation to the general population of this concept as investigated in experimental studies. ${ }^{3,43,44}$ Hence, from a clinical point of view, targeting the microcirculation may lead to decreased risks of developing T2DM. ${ }^{5,6,45,46}$ Nevertheless, since we cannot prove any causal associations, more longitudinal studies and experimental studies are required to unravel the pathophysiology of obesity-related T2DM.

As regards longitudinal studies, the Maastricht Study is valuable for investigating the longitudinal associations between microvascular dysfunction and incident T2DM. The Maastricht Study is ongoing, and annual follow-up on morbidity and mortality is in progress. The Maastricht Study is also valuable because of its extensive phenotyping approach, and in particular the extensive characterization of microvascular function. ${ }^{24}$ This allows the concept of microvascular dysfunction in the pathogenesis of obesity-related T2DM to be investigated with additional measures of microvascular function (i.e., heatinduced hyperaemia, ${ }^{47}$ funduscopy, ${ }^{48}$ dynamic vessel analysis, ${ }^{49}$ markers of endothelial dysfunction, $^{50-52}$ and microalbuminuria ${ }^{53}$ ). In addition, other concepts relating to the microcirculation in health and disease can be investigated.

As regards experimental studies, additional experimental studies are needed to investigate how microvascular dysfunction is determined and how it leads to T2DM. Unravelling this issue may lead to new treatment targets as well as to a better under- 
standing of the reasons why certain existing treatments are associated with decreased risk of developing T2DM (i.e., angiotensin converting enzyme [ACE-] inhibitors, angiotensin receptor blockers [ARBs], and physical activity). It is important to note that the pathogenesis of T2DM is complicated. For instance, the regulation of glucose uptake involves: 1) delivery of insulin and glucose to tissues, 2) transport of insulin and glucose across the endothelial barrier; i.e., transendothelial transport (TET), and 3) uptake of glucose into muscle by translocation of glucose transporter-4 (GLUT-4). ${ }^{54-56}$ Thus, when investigating this issue, it must be kept in mind that not only microvascular dysfunction but also alterations in TET $^{56}$ and/or GLUT-4 translocation ${ }^{55}$ could account for changes in insulin-mediated glucose uptake and thus contribute to insulin resistance and subsequent T2DM.

Besides targeting the microcirculation with drugs, physicians should encourage their patients to lose weight loss and adopt a healthy lifestyle in order to prevent obesity and obesity-related microvascular dysfunction. For instance, several studies have demonstrated improvements of microvascular function after weight loss in morbidly obese patient having bariatric surgery. ${ }^{57,58}$ In addition, a recent study in healthy subjects demonstrated that a dietary pattern characterized by high intakes of high- and low-fat sweets was associated with microvascular dysfunction, while a pattern characterized by increased consumption of vegetable oils, poultry, and fish and seafood was associated with improved microvascular function. ${ }^{59}$ Moreover, physical activity may prevent obesityrelated microvascular dysfunction and consequent obesity-related T2DM. ${ }^{60}$ Indeed, physical activity has been associated with improved microvascular function ${ }^{61,62}$ and, more importantly, regular exercise can enhance vascular insulin mechanisms. ${ }^{63}$ Taken together, these findings suggest that the prevention of obesity and the implementation of a healthy lifestyle may reduce obesity-related microvascular dysfunction and consequent obesityrelated T2DM.

More studies are thus needed to investigate the pathophysiology of obesityrelated T2DM. Their findings may contribute to a more precise assessment of the risk of T2DM and hypertension. In addition, unravelling how microvascular dysfunction is determined and how it leads to T2DM may lead to new treatment targets as well as to a better understanding of the reason why certain existing treatments are associated with a decreased risk of developing T2DM. Importantly, the implementation of a healthy lifestyle may reduce obesity-related microvascular dysfunction and consequent obesity-related T2DM. 


\section{REFERENCES}

1. Kim F, Pham M, Maloney E, Rizzo NO, Morton GJ, Wisse BE, Kirk EA, Chait A, Schwartz MW. Vascular inflammation, insulin resistance, and reduced nitric oxide production precede the onset of peripheral insulin resistance. Arterioscler Thromb Vasc Biol 2008;28:1982-8.

2. Bonner JS, Lantier L, Hasenour CM, James FD, Bracy DP, Wasserman DH. Muscle-specific vascular endothelial growth factor deletion induces muscle capillary rarefaction creating muscle insulin resistance. Diabetes 2013;62:572-80.

3. Kubota T, Kubota N, Kumagai H, Yamaguchi S, Kozono H, Takahashi T, Inoue M, Itoh S, Takamoto I, Sasako T, Kumagai K, Kawai T, Hashimoto S, Kobayashi T, Sato M, Tokuyama K, Nishimura S, Tsunoda M, Ide T, Murakami K, Yamazaki T, Ezaki O, Kawamura K, Masuda H, Moroi M, Sugi K, Oike Y, Shimokawa H, Yanagihara N, Tsutsui M, Terauchi Y, Tobe K, Nagai R, Kamata K, Inoue K, Kodama T, Ueki K, Kadowaki T. Impaired insulin signaling in endothelial cells reduces insulin-induced glucose uptake by skeletal muscle. Cell Metab 2011;13:294-307.

4. Rothman KJ, Greenland S, Lash TL. Modern epidemiology. Vol 3rd ed. Philidelphia: Lippincott Williams \& Wilkins, 2008.

5. de Boer MP, Meijer RI, Wijnstok NJ, Jonk AM, Houben AJ, Stehouwer CD, Smulders YM, Eringa EC, Serne EH. Microvascular dysfunction: A potential mechanism in the pathogenesis of obesity-associated insulin resistance and hypertension. Microcirculation 2012;19:5-18.

6. Jonk AM, Houben AJ, de Jongh RT, Serne EH, Schaper NC, Stehouwer CD. Microvascular dysfunction in obesity: A potential mechanism in the pathogenesis of obesity-associated insulin resistance and hypertension. Physiology (Bethesda) 2007;22:252-60.

7. Serne EH, de Jongh RT, Eringa EC, RG IJ, Stehouwer CD. Microvascular dysfunction: A potential pathophysiological role in the metabolic syndrome. Hypertension 2007;50:204-11.

8. Krakoff J, Funahashi T, Stehouwer CD, Schalkwijk CG, Tanaka S, Matsuzawa Y, Kobes S, Tataranni PA, Hanson RL, Knowler WC, Lindsay RS. Inflammatory markers, adiponectin, and risk of type 2 diabetes in the pima indian. Diabetes Care 2003;26:1745-51.

9. Meigs JB, O'Donnell C J, Tofler GH, Benjamin EJ, Fox CS, Lipinska I, Nathan DM, Sullivan LM, D'Agostino RB, Wilson PW. Hemostatic markers of endothelial dysfunction and risk of incident type 2 diabetes: The framingham offspring study. Diabetes 2006;55:530-7.

10. Sattar N, Murray HM, Welsh P, Blauw GJ, Buckley BM, de Craen AJ, Ford I, Forouhi NG, Freeman DJ, Jukema JW, Macfarlane PW, Murphy MB, Packard CJ, Stott DJ, Westendorp RG, Shepherd J. Are elevated circulating intercellular adhesion molecule 1 levels more strongly predictive of diabetes than vascular risk? Outcome of a prospective study in the elderly. Diabetologia 2009;52:235-9.

11. Song Y, Manson JE, Tinker L, Rifai N, Cook NR, Hu FB, Hotamisligil GS, Ridker PM, Rodriguez BL, Margolis KL, Oberman A, Liu S. Circulating levels of endothelial adhesion molecules and risk of diabetes in an ethnically diverse cohort of women. Diabetes 2007;56:1898-904.

12. Perticone F, Maio R, Sciacqua A, Andreozzi F, lemma G, Perticone M, Zoccali C, Sesti G. Endothelial dysfunction and c-reactive protein are risk factors for diabetes in essential hypertension. Diabetes 2008;57:167-71.

13. Ikram MK, Janssen JA, Roos AM, Rietveld I, Witteman JC, Breteler MM, Hofman A, van Duijn CM, de Jong PT. Retinal vessel diameters and risk of impaired fasting glucose or diabetes: The rotterdam study. Diabetes 2006;55:506-10.

14. Kifley A, Wang JJ, Cugati S, Wong TY, Mitchell P. Retinal vascular caliber and the long-term risk of diabetes and impaired fasting glucose: The Blue Mountains Eye Study. Microcirculation 2008;15:373-7.

15. Nguyen TT, Wang JJ, Islam FM, Mitchell P, Tapp RJ, Zimmet PZ, Simpson R, Shaw J, Wong TY. Retinal arteriolar narrowing predicts incidence of diabetes: The australian diabetes, obesity and lifestyle (ausdiab) study. Diabetes 2008;57:536-9.

16. Wong TY, Klein R, Sharrett AR, Schmidt MI, Pankow JS, Couper DJ, Klein BE, Hubbard LD, Duncan BB. Retinal arteriolar narrowing and risk of diabetes mellitus in middle-aged persons. JAMA 2002;287:2528-33.

17. Wong TY, Shankar A, Klein R, Klein BE, Hubbard LD. Retinal arteriolar narrowing, hypertension, and subsequent risk of diabetes mellitus. Arch Intern Med 2005;165:1060-5.

18. Brantsma AH, Bakker SJ, Hillege HL, de Zeeuw D, de Jong PE, Gansevoort RT. Urinary albumin excretion and its relation with c-reactive protein and the metabolic syndrome in the prediction of type 2 diabetes. Diabetes Care 2005;28:2525-30. 
19. Friedman AN, Marrero D, Ma Y, Ackermann R, Narayan KM, Barrett-Connor E, Watson K, Knowler WC, Horton ES. Value of urinary albumin-to-creatinine ratio as a predictor of type 2 diabetes in pre-diabetic individuals. Diabetes Care 2008;31:2344-8.

20. Wang Z, Hoy WE. Albuminuria as a marker of the risk of developing type 2 diabetes in non-diabetic aboriginal australians. International Journal of Epidemiology. 2006;35:1331-1335.

21. Aalkjaer C, Boedtkjer D, Matchkov V. Vasomotion - what is currently thought? Acta Physiol (Oxf) 2011;202:253-69.

22. Intaglietta M. Vasomotion and flowmotion: Physiological mechanisms and clinical evidence. Vascular Medicine 1990;1:101-12.

23. Jonk AM, Houben AJ, Schaper NC, de Leeuw PW, Serne EH, Smulders YM, Stehouwer CD. Meal-related increases in microvascular vasomotion are impaired in obese individuals: A potential mechanism in the pathogenesis of obesity-related insulin resistance. Diabetes Care 2011;34 Suppl 2:S342-8.

24. Schram MT, Sep SJ, Kallen van der CJ, Dagnelie PC, Koster A, Schaper NC, Henry RM, Stehouwer CD. The maastricht study: An extensive phenotyping study on determinants of type 2 diabetes, its complications and its comorbidities. Eur J Epidemiol 2014;29:439-51.

25. Federation ID: Spreadsheet: Prevalence estimated of diabetes mellitus (DM), 2010. Brussel, belgium. International Diabetes Federation: IDF diabetes atlas, 2010.

26. Thorand B, Baumert J, Chambless L, Meisinger C, Kolb H, Doring A, Lowel H, Koenig W. Elevated markers of endothelial dysfunction predict type 2 diabetes mellitus in middle-aged men and women from the general population. Arterioscler Thromb Vasc Biol 2006;26:398-405.

27. Meigs JB, Hu FB, Rifai N, Manson JE. Biomarkers of endothelial dysfunction and risk of type 2 diabetes mellitus. JAMA 2004;291:1978-86.

28. Benbow SJ, Pryce DW, Noblett K, MacFarlane IA, Friedmann PS, Williams G. Flow motion in peripheral diabetic neuropathy. Clin Sci (Lond) 1995;88:191-6.

29. Stansberry KB, Shapiro SA, Hill MA, McNitt PM, Meyer MD, Vinik Al. Impaired peripheral vasomotion in diabetes. Diabetes Care 1996;19:715-21.

30. Bracic M, Stefanovska A. Wavelet-based analysis of human blood-flow dynamics. Bull Math Biol 1998;60:919-35.

31. Jonk AM, Houben AJ, Schaper NC, de Leeuw PW, Serne EH, Smulders YM, Stehouwer CD. Obesity is associated with impaired endothelial function in the postprandial state. Microvasc Res 2011;82:423-9.

32. Serne EH, Stehouwer CD, ter Maaten JC, ter Wee PM, Rauwerda JA, Donker AJ, Gans RO. Microvascular function relates to insulin sensitivity and blood pressure in normal subjects. Circulation 1999;99:896-902.

33. Jonk AM, Houben AJ, Schaper NC, de Leeuw PW, Serne EH, Smulders YM, Stehouwer CD. Angiotensin ii enhances insulin-stimulated whole-body glucose disposal but impairs insulin-induced capillary recruitment in healthy volunteers. J Clin Endocrinol Metab 2010;95:3901-8.

34. Stefanovska A, Bracic M, Kvernmo HD. Wavelet analysis of oscillations in the peripheral blood circulation measured by laser doppler technique. IEEE Trans Biomed Eng 1999;46:1230-9.

35. Kastrup J, Bulow J, Lassen NA. Vasomotion in human skin before and after local heating recorded with laser doppler flowmetry. A method for induction of vasomotion. Int J Microcirc Clin Exp 1989;8:205-15.

36. Kvandal P, Landsverk SA, Bernjak A, Stefanovska A, Kvernmo HD, Kirkeboen KA. Low-frequency oscillations of the laser doppler perfusion signal in human skin. Microvasc Res 2006;72:120-7.

37. Kvandal P, Stefanovska A, Veber M, Kvernmo HD, Kirkeboen KA. Regulation of human cutaneous circulation evaluated by laser doppler flowmetry, iontophoresis, and spectral analysis: Importance of nitric oxide and prostaglandines. Microvasc Res 2003;65:160-71.

38. Grimes DA, Schulz KF. Bias and causal associations in observational research. Lancet 2002;359:248-52.

39. Stranges S, Rafalson LB, Dmochowski J, Rejman K, Tracy RP, Trevisan M, Donahue RP. Additional contribution of emerging risk factors to the prediction of the risk of type 2 diabetes: Evidence from the western new york study. Obesity (Silver Spring) 2008;16:1370-6.

40. Duncan BB, Schmidt MI, Offenbacher S, Wu KK, Savage PJ, Heiss G. Factor viii and other hemostasis variables are related to incident diabetes in adults. The atherosclerosis risk in communities (aric) study. Diabetes Care 1999;22:767-72.

41. Flegal KM, Carroll MD, Kit BK, Ogden CL. Prevalence of obesity and trends in the distribution of body mass index among us adults, 1999-2010. JAMA 2012;307:491-7.

42. Mokdad AH, Ford ES, Bowman BA, Dietz WH, Vinicor F, Bales VS, Marks JS. Prevalence of obesity, diabetes, and obesity-related health risk factors, 2001. JAMA 2003;289:76-9. 
43. Vincent MA, Barrett EJ, Lindner JR, Clark MG, Rattigan S. Inhibiting nos blocks microvascular recruitment and blunts muscle glucose uptake in response to insulin. Am J Physiol Endocrinol Metab 2003;285:E123-9.

44. Wallis MG, Wheatley CM, Rattigan S, Barrett EJ, Clark AD, Clark MG. Insulin-mediated hemodynamic changes are impaired in muscle of zucker obese rats. Diabetes 2002;51:3492-8.

45. Houben AJ, Eringa EC, Jonk AM, Serne EH, Smulders YM, Stehouwer CD. Perivascular fat and the microcirculation: Relevance to insulin resistance, diabetes, and cardiovascular disease. Curr Cardiovasc Risk Rep 2012;6:80-90.

46. Levy BI, Schiffrin EL, Mourad JJ, Agostini D, Vicaut E, Safar ME, Struijker-Boudier HA. Impaired tissue perfusion: A pathology common to hypertension, obesity, and diabetes mellitus. Circulation 2008;118:96876.

47. Minson CT, Berry LT, Joyner MJ. Nitric oxide and neurally mediated regulation of skin blood flow during local heating. J Appl Physiol 2001;91:1619-26.

48. Houben AJ, Stehouwer CD. Retinal microvascular abnormalities: Can they predict future risk of hypertension? J Hypertens 2009;27:2346-8.

49. Delles C, Michelson G, Harazny J, Oehmer S, Hilgers KF, Schmieder RE. Impaired endothelial function of the retinal vasculature in hypertensive patients. Stroke 2004;35:1289-93.

50. Stehouwer CD. Endothelial dysfunction in diabetic nephropathy: State of the art and potential significance for non-diabetic renal disease. Nephrol Dial Transplant 2004;19:778-81.

51. Stehouwer CD, Fischer $H R$, van Kuijk AW, Polak BC, Donker AJ. Endothelial dysfunction precedes development of microalbuminuria in iddm. Diabetes 1995;44:561-4.

52. Stehouwer CD, Lambert J, Donker AJ, van Hinsbergh VW. Endothelial dysfunction and pathogenesis of diabetic angiopathy. Cardiovasc Res 1997;34:55-68.

53. Stehouwer CD, Smulders YM. Microalbuminuria and risk for cardiovascular disease: Analysis of potential mechanisms. J Am Soc Nephrol 2006;17:2106-11.

54. Kim JA, Montagnani M, Koh KK, Quon MJ. Reciprocal relationships between insulin resistance and endothelial dysfunction: Molecular and pathophysiological mechanisms. Circulation. 2006;113:1888-1904.

55. Shulman GI. Cellular mechanisms of insulin resistance. J Clin Invest 2000;106:171-6.

56. Wang $\mathrm{H}$, Wang $\mathrm{AX}$, Aylor $\mathrm{K}$, Barrett EJ. Nitric oxide directly promotes vascular endothelial insulin transport. Diabetes 2013;62:4030-42.

57. Martin-Rodriguez JF, Cervera-Barajas A, Madrazo-Atutxa A, Garcia-Luna PP, Pereira JL, Castro-Luque J, LeonJustel A, Morales-Conde S, Castillo JR, Leal-Cerro A, Cano DA. Effect of bariatric surgery on microvascular dysfunction associated to metabolic syndrome: A 12-month prospective study. Int J Obes (Lond) 2014;38:1410-5.

58. Rossi M, Nannipieri M, Anselmino M, Guarino D, Franzoni F, Pesce M. Subcutaneous adipose tissue blood flow and vasomotion in morbidly obese patients: Long term effect of gastric bypass surgery. Clin Hemorheol Microcirc 2012;51:159-67.

59. Karatzi K, Protogerou A, Kesse-Guyot E, Fezeu LK, Carette C, Blacher J, Levy BI, Galan P, Hercberg S, Czernichow S. Associations between dietary patterns and skin microcirculation in healthy subjects. Arterioscler Thromb Vasc Biol 2014;34:463-9.

60. Rattigan S, Wheatley C, Richards SM, Barrett EJ, Clark MG. Exercise and insulin-mediated capillary recruitment in muscle. Exerc Sport Sci Rev 2005;33:43-8.

61. Anuradha S, Healy GN, Dunstan DW, Klein R, Klein BE, Cotch MF, Wong TY, Owen N. Physical activity, television viewing time, and retinal microvascular caliber: The multi-ethnic study of atherosclerosis. Am J Epidemiol 2011;173:518-25.

62. Anuradha S, Healy GN, Dunstan DW, Tai ES, Van Dam RM, Lee J, Nang EE, Owen N, Wong TY. Associations of physical activity and television viewing time with retinal vascular caliber in a multiethnic asian population. Invest Ophthalmol Vis Sci 2011;52:6522-8.

63. Clark MG, Wallis MG, Barrett EJ, Vincent MA, Richards SM, Clerk LH, Rattigan S. Blood flow and muscle metabolism: A focus on insulin action. Am J Physiol Endocrinol Metab 2003;284:E241-58. 



\section{SAMENVATTING}

Diabetes mellitus, ofwel suikerziekte, is een veelvoorkomende stofwisselingsziekte die gekenmerkt wordt door hyperglykemie (verhoogde bloedsuikerspiegels) als gevolg van gebreken in de productie en/of de werking van insuline. Op dit moment lijden wereldwijd ongeveer 346 miljoen mensen aan diabetes en naar verwachting zal dit aantal toenemen naar 552 miljoen in 2030. In Nederland is er ook een stijging van het aantal mensen met diabetes te verwachten, van ongeveer 740.000 in 2007 naar 1,3 miljoen in 2025. De meeste mensen (ongeveer 90\%) met diabetes hebben diabetes type 2, waarbij weefsels minder gevoelig worden voor de metabole effecten van insuline, ofwel insulineresistentie. Obesitas wordt beschouwd als één van de belangrijkste risicofactoren voor het ontstaan van diabetes type 2 . Het is echter niet helemaal duidelijk hoe obesitas diabetes type 2 veroorzaakt. In dit proefschrift veronderstellen we dat een verminderde werking van de kleine bloedvaten (de microcirculatie) een belangrijke rol speelt in het ontstaan van diabetes type 2 .

De microcirculatie bestaat uit alle vaten kleiner dan $150 \mu \mathrm{m}$, dit zijn de arteriolen (kleine slagaders), capillairen (haarvaten) en venulen (kleine aders). De microcirculatie speelt een onmisbare rol in het transport en de afgifte van zuurstof, hormonen en nutriënten naar de weefsels. Het hormoon insuline, dat de opname van glucose in de weefsels stimuleert, speelt hierbij een belangrijke rol. Insuline zorgt namelijk voor vaatverwijding, dat resulteert in een verwijdend effect op de precapillaire arteriolen, met een toename van het aantal doorbloede capillairen (m.a.w. capillaire rekrutering) en een toename van de totale spierdoorbloeding. Hierdoor wordt het transport en de afgifte van zuurstof, hormonen en nutriënten naar de weefsels makkelijker gemaakt. Studies hebben aangetoond dat de insulineafhankelijke verwijding van de weerstandsvaten nauw verband houdt met de perifere weerstand terwijl capillaire rekrutering belangrijk is voor de aanvoer van insuline en glucose en daarmee de opname van glucose in spierweefsel. Verder zijn er aanwijzingen dat patiënten met obesitas gekenmerkt worden door een afgenomen insulineafhankelijke microvasculaire doorbloeding en verminderde glucoseopname in spierweefsel. Dit alles heeft geleid tot de hypothese dat een verminderde werking van de microcirculatie (ofwel microvasculaire disfunctie) een belangrijke rol speelt in het ontstaan van diabetes type 2 .

Bovenstaand bewijs is voornamelijk gebaseerd op kleine studies met sterk geselecteerde patiëntengroepen. Het blijft daarom onduidelijk hoe deze bevindingen zich verhouden in de doorsnee bevolking. Met de in dit proefschrift beschreven onderzoeken hebben wij getracht om meer inzicht te krijgen in de rol van de microcirculatie in diabetes type 2 en in personen met een verstoorde glucosehuishouding in de doorsnee bevolking. 
Hiervoor hebben we gebruik gemaakt van verschillende epidemiologische studies, waarvan de Maastricht Studie de belangrijkste epidemiologische studie is. Hoofdstuk 2 geeft een beschrijving van de populatie van de Maastricht Studie en geeft een beschrijving van de verschillende technieken die in dit proefschrift gebruikt zijn voor het meten van de microvasculaire functie. Het meten van de microvasculaire functie is een moeilijke en tijdrovende procedure, in het bijzonder de metingen van de capillaire dichtheid en rekrutering in de huid. Als gevolg hiervan wordt deze techniek vooral gebruikt in relatief kleine experimentele studies. Voor het gebruik van deze techniek in de Maastricht Studie hebben we daarom eerst een semiautomatisch programma ontwikkeld voor de ondersteuning van de bepalingen van de capillaire dichtheid en rekrutering in de huid. Mede door dit programma kan deze techniek eenvoudiger worden ingezet in grotere epidemiologische studies. Het nieuw ontwikkelde programma wordt beschreven in hoofdstuk 2.3.

Ondanks het feit dat het bewijs voor de rol van microvasculaire disfunctie in het ontstaan van diabetes type 2 vooral gebaseerd is op kleine studies, wordt deze hypothese steeds meer onderzocht in grote epidemiologische studies. In deze studies wordt gekeken of het hebben van microvasculaire disfunctie aan de start van de studie, gemeten met relatief makkelijke maten zoals plasmamarkers van endotheeldisfunctie, diameters van de microcirculatie in het oog en microalbuminurie, een verhoogde kans geeft op het ontstaan van diabetes type 2 na een bepaalde tijd. Om meer inzicht te krijgen in de rol van microvasculaire disfunctie in het ontstaan van diabetes type 2 in de doorsnee bevolking, hebben we in de literatuur gezocht naar alle epidemiologische studies die deze hypothese hebben onderzocht. In hoofdstuk 3 worden deze studies (in totaal 23) samengevoegd zodat een totaalbeeld gekregen wordt van de resultaten. In deze zogenaamde metaanalyse bleek dat microvasculaire disfunctie geassocieerd is met een 10 tot $49 \%$ hogere incidentie van diabetes type 2 en met een 8 tot 15\% hogere incidentie op een voorstadium van diabetes type 2 (pre-diabetes). Deze studies bevestigen een belangrijke rol voor een verminderde werking van de microcirculatie in het ontstaan van diabetes type 2.

In hoofdstuk 4 is onderzocht of microvasculaire disfunctie aanwezig is in deelnemers met diabetes type 2 . Om deze hypothese te toetsen is gebruik gemaakt van de capillaire dichtheid (als maat voor microvasculaire structuur) en capillaire rekrutering (als maat voor microvasculaire functie) in de huid van de deelnemers van de Maastricht Studie. De deelnemers met diabetes type 2 bleken een verminderde capillaire dichtheid en rekrutering te hebben ten opzichte van deelnemers zonder diabetes type 2 . Verder bleek een verstoorde glucose huishouding geassocieerd te zijn met een verminderde capillaire dichtheid en rekrutering. Wanneer de deelnemers met diabetes type 2 en microvasculaire complicaties (nefropathie [nieraandoening] en neuropathie [zenuwschade]) uit de analyses werden gehaald, bleven de resultaten hetzelfde. Hieruit 
blijkt dat diabetes type 2 en een gestoorde glucosehuishouding geassocieerd zijn met een verminderde capillaire dichtheid en rekrutering, zelfs als er geen sprake is van zichtbaar aanwezige diabetische complicaties.

Een belangrijke component van de microcirculatie is de microvasculaire vasomotie, ofwel de ritmische veranderingen van de pre-capillaire arteriolaire diameter. Microvasculaire vasomotie reguleert door deze ritmische veranderingen in diameter de bloedstroming naar weefsels. Verder hebben vaatjes met een veranderende diameter een lagere vasculaire weerstand dan vaatjes met een statische diameter. Samengevat wordt aangenomen dat microvasculaire vasomotie een belangrijke component is van de microcirculatie, dat zorgt voor een optimale distributie van voedingsstoffen en zuurstof naar de weefsels (middels de regulatie van de bloedstroming) en voor een optimale regulatie van de lokale weerstand. De ritmische veranderingen in de pre-capillaire arteriolaire diameter veroorzaken een periodieke fluctuatie van de bloedstroom, beter bekend als microvasculaire flowmotie. Microvasculaire flowmotie kan gemeten worden in de huid via laser-Dopplerflowmetingen. In hoofdstuk $\mathbf{5}$ is onderzocht of cardiovasculaire risicofactoren, te weten leeftijd, buikomtrek, de ratio van totaal en HDL cholesterol en roken, geassocieerd zijn met microvasculaire flowmotie. Leeftijd en 24-uurs systole bloeddruk waren positief geassocieerd met microvasculaire flowmotie, terwijl buikomtrek negatief geassocieerd was met microvasculaire flowmotie in de totale populatie van de Maastricht Studie. Wanneer de analyses herhaald werden in de meest gezonde deelnemers van de Maastricht Studie (zonder diabetes type 2 en pre-diabetes, hoge bloeddruk, overgewicht of obesitas en medicatiegebruik), bleven de resultaten hetzelfde. Hoewel de exacte onderliggende mechanismen van deze bevindingen niet bekend zijn, kan de hypothese worden gesteld dat microvasculaire flowmotie een belangrijke component is van de microcirculatie, die zorgt voor een optimale distributie van voedingsstoffen en zuurstof naar de weefsels (middels de regulatie van de bloedstroming) en voor een optimale regulatie van de lokale weerstand onder fysiologische omstandigheden, maar ook onder pathofysiologische omstandigheden wanneer de microvasculaire perfusie verminderd is, zoals gebeurt met een toenemende leeftijd of een hoge bloeddruk. Overgewicht of obesitas heeft negatieve effecten op deze component van de microcirculatie.

Kort samengevat bestaat in de doorsnee bevolking een belangrijk verband tussen microvasculaire disfunctie en diabetes type 2 en een gestoorde glucosehuishouding. Tevens is er bewijs voor een temporaal verband tussen microvasculaire disfunctie en de ontwikkeling van incidente diabetes type 2. Dit suggereert een vicieuze cirkel (Figuur 6.1; pagina 128) van progressieve microvasculaire disfunctie, waarschijnlijk veroorzaakt door obesitas, dat bijdraagt aan de ontwikkeling van diabetes type 2 (hoofdstuk 3). Het hebben van diabetes type 2 resulteert uiteindelijk in een verdere verslechtering van de microvasculaire functie (hoofdstuk 4) en uiteindelijk het ontstaan van microvasculaire 
complicaties. Verder kan worden gesteld dat microvasculaire flowmotie een belangrijke component is van de microcirculatie, die zorgt voor een optimale distributie van voedingsstoffen en zuurstof naar de weefsels en voor een optimale regulatie van de lokale weerstand onder fysiologische en pathofysiologische omstandigheden. Overgewicht of obesitas heeft negatieve effecten op deze component van de microcirculatie wat eindelijk weer bijdraagt aan een verslechterde microvasculaire functie en dus diabetes type 2 (hoofdstuk 5).

Er moet echter worden benadrukt dat we geen causaal verband hebben kunnen aantonen met de studies beschreven in dit proefschrift. Om een beter inzicht te krijgen in dit mogelijke causale verband zijn meer experimentele studies nodig. Het is belangrijk dat deze studies andere determinanten voor de opname van glucose in acht nemen, zoals het transport van insuline door het endotheel (van plasma naar interstitium) en de opname van glucose in de spiercel door de translocatie van de glucosetransporter GLUT-4. Verder is de Maastricht Studie, met een intensieve fenotypering van de microcirculatie van de deelnemers, een uitgelezen kans om de rol van de microcirculatie in het ontstaan van diabetes type 2 te ontrafelen.

Kijkend naar verschillende onderzoeken in de literatuur en de studies beschreven in dit proefschrift stel ik dat verbeteringen van de microvasculaire functie mogelijk een belangrijk therapeutisch doel kunnen vormen ter voorkoming van het ontstaan van diabetes type 2. Buiten deze therapeutische behandelingen moet in het achterhoofd gehouden worden dat een gezonde leefstijl altijd aangemoedigd moet worden bij de bevolking om obesitas en subsequente obesitas gerelateerde microvasculaire disfunctie en diabetes type 2 te voorkomen. Verschillende onderzoeken hebben aangetoond dat verbeteringen van de leefstijl (afvallen, verbeteringen van voedingspatronen en meer fysieke activiteit) geassocieerd zijn met een verbeterde microvasculaire functie, dat mogelijk zorgt voor een verminderde kans op het ontstaan van diabetes type 2 . 



\section{VALORISATION ADDENDUM}

Type 2 diabetes mellitus (T2DM) currently affects an estimated 285 million people worldwide, with a further seven million people developing T2DM each year. ${ }^{1}$ In addition, the prevalence of obesity is increasing worldwide and has reached epidemic proportions in Western society. ${ }^{2}$ As adults with obesity have an approximately 7-fold increased risk of $\mathrm{T}^{2 \mathrm{DM}}{ }^{3}$ it is important to unravel the pathophysiology of obesity-related T2DM. Experimental evidence suggests that microvascular dysfunction may be an intermediate step linking central obesity to T2DM. ${ }^{4-6}$ In the research project reported on in this thesis, we investigated the associations of obesity, T2DM, and other cardiovascular risk factors with microvascular dysfunction in a population-based setting. The population-based studies discussed in this thesis are important because they provide further insight into the pathophysiology of obesity-related T2DM. We demonstrated that microvascular dysfunction is associated with diabetes and prediabetes, and thus contributes to the translation to the general population of this concept as investigated in experimental studies. Our findings do indeed suggest a role for the microcirculation in the pathogenesis of T2DM. Hence, from a clinical point of view, targeting the microcirculation may reduce the risk of developing T2DM. In addition, unravelling how microvascular dysfunction is determined and how it leads to T2DM may lead to new treatment targets as well as to a better understanding of the reason why certain existing treatments are associated with a decreased risk of developing T2DM. Importantly, unravelling this concept may reduce health care costs in the near future (through a lower prevalence of T2DM and its complications).

Although this thesis underlines the importance of microvascular dysfunction in the pathogenesis of T2DM, we cannot prove any causal relationship. More studies are therefore required to unravel the pathophysiology of obesity-related T2DM. Unfortunately, the assessment of microvascular function in specific vascular beds is technically demanding and time-consuming. Therefore, we developed a semi-automatic image analysis application (CapiAna) for the assessment of skin capillary density, which agrees well with the classic manual counting procedure, saves time, and has a better reproducibility than the classic procedure. Since CapiAna saves time, thus eventually reducing research costs, the use of skin capillaroscopy has become feasible in large-scale studies. Hence, this semi-automatic image analysis application considerably extends the possibilities of performing microcirculation research in humans. In addition, making this new software freely available on the Internet may consolidate Maastricht University's reputation as an innovative university. This may then help to attract new Dutch and international students, thus further improving the university's reputation.

It is important to note that this thesis is based on the first dataset of the Maastricht Study (an observational prospective population-based cohort study), and thus 
opens avenues for potential new research in the context of the Maastricht Study. More precisely, the Maastricht Study is valuable for investigating the longitudinal associations between microvascular dysfunction and incident T2DM. The Maastricht Study is ongoing and annual follow-up on morbidity and mortality is in progress. The study is also valuable because of its extensive phenotyping approach, and in particular the extensive characterization of microvascular function. ${ }^{7}$ This allows the role of microvascular dysfunction in the pathogenesis of obesity-related T2DM to be investigated with additional measures of microvascular function (i.e., heat-induced hyperaemia, ${ }^{8}$ funduscopy, ${ }^{9}$ dynamic vessel analysis, ${ }^{10}$ markers of endothelial dysfunction, ${ }^{11-13}$ and microalbuminuria ${ }^{14}$ ). As a consequence, the Maastricht Study will generate new jobs in the Southern part of Limburg. In addition, it creates new opportunities for collaboration with large-scale studies at other Dutch and international universities. This, in turn, may improve the international reputation of Maastricht University.

Besides targeting the microcirculation with drugs, physicians should encourage their patients to lose weight and adopt a healthy lifestyle in order to prevent obesity and obesity-related microvascular dysfunction. For instance, several studies have demonstrated improvements of microvascular function after weight loss in morbidly obese patient having bariatric surgery. ${ }^{15,16}$ In addition, a recent study in healthy subjects demonstrated that a dietary pattern characterized by high intakes of high- and low-fat sweets was associated with microvascular dysfunction, while a pattern characterized by increased consumption of vegetable oils, poultry, and fish and seafood was associated with improved microvascular function. ${ }^{17}$ Physical activity may also prevent obesity-related microvascular dysfunction and T2DM. ${ }^{18}$ Indeed, physical activity has been associated with improved microvascular function ${ }^{19,20}$ and, more importantly, regular exercise can enhance the vascular insulin mechanisms. ${ }^{21}$ Taken together, these findings suggest that the prevention of obesity and the implementation of a healthy lifestyle may reduce obesityrelated microvascular dysfunction and consequent obesity-related T2DM. Besides an important role for physicians, population-based strategies should be introduced to effectively promote lifestyle change, such as media and educational campaigns; product labelling and consumer information; taxation, subsidies, and other economic incentives. ${ }^{22}$

More studies are thus needed to investigate the pathophysiology of obesityrelated T2DM. Their findings may contribute to a more precise assessment of risk of this disorder. In addition, unravelling how microvascular dysfunction is determined and how it leads to T2DM may lead to new treatment targets as well as to a better understanding of the reason why certain existing treatments are associated with a decreased risk of developing T2DM. Importantly, the implementation of a healthy lifestyle may reduce obesity-related microvascular dysfunction and consequent obesity-related T2DM. 


\section{REFERENCES}

1. Federation ID: Spreadsheet: Prevalence estimated of diabetes mellitus (DM), 2010. Brussel, Belgium. International Diabetes Federation: IDF diabetes atlas, 2010.

2. Flegal KM, Carroll MD, Kit BK, Ogden $\mathrm{CL}$. Prevalence of obesity and trends in the distribution of body mass index among us adults, 1999-2010. JAMA 2012;307:491-7.

3. Mokdad AH, Ford ES, Bowman BA, Dietz WH, Vinicor F, Bales VS, Marks JS. Prevalence of obesity, diabetes, and obesity-related health risk factors, 2001. JAMA 2003;289:76-9.

4. Kim F, Pham M, Maloney E, Rizzo NO, Morton GJ, Wisse BE, Kirk EA, Chait A, Schwartz MW. Vascular inflammation, insulin resistance, and reduced nitric oxide production precede the onset of peripheral insulin resistance. Arterioscler Thromb Vasc Biol 2008;28:1982-8.

5. Bonner JS, Lantier L, Hasenour CM, James FD, Bracy DP, Wasserman DH. Muscle-specific vascular endothelial growth factor deletion induces muscle capillary rarefaction creating muscle insulin resistance. Diabetes 2013;62:572-80.

6. Kubota T, Kubota N, Kumagai H, Yamaguchi S, Kozono H, Takahashi T, Inoue M, Itoh S, Takamoto I, Sasako T, Kumagai K, Kawai T, Hashimoto S, Kobayashi T, Sato M, Tokuyama K, Nishimura S, Tsunoda M, Ide T, Murakami K, Yamazaki T, Ezaki O, Kawamura K, Masuda H, Moroi M, Sugi K, Oike Y, Shimokawa H, Yanagihara N, Tsutsui M, Terauchi Y, Tobe K, Nagai R, Kamata K, Inoue K, Kodama T, Ueki K, Kadowaki T. Impaired insulin signaling in endothelial cells reduces insulin-induced glucose uptake by skeletal muscle. Cell Metab 2011;13:294-307.

7. Schram MT, Sep SJ, Kallen van der CJ, Dagnelie PC, Koster A, Schaper NC, Henry RM, Stehouwer CD. The maastricht study: An extensive phenotyping study on determinants of type 2 diabetes, its complications and its comorbidities. Eur J Epidemiol 2014;29:439-51.

8. Minson CT, Berry LT, Joyner MJ. Nitric oxide and neurally mediated regulation of skin blood flow during local heating. J Appl Physiol 2001;91:1619-26.

9. Houben AJ, Stehouwer CD. Retinal microvascular abnormalities: Can they predict future risk of hypertension? J Hyperten. 2009;27:2346-8.

10. Delles C, Michelson G, Harazny J, Oehmer S, Hilgers KF, Schmieder RE. Impaired endothelial function of the retinal vasculature in hypertensive patients. Stroke 2004;35:1289-93.

11. Stehouwer CD. Endothelial dysfunction in diabetic nephropathy: State of the art and potential significance for non-diabetic renal disease. Nephrol Dial Transplant 2004;19:778-81.

12. Stehouwer CD, Fischer HR, van Kuijk AW, Polak BC, Donker AJ. Endothelial dysfunction precedes development of microalbuminuria in iddm. Diabetes 1995;44:561-4.

13. Stehouwer CD, Lambert J, Donker AJ, van Hinsbergh VW. Endothelial dysfunction and pathogenesis of diabetic angiopathy. Cardiovasc Res 1997;34:55-68.

14. Stehouwer CD, Smulders YM. Microalbuminuria and risk for cardiovascular disease: Analysis of potential mechanisms. J Am Soc Nephrol 2006;17:2106-11.

15. Martin-Rodriguez JF, Cervera-Barajas A, Madrazo-Atutxa A, Garcia-Luna PP, Pereira JL, Castro-Luque J, LeonJustel A, Morales-Conde S, Castillo JR, Leal-Cerro A, Cano DA. Effect of bariatric surgery on microvascular dysfunction associated to metabolic syndrome: A 12-month prospective study. Int J Obes (Lond) 2014;38:1410-5.

16. Rossi M, Nannipieri M, Anselmino M, Guarino D, Franzoni F, Pesce M. Subcutaneous adipose tissue blood flow and vasomotion in morbidly obese patients: Long term effect of gastric bypass surgery. Clin Hemorheol Microcirc 2012;51:159-67.

17. Karatzi K, Protogerou A, Kesse-Guyot E, Fezeu LK, Carette C, Blacher J, Levy BI, Galan P, Hercberg S, Czernichow S. Associations between dietary patterns and skin microcirculation in healthy subjects. Arterioscler Thromb Vasc Biol 2014;34:463-9.

18. Rattigan S, Wheatley C, Richards SM, Barrett EJ, Clark MG. Exercise and insulin-mediated capillary recruitment in muscle. Exerc Sport Sci Rev 2005;33:43-8.

19. Anuradha S, Healy GN, Dunstan DW, Klein R, Klein BE, Cotch MF, Wong TY, Owen N. Physical activity, television viewing time, and retinal microvascular caliber: The multi-ethnic study of atherosclerosis. Am J Epidemiol 2011;173:518-25.

20. Anuradha S, Healy GN, Dunstan DW, Tai ES, Van Dam RM, Lee J, Nang EE, Owen N, Wong TY. Associations of physical activity and television viewing time with retinal vascular caliber in a multiethnic asian population. Invest Ophthalmol Vis Sci 2011;52:6522-8. 
21. Clark MG, Wallis MG, Barrett EJ, Vincent MA, Richards SM, Clerk LH, Rattigan S. Blood flow and muscle metabolism: A focus on insulin action. Am J Physiol Endocrinol Metab 2003;284:E241-58.

22. Mozaffarian D, Afshin A, Benowitz NL, Bittner $V$, Daniels $S R$, Franch HA, Jacobs DR, Jr., Kraus WE, KrisEtherton PM, Krummel DA, Popkin BM, Whitsel LP, Zakai NA. Population approaches to improve diet, physical activity, and smoking habits: A scientific statement from the American heart association. Circulation 2012;126:1514-63. 



\section{DANKWOORD}

Het spreekt voor zich dat ik dit proefschrift nooit alleen had kunnen schrijven. Ik ben dan ook dank verschuldigd aan de vele mensen die me hierbij hebben geholpen.

Als eerste natuurlijk mijn promotieteam, prof. dr. C.D.A. Stehouwer, dr. A.J.H.M. Houben en dr. M.T. Schram; Coen, Boy en Miranda.

Beste Coen, het is al vaker gezegd, maar ook ik vind het bewonderenswaardig met welke snelheid en precisie je mijn manuscripten in de afgelopen jaren hebt nagekeken. Als ik het niet meer zag zitten, of zelfs 'clueless' was, bleef jij onverstoord doorgaan. Naast het nakijken van manuscripten heb ik het gevoel dat je je promovendi ook klaarstoomt voor de periode na de promotie. Zo bezorgde je eerste 'vurige' mail, als antwoord op mijn mail, mij het schaamrood op mijn kaken. Er bleek geen vraag in mijn mail te staan. Het gevolg was dat ik de eerste paar keren met knikkende knieën naar je kamer liep voor onze voortgangsgesprekken én dat ik nooit meer een mail heb gestuurd zonder een duidelijke boodschap of vraag. Coen, bedankt voor alles!

Beste Boy, na de sollicitatieprocedure sloeg je meteen over naar het Limburgs dialect en vanaf dat moment heb ik me altijd thuis gevoeld. Misschien zelfs iets té goed, want ik kan me niet voorstellen dat ik in de toekomst ooit nog met mijn begeleider of manager zal zingen in een karaokebar (hopelijk is het bewijs vernietigd). Op wetenschappelijk gebied hebben de eindeloze discussies en werkoverleggen op je kamer - met veel te veel koffie me enorm geholpen. Ik weet ook zeker dat dit de kwaliteit van het proefschrift ten goede is gekomen. Bedankt! Hopelijk zullen we elkaar nog vaker zien tijdens feestjes en promoties.

Beste Miranda, vooral in het begin was het niet altijd eenvoudig voor me dat je $\mathrm{m}^{\prime} \mathrm{n}$ begeleider én de manager van de Maastricht Studie was. Maar naarmate de tijd vorderde zag ik je steeds meer als m'n begeleider. Ik wil ook jou bedanken voor je geduld en alle lessen in wetenschappelijk schrijven, epidemiologie en statistiek!

Alle leden van de beoordelingscommissie, prof. dr. P.W. de Leeuw, prof. dr. A.C. Nieuwenhuijzen Kruseman, prof. dr. A.J. Smit, dr. L. Engelen en dr. E.H. Serné wil ik graag bedanken voor het lezen en beoordelen van mijn proefschrift.

Tijdens mijn promotie ben ik werkzaam geweest bij de Maastricht Studie en bij de vakgroep Interne Geneeskunde.

De Maastricht Studie, uiteindelijk zal ik spreken van een haat-liefde verhouding met deze studie. Zonder de Maastricht Studie was dit proefschrift er nooit geweest, maar wat heb ik moeite gehad met de eindeloze, lange meetdagen. Gelukkig vormden we met de eerste medewerkers, Marcelle, José, Joséphine en Jos en later Thomas, Peggy, Fleur en 
Yvette, een sterk blok dat voor elkaar stond en elkaar hielp. Later werd het allemaal een stuk makkelijker, waarschijnlijk door de komst van nieuwe collega's: Stefan, Karin, Chantalle, Pauline, Julianne, Remy, Frank, Ben en Marnix. ledereen succes met het afronden van de promotie, vooral Marcelle, want zonder Marcelle was de logistiek rondom de dataset en metingen van de Maastricht Studie nooit zo goed geregeld geweest.

Interne Geneeskunde, hier moest uiteindelijk het 'echte promoveren' plaatsvinden. Het begon allemaal in het lab met veel lezen over de microcirculatie. Gelukkig werd dit afgewisseld met het bekijken van de filmpjes van New Kids met Marjo. Hierna kreeg ik een plek in de kamer van Jean en Barry. De discussies met flink veel humor waren een perfecte afwisseling op de urenlange vasomotie analyses. Ook wil ik de andere collega's van Interne Geneeskunde - Lian (nogmaals dank voor het nakijken van het proefschrift!), Katrien, Olaf, Kristiaan, Nordin, Nick, Petra, Vicky, Casper, Margee, Marleen, Teba, Roel, Johanna, Marcelle, Elisabeth, Bas, Stijn, Yvo en Dionne - bedanken voor de leuke tijd op de afdeling, de goede samenwerking, de uitstapjes, de cursussen en de congressen!

Een speciaal woordje voor Jean, Nordin en Olaf. De filmavonden en uitstapjes waren geweldig. Olaf, hoewel we aan het eind niet de 'zonnetjes in huis' waren, denk ik toch dat de vele treinreizen uiteindelijk goed voor ons zijn geweest. Jean, de afwisseling van hard werken - echt niets is te veel gevraagd - en humor zijn bewonderenswaardig. Ik hoop dat mij dit ook ooit zal lukken! Nordin, ik heb grote bewondering voor je interesse in alles en je eeuwige optimisme. Bedankt mannen, ik heb veel van jullie geleerd!

Dan het tellen van capillairen van de 866 proefpersonen op het veel te kleine kamertje van Boy. Omgerekend heeft dit ongeveer 25.980 minuten gekost. Geestdodend of niet, we hebben het voor elkaar gekregen. Ik zeg 'we' omdat het zonder Ümit nooit was gelukt. Ümit, dank voor je geweldige doorzettingsvermogen. Ook ben ik dank verschuldigd aan $\mathrm{Ed}$, want deze opgave was natuurlijk nooit gelukt zonder het semi-automatische telprogramma.

Ik wil mijn nieuwe collega's in het Catharina Ziekenhuis, Hanneke B., Marja, Dorlie, Leonie, Pieter, Mirjam, Schelte, Daniela, Hanneke P., Karin, Elles, Manon en Marjolein, bedanken voor de nieuwe uitdaging die ze me hebben aangeboden. Ik heb de afgelopen maanden erg veel mogen bijleren en ik zit goed op mijn plek!

Het leven bestaat (gelukkig) niet alleen maar uit werken. Er zijn tal van bijzondere mensen waarop ik iedere dag weer kan vertrouwen en terugvallen.

Ten eerste Rob, Michelle, Jason, Wendy, Kevin, Dennis, Jeroen, Marianne, Ronald en Suzanne. Ook al hebben jullie niet direct een bijdrage geleverd aan dit proefschrift, zonder de gezellige avonden was het nooit gelukt om dit voor elkaar te krijgen. 
Een speciaal woord voor de paranimfen Jason en Rob. Jason, ik denk dat niet veel mensen hun schoonbroer kunnen beschouwen als een vriend. Dat geluk heb ik wel! Bedankt voor alle hulp met het proefschrift en de kaft. Rob, al eeuwen vrienden, althans zo voelt het. We hebben genoeg leuke en minder leuke dingen met elkaar mogen meemaken. Onze grote droom, veel reizen, staat wat mij betreft als een huis. Ik zal er dan ook alles aan doen om deze droom uit te laten komen!

Lieve zus, ondanks het feit dat onze levens totaal niet op elkaar lijken, kijk ik altijd erg uit naar de 'vrijdagmiddaglunch' bij pap en mam. Waarschijnlijk lijken we toch meer op elkaar dan we op dit moment denken. Ik hoop dat we er de komende jaren alles aan doen om deze overeenkomsten te vinden.

Lieve pap en mam. Natuurlijk klopt het dat ik hier nooit had kunnen staan zonder jullie. Maar veel belangrijker vind ik de onvoorwaardelijke steun en liefde die jullie me al mijn hele leven geven. Bedankt voor alle mogelijkheden die jullie me hebben geboden, maar ook voor alle geduld, levenslessen, warmte, advies, uitstapjes, vakanties en etentjes. Jullie zijn en blijven mijn allergrootste voorbeeld!

Allerliefste Debbie. Uiteindelijk begrijpt iedereen dat deze 158 pagina's waardeloos zijn zonder datgene waar het echt om draait in het leven, liefde en vriendschap. Ik ben de gelukkigste man op aarde dat jij degene bent die deze twee belangrijke zaken invult in mijn leven. Ik vind het heerlijk om 's avonds samen met jou op de bank te ploffen, ik vind het heerlijk om urenlang met je te eten en te discussiëren over de toekomst, ik vind het heerlijk om met je te reizen, ik hou van je! 

Curriculum Vitae

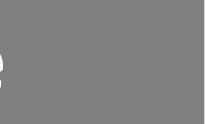

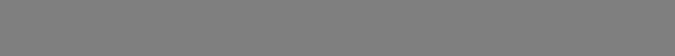




\section{CURRICULUM VITAE}

Dennis Muris werd geboren op 1 januari 1987 te Heerlen. In 1999 begon hij aan zijn middelbare schooltijd op het Sintermeertencollege te Heerlen, waaraan hij in 2005 zijn VWO diploma behaalde. Datzelfde jaar startte hij met Gezondheidswetenschappen aan de Universiteit van Maastricht, met als hoofdvak Bioregulatie en Gezondheid en als bijvak Bewegingswetenschappen. Mede door zijn interesse in biologie en de wetenschap, startte hij na het afstuderen in 2009 met zijn promotieonderzoek aan de Universiteit van Maastricht bij de vakgroep Interne Geneeskunde, waarvan de resultaten staan beschreven in dit proefschrift. Sinds juli 2014 is hij werkzaam in het Catharina Ziekenhuis Eindhoven als senior adviseur kwaliteit en veiligheid. 


\section{LIST OF PUBLICATIONS}

Muris DM, Houben AJ, Schram MT, Stehouwer CD. Microvascular dysfunction is associated with a higher incidence of type 2 diabetes mellitus: a systematic review and meta-analysis. Arterioscler Thromb Vasc Biol. 2012;32:3082-94.

Muris DM, Houben AJ, Schram MT, Stehouwer CD. Microvascular dysfunction: an emerging pathway in the pathogenesis of obesity-related insulin resistance. Rev Endocr Metab Disord. 2013;14:29-38.

Muris DM*, Gronenschild EH*, Schram MT, Karaça Ü, Stehouwer CD, Houben AJ.Semiautomatic assessment of skin capillary density: proof of principle and validation. Microvasc Res. 2013;90:192-8. * Both authors contributed equally.

Karaça Ü, Schram MT, Houben AJ, Muris DM, Stehouwer CD. Microvascular dysfunction as a link between obesity, insulin resistance and hypertension. Diabetes Res Clin Pract. 2014;103:382-7.

Muris DM, Gronenschild EH, Schram MT, Karaça Ü, Stehouwer CD, Houben AJ. Response to comment on: semi-automatic assessment of skin capillary density: proof of principle and validation. Microvasc Res. 2014;94:7-8.

Montero D, Padilla J, Diaz-Cañestro C, Muris DM, Pyke KE, Obert P, Walther G. Flowmediated dilation in athletes: influence of aging. Med Sci Sports Exerc. 2014;46:2148-58.

Muris DM, Houben AJ, Kroon AA, Henry RM, van der Kallen CJ, Sep SJ, Koster A, Dagnelie PC, Schram MT, Stehouwer CD. Age, waist circumference, and blood pressure are associated with skin microvascular flow motion: the Maastricht Study. J Hypertens. 2014;32:2439-49.

van Sloten TT, Czernichow S, Houben AJ, Protogerou AD, Henry RM, Muris DM, Schram MT, Sep SJ, Dagnelie PC, van der Kallen CJ, Schaper NC, Blacher J, Hercberg S, Levy BI, Stehouwer $C D$. Association between arterial stiffness and skin microvascular function: the SUVIMAX2 Study and the Maastricht Study. Am J Hypertens. 2014. 